\title{
TRANSLATIONS OF SECURITY
}

\section{A FRAMEWORK FOR THE STUDY OF UNWANTED FUTURES}

Trine Villumsen Berling, Ulrik Pram Gad, Karen Lund Petersen, and Ole Wæver
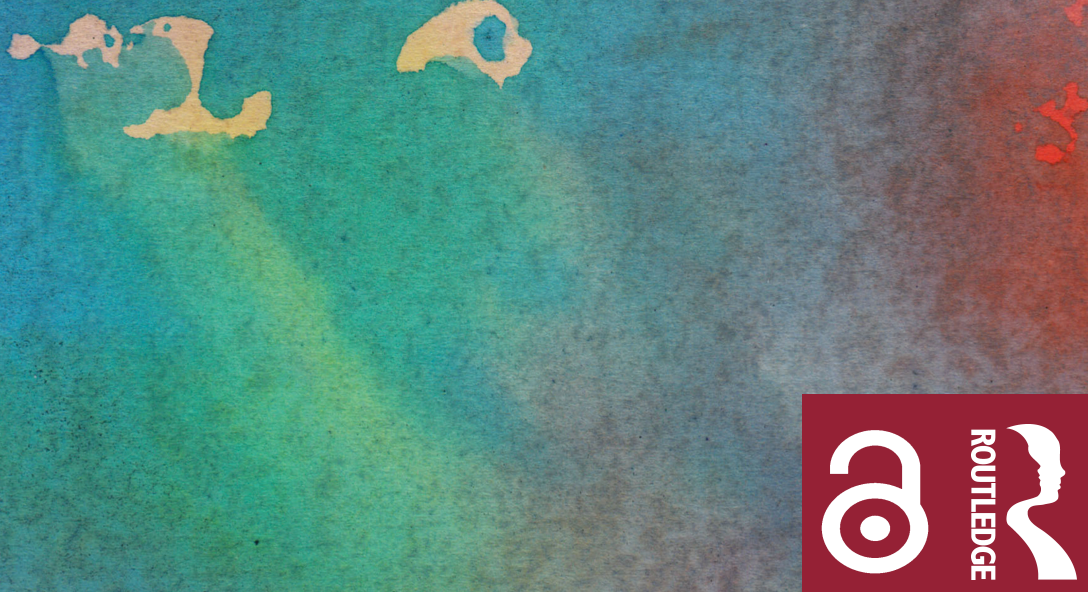


\section{Translations of Security}

This book scrutinises how contemporary practices of security have come to rely on many different translations of security, risk, and danger.

Institutions of national security policies are currently undergoing radical conceptual and organisational changes, and this book presents a novel approach for how to study and politically address the new situation. Complex and uncertain threat environments, such as terrorism, climate change, and the global financial crisis, have paved the way for new forms of security governance that have profoundly transformed the ways in which threats are handled today. Crucially, there is a decentralisation of the management of security, which is increasingly handled by a broad set of societal actors that previously were not considered powerful in the conduct of security affairs. This transformation of security knowledge and management changes the meaning of traditional concepts and practices, and calls for investigation into the many meanings of security implied when contemporary societies manage radical dangers, risks, and threats. It is necessary to study both what these meanings are and how they developed from the security practices of the past. Addressing this knowledge gap, the book asks how different ideas about threats, risk, and dangers meet in the current practices of security, broadly understood, and with what political consequences.

This book will be of interest to students of critical security studies, anthropology, risk studies, science and technology studies and International Relations.

Trine Villumsen Berling is a Senior Researcher at the Danish Institute for International Studies (DIIS).

Ulrik Pram Gad is a Senior Researcher at the Danish Institute for International Studies (DIIS).

Karen Lund Petersen is a Senior Researcher at the Danish Institute for International Studies (DIIS) and Professor II at Stavanger University, Norway.

Ole Wrver is a Professor at the University of Copenhagen, Denmark and is the founder of CAST (Centre for Advanced Security Theory) and CRIC (Centre for Resolution of International Conflicts). 


\section{Series: Routledge New Security Studies}

The aim of this book series is to gather state-of-the-art theoretical reflection and empirical research into a core set of volumes that respond vigorously and dynamically to new challenges to security studies scholarship. Routledge New Security Studies is a continuation of the PRIO New Security Studies series.

Series Editors: J. Peter Burgess, École Normale Superieur (ENS), Paris

\section{Energy Security Logics in Europe}

Threat, Risk or Emancipation?

Izabela Surwillo

\section{Crypto-Politics}

Encryption and Democratic Practices in the Digital Era

Linda Monsees

\section{Negotiating Intractable Conflicts}

Readiness Theory Revisited

Amira Schiff

\section{Standardization and Risk Governance}

A Multi-Disciplinary Approach

Edited by Odd Einar Olsen, Kirsten Juhl, Preben Lindoe and Ole Andreas Engen

Nordic Societal Security

Convergence and Divergence

Edited by Sebastian Larsson and Mark Rhinard

\section{The Molecularisation of Security}

Medical Countermeasures, Stockpiling and the Governance of Biological Threats Christopher Long

For more information about this series, please visit: https://www.routledge.com/ Routledge-New-Security-Studies/book-series/RNSS 


\section{Translations of Security}

A Framework for the Study of

Unwanted Futures

\section{Trine Villumsen Berling \\ Ulrik Pram Gad \\ Karen Lund Petersen and \\ Ole Waver}


First published 2022

by Routledge

2 Park Square, Milton Park, Abingdon, Oxon OX14 4RN

and by Routledge

605 Third Avenue, New York, NY 10158

Routledge is an imprint of the Taylor \& Francis Group, an informa business

(C) 2022 Trine Villumsen Berling, Ulrik Pram Gad, Karen Lund

Petersen, and Ole Wæver

The right of Trine Villumsen Berling, Ulrik Pram Gad, Karen Lund Petersen, and Ole Wæver to be identified as authors of this work has been asserted by them in accordance with sections 77 and 78 of the Copyright, Designs and Patents Act 1988.

The Open Access version of this book, available at www.taylorfrancis. com, has been made available under a Creative Commons AttributionNon Commercial-No Derivatives 4.0 license

Trademark notice: Product or corporate names may be trademarks or registered trademarks, and are used only for identification and explanation without intent to infringe.

British Library Cataloguing-in-Publication Data

A catalogue record for this book is available from the British Library

Library of Congress Cataloging-in-Publication Data

Names: Berling, Trine Villumsen, author. | Gad, Ulrik Pram, author. | Petersen, Karen Lund, author. | Wæver, Ole, 1960- author.

Title: Translations of security : a framework for the study of unwanted futures / Trine Villumsen Berling, Ulrik Pram Gad, Karen Lund Petersen, and Ole Wæver.

Description: Abingdon, Oxon ; New York, NY : Routledge, 2022. |

Series: Routledge new security studies | Includes bibliographical references and index.

Identifiers: LCCN 2021015393 (print) | LCCN 2021015394 (ebook) | ISBN 9781032007090 (hardback) | ISBN 9781032007151 (paperback) | ISBN 9781003175247 (ebook)

Subjects: LCSH: National security--Methodology. | International relations--Risk assessment. | Interdisciplinary approach to knowledge. | Intercultural communication.

Classification: LCC UA10.5 .B47 2022 (print) | LCC UA10.5 (ebook) |

DDC 355/.03--dc23

LC record available at https://lccn.loc.gov/2021015393

LC ebook record available at https://lccn.loc.gov/2021015394

ISBN: 978-1-032-00709-0 (hbk)

ISBN: 978-1-032-00715-1 (pbk)

ISBN: 978-1-003-17524-7 (ebk)

DOI: $10.4324 / 9781003175247$

Typeset in Times New Roman by MPS Limited, Dehradun 


\section{Contents}

List of figures $\quad$ vi

List of tables vii

List of briefs and boxes viii

Preface $\quad \mathrm{x}$

1 Introduction: translations of security 1

2 Theorising translation 27

3 Translations across disciplines and professions $\quad 50$

4 Translations across cultures 104

5 Translations across scales 142

6 Conclusion: analysing translations of security 195

$\begin{array}{ll}\text { Index } & 212\end{array}$ 


\section{Figures}

2.1 Translations as attempts at perfection, distortion and articulation between the 'vanishing points' of incarnation, incommensurability, and emergence

2.2 Translations of security according to Copenhagen School securitization theory

2.3 Translations of security according to the security/risk literature

2.4 Translations of security according to ANT-like security studies

2.5 Translations of security according to Paris inspired securitization theory

2.6 The approach to translations of security in this book

6.1 Oscillation of conceptual tightness in Security Studies 


\section{Tables}

3.1 Translation zone between functionally differentiated expertise - disciplines and professions

3.2 Translation zone between expertise and non-expertise

4.1 Translation zones across cultures - spectrum from national to organisational

4.2 Translation zone between cultures and universalisation

5.1 Translations across scales

5.2 Translation zone between scales and networks

6.1 Translation zones negotiating support of state and knowledge

6.2 Our analytical grid pointing out potential and potent translation zones

6.3 Our definitions and examples of where to look and what to look for when analysing the translation of unwanted futures

6.4 Example of case study notes guided by our analytical grid and definitions of what to look for 


\section{Briefs and Boxes}

\section{Briefs}

1.1 Translations of security 3

1.2 Analysing translations of security 17

6.1 How to carry out an empirical translations analysis? 200

\section{Boxes}

1.1 The Other State of Emergency 20

2.1 Who heard what Trump said to Putin? Only one other American

3.1 Securitization in medicine. Danger replacement and politically productive dreams of safety

3.2 "It is difficult to look busy while thinking":

Translation Advice for Human Terrain Teams (HTTs) 57

3.3 Translating energy security in the United States:

What happened to climate change?

3.4 Translating nature, law and sovereignty in the Arctic: a question of security?

3.5 Beyond control. The economic translation of security 70

3.6 Talking Curves at Montreux $+5 \quad 76$

3.7 Interventions into Intelligence: Some Early Observations 85

3.8 I see dead people 93

3.9 Security and the anthropology of potentiality 95

4.1 Hot Tea with Sugar and the Translation(s) of Torture 110

4.2 "In this house we're revolutionaries, damn it!". A visceral translation to Cuba 114

4.3 Translations of security cascading at Thule 125

4.4 The security of cultural rights 131

5.1 "To live on the edge is not the same as to live on the margins" 150

5.2 Translating emergency in Alaska 153

5.3 Conflicting universalisms 157

5.4 Securitizing things: Recovering a lost material history of the fear of the next war 
5.5 Translating national threats to individual security: Muslims in the Danish Armed Forces

5.6 How the single Leg Amputee Sports Club Became a Matter of Peacebuilding

5.7 Translating Visual Insecurity: The case of HIV/AIDS 177

$\begin{array}{lll}5.8 \text { Voices of Data Doubles } & 182\end{array}$

$\begin{array}{lll}5.9 \text { Visual translations of (in)security } & 189\end{array}$ 


\section{Preface}

This book has travelled a long way for a number of years. Starting as an idea in the late 2000s when the Centre for Advanced Security Theory (CAST) was first established under the leadership of Professor Ole Wæver, the idea transformed into a research agenda for understanding how different conceptual universes intersect and entangle when dealing with what we in this book have ended up calling "unwanted futures." All the different visions of the future that might turn into something we might otherwise associate with security, risk, unsustainability, catastrophe and the like constitute such unwanted futures. The meeting between these different structures of meaning is what we intend to capture through the term translations.

Coming from different corners of critical security studies, but still with a firm anchor in the early Copenhagen School idea of securitization, the authors of this book took up discussing how we might capture the developments in security practice and theory today, without falling too easily into theoretical camps (or even trenches) and keeping an open mind to observing and taking at face value the interventions from different disciplines and practitioners. Karen Lund Petersen's firm grasp on the risk literature and the role of private business in dealing with new threats, Ulrik Pram Gad's insistence on the role of identity politics in sustainability debates, and Trine Villumsen Berling's sustained interest in the role of science and expertise in security matters combined well with Ole Wæver's initial hunch that something new was on the verge of reshaping the conceptual and practical worlds we live in.

Taking a step back from theory and observing constitutes a conscious analytical approach. At the same time, it is a normative choice. Stepping back and observing now will allow us to contemplate how this might - with time develop into a new theory of security. For the time being, however, what we offer is different.

Empirically speaking, the entanglement of different disciplines is already a fact. Scientists and practitioners are asked to compare their different "threat" analyses and tell politicians which one to react to first. And in the working groups and advisory boards, we are negotiating new meanings and are developing concepts across disciplinary and practical boundaries. Yet, we do not have a framework for grasping these processes yet. Therefore, this book 
builds exactly such a framework for the study of unwanted futures. It is meant as a way of understanding what is happening right now, and as a tool in the hands of students and researchers who want to grapple with all the translations of security currently shaping our disciplines and professional practices.

In the process of coining this idea, we have had numerous discussions with colleagues. In this book, some of them have agreed to participate with a "boxed tale of translations." This is a short, empirical story of unwanted futures. We encourage you to read all of them. They can be read independently or as part of the book as a whole. We are grateful to Rune Saugmann Andersen, Jonathan Austin, Didier Bigo, Mats Fridlund, Niels Peter Hahnemann, Lene Hansen, Martin Holbraad, Ieva Jusionyte, Bruno Latour, Anna Leander, Klaus Lindgaard Hoeyer, Jonna Nyman, Lise Philipsen, Helle Porsdam, Frank Sejersen, Nisha Shah, Jeppe Strandsbjerg, Henrik Vigh, Kathleen Vogel, and Maja Zehfuss for allowing us to reprint their work here. Most of them also contributed with ideas at a conference in Copenhagen in May 2014.

A number of research assistants helped us along the way. Emilie RandløvAndersen did a tremendous job at DIIS in late 2020 and early 2021, but before her Ateebah Chaudry and Ida Mosegaard worked tirelessly on the bibliography at CAST at the University of Copenhagen in early 2020. Kasper Krog Pedersen kept his cool when preparing and hosting the international conference on translations of security in 2014 in Copenhagen. We couldn't have done it without you guys.

We would also like to thank the anonymous reviewers for insightful and constructive comments, Nordforsk for economically supporting the book project as part of the Nordic Centre of Excellence on Security Technologies and Societal Values (NordSTEVA), and the University of Copenhagen for financing CAST through its 'Excellence Programme for Interdisciplinary Research' and thereby enabling us to jointly conduct the research leading to this book. 


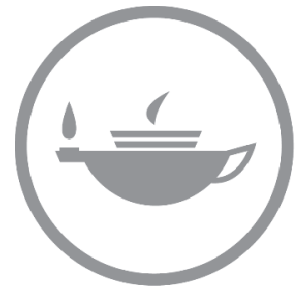

Taylor \& Francis
Taylor \& Francis Group http://taylorandfrancis.com 


\section{Introduction: translations of security}

On March 11, 2020, Danish Prime Minister Mette Frederiksen addressed the Danish nation in a press conference broadcast live from the "Hall of Mirrors" in the Ministry of the State. The setting was grandiose, the tone was serious, the future gloomy. The corona pandemic was here, and it was threatening the Danish citizens, the healthcare system, the welfare state. Frederiksen announced an immediate and two weeklong lockdown of Denmark. Now was the time to show "community spirit." Each and every citizen was called upon to work collectively to protect vulnerable individuals, societal cohesion and the survival of the Danish state. Gone were the threats from climate change, which dominated the general election less than a year earlier. If border control was relevant, the reason was no longer the migrants and refugees whose "influx" and "failure to integrate" had fundamentally re-configured the Danish party system over the last decades. A classic act of securitization requiring the concentration of all attention and resources on emergency measures to fight off an existential threat, some would argue. However, with this book we argue that what happens in instances like this is more complicated. It constitutes a complex web of translations of this security message into the daily practices of government agencies, private companies, and of citizens. The aim of this book is to provide a framework, which should make us better equipped for analysing and understanding such translations.

Zooming out in the press conference room, a number of other people appeared at lecterns beside the prime minister's, representing different forms of authority and expertise in different sectors, at different levels ranging from the individual to the international. The Minister of Health, The Head of the Danish Health Authority, A medical doctor, A senior representative of the Ministry of Foreign Affairs, The Head of the Danish National Police. Together with the Prime Minister, these voices translated what kind of unwanted future, the corona pandemic foreshadowed and how it could be handled. This book argues that to understand what was unravelling before our eyes on that March day, security analysis should be heading in a new direction. This book tries to systematise and think through thoroughly how such an analytic would look like. 


\section{Introduction: translations of security}

Because before and beyond the pandemic, the security field has escaped its classical confines. National security is more and more concerned about issues such as terrorism, cyber security and organised crimes, which does not respect the traditional boundaries between a state's external and internal security. Migration is increasingly cast as a security issue, equally conflating the internal and the external: treated as policing, border control, the fight against international organised crime, and in some cases inter-civilisational conflict, the issue takes amorphous shapes that are not easily grasped within classical terminology. Issues pertaining to environmental degradation, food safety, and pandemics bring in areas of expertise far beyond the traditional security studies field. Risk-assessment in relation to energy, industry, transportation, and health enter national security under the heading of "critical infrastructure protection" and challenge sedimented divisions. Economists analyse risk at different levels of analysis, but face challenges, when e.g. the threat from terror upsets the relationship among the categories of uncertainty, economic risk, and political risk. Each of these areas assesses, selects, and governs unwanted futures - risks, dangers, or threats - but they do so in different ways.

Also, dangers and risks that were previously seen as substantially separate are more often connected, compared and weighed against each other. For example, climate change and violent conflict are linked in at least two ways: first they are "compared" when policy makers prioritise different "threats" and make statements (typically backed by experts) about one being bigger than the other, and second, because they sometimes get causally connected, as if one might trigger the other. In Box 1.1 of this book, Bruno Latour demonstrates how the issues of terrorist attacks and climate change are being linked. In his reflection on the atrocious 2015 terror attack against the French concert venue Bataclan, he shows how the action against the perpetrators were weighed against action to prevent climate change.

Likewise, we are witnessing a collapse of established boundaries as different scholarly agendas and social practices are gradually merging and finding distinct ways of governing. Indeed, policy makers are expecting researchers and other experts to handle potential challenges on a joint basis. Specialised terminologies embedded simultaneously in different theoretical traditions and in different societal practice fields that previously evolved for distinct professions, disciplines or organisations increasingly intersect and interact. But even though the experts, called upon, speak to the same objects, they are speaking different disciplinary languages without much mutual contact or understanding. A key challenge for both security studies and for other disciplines theorising and contributing to the practical management of security today is to understand how these separate bodies of knowledge meet and produce unforeseen political consequences.

Translations of security thus happen all the time, with consequences for how we understand the political possibilities for action. While we all might recognise this pattern, we lack a conceptual and analytical apparatus to fully 


\section{Brief 1.1 Translations of security}

\section{What is a translation zone?}

A translation zone is a point of observation that describes (1) how different conceptual expressions of how to handle unwanted futures meet, and (2) how new meanings are negotiated.

\section{Why should we study translations of security?}

By studying translations of security, we (1) come to understand changes in the current security landscape, and (2) enable a qualified and reasoned critique of current political practices of security.

understand what is at stake in these translations: how they define, restrain or enable action. This book suggests a conceptual framework for how to analyse these translations of security (Brief 1.1).

In this introductory chapter, we first recount the evolution of the most basic concepts organising how our societies manage threats and unwanted futures and explain how our approach should be of interest across academic disciplines (beyond standard calls for interdisciplinarity). We then discuss our core analytical choice - focusing on the forms of translation occurring in "meetings of meanings" - and explain how that choice makes sense in relation to our own disciplinary background in security studies. Finally, we introduce the foundational elements of our analytical framework: our focus on conceptual meetings in "translation zones" across central modes of societal differentiation - and how this focus organises the volume.

\subsection{The diversity of unwanted futures}

Our basic claim is that in order to understand how society handles some of the most important problems it faces today, we need to pay attention to how different ideas about threats, risk, and dangers meet and what new meanings and future political possibilities are prescribed in the translations that take place in these meetings. A precondition for talking about "meetings" is of course that some pre-existing entities exist which may enter into a meeting. Apart from security, this family includes members like various versions of risk thinking attempting to calculate the value of unwanted futures (Adams 1995; McDaniels \& Small 2004; Renn 1992); versions of uncertainty thinking inviting resilience, precaution, pre-emption or threat assessments (Vogel Vogel 2012 Callon et al. 2009; Chandler 2014; Vogel, 2012); and sustainability thinking asking for technical-rationally informed adjustments of socio-economic development (Duffield 2001; Gad \& Strandsbjerg 2019).

While the concepts of security and risk share many features, the two concepts embody distinct histories; being occupied with the possibility to 


\section{Introduction: translations of security}

form: decision-making within distinct fields. Where studies on security have focused on the political management of the exception, risk studies have historically been preoccupied with the private (economic) management of everyday perils and opportunities. Until the 1980s, the concept of security was mainly tied to the realist conceptions of the nation state and military matters, concerned with order, territory and war. This understanding of security came under pressure during the 1980s, when security scholars problematised the narrow focus on states and military matters and showed how the concept of security constituted the political possibilities within a wider field of non-military matters, e.g. environmental politics, immigration, and religion (Buzan 1983; Buzan et al. 1998; Laustsen \& Wæver 2002).

Almost parallel to this development in security studies, sociologists and anthropologists started to point to the political nature of risk. Most prominently, Ulrich Beck (1992) linked the power of risk management to the evolution of the industrial society and Mary Douglas emphasised the political choices involved in the societal selection of risks and dangers (Douglas \& Wildavsky 1982). Likewise, poststructuralist scholars pointed to the disciplining effects and neoliberal character of the dominant economic and social practices of risk analysis (Ewald 2001; O’Malley 2004; Simon 2002).

Recently, a number of neologisms have entered the debates on risk and security, in many ways spanning the two debates by questioning the risk management idea of forecasting and control, and security studies' focus on the survival of collective and delineated referent objects (Petersen 2016). Precaution, resilience and sustainability are examples of some of the most powerful neologisms of today. While these concepts differ in many respects (see, e.g. Gad \& Strandsbjerg 2019; Stirling 2007), they all share a common focus on the problem of managing uncertain (possibly catastrophic) futures and problematise the possibility of a spatial limitation of today's risks and dangers.

This brief sketch is a history of conceptual boxes. But it is also a history of how these boxes are connected; how their conceptual content is mixed; and how their delineation is negotiated. Increasingly, any given issue is shaped by the fact that it does not fit neatly into one space, but traverses several categories. Every single way of governing a specific challenge connects actors who are anchored in different "universes" (Wigen 2018: 49). Their engagement with this issue and with each other might re-shape the actors themselves and the social worlds they originally acted with reference to. Over time, the boundaries of the social placement of a given issue are likely to change. Our contention is that we are now approaching a situation, where these changes are often as important as the fixed categories and the predictable processes they encompass. Simultaneously, these changes can only be understood if taking into account those universes of meaning that actors speak from and how these are embedded in large societal patterns. Therefore, it is urgent to study how the meaning of security is shaped by 
processes of translation - by actors approaching it with different symbolic repertoires and yet interacting over a given issue despite these differences.

\subsection{The value of science - disciplinary and interdisciplinary}

We do not venture into this terrain to suggest (better) translation among mutually estranged modes of communicating. We do however believe that understanding better the full spectrum of how translations happen, will make for more reflexive attempts, and certainly (as we will show in chapter three in relation to academic disciplines), an improved understanding of translations might improve democratic accountability. But these are both secondary effects to our core project. Our approach is basically empirical and explorative: We intend to study the actually happening phenomenon of translations; what is happening out there, right now.

Therefore, our "translations" approach to security is not meant to be the universally brilliant, timeless contribution that security studies has regrettably ignored in the past and should uniformly ascribe to in the future. The relevance of this approach emerged at a particular time and place. It is a response to a specific situation in which, on the one hand, "security" has assumed new centrality in public and private policy-making - while, on the other hand, we are witnessing not just the specific security mode expanding, but several competing styles and codifications simultaneously gaining wider circulation and therefore increasingly intersecting.

Some would argue that a standard interdisciplinary framework would be able to tackle this challenge. We believe that this is simply not enough. The current populist post-factual trend to discredit scientific or expert statements because of the obvious existence of scientific disagreement (Berling \& Bueger 2017 ) is partially a result of the way the different disciplines seek to police the boundary around their specific way of approaching a problem. The disciplines render themselves vulnerable to fake news forms of criticism when claiming authority on the grounds of such disciplinary policing.

We offer a different starting point: we can no longer take for granted any "natural" or standard division of labour between disciplines when it comes to threats and security issues. Quite the contrary; the renegotiations of these divisions of labour are exactly that on which we need to focus our analysis. For the same reason, we cannot just repeat what we - literally - used to do, when the security agenda began expanding decades ago. In the 1980s and 1990s, ever-new phenomena were treated as a security issue either because they were argued to involve threats in their own right or because they were causally linked to established security threats. In essence, a widespread reaction in Security Studies was observing this tendency as if the category of security was exported un-altered to new fields while treating these new fields as pristine, un-conceptualised domains. In contrast, in the present book we engage with the conceptual and theoretical practices already taking place within these other fields. Thereby we allow ourselves to observe how the 


\section{Introduction: translations of security}

processes of translation are more complex than the label "securitization" suggests.

Some work of this sort has been carried out under the heading of "risk," yet not in a sufficiently systematic sense. Rather, this debate has shown that there are many different concepts of risk in play in the debate - marking different understandings of control and uncertainty (Beck 1992, 2002; Ewald 1986) and that different communities, cultures, disciplines, and agencies practice (or translate) risk differently (Douglas \& Wildavsky, 1982; Jasanoff 1998).

The emphasis on interdisciplinarity in this book is not the often-heard (and sometimes rather hypocritical) claim that interdisciplinarity is good per se, or that better understandings always result from joining forces among several disciplines. Quite on the contrary, the rationale behind the present volume is that "security" is an inescapably interdisciplinary challenge because different academic fields are already co-constitutive of different parts of "security" as a practice field. Rationalities and theories from different disciplines are built into the way society handles different challenges: from economic risk analysis over technical system assessments to military threat analysis. Interdisciplinary collaboration is needed to keep up with ongoing transformations in the social construction and handling of threats, risks, and security, and even if the different disciplines tried to do so, they could not protect the purity of their objects of analysis, for the different rationalities of security are already intermingled. The diversity of already existing modes of handling the current situation calls for an approach that does not take one particular form as privileged but explores the non-hegemonic meetings between these different terminologies, conceptualisations, and practices. With such an understanding as the backdrop, disciplines can become much more reflexive regarding their relations to neighbouring scientific discussions and thereby build in comparisons and constructive disagreement when communicating results. Simple anti-expertise claims will then be much harder to make successfully. If such scientific disagreement and collaboration become the "new black" across disciplines, a new path is ready to be tread for a resurrection of science-respecting expertise.

Hence, the impetus behind this book stems from a growing discomfort with the way in which security studies have conceptualised the expansion and merger of various ways of managing unwanted futures. At the same time, our ambition has been to formulate a framework for analysis and a basis for reflection which lends itself to disciplines, scholarship, and practitioners approaching these issues from other traditions. If our diagnosis is right, the analytical perspective not only deserves to be made available to a wide range of fields - in fact, these are all already part of the conversation. Therefore, both the framework and the findings will be presented in a manner that does not presuppose particular familiarity with security studies terminology, while we will also make the necessary clarifications vis-à-vis those security readers who legitimately expect this. 


\subsection{Beyond securitization theory}

A number of theoretical frameworks emerged in Security Studies in the 1990s, and while it is certainly still worthwhile to develop the different theories by careful applications and evaluations, it is also a good time for "stepping back"; for taking care not to force cases into pre-established, elaborate theories; and for generating nuanced observations. There will come a time for theory building again on the basis of the current work, but this book refrains from doing so. Within what is sometimes called "New Security Studies" (Burgess 2010) or "New European Security Theory" (Büger \& Stritzel 2005), a productive theoretical tension has been one between approaches that present a fairly formalised framework for analysis and those that celebrate the possibilities of total emergence. In this debate the Copenhagen School is a well-established name (McSweeney 1996) for an approach increasingly defined by the concept of securitization (Buzan et al. 1998; Wæver 1995). Scholars in this tradition organise their analyses around the speech acts that constitute particular issues as security concerns, the implications of such securitizations and the political struggles over what to (de)securitize how.

Critical security scholars have (rightly) criticised the formalistic nature of the Copenhagen School concept of securitization, and its use of one distinct conceptualisation to organise the whole field of analysis. These scholars argue that analysts of securitizations often ignore the political power of new institutional arrangements (police, military, customs, border guards, etc.) and technological and other practices within the field of security by restricting the study of security to a certain speech act and to spectacular situations. Didier Bigo and Jef Huysmans (the Paris School, C.A.S.E. 2006; Wæver 2012) have forcefully argued that the Copenhagen School thereby risks underestimating the politics of unease and becomes blind to the political power of everyday micro-practices of security (Didier Bigo 2006b, 2006a; Huysmans 2011; Huysmans 2006). This critique is valid and important because it confronts an inherent dilemma in any conceptual analysis of politics and change: that it is impossible to grasp political change and the performative power of concepts without stabilising meaning.

Securitization theory was not set up to just describe a reality of security politics. Rather, the construction of the concept of securitization also reflected political and ethical considerations about the political performativity involved in any use (or non-definition) of security: that the concept of security is doing something to politics. Consequently, the introduction of securitization as an academic concept was also meant to impact the politics of security in a particular way, notably by politicising and by challenging all attempts to naturalise security policy as "necessary" responses to particular threats (Wæver 2011). Stritzel (2011a: 347) and others miss this important feature when referring with open irony to Buzan et al. (1998: 4) that "one suddenly finds references to "exploring the 


\section{Introduction: translations of security}

logic of security itself' (as though there existed a universal, transhistorical 'logic')." Stritzel subsequently concludes that Wæver's conceptualisation of securitization is "not only ahistorical but arguably also non-critical/ anti-progressive" (Stritzel \& Vuori 2016: 347). ${ }^{1}$ The political and normative move is quite simply missed by many. Similarly, the Paris School was a political move at a given time and place with an aspiration to bring out from the shadows a newly intensified set of struggles between agencies of protection all mobilising new technologies in a fluid political situation where boundaries and domains were redrawn (Bigo 1996). In much the same vein, this book seeks to retain the normative drive to question current security practices by putting forward a new perspective from where to look. We stabilise this novel perspective by looking from a set of historically sedimented concepts: professions, cultures, and scales, and their challengers: amateurs, civilisations, and networks. This allows readers to follow our argumentation, and at the same time retain the possibility to challenge us. From our point of view this makes it possible to grasp the myriad of fluidities we currently encounter, without ourselves being pulled down into the quagmire - analytically speaking. This framework is not built from novel conceptualisations of the "logic" of security, risk or other key concepts. Those we observe in all their nuances, variations and messiness, and we do so from a framework that maps out the different types of meetings of meanings involved in the translations of security. Thus, we share the original Copenhagen concern with concepts but go about studying them the opposite way from securitization theory.

The present book - written by a group of authors coming out of Copenhagen and influenced by securitization theory - moves closer to the kinds of cases and the forms of analysis practiced by the Paris School. However, the over-arching framework and interpretation presented by the Paris School are in need of as much criticism as the Copenhagen School. It is equally problematic to repeat invariably a standardised analytical format, where the powers-that-be stimulate unease, agencies uniformly expand their apparatuses of surveillance and control, and interagency struggles roughly follow a logic of bureaucratic politics. The most meticulous empirical analyses from a Paris School background are nuanced enough to fulfil the criteria for a translations type of analysis - as would probably the most nuanced and elaborate Copenhagen School analyses. The main point here is, however, that it is time to combine a Paris kind of attention to complex and often bureaucratised cases with a Copenhagen style attention to the historicity and performativity of concepts. Such combination creates an analytical clarity, which enables us to identify change and thereby critically evaluate today's security governance. Framing our project in relation to "Copenhagen" and "Paris" might sound very 2000ish but serves to introduce some principled strategic choices especially regarding key concepts. Also, theoretical debates since then have only to a limited extent crystallised distinct new approaches and to a large extent operate in relation to the 
matrix produced in the field's dramatic recasting in the 1990s (Wæever \& Buzan 2021).

Looking beyond Copenhagen and Paris, one of the most popular and productive approaches in the last decade, ironically, represents yet another homogenising model. A very compelling analysis of "the politics of possibility" shows how risk management is established across a range of actors in situations where actual calculation of probabilities fails. But exactly in this void a horizon of possible futures becomes the foundation for a governance of the present (probably most clearly in Louise Amoore 2013; but see also Adey et al. 2015; Amoore \& de Goede 2008; Aradau \& van Munster 2011; Goede 2012; de Goede et al. 2014; Leese 2016). These writings constitute maybe the most powerful research programme to emerge after the Copenhagen/Paris debate. Yet, while often presented as a contrast to the exceptionality of securitization, the approach tends to stabilise a new figure, a new form as the centre of analysis, where the power to perform this new form of governance is not locked to a particular actor but floating freely (as securitization) to be appropriated by any actor able to pull it off. It is, however, highly improbable that one conceptual figure has the constancy and clarity that allows this kind of uniform analysis. In contrast, in what follows, we propose to carefully and more flexibly study the many different codifications that emerge in the meetings of actors coming with different approaches to future dangers, risks, and uncertainty. In chapter two, we go into more detail with this focus on the translation rather than the forms themselves.

In contemporary "critical security studies," the most powerful tendency is to draw in various ways on Science and Technology Studies (STS) - often with a special emphasis on Actor-Network Theory (ANT; and post-ANT) leading to what is sometimes called "the materiality debate on securitization" (Pelizza 2021). This creates three challenges to our project: terminological, meta-theoretical, and theoretical. The terminological issue relates to "translation" which is a key concept in ANT, where, however, it has a distinct and unusual meaning, which we are not adopting in this project. This is spelled out in the first part of chapter 2. The second issue is metatheoretical (or anti-theoretical) and relates to the issue discussed earlier in the present sub-section: do you want to fix anything as theoretical categories in a framework for analysis? The original securitization theory as well as the "politics of possibility" form of risk governmentality studies are centred on a particular "form"; the (early?) Paris school had a specific process at the centre. More recent critics and transcendences of securitization theory attack fixations and conceptualisations as such, denouncing any such as "static" and unable to capture the nuances of specific cases. These approaches implicitly or explicitly posit an ideal of studying cases with no preconceived theoretical notions. While seemingly impossible, (early/original) ANT was in one reading exactly an attempt to do this, a radical semiotics which demanded that no actors, issues, concepts or objects could 
enter the analysis until their emergence had been traced (Law 1999; Latour 2005, 2013b) (More on this in section 2.1 and 2.2). Most interventions in security studies did not fully take this leap, which at least would have been consistent (but probably impossible), and instead they often traded on echoes of the theories they criticised, i.e. "securitizations is not only ..., but also ...," where the starting point was borrowed from the theory one claimed to get rid of. In the current book, we aim to present explicitly a new and different framework for analysis, where anchorage is different from both securitization theory and its critics. We focus on a specific phenomenon, translations, which we study in a matrix of the major types of differences, and with an interest for what happens to concepts from the family security, risk, danger, uncertainty, and so forth. The third challenge is in some ways continuous with the second, in another sense it is in tension with it: Critical Security Studies today privileges materiality (things, artefacts, devices, etc.). In today's theory landscape, the present project might seem untimely, because it does not accommodate this foregrounding of objects, but our approach is both more inclusive because it studies translations both by following "things" and in other kinds of meetings; and it is more politically responsible, because it includes an analytical apparatus for exploring the ensuing concepts of unwanted futures, where neo-materialist security studies often rest satisfied with showing that securitizations and the like are produced through material qualities of artefacts and infrastructures with the involvement of a multitude of actors, not well attuned to exploring the political stakes and investments. As spelled out further in chapter 2, the political importance of concepts and the theoretical tools for their study is crucial to our framework.

The neo-materialist movement enriched Critical Security Studies by bringing attention to complex entanglements of diverse actors in many processes of (alleged) risk and security management including an often decisive role for material things. In addition to analytical and empirical insights, this intervention had political value when politics was "hiding" in seemingly technical or scientific procedures. Mike Bourne (2012), especially, has argued convincingly that "blackboxing" in technologies has hindered possible political interventions, e.g. in classical security areas likes arms control and disarmament. Similarly, Marieke de Goede (2020) has discussed how new forms of critique are enabled by fine-grained analysis of technical practices (Amicelle et al. 2015; Aradau \& Blanke 2017; Lisle \& Bourne 2019). However, the general swell of security studies with a material focus rarely shows such reflexivity. On the contrary, it follows the general pattern of the so-called "turns" in International Relations, where it too often is implied that an analysis is "critical" or "progressive," if it centres on "new" media like images, emotions, or materiality (Epstein \& Wæver 2019). The critical contribution then is to show that this new dimension "mattered," whereas an actual political analysis of constellations, actions, responsibility or possibilities is harder to find; often because of an ironic black-boxing of key 
concepts like risk and security, where actually politics is often vested exactly in the precise shape of these key concepts - exactly emerging at the intersection of numerous, increasingly diverse actors. Ironically, the STS impulse in Critical Security Studies delivers less and less on the meta-theoretical obligation to not pre-privilege anything and turns into a search for "materiality" as the "finding" article after article. Complex entanglements of diverse actors are indeed the key challenge today, but this should be studied more inclusively, capturing "translations" whether they centre on material objects or not, and with a theoretical apparatus to designate what is going on in these translations in terms of concepts of security, risk, danger, sustainability, precaution, and prevention, and what this does politically.

\subsection{Translation as point of observation}

The framework presented in this book takes its point of departure in how "meanings meet": observing politics as meetings of different conceptual expressions of unwanted futures. This choice involves a certain structuralism as the specific ways of addressing security issues depend on each their sedimented structure of meaning. When disciplines meet - in interdisciplinary research or in policy formulation - they bring each their approach to security, risk, or danger. When different functional systems encounter risks or dangers, they make sense of it in each their way. When an organisation or a nation state seeks inspiration with a neighbour in imagining a dangerous future or how to handle it, different cultural conceptions of security meet. What meets is not just a - explicit or implicit - policy or programme for handling a particular issue; every meeting also entails a variety of co-texts of meaning. As we explain in chapter 2, these meetings constitute "translation zones": occasions for translation between one structure of meaning and another. Below we return to a more detailed explanation of what kind of phenomena we imply with the label "translation"; for now, it suffices to note that processes of translation inevitably are political in that they involve the realisation of some futures rather than others.

As stated in brief above, translations, which occur in meetings between sedimented structures of meaning (concepts), is the central site from which we choose to observe current policies. ${ }^{2}$ It is productive, we argue, to focus on translations where specific cases are handled at the intersection of different conceptual universes.

This methodological choice of ours might sound almost trivial: the world is not made anew each day; every negative situation is not conceptualised as a new start; each committee in a bureaucracy is not assembled by people trained specifically for this purpose, but coming out of different scholarly, occupational, and cultural backgrounds; people meeting strangers bring with them mental baggage. In the contemporary intellectual climate of Critical Security Studies and many other social science and interdisciplinary fields, however, it is easier to uphold the meta-theoretical position of total 


\section{Introduction: translations of security}

emergence - probably due to a widespread and sound suspicion of approaches that lock down givens outside and ahead of actual analysis. In this book we have taken pains to develop a perspective centred on translations as such, not pre-conceiving what happens in these translations in any substantial manner, but still making past conceptualisations a central concern.

By developing this analytical focus, we have deliberately kept open for empirical analysis what exactly such meetings may result in. In that sense "translation" is kept as a point of observation which will allow empirical accounts of meetings between structures of meaning prescribing certain ways of handling unwanted futures.

Our focus on translations is a focus on change and the meeting between different fields, spheres, or sites of meaning. It asks what happens to conventional understandings of security, risk, uncertainties and dangers when practiced within and across new spaces of professions, disciplines, organisations, cultures, and scales. As argued below, the aim of this book is to think security beyond securitizations and not "only" study how different sectors or fields incorporate a given security logic (securitization). This aim springs from an ambition to take the critical debate on security further and ask how to theoretically understand and methodologically grasp different logics of security, such as how precaution and risk are constantly negotiated and with what political consequences. This is why we, as a heuristic device, conceptualise meetings as translation with a preference for theoretical minimalism. Such minimalism is not our general inclination or a universal recommendation for how to do research. Situating, briefly, the book in the current landscape of Critical Security Studies should explain why we find this minimalism justified at the current juncture.

\subsection{Observing change: new and old constructions of unwanted futures}

To carry out this study of translations, it is necessary to make some methodological decisions and they entail theoretical investments. However, we have strived for a theoretical minimalism, because we try to create space where it becomes possible to tell tales of translations that make actual studies which enrich our understanding of both the many ways in which security, risk, danger, threat, and uncertainty are understood and of the processes involved in actually instantiating these in complex, combined actions. We want to enable a mode of observation, not an elaborate shared terminology.

The basic idea behind the project is that we want to zoom in on cases where different conceptual rationalities are simultaneously at play. Not because this is necessarily always the case, but because it is an analytical strategy that will bring insights, which are timely when categories are in flux. Typically, by focusing on such situations, two kinds of observations are possible. On the one hand, comparisons become possible and with it an 
increased understanding of how concepts (e.g. risk, security, threat) differ and are used differently in given spaces. On the other hand, such studies simultaneously throw light on that which happens in the new, hybrid situations where several worlds intersect and are negotiated.

We zoom in on cases that somehow "move" or emerge at the intersection of several previously more distinct spaces. This naturally implies that there are different "places" and that universes of meaning and communication differ among these. What each of these worlds or conceptual universes are made up of and how they are delineated will, however, only emerge on a case-by-case basis.

We discuss these meetings as taking place in "translation zones." In developing this analytical concept, we combine inspiration from a variety of approaches to translation and Peter Galison's ethnographic studies of "trading zones." In these zones, Galison observes how collaboration takes place between e.g. scientists from different disciplines and engineers. Despite their ultimate adherence to radically different systems of meaning and forms of expertise, they collaborate and coordinate through all kinds of ad hoc rules and even emergent languages (Galison 1997). Often the management of a given challenge in the new security field takes a similar form where project teams or hybrid administrative units produce a terminology for the given purpose. Bureaucrats, experts and other participants in the handling of a given challenge typically draw on different background universes while they jointly produce documents, practices, and policy actions that cohere around the specific challenge and practices attached to it. A discourse analyst will tend to emphasise the "competition" between the different programmes involved. In contrast, a "trading zones" analysis will focus on the practical coordination that takes place in spite of what would in theory count as incompatible discourses. The expertise produced in a trading zone thus combines a number of different background disciplines and practices and is formed in the specific application. But it does not necessarily transform disciplines nor practices. That is, the fact that these different actors co-act in a specific context does not produce a merger or synthesis of their different meaning systems. In contrast they develop ways to get by that draw on their still very different ways of making sense of what they do.

In what follows, like Apter (2006), we prefer the label "translation." In our usage, the label refers to meetings between different concepts of unwanted futures and, following on from that, different modes of handling them. As we will discuss in detail in chapter 2, other scholars have theorised and studied "translations" in relation to a range of other objects of study than the politics of unwanted futures. We could alternatively have opted to employ labels like "assemble," "articulate," "perform," or "interpret" to denote the phenomenon we are attempting to delimit; each option would have meant co-importing wanted and un-wanted connotations. For now, the important point we want to make is that we have chosen "translation" because of the polyvalence of the term rather than to import the theoretical 


\section{Introduction: translations of security}

baggage involved in any one theorisation: we want to keep open to empirical analysis, what happens in these meetings. ${ }^{3}$ Again, the reason for our preference is the ambition to keep our analytics open: The metaphor of "trading" connotates an exchange on a market, where each party contributes something and takes something away in return - even if the whole point of Galison's analysis is to show how the transaction indeed - at times produces something new. In a "translation zone," in our use, there might be exchanges, and/or some new constellation of concepts, practices, agency, and so forth may arise. But that's not necessarily what happens: Meetings may alternatively consist of unilateral extraction; of inconsequential encounters; of conflictual clashes. Translation zones, hence, are meetings between conceptualisations of unwanted futures and programmes for their management.

Simplifying a bit, one might say that meta-theoretically anything but two extremes will do (two extremes which we are - paradoxically - inspired by!). At one extreme, some forms of Systems Theory à la Luhmann would not leave room for the studies, which we want to do: If each differentiated social system is defined and delimited by an inner code, and the only meeting possible is structural coupling where other systems become an irritant that is codified from within a given system, there is no such thing as translation taking place. What happens are internal processes of communication inside each system - systems that in turn produce events that other systems might re-describe through their internal communication (Luhmann 1992). Second order observers might look at these parallel systems and observe them simultaneously, but their communication is then anchored in this third place, not in either first order system and certainly not in both at one and the same time. It is in principle impossible to locate a process of translation as a "meeting" of two systems - in the extreme interpretation of this approach.

At the opposite extreme, some forms of ANT are radically actualist and only leave room for studying what is realised and how new phenomena emerge in a unique situation, producing actors, networks and meaning. This is not what we aim for in the present study. Thus, although ANT actually plays a considerable role in our own thinking about these issues, we do not employ the term "translation" here in the technical sense it has in, e.g. Callon (1986) who employs the term to denote the way a network is represented by some entity, the basic mechanism by which worlds take form. Actually, even Latour recognises - in his project on "modes of existence" (Latour 2013b, 2013a; Tresch 2013) presented as complementary to ANT that it is necessary to operate with some conception of different, more stable forms that complement the study of emergent uniqueness.

At some very general level, the basis for the present study is therefore (the unlikely) Latour-meets-Luhmann (Farias 2014), but in the very flexible sense that one can draw on various different social science terminologies within this space. In one respect, these two extremes are vanishing points for our analytical ambition in the sense that they constitute the two positions from 
which this project will become impossible - either because all communication is internal to systems, or because each event creates the world anew. In another respect, these two perspectives are the poles between which the analysis of this book is extended: it is necessary to have both a Luhmannian component (communication always being generated on the basis of codes and particular social factions) and equally necessary (with ANT) to take each particular event as producing a new centre that draws elements together in ways that can constructively be seen in relation to the event itself.

While we base our study firmly in mid-air between these two incompatible social theories, one more dimension is required in order to capture what is at stake today. If we look at a more classical humanist conception of translation, we find a tradition of thought where relatively stable systems of meaning do exist as the basis of translations - and meaning may actually be transmitted undisturbed between these stable systems of meaning. We argue that while linguistic translation studies have generally left the realisation of this ideal behind, the ideal lives on in much of the empirical material: Practitioners relentlessly venture to understand the Other, believing - in spite of Social Theory - that this is possible. The complications, which this phenomenon presents for the analysis are unfolded in chapter two.

\subsection{How to observe translations: the role of concepts and their historical and social categories of organisation}

What exactly is negotiated in these "translation zones" and where do we find them? These are important questions, as we aspire to be sensitive to the variety of possible meetings and meanings, while setting up our own point of observing them all simultaneously and consistently. In these last paragraphs of our introduction, we, first, explain why concepts are key, when analysing the meetings of distinct bodies of meaning. Finally, we argue the relevance of key forms of societal differentiation, when looking for the translation zones where these meetings are likely to take place. The organisation of the analytical chapters follow from this argument.

So, what is it that meets? As hinted to above, we approach these meetings in conceptual terms, inspired by conceptual history. Accordingly, our approach attends to the negotiations of a number of concepts of risk, security, insecurity, threat, danger, unsustainability, etc. The intellectual toolbox of conceptual history will allow us to zoom in on the variety of current and past synchronic negotiations of meaning and to situate those in the diachronic structures (i.e. how they are placed in the longer history of concepts). Translations are, in these terms, expressions of synchronic conceptual negotiations: the battles on meaning in a given context, time, or event. The distinction between diachronic and synchronic is an analytical one, as synchronic expressions always will relate or depend upon its place in the "longue durée" of historical time. Likewise, a diachronic analysis will always be an expression of the many synchronic conceptual understandings. 
But what is a concept? Quentin Skinner and Reinhart Koselleck identify concepts as "attitudes," "mediums for shared understanding" or "concentrates of meaning" (Koselleck 1985: 84; Skinner 1989). Concepts are in these terms a negotiated "image" of a social and political reality. ${ }^{4}$ Koselleck contends that concepts are mirrors of our political and social experience and that we therefore can come to understand social and political history better by studying these struggles over conceptual selection, delineation and sculpting. A concept does something, Skinner and Koselleck argue; a concept makes a difference by ordering a social and political reality and, hence, introducing particular possibilities and alternatives (Koselleck 1985; Margolis \& Laurence 2011; Skinner 2002). A concept is however not just an idea, a thought. It is not purely mental but materialised in actual communication, words and utterances, practices and programmes. In other words, a concept produces social categories of ordering.

A productive way to approach and analyse a concept is to focus on how oppositional concepts co-constitute each other in semantic fields. Skinner e.g. asks, "What do practitioners do in talking about the state?" (Skinner 2002: 90-102). What are they up against (conventions) and what is the political outcome (what is suppressed and enabled)? What are the possibilities for change? By asking these questions a conceptual landscape emerges, which specifies the limits of possibility inherent in how a concept has been stabilised.

Where Koselleck mainly concentrates on writing the history of winning concepts and their expressions of temporality, Skinner has an explicit focus on political battles. On how speech acts promote specific concepts to specific audiences in conflict with alternative attempts at ascribing meaning (Skinner 2002). For instance, when a series of complex speech acts ranging from philosophical treatises to political speeches installed the concept of sovereignty in early modern politics, the conditions altered for social and political activities in numerous domains.

In this book, we study the synchronic political battles over conceptual meaning. We focus on how conceptual expressions meet, on the means which are mobilised and on the claim to authority on which they rely. Yet, in order for these battles to appear meaningful, they must draw upon, relate to or break with the historical diachronic patterns of meaning (or conventions, as Skinner calls them). In other words, in order to identify political and social changes, one must recognise the historical authority at stake in the battles over meaning and how they challenge more sedimented structures of meaning. Otherwise, we risk reproducing these historical, authoritative meanings. Thus, as Skinner shows in various writings, Hobbes's successful construction of the image of the modern liberal constitutional state gained a powerful position because it innovatively relied upon former authoritative constructions of the protective state.

For setting up an analytical grid for this book, we have identified some of the main conventions, or diachronic patters of conceptual authority, on 
which modern discourses on security, risk, and dangers rely. Following Luhmann (1977), we argue that modern society and modern concepts (often) engage three forms of differentiation: functional differentiation (represented in our analysis as professions and disciplines), segmentational differentiation (we focus on national and organisational "cultures"), and stratification (which we discuss as "scales"). These are all modern forms of organisation and discursive conventions that many translations of security revolve around. While being historical categories, they are also social categories of ordering, important for understanding what is at stake in the current times of translation.

In this book, the selection of functions, cultures and scales is an analytical choice, and a way to exemplify to the reader not only how one may look, but also to make visible how we, as authors of the book, observe changes in current practices of security, risk, and danger. We suggest a framework for analysis that centres on how concepts of unwanted futures meet and are mobilised. We ask by which means and with what claims to authority these meetings (translations) occur and what are the consequences of those meetings for political practices.

\section{Brief 1.2 Analysing translations of security}

\section{How can we observe a translation of security?}

- One can identify translations by studying how conceptual meaning meets and is negotiated across functionally differentiated professions and disciplines, cultures and scales.

- Focus is on conceptual mobilisation and change: On the means (linguistic or physical) activated in the translations; on the claims that makes the translation authoritative and legitimate; and on the consequences and changes produced.

What roles do professions and disciplines, cultures, and scales play in the analysis?

- Professions and disciplines, cultures, and scales are historical categories of ordering, that describe the sedimented structure of meaning on which concepts of security (often) rely.

- Current translations are historically conditioned by these categories of ordering, as translations of security tend to either stabilise, change or dissolve the conceptual meanings attached to these.

- In this book, these three categories of ordering are considered "translation zones": the main points of observation from where translations are studied. 


\subsection{Organisation of the book: functions, cultures, and scales as categories of ordering}

The analytical choices, presented above and elaborated on in chapter 2, are fundamental to the organisation of this volume. As such, the main body of the book will be devoted to showing how the social categories of ordering, functional differentiation (chapter 3), culture (chapter 4) and scale (chapter 5), can be used as points of observation (translation zones) which can help us grasp and comprehend current translations of security. By focusing on each of these categories of ordering, we will show by which means and with what claims to authority translations of security occur and come to challenge (or uphold) our concepts of and the practices associated with unwanted futures.

In chapter 3, we argue that professions and disciplines are important social organisations of societal differentiation: they are logically alike in the way they are functionally differentiated. Each discipline and profession claims "jurisdiction" over some field or function of society and each carry with them certain concepts of risk, security, and dangers. In this chapter, we discuss how different academic disciplines and professions treat and approach security, risk, and dangers - and what kinds of translations occur when disciplines and professions meet. Further, the chapter discusses how the concepts of "professional" and "amateur" challenge conventional boundaries of conceptual authority.

In chapter 4, we turn - as an important example of segmentation - to cultures, legitimised exactly by the way they are doing the "same" thing in different ways (as functionally equal units): Nations base their legitimacy in cultural uniqueness; organisations bring competition to markets by developing unique organisational cultures. The chapter zooms in on translations across cultures - national and organisational - to show how the prism of culture can capture other aspects of the translations of security that continuously take place. The chapter also discusses the translations occurring when processes of universalisation interfere with neat cultural demarcations.

Finally, chapter 5 focuses on translations across scales and how scaling produces and fixates space in ways that create hierarchies between the individual and the global level. Scales are considered a result of stratification (i.e. hierarchical ordering) of processes and identities of different scopes. Analogously to how amateurs increasingly question the expertise of professions and disciplines and cultural equality is repeatedly betrayed by universalising projects, modern forms of scalar ordering are challenged by networks redistributing agency and authority. By the end of the chapter, we discuss the translations involved when de-territorialised networks challenge the scalar imagination.

Hence, in relation to each of these modern forms of organisation, our discussion focuses on two types of translation zones: First, we analyse translations within the logic of the organising differentiation in question - 
e.g. translations between one profession and a second profession; between one culture and a neighbouring culture; between one scale and another scale. Second, we analyse translations that do not fit but rather challenge the functional, segmentational or stratificatory logic in focus. Approaching the concepts organising unwanted futures at these two points of observation allows us to see both continuity and change. These distinctions, we claim, will help us to analytically grasp the different forms of functionality, culture, and scale, and the negotiations of new meanings going on in the everyday translations of security, risk, and danger. In its attempt to create new meanings, a translation will, it is argued, always entail a negotiation of these distinctions.

Regarding empirical material, our aim has not been to conduct an exhaustive survey of current translations of security. Rather, in line with our stepping back from both established theories and premature theorising, the ambition has been to collect as diverse a sample as possible, allowing us to discuss not only the most important features of security translations but also its diversity as such. With this ambition in mind, we have chosen to not conduct in-depth analysis of one or a few cases. However strategically hand-picked, such a limited number of cases would inevitably limit the range of translations observable. Instead, we have opted to discuss as many instances of translations as possible, in as little depth as necessary to be able to add a number of distinct observations to our charting of the variety of translations of security. In casting our net widely, we are grateful for being able to include a number of "boxed tales," each reporting a single or a constellation of translations of security. (You already encountered one of these boxed tales in this chapter.) On the one hand, we have squeezed our analytical points out of the tales, and you could read each of them for further explanation. On the other hand, the tales are richer than our rendition, so you should read them just for this richness. $^{5}$

Before proceeding based on this framework for analysis, the next chapter revisits theories of translation from theology and literary studies to social science. It discusses what enters into a translation, by what means (vocabularies, images, media etc.) and with what claims to authority translations take place. The chapter also reflects on what comes out of a translation and with what effects. Equipped with this framework, chapters 3, 4, and 5 ask how one could study and understand current security translations and how they confront established social categories of ordering: professions, culture, and scale. The concluding chapter recapitulates our agenda for how to do security studies, reflects on the usefulness of studying translations of security for the times we live in, and point to some fundamental changes, which the processes detected with our framework bring about. 


\section{Box 1.1 The Other State of Emergency}

Bruno Latour ${ }^{a}$

What is so discouraging about the terrorist acts is that our discussion of what motivated the operations is as insane as the acts themselves. With each attack of this nature, we restage the grand war drama, the nation in peril and the protector-state purporting to rise up against barbarity. This is what states do, we say: we should have a basic expectation of security, and the state should have the means to provide it. End of story.

But what makes the current situation so much more dismaying is that the crimes committed on 13 November have occurred within a few days of another event about to take place that involves tragedies of a different kind, ones that will require that we come up with very different answers to wholly different threats that have nothing to do with ISIS/Daech. I am referring, of course, to the World Climate Change Conference in Paris, the COP21, which we are now liable to deem less serious, less urgent than the police response to the bloody escapades of those machineguntoting lunatics. To do so would amount to a serious misapprehension of the order and scope of the threats looming over states today. Armed fanatics are criminals, no question, but they hardly jeopardise the way we live, think, produce, learn or inhabit space. We need only defend ourselves against them. But nothing in their ideology jeopardises our deepest-held values, no more than pirates threaten the values of international trade. We have to fight against them, and that's all there is to it. This fight produces no political message or even any tactical originality, and needless to say, no spiritual lesson of any kind. Name one scientist, one citizen, or artist, name a judge, a mother, a musician or athlete who aspires to live under ISIS/Daech rule. I would even add: name a person of faith. This situation has nothing to do with the civil wars of times past that divided from within. This kind of thuggery is a law-and-order matter, not war, despite all the flag-waving and calls to arms. It's a very different story when it comes to climate change. Global warming threatens all states in every way: from industrial production, business and housing to culture and the arts. It threatens our values at the deepest level. Here is where states are actually at war with each other, battling for market share and economic development, not to mention the soft power of culture. And each of us feels divided against ourselves. If indeed there exists a "clash of civilizations," then this is it, and it concerns each and every one of us. Yet, we know that national 
governments are just as lost and helpless here as they are when facing the terrorist threat. The police aren't enough. Rather, civil society as a whole has to take its fate into its own hands and compel political institutions to find answers.

We are looking at how dangerous it would be if anti-terrorist measures, however necessary, were to require the French state to limit the COP21 to a diplomatic discussion among bureaucrats and specialists, inside the fortified camp of Bourget, transformed into a kind of Baghdad Green Zone. How ironic that this should happen right when the whole climate issue has finally taken on a civilisational dimension heretofore lacking. This is why it is important to step up the pressure so that, despite the new security requirements, civil society, whose stake in the matter is enormous, will get the chance to peacefully express its views. Eradicating ISIS/Daech is a long-term proposition, but the death sentence has been issued. The terror may well continue, but it is already yesterday's fight, with nothing new, only one suicide belt added to another. The threat implied in the term "Climate Change," on the other hand, is tomorrow's challenge and depends on how all of us, not just the police, are able to deal with the issues. It makes no sense to tackle the one problem and neglect the other. As it turns out - and this should come as no surprise - the two challenges are actually very closely linked. I'm not referring here to the tenuous, or at least too oblique, connection between climate change in the Middle East and the crisis in Syria. Nor am I talking about the horror of the refugees hounded out by the terrorists, by the wholesale destruction of their country, or about the way we have reacted to the matter. Rather, I'm referring to that hideous attraction whereby suicide bombers prefer death and the afterlife to an earthly existence in the now. Candidates for this kind of self-destruction display a simplistic form of nihilism, to be sure, but however inept and atrocious, their acts call to mind the image of our collective suicide that the ever-expanding development model of modernisation has yielded. The 13th of November is a foreshadowing of the catastrophe that will follow the failure of the Paris conference and others to come. If you rightly use the word nihilism to describe these militant madmen, it would seem to me that the word also applies, but with more far-reaching implications, to those who, in a twisted way, are expressing a death wish of their own. Just like those who kill themselves in the act of killing, people in positions of responsibility who fail to take on the issue of global climate change with the greatest seriousness is shouting in unison with the terrorists: Long live death! It would be truly 
tragic if, by rightly seeking out and destroying those who, within a limited time and place, go about killing innocent people, we delay yet again the necessary work of addressing those who would kill on a deliriously massive scale, over a long period, sweeping away life in all its forms, human or otherwise. Though it is legitimate that a well-calibrated state of emergency allows for secure street demonstrations, the powers that be have to remember that they could declare a different state of emergency, an extreme one this time, that could teach the citizenry how to identify and grapple with the larger enemy. All the more so, since this is a war that finds us very much divided, among nations, territories and peoples, and tragically, within ourselves, as we argue endlessly over the causes and the cures of global warming. Government alone is helpless: it needs all its citizens in this effort. And government should not impede those citizens who, by demonstrating, are trying to help their elected officials-it might even be an occasion to invent demonstrations more innovative than yet another march from Place de la République to Place de la Nation.

\section{Notes and References}

a English translation by Jane Kuntz, originally published in French in Reporterre in the wake of the seven coordinated terrorist attacks including the concert venue Bataclan in Paris right before the COP21 in Paris, reprinted with permission.

\section{Notes}

1 In a later piece Stritzel acknowledges this oversight and argues that securitization theory was not only an analytical project, but meant "ultimately also to potentially escape this dangerous logic of security" (Stritzel, 2018: 42). This development in the conceptual understanding can have been influenced by his co-author of another chapter in a volume that appeared a few years prior (Stritzel \& Vuori 2016). Even this formulation, however, captures only half the political agenda of the original "theory move" from Copenhagen: attention to the power and paradoxes of securitization enables critique of instances of its deployment, but the choice to work with and from the traditional concept of security instead of denouncing it from some alternative, external point represented a deliberate, Derridean, deconstructive attempt to destabilise and change the traditional concept itself from within (Wæver 1989a, 1989b). The latter is increasingly overlooked partly because it has been successful to a degree where it has become taken for granted. "What is security?" is increasingly answered reflexively as a practice rather than naively as an innocent good, the way it used to.

2 Following scholars on Actor Network Theory (cf. Latour), one could also imagine more radically emergent and hybrid forms, i.e. that meaning is constructed anew for any given case. We, however, assume that it is more likely that actors will 
speak into the communities they hail from and thus to draw upon resources from these worlds. See chapter 2 for a longer discussion on this.

3 Some of this polyvalence is revealed by the way in which the very term is translated into non-Indo-European languages: translating "translation" back literally from, i.a., Chinese and Finnish would include results such as "turn," "move," and "decode," which all hint at qualitative processes falling within the parameters of what we count as "translations." (We thank Juha Vuori for drawing our attention to these examples.)

4 Concepts are by definition complex and ambiguous. If it were possible to define precisely a concept - re-describe it by other words - it would not be a concept, just a word. A concept makes a difference that cannot be captured without reference to this particular concept. Imagine that the concept of "freedom" had never emerged. The world could hardly be what it has become. This does not entail that it is easy to pin down what constitutes that difference and exactly how it has worked out, because freedom is a complex, contested, and multi-dimensional concept linking many spheres, ideas, and images. However, it is exactly this particular linking that is incomprehensible without paying attention to the concept as such. No wonder that one of the concepts most often left unexplained is the concept of concept.

5 Most of the tales were presented orally to our conference on Translations of Security; a few were commissioned at a later stage or we obtained permission to reproduce tales, which we found pre-existing but fitting to our purpose.

\section{References}

Adams, John. 1995. Risk. London: UCL Press.

Adey, Peter, Ben Anderson, and Stephen Graham. 2015. Governing Emergencies. Vol 32, no 2. Special Issue of Theory, Culture and Society.

Amicelle, Anthony, Claudia Aradau, and Julien Jeandesboz. 2015. 'Questioning Security Devices: Performativity, Resistance, Politics'. Security Dialogue 46: 293-306. 10.1177/0967010615586964.

Amoore, L. and M. de Goede. 2008. 'Transactions After 9/11: The Banal Face of the Preemptive Strike'. Transactions of the Institute of British Geographers 33 (2): 173-85.

Amoore, Louise. 2013. The Politics of Possibility: Risk and Security Beyond Probability. Durham: Duke University Press.

Apter, Emily. 2006. The Translation Zone. A New Comparative Literature, Princeton: Princeton UP.

Aradau, Claudia and Rens van Munster. 2011. Politics of Catastrophe: Genealogies of the Unknown. London: Routledge.

Aradau, Claudia and Tobias Blanke. 2017. 'Politics of Prediction'. European Journal of Social Theory 20: 373-391. 10.1177/1368431016667623.

Beck, Ulrick. 2002. 'The Terrorist Threat: World Risk Society Revisited'. Theory Culture \& Society 19(4): 39-55.

Beck, Ulrick. 1992. Risk Society. Towards a New Modernity. London: Sage.

Berling, T.V. and Christian Bueger (2017) 'Expertise in the Age of Post-Factual politics: An outline of reflexive strategies', Geoforum, 84: 332-341.

Bigo, D. 1996. Polices en réseaux: L'expérience européenne. Paris: Les Presses de Sciences Po.

Bigo, Didier. 2000. 'When two become one: Internal and external securitisations in Europe', in Morten Kelstrup and Michael C. Williams (eds.) International 
Relations Theory and the Politics of European Integration. London \& New York: Routledge: 171-204.

Bigo, Didier. 2006a. 'Globalized-in-security: The field and the ban-opticon'. in John Solomon and Naok Sakai (eds.) Translation, Biopolitics and Colonial Difference, vol. 4, 109-56. Hong Kong: Hong Kong University Press.

Bigo, Didier. 2006b. 'Security, exeption, ban and surveillance'. in David Lyon (ed.) Theorizing Surveillance. Devon, UK: Willian Publishing.

Bigo, Didier. 2007. Policing Insecurity Today: Defence and Internal Security. Palgrave: MacMillan. CERI Series in International Relations and Political Economy.

Bourne, Mike. 2012. 'Guns Don't Kill People, Cyborgs Do: A Latourian Provocation for Transformatory Arms Control and Disarmament'. Global Change, Peace \& Security 24: 141-163. 10.1080/14781158.2012.641279.

Büger, Christian, and Holger Stritzel. 2005. 'New European Security Theory: Zur Emergenz eines neuen europäischen Forschnungsprogramms'. Zeitschrift für Internationale Beziehungen 12 (2): 437-46.

Burgess, Peter. 2010. The Routledge Handbook of New Security Studies. London: Routledge.

Buzan, Barry. 1983. People, States and Fear: An Agenda for International Security Studies in the Post-Cold War Era. Sussex, UK: Wheatsheaf Books.

Buzan, Barry, Ole Wæver, and Jaap de Wilde. 1998. Security: A New Framework for Analysis. Boulder CO: Lynne Rienner.

Callon, Michel. 1986. 'Some elements of a theory of tranlation: Domestication of the scallops and the fishermen of St Brieuc Bay', in John Law (ed.) Power, Action and Belief: A New Sociology of Knowledge? London: Routledge: 196-233.

Callon, Michel, Pierre Lascoumes, and Yannick Barthe. 2009. Acting in an Uncertain World: An Essay on Technical Democracy. Translated by Graham Burchell. Cambridge, MA: The MIT Press.

C.A.S.E. 2006. 'Critical Approaches to Security in Europe: A networked Manifesto'. Security Dialogue 37 (4): 443-487.

Ceyhan, Ayse and Anastasia Tsoukala. 2002. 'The Securitization of Migration in Western Societies: Ambivalent Discourses and Policies'. Alternatives 27 (February): 21-40.

Chandler, David. 2014. Resilience: the Governance of Complexity. London and New York: Routledge.

de Goede, Marieke. 2020. 'Engagement all the way down'. Critical Studies on Security 8: 101-115. 10.1080/21624887.2020.1792158.

de Goede, Marieke, Stephanie Simon, and Marijn Hoijtink. 2014. 'Performing preemption'. Security Dialogue 45: 411-422. 10.1177/0967010614543585.

Douglas, Mary and Aaron Wildavsky. 1982. Risk and Culture: An Essay on the Selection of Technical and Environmental Dangers. Berkeley: University of California Press.

Duffield, Mark. 2001. Global Governance and the New Wars: The Merging of Development and Security. London: Zed Books.

Epstein, Charlotte and Ole Wæver. March 2019. 'Whither the political in all these turns'. paper present at the panel "A return to politics - Combating the depoliticization performed in IRs recent turns", ISA conference in Montreal.

Ewald, Francois. 2001. 'The return of Descarte's malicious demon: An outline of a philosophy of precaution', in T. Baker and J. Simon (eds.) Embracing Risk: The 
Changing Culture of Insurance and Responsibility, Chicago and London: University of Chicago Press, pp. 273-302.

Ewald, Francois. 1986. L'Etat Providence. Paris: Bernard Grasset.

Farias, Ignacio. 2014. 'Virtual Attractors, Actual Assemblages: How Luhmann's Theory of Communication Complements Actor-Network Theory'. European Journal of Social Theory 17(1): 24-41.

Gad, U.P. and Strandsbjerg J. (eds.). 2019. The Politics of Sustainability in the Arctic. Reconfiguring Identity, Space, and Time, Routledge.

Galison, Peter. 1997. Image \& Logic: A Material Culture of Microphysics. Chicago: University of Chicago Press.

Goede, Marieke de. 2012. Speculative Security, the Politics of Pursuing Terrorist Monies. Minneapolis, MN \& London: University of Minnesota Press.

Huysmans, Jef. 2002. 'Shape-Shifting NATO: Humanitarian Action and the Kosovo Refugee Crisis'. Review of International Studies 28 (3): 599-618.

Huysmans, Jef. 2006. The Politics of Insecurity: Fear, Migration and Asylum in the $E U$. London \& New York: Routledge.

Huysmans, Jef. 2011. 'What's in an act? On security speech acts and little security nothings'. Security Dialogue 42: 371-83. 10.1177/0967010611418713.

Jasanoff, Shiela. 1998. 'The Political Science of Risk Perception'. Reliability Engineering and System Safety59: 91-99.

Koselleck, Reinhart. 1985. Futures Past. Cambridge, Mass: MIT Press.

Latour, Bruno. 2013a. An Inquiry into Modes of Existence. Cambridge, Mass: Harvard University Pressq.

Latour, Bruno. 2013b. 'Biography of an Inquiry: On a Book about Modes of Existence'. Social Studies of Science 43(2): 287-301.

Laustsen, Carsten Bagge and Ole Wæver. 2002. 'In Defence of Religion: Sacred Referent Objects for Securitization'. Millennium 29(3), 705-739.

Law, John. 1999. 'After Ant: Complexity, Naming and Topology'. The Sociological Review 47: 1-14. 10.1111/j.1467-954x.1999.tb03479.x.

Leese, Matthias. 2016. 'Seeing futures - Politics of Visuality and Affect'. in Louise Amoore and Volha Piotukh (eds.) Algorithmic Life: Calculative Devices in the Age of Big Data. Milton Park/New York: Routledge: 148-64.

Lisle, Debbie and Mike Bourne. 2019. 'The Many Lives Of Border Automation: Turbulence, Coordination and Care'. Social Studies of Science 49: 682-706. $10.1177 / 0306312719870868$.

Luhmann, Niklas. 1977. 'Differentiation of Society'. Canadian Journal of Sociology 2(1):29-53.

Luhmann, Niklas. 1992. 'Operational Closure and Structural Coupling: The Differentiation of the Legal System'. Cardozo Law Review 13(5): 1419-41.

Margolis, Eric and Stephen Laurence. 2011. 'Concepts'. Stanford Encyclopedia of Philosophy. http://plato.stanford.edu/entries/concepts.

McDaniels, Timothy and Mitchell Small. 2004. Risk Analysis and Society: An Interdisciplinary Characterization of the Field. Cambridge University Press.

McSweeney, Bill. 1996. 'Identity and Security: Buzan and the Copenhagen School'. Review of International Studies 22(1): 81-94.

O’Malley, Pat. 2004. Risk, Uncertainty and Governance. London: Glasshouse.

Petersen, Karen Lund. 2016. 'Risk and Security', in Myriam Dunn Cavelty and Thierry Balzacq (eds.), Routledge Handbook on Security Studies. Routledge. 
Pelizza, Annalisa. 2021. 'Identification as translation: The art of choosing the right spokespersons at the securitized border'. Social Studies of Science: 1-25. .10.1177/ 0306312720983932

Renn, O. 1992. 'Concepts of Risk: A Classification', in Shelson Krimsky and Dominic Golding (eds.) Social Theories of Risk. Westport, CT: Praeger.

Simon, Jonathan. (ed.) 2002. Embracing Risk: The Changing Culture of Insurance and Responsibility. Chicago and London: The University of Chicago Press.

Skinner, Quentin. 1989. The State. Cambridge: Cambridge University Press: 90-131.

Skinner, Quentin. 2002. Visions of Politics. Volume I. Regarding Method. Cambridge: Cambridge University Press.

Stirling, Andrew. 2007. 'Risk, Precaution and Science: Towards a More Constructive Policy Debate'. EMBO Report 8(4): 309-15, http://www.ncbi.nlm.nih.gov/pmc/ articles/PMC1852772/

Stritzel, Holger. 2018. The travelling concept of organized crime and the stabilization of securitized international cooperation. A translational reading' in Tobias Berger and Alejandro Esguerra (eds.) World Politics in Translation: Power, Relationality, and Difference in Global Cooperation. London \& New York: Routledge: 39-57.

Stritzel, Holger. 2011. 'Security, the translation'. Security Dialogue 42(4-5): 343-355.

Stritzel, Holger, and Juha, Vuori. 2016. 'Security', in Felix Berenskoetter (ed). Concepts in World Politics, SAGE Publications Ltd., 41-56.

Tresch, John. 2013. 'Another Turn after ANT: An Interview with Bruno Latour'. Social Studies of Science 43(2): 302-13.

Vogel, D. 2012. 'The transatlantic shift in regulatory stringency', in D. Vogel (ed.) The Politics of Precaution: Regulating Health, Safety, and Environmental Risks in Europe and the United States. Princeton: Princeton University Press: 1-21.

Wigen, Einar. 2018. State of Translation. Turkey in Interlingual Relations, Ann Arbor: University of Michigan Press.

Wæver, Ole. 1989a. 'Beyond the 'Beyond' of Critical International Theory'. in COPRI Working Papers 1/1989, Copenhagen: Copenhagen Peace Research Institute.

Wæver, Ole. 1989b. 'Security, The Speech Act: Analysing the Politics of a Word'. 2nd draft. Paper presented at the Research Training Seminar, Sostrup Manor.

Wæver, Ole. 1995. 'Securitization and desecuritization', in Ronnie D. Lipschutz (ed.) On Security. New York: Columbia University Press: 46-86.

Wæver, Ole. 2011. 'Politics, Security, Theory'. Security Dialogue 42(4-5): 465-80.

Wæver, Ole. 2012. 'Aberystwyth, Paris, Copenhagen: the Europeanness of New 'Schools' of Security Theory in an American Field', in Arlene B. Tickner and David L. Blaney (eds.) Thinking International Relations Differently, Worlding Beyond the West. Abingdon: Routledge: 48-71.

Wæver, Ole and Barry Buzan. 2015. 'After the Return to Theory: the past, present and future of security studies', in Alan Collins (ed.) Contemporary Security Studies. Oxford: Oxford University Press. 10.1093/hepl/9780198708315.003.0028. 


\section{Theorising translation}

What do we talk about when we talk about translations? Well, for one thing, "translations of security" is a diagnosis of our times. Translations of unwanted futures have certainly happened throughout times, but for a period of time - sometimes referred to as high modernity - functional differentiation and national cultures seemed to solidify, making the division of labour appear relatively clear in relation to each specific trouble ahead. Not so any more. As discussed in the introduction, translations are happening all the time, reconfiguring the boundaries between disciplines, professions, cultures, scales. In this chapter, we present our analytical gaze for how to approach the current predicament through a discussion with established traditions for theorising translation as a phenomenon. Three extreme concepts of translation steer our discussion: the impossibility of translation between systems, as defined by Luhmann's systems theory; the insistence on emergence drawn from ANT; and the possibility of seamlessly transferring meaning of early translations theory and theology. These three positions constitute what one could call the "vanishing points" for our analysis.

We argue that thinking of translation as a meeting between different conceptual expressions of ways to handle unwanted futures provides for fruitful analyses of this complex universe. In the description of those expressions new meanings are pointed out, occasionally reconfiguring or undermining the distinction originally occasioning the translation. We specify these meetings further through the term translation zones. By zooming in on translation zones, as our point of observation, we focus on the synchronic negotiations of meaning that happen in everyday meetings, rather than on the macro-historical diachronic developments in the concept of security. Some of these zones occur from scratch when new kinds of meetings are provoked (e.g. when a committee of scientists from various disciplines is formed and a new concept is coined such as resilience or sustainability); other translation zones have been institutionalised for centuries (through practices of e.g. war, diplomacy, and contracting). Translations, however, do rely on rather sedimented structures of meaning or diachronic patterns of conceptual authority (conventions, fields, discourses, cultures, functionally differentiated systems, etc.). Therefore, the analyses included in this book 
zoom in on a number of "translation zones" across these structures of meaning: professions, cultures and scales.

The concept of "translation zone" has been used previously by Emily Apter (2006) in the context of comparative literature and (especially) world literature. While her conceptualization has its own agenda in relation to debates in another field, basic ideas are similar. As further clarified in her 2013 book, Against World Literature: On the Politics of Untranslatability, a key move is to posit a limit to translatability with inspiration from Benjamin, Derrida, Weber, Spivak and others. This is in line with another theorist who presented an image of conceptions that move around: Edward Said's "Travelling Theory" $(1983,2000)$. He is interested in what happens, more than where it comes from, i.e. in the productivity of translations, exactly because they should not be measured as misreadings and misrepresentations, and their power exactly draws from mobilising both important impulses from their starting points and from the new settings. In this sense, intranslatability is an important reason why translation is such a productive research agenda.

The chapter is structured as follows: First, we discuss important academic approaches to translations and contrast them with our own. Then we present our analytical gaze - or mode of observation - in more detail before we, as the final section in this chapter, contrast this gaze with a discussion of how translations have been perceived within security studies up until now.

\subsection{Translation theories: transfers, originals, distortion, and performativity}

Translation as a concept has a long history within a range of disciplines. However, the concepts of translation discussed may all be placed between three "vanishing points" for the concept of translation. In these extremes, translation means - respectively - meaningless external "irritation" of a closed system; emergence of new meaning substantially unrelated to what appears to be its "sources"; and unproblematic transfer of meaning across domains. In this section, we briefly trace those meanings and argue that together they delimit an understanding of translation, which is valuable for grasping current security politics.

Classical debates over linguistic translation began over the search for a direct translation - "word for word", sometimes a 1:1 translation (literal, a correspondence), sometimes an equivalent - in order to translate a text into a new language. The aim was somehow to transfer text from one language to another through a transparent medium - the translator. But as linguistics discovered long ago, this task is often next to impossible. Hence, a debate arose over how to translate the "message" or the "meaning" of a text into another language - even if this requires subjective and intersubjective decisions to be taken, which moves the text away from its original face value, so to speak. 
Within linguistics, a defining scholar in this respect is (Jakobson 1959). ${ }^{1}$ For Jakobson, a translation presupposes that you are able to define and track an initial meaning. He argued that any study on conceptual change and tropes requires a definition or understanding of what to look for: a fixation of the relation between signifier and signified. In the face of pessimists such as Benjamin Lee Whorf, who claimed that "Facts are unlike to speakers whose language backgrounds provides for unlike formulation of them" (Whorf 1956: 235; quoted in Jakobson 1959: 234), ${ }^{2}$ Jakobson optimistically insisted that "A faculty of speaking a given language implies a faculty of talking about this language. Such a "metalinguistic" operation permits revision and redefinition of the vocabulary used. [... Hence,] all cognitive experience and its classification is conveyable in any existing language. Whenever there is deficiency, terminology may be qualified and amplified by loan-words or loantranslations, neologisms or semantic shifts, and... circumlocution" (Jakobson 1959: 234). The purpose of translation for Jakobson became trying to find or construct synonymous or equivalent terms or signs within or across languages. The meaning, however, was taken to be stable and translatable to different levels of success through decoding practices.

The move from literal translation and correspondence to a focus on meaning is an important first step for understanding translations beyond 1:1 transfers. Hence, after Jakobson, linguistics and translation studies directed its search for a transfer of a stable "meaning" or "effect" of the original text (Venuti 1999: 5). The original meaning was to remain the same after translation - or in other words, meaning was to be "carried over" to a different context or language. Various means were employed towards this goal under labels like "cultural" or "organisational rewriting"; "pragmatic," "functional" or "communicative equivalence" (Venuti 1999: 122-123); and controlling through "back translation" (Müller 2007). ${ }^{3}$

Gradually, the question of the autonomy of the translated text became central within translation studies as well as in different theories of language. Venuti (1999: 5-6) organises the debates over this question as an exchange between instrumental and hermeneutic theories of language: Instrumental theories see translation as mediating objective information, whereas the hermeneutic theory of language emphasises the interpretation of creative values and thus focuses on social functions and effects. With the publication of Susan Bassnett's (Bassnett 1980) Translation Studies the autonomy of the translated text took centre stage (Venuti 1999: 215). ${ }^{4}$

For Christian theology, however, successful translation remains pivotal. Notably, this is a particularly Christian standpoint - not even a monotheistic one. Islam is more reserved on the matter of the possibility of translation; translated texts occur, but they are never treated as an authoritative communication of the original (Ellingworth 2002). Judaic traditions accept a range of exegetic operations ranging from the "straight peshat via the allegoric remez and inquisitive derash to the esoteric sod"-involving corresponding, but still controversial, approaches to linguistic translation (Friedman 2001; Rees et al., 
2008). The extreme character of this Christian and Modern ambition of perfect translation becomes clear when contrasted to non-modern notions of translation which refrain from setting up universal standards for translating, e.g. the phenomenon "water" between two cultures through the precise term ' $\mathrm{H} 2 \mathrm{O}$ ' or "God' trough a universal term "divinity." Instead, translation could be achieved by alliteration, rhyming and other rhetorical devices (Chakrabarty 2000: 85-86). Other traditions even devalued exact reproduction, valuing rather eloquent variation (Wigen 2018: 46-47).

But for Christian theology, precise translation remains serious business; a matter of not just life and death but one of salvation versus eternal damnation. Fortunately, the discipline's substance matter includes its own powerful tools. While questions of language and the proper translation of words have been central, ${ }^{6}$ and equivalence theory was dominant for almost four decades (Noss 2002), theological debates on bible translation includes a dimension not present in, e.g. linguistics: the translation of the mystery of the divine. To some, theology is translation. It is impossible for the translator to refrain from critically interpreting (perform exegesis) when translating the Bible. Nevertheless, centrally, in dogmatic theology, translation has been equated with incarnation. Črnivec (n.d.) argues that all proclamation of the message of God rests on a translation, a mediation of the act of God. The primary, most potent manifestation is the translation of God in the incarnation in Christ. Secondly, the message of God is translated into the written word of God (in the Scriptures), while at a third level, we find the proclamation of the Church. ${ }^{7}$ Between these three levels, translations take place. ${ }^{8}$ But where linguistic translation grappled with the degree of transfer of meaning with varying degrees of success or distortion, the translation of God is inherently a re-making or restatement of the first level. While the role of dogmatic theology was to observe the proclamation done by the Church in light of the other two levels and assess the adequacy and precision of its treatment of the divine (a mediation) (Barth 2004, referenced in Črnivec n.d.), the translation inherent in the proclamation can also be considered to be world-making in itself. Every Bible translation is a "rebuilding of a conceptual world" with an "absolute force' (Črnivec n.d.: 3). This translation force can at times be used to pursue political ${ }^{9}$ or theological agendas ${ }^{10}$ and as such be coercive (Omanson 2002) - a distortion. But in general, translation is still considered a stage in God's selfdisclosure and thus a divine process (Črnivec n.d.: 4). Hence, bible translators are most often anonymous (Noss 2002: 341) ${ }^{11}$ related to the idea that they carry out an act, which is necessarily more than just a human act, because it takes place in a paradox between the communication of meaning and the mediation of a transcendent mystery. As such, translation forms part of fulfilling God's plan by spreading the gospel. Translation, hence, is a theandric act - a process conducted by God in and by a human - based as much on scientific and scholarly expertise as on prayer, hope and re-creation.

So linguistic translation studies left the possibility of perfect translation behind - while theology only saved the ideal by divine intervention. 
Nevertheless, the ideal of translations incarnating meaning seamlessly across conceptual universes, cultures and scales lives on in a host of everyday practical human endeavours - from intimate spousal conversations to huge collective enterprises: We continue to explain and to listen because we think that both we and they may make sense to each other. In addition, a number of academic disciplines have a raison d'etre, which prompts them systematically to continue the search for translation-as-incarnation. Either because they are tasked with solving problems which demand that they perform or explain translations between "third parties"; because they need to translate their own knowledge to "export" it effectively to others; or because they need to translate from foreign structures of meaning to "import" knowledge. Boxed tale 2.1 gives just one example of how even the most professional pursuance of this ideal may be politicized.

Within organisation theory, a huge audience of practitioners remains susceptible to this logic of a stable meaning, which can be transferred or diffused. According to such theories, a concept, a body of knowledge or item of meaning (such as a new strategy for creating efficient workflows - think LEAN) can travel or move as a neatly closed package from one place to another without any change to its content. The package can then be "unpacked" in new organisations or in a new national culture and used for its original purpose. The process can be slow ("an idea can hibernate") or it can be fast ("an idea can be viral") (Røvik 2011). The effects of the knowledge item are taken to be largely the same, but some distortion can occur - if the process is suboptimal or the content is somehow misunderstood. (Below, we elaborate on how the idea of distortion takes centre stage in other sociological approaches to translation.)

In international relations, Stritzel's $(2011 b, 2014)$ reading of the transfer of the American "names" or "threat texts" (in his vocabulary) of organised crime and rogue states into a German context follows this logic. He divides the process up into three mechanisms: 1. Translatability, 2. Resonance, and 3. Adaptation/localisation (Stritzel 2011b: 2495). In a recent edited volume called World Politics in Translation a different take is offered to understand the lack of perfect diffusion of what the editors term "objects" across cultural contexts. Building primarily on the literature on norm diffusion the editors offer two perspectives which structure the contributions to the book: From many to one, and from one to many, or in other words: the dual process of many different understandings culminating in one shared understanding, or the one idea propelling outwards into many different ideas (Berger \& Esguerra 2018). Wigen notes how "the dichotomous manner" in which such analyses are conducted, often "ignores the reinterpretation that occurs when meaning gets translated" (2018: 40, 14).

Parallel ambitions are clear in a number of the tales told about requests for translation across cultures in Chapter 4. To take an example, in what has become known as the "Area Studies Controversy," particularly Middle East Studies found itself under siege, chastised for not foreseeing the 9/11 attacks: 
Even if offered ample funding and up-to-date social science theory, they nevertheless failed to use their intimate philological and ideographic knowledge to translate what Muslims were plotting (Jung 2014: 247-250). Particularly in the US, area studies were historically promoted as important for security reasons: Competence in foreign languages and cultural knowledge was deemed necessary to produce qualified foreign and security policy advice (Valbjørn 2008).

A related discussion is found in the field of health and healthcare, where the transfer of knowledge (from science via individual doctor to patient in treatment) is often referred to as "from bench to bedside" (Freeman 2009: 429). The result of this understanding of translation has been argued to install a hierarchy between the "original" and the "inferior copy," thereby leaving the copy an incomplete rendition, a blurred image or partial truth (Freeman 2009: 430). The original source becomes the principal actor, whereas the ideal translator is secondary or negligible - if not, $\mathrm{s} / \mathrm{he}$ is a problem in the sense that his or her intervention means a deterioration of the quality of knowledge. Both chapters 4 and 5 on translations across cultures and scales return to various instances of this figure of an enlightened centre pushing to translate its truth to peripheries.

The impossibility of "perfect" translation immediately gives rise to the question of the ethics of 'imperfect' translation. Eco asks us to embrace imperfect translation as the only "true" language of Europe (Eco 1995; Minca \& Bialasiewicz 2005: 370) - whereas Spivak (Spivak 1993) dissects the power effects of trying to navigate the discursive structures of race, gender and class when translating across them. Müller suggests "holus-bolus," i.e. keeping the foreign term in the translated text (Chakrabarty 2000: 85-86; Müller 2007: 210-211), as one effective means to underscore its untranslatability and, hence, by alienating the reader keeping her/him alert to the politics of translation. ${ }^{12}$ Such concerns are integral to some disciplinary debates on efficient means of translation - whereas in others, they are at best punctual afterthoughts or critical interventions.

If we turn to social theory, the approach to the problems related to the fixation of meaning and the difficulties inherent in translation has long been based on the same premises as those arrived at in linguistic translation studies. A prominent example is Pierre Bourdieu to whom every "form of meaning" is locally bound and any attempt to transport this form of meaning to other spheres will be distorted. ${ }^{13}$ No field outside the field where a certain meaning was first constituted will understand quite the same by the concept and practice. To a large extent, Bourdieu's argument concerned translation between national contexts or cultures (Bourdieu 1997; Crossley 2004). However, the same point goes for the translation between different spheres in society (academic field, cultural field, economic field). Any field will understand a concept or a practice on its own terms, in connection with the power struggles structuring the field, which are highly conservative. ${ }^{14}$ Translation as "transfer" is therefore next to impossible from this 
perspective and the message brought into a new system will not be "carried over" but "taken over" in power configurations in the field in question. This makes the 'copy' as important as the 'original' and the translator takes on the important role vis-a-vis the author. Put in other words, you might say that translation as an objective practice in which the translator is a transparent medium - "the éminence grise and black box" - is substituted by translation as a political act (Müller 2007: 211). Along similar lines, Stritzel (2011b: 2496) refers to Farrell's (2005) idea of "strategies of stretching" in which local elites try to make a "threat text/name" appear local and thus more digestible. Wigen similarly stresses the agency of translators employing a variety of resources to "yoke" together concepts in different languages (2018: 28, 41-43).

As mentioned in the introduction, when taken to its extreme, the impossibility of translation has been explored by Niklas Luhmann. In his view, every system is - by definition - creating its story of the world as seen from its own perspective; using its own self-generated media and codes of communication. Luhmann defines a code as that which makes it possible to evaluate every statement in yes/no within a specific system and as that which determines whether a statement belongs in that system or not. To take an example, in the economic system, the concept of risk will always be conceptualised through the medium of money. One can say that money is the principal medium of communication due to the circumstance that money is the medium that converts future risks into a material present (Luhmann 2002: 59).

While seemingly strong, the code also reveals the contingent character of every statement: belonging (to a system) is only possible in terms of not belonging to something else. This distinction is what creates the identity of the system (Luhmann 1990: 17-19). But it is also always what de-stabilises or, to use the words of Luhmann, renders the system paradoxical (Luhmann 2002: 101-103). Through the system's observation of itself, its established ontology is questioned. Yet, the system will always try to de-paradoxify and thereby stabilise the meaning and communicative logic of the system. A common example given by Luhmann on de-paradoxification is when it comes to talking about the irrational in a rational manner. When this occurs, the rational/irrational distinction becomes part of what constitutes the meaning of "rational." What happens are internal processes of communication inside each system - systems that in turn produce events that other systems might re-describe (through their internal communication) (Luhmann 1992). As mentioned in the introduction, second order observers might look at these parallel systems and observe them simultaneously, but their communication would then be anchored in this third place. ${ }^{15}$

To Luhmann, translation is impossible; what Bourdieu sees as severe distortion is in Luhmann replaced by incommensurability, or rather the absurdity of comparing the "inside" of different systems. However, a third radical - way of escaping the logic of unproblematic incarnation of meaning across context presents itself. It even goes under the label sociology of 
translation - when it is not promoted under the alias Actor-Network Theory (ANT). Primarily associated with Bruno Latour and Michel Callon, ANT defines translation as "all the negotiations, ....acts of persuasion and violence thanks to which an actor of force takes... authority to speak or act on behalf of another actor or force" (Callon \& Latour 1981: 279). A translation is thus a process in which chains of "actants" (agents, things) are created in such a way that a specific person or institution becomes the natural spokesperson of a certain idea or power relation. The strength and success of processes of translation lies in "the ability to bind together forces, to make them compatible and equivalent" (Callon \& Latour 1981: 292). Core to this understanding of translation is a radical take on the construction of both social meaning, identities, agents and things. ANT stresses that also "things act" on the social construction of meaning to the extent that we can talk about "co-production" of the material and the social (Jasanoff 2004).

Translation is thus an analytical take on the study of modern societies within ANT. It is promoted as the point from where an observer can address processes that collapse the difference between the micro and the macro, between different spheres in society and between cultures (Latour 1988). As abstractions, these categories are only present in academic minds. Looking for processes of translation will make clear how these categories are continuously collapsed and combined. If we take the example of science, it is taken to be merely "a process of 'heterogeneous engineering' in which bits and pieces from the social, the technical, the conceptual, and the textual are fitted together, and so converted (or "translated") into a set of equally heterogeneous scientific products" (Law 1992: 321). Science as a field does not make sense without understanding that scientific facts are themselves products of translation. By selecting data, leaving out some parts and underlining others, the researcher translates the research into stable messages (Freeman 2009: 430). Meaning is therefore not taken to exist prior to the translation within ANT (Freeman 2009: 437). Hence, Haraway may applaud how the deconstruction of science in (Latour 1988) support tolerance for the lack of universal translations, clearing spaces for situated translations:

We [feminists] don't want a theory of innocent powers to represent the world, where language and bodies both fall into the bliss of organic symbiosis. We also don't want to theorize the world, much less act within it, in terms of Global Systems, but we do need an earth-wide network of connections, including the ability partially to translate knowledges among very different - and power - differentiated - communities. (1988: 579-580)

Further, translation does not remain within one domain, field or system. It involves crossing and combining different domains. In a letter from Louis Pasteur in which he proposes a study of fermentation to the French Minister of Public Education, Pasteur attempts to bind scientific, agricultural, commercial and political interest together by positing his own research as the 
common denominator (Freeman 2009: 431; Latour 1991). In ANT, this amounts to a translation through policy-making. In the process, the social world is remade and reshuffled and power hierarchies are built. Translations are, in a word, performative: They literally bring worlds into being. Following from this, the translator becomes central: A legislator of a particular kind (Freeman 2009: 440). So from perceiving of the translator as an ideally transparent medium in classical translation studies, translation is considered a performative act in which otherwise unrelated elements are brought together in a persuasive narrative/configuration. Translation should, as Spivak insists, be considered a political act (1993).

The meaning of the term "translation" in ANT is deeply defined by the whole perspective and network of concepts (cf. the usage of the name "sociology of translation" as synonymous with ANT) and quite far from everyday usages of the term. Therefore, the definition above only works for studies that fully adopt this approach.

\subsection{Our analytical gaze: translations between incommensurability, emergence, and incarnation}

While we sympathise with ANT's open and flat ontology, we find it to be too ahistorical for the analytical task at hand, if applied in its radical form alone. On the one hand, as has been argued elsewhere, security is a highly structured field (Buzan et al. 1998: 31, Wæver 1995); it will not easily shed its historical sedimentations in terms of organisational, national and disciplinary vocabularies and practices. On the other hand, as argued earlier, the current times demand of us to be able to tear the conceptual buildings down in order to capture the processes at work in reshaping security. If we were to turn to old school "archaeological" discourse analysis, uncovering the logics and limits of what counts as meaningful (Foucault 2002), that would make our analysis a question of assigning cases to pre-existing boxes: either this is a case of security discourse $\mathrm{X}$ or it is a case of $\mathrm{Y}$. In such approaches, the relationship between structures of meaning becomes one of pure external competition (repeating, in our scheme, the extreme presented by Luhmann's ontology, only this time in a static version), whereas we want to be able to observe also when $\mathrm{X}$ and $\mathrm{Y}$ interact and compromise each other (which Luhmann theorises as processes of paradoxes and de-paradoxification). Moreover, in the processes, which we want to study, the emergence of something brand new (as observed by ANT) is one extreme option. We argue that what we see, however, will most often be translation of - and away from - something pre-existing.

One way of mediating between the highly structured image of discourses in early Foucauldian discourse analysis and the focus on agency (whether of actors or actants) is found with Laclau \& Mouffe's attention to articulatory practice. "Articulation" in Laclau and Mouffe designates the operation of fixing a previously ambiguous element as a moment in discourse by "any practice establishing a relation among elements such that their identity is 
modified as a result of the articulatory practice" (Laclau \& Mouffe 1985: 105). Hence, articulations take place in productive arenas - translation zones, if you like - where one discourse might succeed in generating a new inclusive conception that temporarily pulls the other in on its terms. The discourse from which this hegemonic practice originates will be modified more or less radically by this practice, but still the different discourses are the semi-stable systems enabling meaning production - and the productive intersections are not places separate from discourse. In this approach, it is hard to imagine how brand new inventions, unrelated to existing structures, can become the nodal point for future structures - this kind of situations are the vanishing point of that theory. If, however, we relieve Laclau \& Mouffe's theory of its "Lacanian motor" - the urge for stabilisation which leads each discourse to seek hegemony (Gad 2010: 108-113, 512) - the idea of "articulation" appears next door neighbour to ANT's image of translation. Laclau \& Mouffe's image of "translation" is quite like ANT's image of a forceful assemblage of elements hitherto unrelated - only Laclau \& Mouffe provide for an analysis of the way elements may not be free-floating but products of pre-existing discourses, more or less sedimented.

So we accept with ANT and Luhmann that a meeting between different structures of meaning may result in the transfer of nothing - either because something new emerges or because each system is closing itself off to the outside, so to speak. In this way, we include both contingency and openendedness but also stabilisation and sedimentation as possible outcomes of the meeting. In between these extremes, we expect to find instances where meaning appears to be transferred - but only "succeeds" in distorted or re-articulated form. In theory, Luhmann and ANT may both be right in a certain sense: the structures of meaning do not understand each other and something new emerges which is not identical to either in a strict sense. However, observed via the theoretical lenses of distortion or articulation, one may see the relation from the mis-communication and the new meaning to specific, preceding practices and structures of meaning. In some instances, the will and competence of a translator will be important. In other instances, a central concept or practice will be at the steering wheel - or perhaps a more fitting metaphor would be that concepts or practices will appear as bricks on the gas pedal, feeding dynamics leading to a particular meeting and translation. This is where the ideal of perfect, undistorted transfer of meaning comes in: Not as an ideal that can be realised but as an "effective ideal"; an ideal, inbuilt in the logic of certain discourses, driving actors and institutions to try to achieve it.

In sum, theology upholds the ideal of perfect, undistorted incarnation of meaning from one context to another; a range of applied sciences and practitioners strives on a daily basis to perform, theorise and evaluate such ideal translations. Luhmann presents us with one vanishing point of "translation" the point of incommensurability; Bourdieu theorises translations bordering incommensurability as distorted. In parallel, ANT represents another vanishing point of "translation" - the point of emergence; while Laclau \& Mouffe 
theorise the emergence of novelties as the result of articulations necessarily compromising the identity of the structures of meaning articulated. As illustrated in Figure 2.1, these three extremes (incarnation, incommensurability, and emergence) delimit our concept of translation, and the individual processes we observe in the translation zones may be characterised as perfection, distortion and/or articulation.

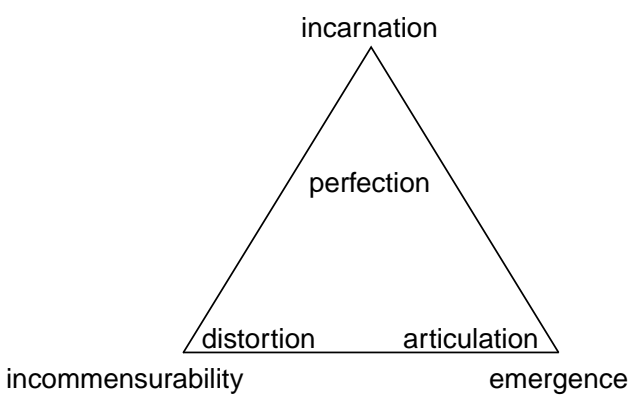

Figure 2.1 Translations as attempts at perfection, distortion and articulation between the 'vanishing points' of incarnation, incommensurability, and emergence.

\subsection{Trajectories of security translations}

When preparing for an analysis of the security landscape in the decade following 1989, it made sense to define security as a specific speech act which could be articulated to new issues - ideally incarnating the meaning with which it was invested in the heyday of the Cold war, distorted somewhat (but not beyond recognition) by the new contexts into which it was introduced. The picture was never perfect - but the imperfections highlighted by approaching the security landscape with the lens of "securitization" produced important understandings of central dynamics. It still does, but increasingly important dynamics seem to escape this kind of analysis.

If we turn our attention towards the present security landscape, we may use the theoretical considerations about translation to reformulate the task ahead in the following terms: "security" is (no longer only - if it ever was) a specific speech act whose structure can travel anywhere and remain unchanged, therefore lending itself to observation with the same tools across nations, scales or disciplinary/professional boundaries. So we need to ask: what happens, when the conceptual 'package' is not sealed properly - to stay in the language of the transfer. What if the conceptual package itself - its meaning, shape, effects - changes in the meeting with a new culture or on a different scale? What if there will never be a neat transfer of meaning from one social context to another? It might have been the case in an earlier phase. But what happens now, when all boundaries are blurring? Is it not to be expected that 
even the form of security - the package itself - might change? The ambition to be able to answer this kind of questions has led us to conceptualise translations as whatever happens in the "zones" produced by meetings between different ways of approaching forms of unwanted futures.

Overall, the approach chosen in this book can be compared schematically to a wider range of other approaches to the study of security by depicting their general image of semantic fields, semantic events and lines of movement. The presentation in this section is not meant to be respectful of nuances but to show how each approach has an underlying "plot," a narrative of time and change that structures the way meaning is organised (White 1987).

The standard narrative from securitisation theory has one stable form (security) extended to new domains (Buzan \& Wæver 2009; Buzan et al. 1998; Wæver 1995). This is the story of widening of the conceptual reach of security; of more and more fields being dealt with as security issues; the basic contours of one logic of security incarnated across new fields.

To apply this to the situation today would mean to treat the new developments as one more chapter in the widening story unfolding since around 1980. The only "translation" that happens in this set-up (illustrated in Figure 2.2) is a stable meaning being translated into new settings and contexts, maybe adapted to and merged with "indigenous" vocabularies but not changing in its core. The core is in this case defined as form. It is not a particular domain or "culture" that has a given code of communication. It is the speech act that has constancy.

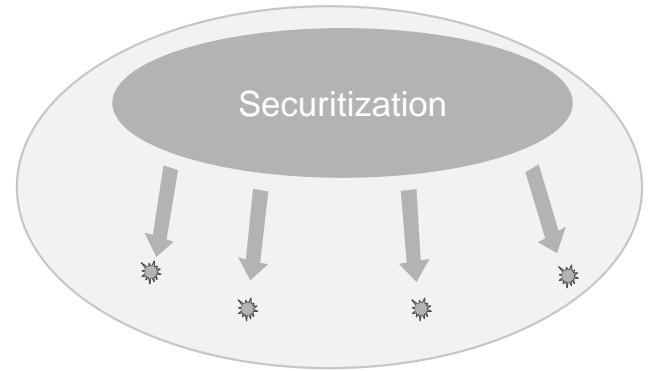

Figure 2.2 Translations of security according to Copenhagen School securitization theory: incarnation of the form of the speech act of security across new spheres.

The security-risk literatures (Aradau 2006; Aradau et al. 2008; Coker 2002; Heng 2006; Rasmussen 2001, 2006) contain many instances of an alternative story (illustrated in Figure 2.3), where risk is depicted as the replacement for security. Usually, security is presented as a stable codification that is increasingly losing grip on actual instances of policy. Risk is either 
depicted as another stable format that is taking over the regulation of more and more issues, or as an evolving social practice that engulfs (embraces) more and more of what used to be considered security. The image is akin to that produced by a discourse analysis: a new discourse successfully hegemonises elements previously articulated as security. In this image of risk, it is often the neoliberal vision of governance, which is stressed as increasingly important to the practice of security. Over the last decade quite a range of different approaches have studied the intersection of security and risk, but common to most of them is that "risk" (in a relatively unitary conception) is posited as ascending and contrasted to a prior regimen of "security." In this reading, the stable cores are usually the concepts, conceived of as rationalities. ${ }^{16}$

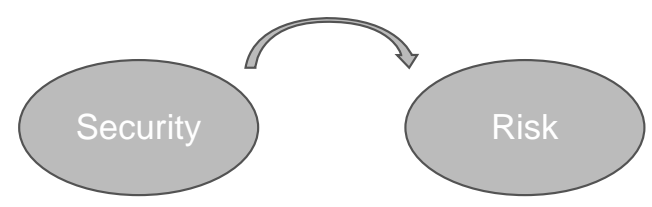

Figure 2.3 Translations of security according to the security/risk literature: hegemonic switch of issue from one predefined logic to another.

Many critics of the Copenhagen School and of other established approaches de facto employ a rationality of pure emergence (illustrated in Figure 2.4). The uniqueness of each event is underlined (Bubandt 2005; Salter 2008; Salter \& Mutlu 2013; Trombetta 2011). While this is rarely presented as an approach in its own right - although increasingly so in the emerging (!) literature on ANT meets security studies; (Schouten 2014; Salter 2019), it is more often present as an implicit basis for critique of any approach that works from any stable basis (cf. our discussion in chapter 1).
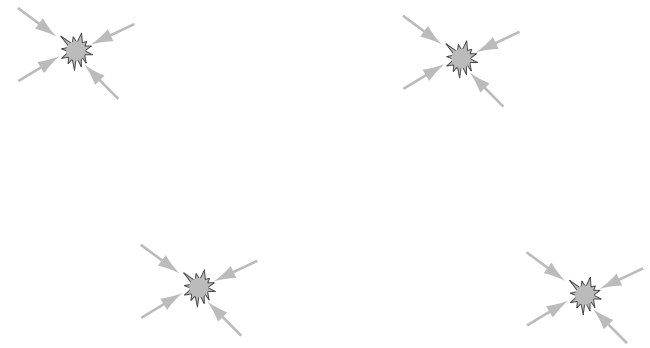

Figure 2.4 Translations of security according to ANT-like security studies: emergence of new practices. 

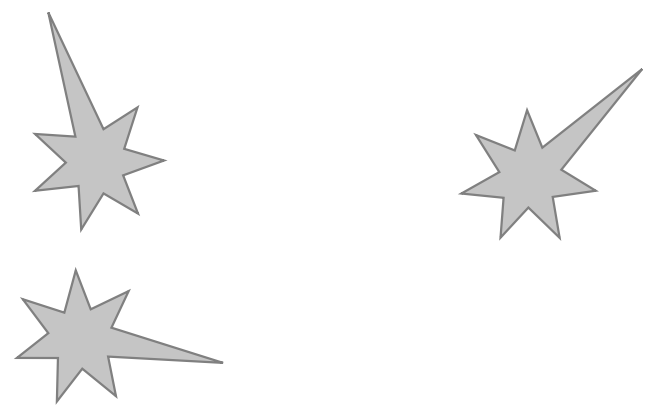

Figure 2.5 Translations of security according to Paris inspired securitization theory: emergence of new practices on the background of a modest pre-history.

If one draws the same model as one of "stars with a tail" (as done in Figure 2.5), this would probably capture most of the so-called sociological securitisation theory (Balzacq 2010, 2015; McDonald 2008; Stritzel 2011, 2007).

According to these authors, who are often inspired by the Paris school, but presents (especially in the case of Balzacq and Stritzel) their approach as a revised version of securitisation theory, one should study each individual instance as produced in a process over time, but without any stable foundations. The speech act of securitisation must not be given a too stable and constant content, and every specific case study has to include more contingent, empirical factors than in classical securitisation analysis. Stritzel argues that "[f]rom a translational perspective, it is problematic to impose an artificial notion of universality or fixity of meaning with regards to the concept/practice of security" (Stritzel 2011a: 346). Thus, the meaning of security and other key concepts is unique in each situation and should be understood as "local, discursive productions of security meanings". At the same time, it is underlined by this approach that each speech act should be seen less as a self-referential event, and more as developing out of previous discourses, practices, institutions and psychological conditions. Thus, every event has a pre-history, but neither the event nor the basis from which it is explained are given any solid ontological existence. The events are not productive or performative in a strong sense, so emphasis ends up on the immediate pre-history to each that explains it or in a combination study of synchronic and diachronic versions of a "threat text" or a "name" like Stritzel's analysis of organized crime and rogue states (Stritzel 2011a, 2011b, 2014). Each event is to be contextualised and explained as a product of a wide range of practices at many levels, but none of these is anchored in any pre-designated structures or systems (e.g. specific institutions, professions or some other known set of rationalities). Thus, the resulting picture is one of events with a modest pre-history. A powerful trend in critical security studies the last decade has been to develop studies modelled on basically the same figure, but becoming less 
explicit of their de facto dependence on the theories of the 1990s. Very empirically nuanced studies of complex entanglements of many practices claim to be about "security" or "risk" without spelling out exactly what makes for securitiness or risk-character - if not purely nominalistic, these studies often assume that security means something like but not confined to securitization, and risk is somewhere between Beck and Foucault (Aradau 2010; Aradau \& Blanke 2015; Davidshofer et al. 2016; de Goede 2017; Dijstelbloem \& Walters 2019; Suchman et al. 2017). This allows these studies to write about security and risk in a mode that is not constricted to any fixed meaning - but possibly more dependent on the preceding theorisations than admitted.

The approach to translations developed in this book combines characterisation of contrasting systems of meaning (be they disciplines, professions, organisations, cultures or what have you) with a focus on the specific meanings produced around a new case. How does this particular new challenge get codified by a coalition of actors who have their roots in very different spaces? Or does it move over time between different spaces in a way that make these spaces intersect in the codification of this particular issue? Current neo-materialist security studies do such studies, but only when it is possible to organise these around an object that moves across spheres or does the crystallization of new constrellations (Mats Fridlund provides a very convincing example in Box 5.4; cf. Best \& Walters 2013....Walters 2014), which is on our framework only one of several possibilties. Figure 2.6 shows first a situation (a) where a new issue is addressed by actors who come from different spaces and generate in the new setting a conceptual apparatus that is simultaneously original and anchored for each in their background systems - thus it is a product of translations. The second situation depicted (b) has only well-established spaces, not a dramatically new one, but an issue moves from setting to setting - and the meanings attached to it, drawing from the first settings - have to be translated in new settings.
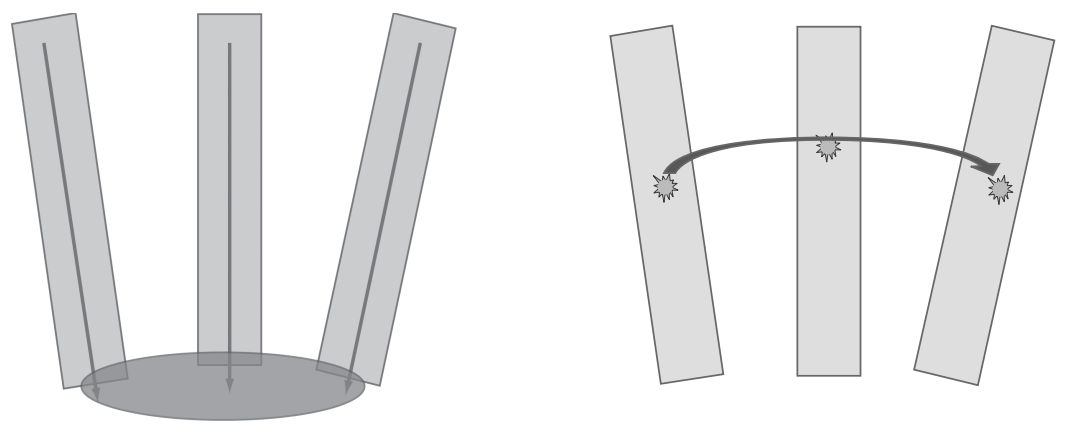

Figure 2.6 The approach to translations of security in this book: a. Joint establishment of new conceptual apparatus and/or practices for dealing with new unwanted future. b. New unwanted future serially translated across settings. 
This is what we talk about when we talk about translations. And with the discussion in this chapter as the backdrop, we now delve into the empirical world of translations of security. Three chapters focus on translations of security across functional differentiation, segmential differentiation and stratificatory differentiation, respectively. In each chapter, we tend to the means of translation, to what conceptual changes are involved, and to the political stakes. As explained when introducing our analytical strategy towards the end of chapter 1, in each chapter, we analyse two kinds of translation zones: First, we focus on translations across units which adhere to the logic of differentiation discussed - e.g. translation involving two professions or two cultures. Then we move on to discussing translations which challenge the logic in question - e.g. translations occasioned by the introduction of networks into a scaled universe, or by the invasion of a universe of expert knowledge by amateurs.

\section{Box 2.1 Who heard what Trump said to Putin? Only one other American}

\section{Emily Cochrane ${ }^{a}$}

Marina Gross, the only other American in the room during President Trump's meeting on Monday with President Vladimir V. Putin of Russia, was the interpreter for Laura Bush at the Russian resort of Sochi in 2008 and interpreted for former Secretary of State Rex W. Tillerson in Moscow in 2017. She appears to live in an apartment in Arlington, Va., is an employee of the State Department and is, unsurprisingly, fluent in Russian.

Little else is known publicly about Ms. Gross, who has been thrust into the spotlight as potential corroboration for what transpired between the two leaders during their two-hour meeting in Helsinki, Finland. As furor over the meeting grows, she faces increasing calls from Congress to testify about what she heard. Her fellow interpreters, who pride themselves on their discretion and invisibility, are outraged about those demands.

Ms. Gross's white pad of notes, visible in photographs from the summit meeting, are probably useless, experienced government interpreters said, dictated in her personal shorthand that would be illegible to anyone else. And if she were to say what, exactly, transpired, she would violate an ethics code of confidentiality similar to lawyer-client privilege or the silence of a priest during confession.

Only Mr. Trump, who has alternately contradicted his own narrative of what was said and complained about a lack of fair coverage from a meeting only four people witnessed, could permit Ms. Gross to tell 
anyone about what she heard. The White House has not said whether Mr. Trump has asked her to do that.

"This is an absolutely nightmarish situation for anyone to be in," said Stephanie van Reigersberg, who assigned interpreters to such meetings as the chief of the interpreting division in the State Department's Office of Language Services for 18 years. "It's a very difficult situation to be in, both in the point of her being asked to give information about what was a confidential meeting and because when you're doing that kind of interpreting, there are memory issues."

But some lawmakers have already called for Ms. Gross's notes, wary of what assurances were exchanged between a Russian leader known for blatant denials and an American president known for frequent falsehoods.

"Given this history, the American people deserve to know if Trump used his position or this meeting with Putin to continue to pursue his own financial interests," Representative Bill Pascrell Jr., Democrat of New Jersey, wrote in a letter this week asking the House Committee on Oversight and Government Reform to hear public testimony from Ms. Gross.

So far that seems unlikely. Republicans on the House Intelligence Committee voted to deny a formal attempt from Democrats on Thursday to subpoena Ms. Gross, and State Department officials declined to comment on a hypothetical situation.

But interpreters said that even the discussion over whether Ms. Gross should testify threatened to jeopardize their work.

They point to the code of ethics that binds their profession: Interpreters are "bound by the strictest secrecy" towards anyone and any information disclosed in an environment not open to the public.

"I hope this will remain just a desire expressed by some congressmen," said Yuliya Tsaplina, 45, a freelance Russian interpreter based in Paris, who said the demands from American lawmakers had ignited heated debate and concern among several of her international colleagues. "We are only as valuable as we can interpret faithfully, accurately, and keep things in confidence. It will essentially destroy all trust in our profession."

A government official with knowledge of current interpreting practices, speaking on the condition of anonymity, said that even in an interpreter's personal lexicon-symbols, doodles and words used to recall a thought or idea-the meaning can evolve from day to day. This makes it difficult for interpreters to recall chunks of thought. In addition, many 
interpreters often destroy their notes if a security official has not already requested them after highly classified conversations.

"They go into the garbage bin pretty immediately," Ms. Tsaplina said of her notes. "Because they're useless."

The official said that the calls by Capitol Hill for Ms. Gross's testimony were shortsighted on behalf of the lawmakers, who frequently use interpreters for their own private meetings. The State Department currently has 12 staff interpreters in Arabic, French, Japanese, Korean, Mandarin, Russian and 16 staff translators-who translate the written word -in Arabic, Russian and Ukrainian, a State Department official said. The department also has three language specialist positions in Bulgarian and Polish, and often supplements staff with contracted interpreters.

Ms. van Reigersberg said that in her experience interpreting in Spanish, she was joined in one-on-one meetings or phone calls by an official note taker or a top security official. If she received permission by the official she was interpreting for, she said, she would often provide a summary to another official that could be corroborated by the note taker. The challenge came, she said, from recalling the big picture of the conversation after relying on short-term memory to interpret.

"Do you really believe a person who has worked that hard, that intensely in that sort of way for so long, can really remember every detail of what she has done?" she said. "You're listening, you're writing, you're figuring out how to render it in the other language, you're repeating it."

Stenography, Ms. van Reigersberg added, is "not what our job is."

The challenge of record-keeping when an American president enters a highly sensitive meeting with a foreign leader, particularly an adversarial one, has long vexed administration officials. Even when President Ronald Reagan and President Mikhail S. Gorbachev of the Soviet Union brought a small rotation of interpreters for a 1986 summit meeting in Reykjavik, Iceland, the lack of a verbatim transcript prompted accusations of "distortion." When the pair had met previously with only interpreters, Mr. Reagan had personally briefed members of his delegation twice a day from memory.

Michael A. McFaul, a former American ambassador to Russia, said in an interview on Thursday that note takers were crucial. He described a photo he had of himself, notepad and pen in hand, off to the side as President Barack Obama met with Mr. Putin during Mr. Obama's first term.

"I was the official note taker for the meeting," said Mr. McFaul, who has become entangled in conflicting interpretations of whether the White 
House would allow Moscow to question him. "That's what's missing from the Trump-Putin meeting."

Alexander Vershbow, a former ambassador to Russia under President George W. Bush and a National Security Council aide under President Bill Clinton, said it would most likely be a violation of executive privilege to force Ms. Gross to appear before Congress.

"I think it's more a reflection of the mistrust of President Trump and his judgment in dealing with Russia, that the interpreter is being used as a whipping boy," said Mr. Vershbow, who is now a fellow at the Atlantic Council. "I think it's an unfortunate attempt to politicize the role of the interpreter".

\section{Notes and References}

a First published as https://www.nytimes.com/2018/07/19/us/politics/trumpputin-interpreter.html.

\section{Notes}

1 Since Jakobson, the linguistic discipline has developed to include debates about interlingual, intralingual and intersemiotic translations (Jakobson 1959: 233). Wigen (2018: 45f) explains how this distinction, on the one hand, inevitably breaks down in practice, while it, on the other hand, remains relevant to uphold for analytical purposes.

2 The very idea that you can only fully understand something when you share a culture - which ultimately includes language, history and concrete living principally emerged with German romanticism (and Herder's theory of language) from the late 18th century (Vico being an interesting forerunner) (Berlin 2013). Communication was no longer only "content" but meaning which demanded the depth of a total understanding, which in turn had to evolve historically in a specific culture. Other cultures could be studied, not lived and fully grasped. The rationalism, that this was a reaction to, did not meet such limits, because reason was universally available and alike. And before this "words" and "things" were not separate in a way that allowed the question to emerge (Foucault 1970 [1966]; Epstein 2021: 110ff).

3 Trying to translate a translated text back to the source language to test for accuracy (Müller 2007: 211).

4 See also George (Steiner 1975) After Babel in which he discusses how original meaning will always be lost in translation.

5 On the perils of translating the concept of "monotheism" into Hindi, see Nancy (quoted in Spivak 1993: 173f).

6 The translation of the Hebrew alma (young woman of marriageable age) as parthenos (virgin) is an example of this problematique which has had palpable effects (Ellingworth 2002: 304-5). For a meticulous overview of the use of the notion of translation in theology, see Ellingworth (2002). 
7 The actual translation of the Bible is of utmost importance here (Noss 2002).

8 Noss (2002) includes the interpretation of the individual Christian as yet another layer of translation.

9 One example is a Marxist translation where the disciples of Jesus are referred to as "comrades" or "militants" (Ellingworth 2002: 306).

10 Think of the Reformation and Luther's re-translation of the Bible.

11 Bible Societies normally prefer to support translations by interconfessional teams of translators, because theological tendencies are thus discussed in the making of the translation (Ellingworth 2002: 306). This preference in practice confirms the point that translation is always political over the theological point that it may be perfect. For an analysis of a particular instance of Bible translation, see (Noss 2002).

12 Müller spells out the consequences for any scholar doing research in one language and translating it into another - typically his/her European mother tongue or global/ imperial English: The translating scholar is an active agent who moulds the production of meaning (2007: 207). Ethically, it is the responsibility of the researcher to make the "translation act visible" in order to maintain the complexity and contingency inherent in any translation process (2007: 210). Wigen (2018) constitute a powerful argument that monolingual Anglophone scholarship cannot adequately account for wide parts and important dynamics of international relations.

13 Bourdieu arrives at this position via the (post)structuralist digest of Heidegger (Bourdieu 1991). Venuti (Venuti 1999: 68-69) mentions Nabokov and Quine as arriving at similar positions in the 1940s and 1950s.

14 For an overview of Bourdieu in translation studies, see Inghirelli (2005).

15 Compare with Galison's rendition of Kuhn's paradigms (Kuhn 1970): "Where Carnap and Quine argued that there would always be more than one translation, Kuhn shocked readers by claiming that there wouldn't even be one. Speakers of "Newtonian", as it were, could never, without gaps and awkwardness, fully translate what they had to say about the world into "Einsteinian"” (Galison 2010: 42). Kuhn himself later denied this interpretation, insisting that he only ruled out "commensurability," not translatability (Kuhn 1982), but it is clear that his work became part of a general shift towards wide-spread acceptance of nontranslatability (Davidson 1973; Wæver 1996).

16 A few contributions to the security-risk literature have challenged this (Corry 2012; Petersen 2011).

\section{References}

Apter, Emily S. 2006. The Translation Zone: A New Comparative Literature. Princeton \& Oxford: Princeton University Press.

Aradau, Claudia, Luis Lobo-Guerrero, and Rens van Munster. 2008. 'Security, Technologies of Risk, and the Political: Guest Editors' Introduction'. Security Dialogue 39(2-3): 147-54. https://doi.org/10.1177/0967010608089159.

Aradau, Claudia. 2006. 'Limits of Security, Limits of Politics? A Response'. Journal of International Relations and Development 9(1): 81-90.

Balzacq, Thierry. 2010. Securitization Theory: How Security Problems Emerge and Dissolve. London: Routledge.

Barth, Karl. 2004. Church Dogmatics. New York \& London: T\&T Clarke.

Bassnett, Susan. 1980. Translation Studies. London \& New York: Methuen.

Berger, Tobias and Alejandro Esguerra (eds.). 2018. World Politics in Translation: Power, Relationality and Difference in Global Cooperation, Milton Park \& New York: Routledge. 
Berlin, Isaiah. 2013. Three Critics of the Enlightenment: Vico, Hamann, Herder, in Henry Hardy (ed.) 2nd ed. Princeton University Press.

Bourdieu, Pierre. 1991. The Political Ontology of Martin Heidegger. Stanford: Stanford UP.

Bourdieu, Pierre. 1997. 'Passport to Duke'. Metaphilosophy 28(4): 449-55.

Bubandt, Nils. 2005. 'Vernacular Security: The Politics of Feeling Safe in Global, Local and National Worlds'. Security Dialogue 36 (3): 275-96.

Buzan, Barry, Ole Wæver, and Jaap de Wilde. 1998. Security: A New Framework for Analysis. Boulder CO: Lynne Rienner.

Callon, Michel and Bruno Latour. 1981. 'Unscrewing the Big Leviathan: How Actors Macrostructure Reality and How Sociologists Help Them to Do So', in Karin Knorr Cetina and Aaron V. Cicourel (eds.) Advances in Social Theory and Methodology. Toward an Integration of Micro- and Macro-Sociologies. Boston: Routledge and Kegan Paul: 277-303.

Chakrabarty, Dipesh. 2000. Postcolonial Thought and Historical Difference. Princeton \& Oxford: Princeton University Press.

Coker, Christopher. 2002. Globalisation and Insecurity in the Twenty-First Century: NATO and the Management of Risk. London: International Institute for Strategic Studies: 345 .

Corry, Olaf. 2012. 'Securitisation and "Riskification": Second-Order Security and the Politics of Climate Change'. Millenium 40(2): 235-58.

Črnivec, Matjaž. n.d. 'Theology of Translation. An Introductory Inquiry'. Paper uploaded to Academia.Edu downloaded 15 March 2015.

Crossley, Nick. 2004. 'On Systematically Distorted Communication. Bourdieu and the Socioanalysis of Publics'. The Sociological Review 52(1): 88-112.

Davidson, Donald. 1973. 'On the Very Idea of a Conceptual Scheme'. Proceedings and Addresses of the American Philosophical Association 47: 5-20.

Eco, Umberto. 1995. The Search for the Perfect Language. The Making of Europe Series. Oxford: Blackwell.

Ellingworth, Paul. 2002. 'Theology and Translation'. Bible Translator 53: 302-7.

Epstein, Charlotte. 2021. Birth of the State: The Place of the Body in Crafting Modern Politics. Oxford: Oxford University Press.

Farrell, Theo 2005. 'World Culture and Military Power'. Security Studies 14(3): 448-88.

Foucault, Michel. 1970. 'The Archaeology of Knowledge'. Social Science Information 9: 175-185.

Foucault, Michel. 2002. Archaeology of Knowledge. Milton Park: Routledge.

Friedman, Richard. 2001 'Studying Torah: Commentary, Interpretation, Translation', Judaism 50(3):295-306.

Friedman, Richard. 2009. 'What Is "Translation"”. Evidence and Policy 5: 429-47.

Gad, Ulrik Pram. 2010. (How) can They become like Us? Danish identity politics and the conflicts of 'Muslim relations', unpublished $\mathrm{PhD}$ dissertation, Department of Political Science, University of Copenhagen. https://static-curis.ku.dk/portal/ files/128740920/2010_Gad_Dissertation_How_Can_They_Become_Like_Us.pdf

Galison, Peter. 1997. Image \& Logic: A Material Culture of Microphysics. Chicago: University of Chicago Press.

Galison, Peter. 2010. 'Trading with the Enemy', in Michael E. Gorman (ed.) Trading Zones and Interactional Expertise. Creting New Kinds of Collaboration (Inside Technology). Cambridge, MA: MIT Press. 
Heng, Yee-Kuang. 2006. War as Risk Management: Strategy and Conflict in an Age of Globalised Risks. New York: Routledge.

Inghirelli, Moira. 2005. 'Bourdieu and the Sociology of Translation and Interpreting'. The Translator. Studies in Intercultural Communication 11.

Jakobson, Roman. 1959. 'On Linguistic Aspects of Translation', in Reuben A. Brower (ed.) On Translation. Cambridge, MA: Harvard University Press: 232-39.

Jasanoff, Sheila. 2004. 'The Idiom of Co-Production', in Sheila Jasanoff (ed.) States

of Knowledge: The Co-Production of Science and Social Order. New York: Routledge: $1-12$

Jung, Dietrich. 2014. 'The "Ottoman-German Jihad": Lessons for the Contemporary "Area Studies" Controversy'. British Journal of Middle Eastern Studies 41(3): 247-65. https://doi.org/10.1080/13530194.2013.878517.

Kuhn, Thomas. 1970. The Structure of Scientific Revolutions, 2nd ed. Chicago, London: University of Chicago Press.

Kuhn, Thomas. 1982. "Commensurability, Comparability, Communicability". PSA: Proceedings of the Biennial Meeting of the Philosophy of Science Association. 2: 669-88.

Laclau, Ernesto and Chantal Mouffe. 1985. Hegemony and Socialist Strategy: Towards a Radical Democratic Politics. London \& New York: Verso.

Latour, Bruno. 1988. The Pasteurization of France. Cambridge, MA: Harvard University Press.

Latour, Bruno. 1991. 'Technology Is Society Made Durable', in John Law (ed.). A Sociology of Monsters: Essays on Power, Technology and Domination. London: Routledge \& Paul Kegan: 103-131.

Law, John. 1992. 'Notes on the Theory of the Actor-Network: Ordering, Strategy, and Heterogeneity'. Systems Practice 5(4): 379-93. https://doi.org/10.1007/ BF01059830.

Luhmann, Niklas. 1990. 'Risiko Und Gefahr'. In Soziologische Aufklärung 5. Konstruktivistische Perspektiven. Westdeutscher Verlag: 131-69.

Luhmann, Niklas. 1992. 'Operational Closure and Structural Coupling: The Differentiation of the Legal System'. Cardozo Law Review 13 (5): 1419-41.

Luhmann, Niklas. 2002. Theories of Distinction: Redescribing the Descriptions of Modernity. Stanford, CA: Stanford University Press.

McDonald, Matt. 2008. 'Securitization and the Construction of Security'. European Journal of International Relations 14(4): 563-87.

Minca, Claudio and Luiza Bialasiewicz. 2005. 'Old Europe, New Europe: For a Geopolitics of Translation'. Area 37(4): 365-72.

Müller, Martin. 2007. 'What's in a word? Problematizing Translation between Languages'. Area 39: 206-13.

Noss, Philip A. 2002. 'Translators' Words and Theological Readings'. Bible Translator 53: 331-43.

Omanson, Roger L. 2002. 'Theology, Interpretation, and Translation'. Bible Translator 53: 353-62.

Petersen, Karen Lund. 2011. 'Risk Analysis - a Field Within Security Studies'. European Journal of International Relations 18(4): 693-717.

Rasmussen, Mikkel Vedby. 2001. 'Reflective Security: NATO and International Risk Society'. Millennium 30(2): 285-309. 
Rasmussen, Mikkel Vedby. 2006. The Risk Society at War. Terror, Technology and Strategy in the Twenty-First Century. Cambridge: Cambridge University Press.

Rees, Margo. 2008. Lishan Didan, Targum Didan: Translation Language in a NeoAramaic Targum Tradition. Piscataway, NJ: Gorgias Press.

Røvik, Kjell-Arne. 2011. 'From Fashion to Virus: An Alternative Theory of Organizations' Handling of Management Ideas'. Organization Studies 32(5): 631-53.

Salter, Mark B. 2008. 'Imagining Numbers: Risk, Quantification, and Aviation Security'. Security Dialogue 39(2-3): 243-66. https://doi.org/10.1177/0967010608088777.

Salter, Mark B. 2019. Security Actor-Network Theory: Revitalizing Securitization Theory with Bruno Latour. Polity 51 (2): 349-67.

Salter, Mark B., and Cann E. Mutlu. 2013. 'Securitisation and Diego Garcia'. Review of International Studies 39 (4): 815-34.

Schouten, Peer. 2014. 'Security as Controversy: Reassembling Security at Amsterdam Airport'. Security Dialogue 45(1): 23-42.

Spivak, Gayatri Charkravorty. 1993. 'The Politics of Translation'. In Outside in the Teaching Machine. New York: Routledge: 179-201.

Steiner, George. 1975. After Babel. Aspects of Language and Translation. London, Oxford \& New York: Oxford University Press.

Stritzel, Holger. 2007. 'Towards a Theory of Securitisation: Copenhagen and Beyond'. European Journal of International Relations, 13(3): 357-383.

Stritzel, Holger. 2011a. 'Security: The Translation'. Security Dialogue 42(4-5): 343-55.

Stritzel, Holger. 2011b. 'Security as translation: threats, discourse, and the politics of localisation'. Review of International Studies 37(5): 2491-517.

Trombetta, Maria Julia. 2011. 'Rethinking the Securitization of the Environment: Old Beliefts, New Insight', in Thierry Balzacq (ed.) Securitization Theory. London: Routledge: 135-49.

Valbjørn, Morten. 2008. A 'Baedeker' to IR's Cultural Journey before, during and after the Cultural Turn - Explorations into the (Ir) Relevance of Cultural Diversity, the IR/Area Studies Nexus and Politics in an (Un)Exceptional Middle East. Aarhus: Forlaget Politica.

Venuti, Lawrence. 1999. The Translation Studies Reader. London \& New York: Routledge.

Wæver, Ole. 1995. 'Securitization and Desecuritization'. In Ronnie D. Lipschutz (ed.) On Security. New York: Columbia University Press: 46-86.

Wæver, Ole. 1996. 'The rise and fall of the inter-paradigm debate', Steve Smith, Ken Booth, and Marysia Zalewski (Eds.) International Theory: Positivism and Beyond, Cambridge: Cambridge University Press: 149-185. 10.1017/cbo9780511660054.009.

White, Hayden. 1987. The Content of the Form. Baltimore \& London: The Johns Hopkins University Press.

Whorf, Benjamin Lee. 1956. Language, Thought and Reality, Selected Writings. New York: John Wiley.

Wigen, Einar. 2018. State of Translation. Turkey in Interlingual Relations. Ann Arbor: University of Michigan Press. 


\section{Translations across disciplines and professions}

In our quest for understanding translations of security we start our observations from a number of sedimented structures of meaning (or social forms of organisation) developed over time. As argued in Chapter 1 we find the structures most pertinent for our purpose to be constituted by distinctions based on function, segmentation, and stratification. Following this line of thought, in this chapter we attend to the functional differentiation between professions or disciplines, and how translations of security draw upon and challenge this logic of ordering. The following two chapters will move on to cultures as segmentational differentiation, and scales as stratification.

Different threats have been parcelled out to distinct fields of expertise and management: commonly viewed as professions and disciplines. Insurance agencies, medical risk analysers, intelligence agencies, national security advisers, and climate experts have all for long been talking about risks, threats, and security, but separately. Increasingly, threats interact: they are measured up against each other, and they often amplify each other. Politicians manoeuvre among the threats, estimating and ranking them, often with no explicit criteria - because no general measure exists. Measures exist, but they are particular, not general. Numerous experts offer rational valuations of particular threats, but these various forms of expertise are often incommensurable and disconnected: they simply cannot talk with each other. Many scientific disciplines project images of an unacceptable future threats, disasters, dangers, and risks. But each does so in its own way, each with its own terminology and using distinct "formulae" or rules of engagement. Politicians and other decision makers in turn use their own procedures to pass judgment across fields - because it is their job to do so and the distinctiveness of knowledges therefore cannot imply separateness anymore.

When we observe that a particular discipline "thinks" about risk in some specific manner, or a profession approaches danger in some format, it is not a matter of just "habit" or path-dependent "prejudice" - or a vehicle for broader societal struggles over the "construction" of threats. Professions and disciplines are organised around a body of knowledge that serves various purposes for society in regulating social resources, drawing boundaries,

DOI: $10.4324 / 9781003175247-3$ 
and reproducing social structures both internally and in relation to outsiders. If their impact is abstracted as purely ideational, one misses the dynamics stemming from their particular nature as professions and disciplines. One example, relevant for security studies, is the intelligence profession, which in many ways is defined by its place between a national security logic of exception and a bureaucratic logic of legal regulation. This place of the intelligence profession supports an identity of expertise based on secrecy on the one hand and parliamentary control on the other (Bar-Joseph 2010: 14). As we see later in the chapter, this idea of intelligence expertise, this way of ordering society, has come under pressure in the current debates on intelligence, which stress public participation as essential to the success of counterterrorism.

Overall, there are two main ways of studying disciplines and professions: one is to look at the role of state bureaucracies in defining expertise and socio-political power; another is to study how professional expertise is defined by certain functionally differentiated logics that make them appear meaningful. First, the role of the state in relation to professions and disciplines has historically been very powerful, mainly because professions and disciplines often are dependent on getting institutional acceptance by a government, either institutionally by providing formal education, or by handing out certifications. Due to this connection, scholars have studied the close link between the state, professional identities, and their constitution of expertise (Taylor 1995).

Disciplines and professions can, however, also be approached as fields of expertise structured by certain functional forms of professionalism (Saks 2010). These fields of expertise condition the management and local practices of security, risk and dangers. A good example is the insurance underwriter who after 9-11 had to translate national security issues into something that could be traded - to translate something highly unpredictable, uncertain and interlinked with political action into an economic logic of risk (Huber 2002; Smetters 2004).

New situations thus constantly arise, where issues appear on the agenda in ways that do not fit easily into existing professional fields, and where different professions and disciplines are drawn together over certain challenges or unwanted futures. In this chapter, we set up a framework for how to study the functional logics implied in the meanings of professions and disciplines and ask, what happens to unwanted futures when they are translated across versions of professional expertise? This is not to ignore the role of the state, authority and power, but to open up for investigations of how current and local practices of translations across these structures of professionalism construct new meanings of security expertise; meanings that might either reinforce or challenge established understandings.

We start from the argument that in a zone defined by different forms of professionalisms, two main distinctions exist: One is the distinction between different professional identities and the other is between professionalism and 
amateurism. Based on this, the chapter first discusses the translation zone across professional identities, what is translated and how this is supported by a number of means. The second part of the chapter then turns to the translations beyond professional identities involving forms of amateurism and how these have been supported by different concrete technological developments such as the rise of the internet. In the third part of the chapter, we analyse what concepts of security emerge in these processes, before the final part of the chapter zooms in on the political consequences and trends we observe. We discuss how historically sedimented structures of meaning are both challenged and upheld in today's translations of security and we observe negotiations of meaning that attempt to redefine disciplinary and professional boundaries as well as relations between security professionals (defined by their belonging to the state apparatus) and amateurs (lay people or the "public"). On top of these changes, we observe a fundamental change in the role and authority of the state. Communication on national security practices increasingly takes the form of involvement of amateurs, and a trend of a general responsibilisation is visible. In this process, new professional identities are created, not belonging to the traditional ones.

\subsection{Negotiating professional identities and practices}

As argued in Chapter 1, we developed our concept of translation zones with inspiration from Peter Galison's work on trading zones to understand the synchronic negotiations of meaning that happen in the everyday translation of unwanted futures. In a "translation zone" there might be exchanges, new constellations of concepts, practices or meetings may alternatively consist of unilateral extraction; of inconsequential encounters; of conflictual clashes. Translation zones, hence, are quite simply meetings between conceptualisations of unwanted futures and programmes for their management. We argue that a translation takes place across structures of meaning; in this chapter referred to as "professions" and "disciplines," or just "professionalisms." But how are these fields structured and what kind of logic of ordering applies? Said differently: What is negotiated when talking about professions and disciplines? We zoom in on meetings, cooperation, and connections without the assumption that deep disagreements are ironed out; in fact, joint performance can be achieved despite continuous difference in their understanding of the issues and of what they are actually doing. In this "translation zone," at the meeting point, languages and practices evolve that work for the task at hand. This points to the possibility that new meanings can emerge as a result of the new constellations, despite the continued differences among the parties participating in its production. This is the joint frame for all three analytical chapters - and the next step is then to find out what characteristic patterns emerge when the translations take place across disciplines/professions, cultures, or scales, respectively. This chapter looks, 
as mentioned earlier, at disciplines and professions as part of a general functional differentiation in society.

Our investigation starts out by identifying the translation zone under scrutiny. What is the main form of organisation or logic of ordering? Which conceptual meanings are invoked and what kind of sedimented structures do they rely on? The chapter finds that two main distinctions are fundamental for understanding the translation zone of disciplines and professions. One is horizontal across different disciplines and professions. The other cuts through this mode of organization vertically and includes the distinction between the professional and the amateur. These two distinctions are negotiated with various means and mobilise a range of authority claims (scientific language, utility, etc.). These distinctions, we claim, will help us to grasp analytically the different forms of professionalism, and the negotiations of new meanings going on in the everyday translations of security, risk and danger. In its attempt to create new meanings, a translation will, it is argued, always entail a negotiation of these distinctions. Towards the end of the chapter we argue that the translations have fostered a number of new conceptual developments and untraditional forms of governance.

\subsubsection{What are professions and disciplines?}

This chapter studies disciplines and professions as part of the same domain or as different modalities for organising functionally specific knowledge. Following from this, we view both disciplines and professions as expressions of established functional identities. In this section, we draw out some of the elements that distinguish disciplines from professions and some, which are shared, all in order to reach a better understanding of the conditions for translations between and across these functional identities. For this purpose, it makes most sense to start with professions and then proceed to disciplines because disciplines have some of the key features of a profession and then one particular dynamic that professions do not have.

In classical, as well as recent, works on professions, a profession is considered a special kind of occupation (or vocation) that one can fill only after special training that inculcates both a professional ethos and specific skills. The various professions, that achieved this status through history, have typically established an increasingly formalised system of certifications and associations that regulate the production of new members as well as their obligations (Abbott 1988; Dingwall \& Lewis 2014; Gieskes 2006; Saks 2010, 2012). In modern society, the mutual recognition between state and professional association has been a central issue. Historically speaking, three professions were foundational: Medicine, Law and Divinity, yet in modern societies, classical professions have in many countries included pharmacy, medicine, law, police, military, ${ }^{1}$ dentistry, actuarial science, civil engineering, and accounting. Those professions are defined by a particular activity that one is only allowed to carry out if sanctioned by the profession to do so. 
In many ways, a discipline shares features with a profession and is occasionally analysed as if the same. To some extent, this might be seen as a particular evolution of a profession. However, as argued probably most precisely by Richard Whitley (2000) (see e.g. Abbott 2001, 1988), a discipline is like a profession, only you have to prove your membership over and over again. You are a dentist, if you have passed the exam and been recognised as such (and keep renewing maybe a specific membership or authorisation). To represent a discipline (be a scientist) you have to make contributions to science. And what that means is judged by the community of scientists at any given time (cf. Kuhn 1996; Merton 1973). This is what defines (scientific) disciplinary knowledge in contrast to professional, and thus the occupational challenge of being a scientist in contrast to a practicing professional.

Traditional professions and academic disciplines, however, differ on one more dimension: "professions are exclusive occupational groups applying somewhat abstract knowledge to particular cases" (Abbott 1988: 8). The defining feature is the ability to apply the knowledge and emphasis is therefore on acquiring knowledge skills. Members of a scientific discipline, on the other hand, are those who are able to produce new knowledge within the given domain.

Given these differences between professions and disciplines, different regulatory functions are in play. For a profession its social role is highly regulated by its power over the production or consecration of new members (often sanctioned and empowered by the state) (Abbott 1988; Bourdieu 1998); its ability to defend its sovereignty to make decisions on own practice; and the possibility of maintaining the outer boundaries of its domain vis-à-vis other professions. The most important means are certification and admission. The military profession and the definition of the officer is an obvious example of a highly regulated profession, where the uniform helps to visualise membership and where the practice of $\operatorname{war}^{2}$ defines the skills (see e.g. Huntington 1957). The boundary of this profession is often defined by referring to "civilian" professions, e.g. health care (see Box 3.1). Yet, what we see today is also how some civilian skills in e.g. economics, conflict resolution, and health care "threaten" this perception of the profession and push for new negotiated meanings of the military profession (cf. current and past debates on civil military relations). On exactly the theme of how the military profession is evolving, Katrine Nørgaard in her work shows how the military profession attempts to bridge the logic of war with bureaucratic needs for political responsiveness. In addressing these opposing management needs, a trust versus an accountant logic of governance, the profession is developing an entirely new identity, she argues (Nørgaard 2010: 61) (See also Maja Zehfuss's tale in Box 3.2 on the American Human Terrain System).

For a discipline, in contrast, its relative social status vis-à-vis other disciplines, ${ }^{3}$ the degree of scientific-ness, has traditionally defined boundaries and domains. Recently also questions of usefulness, relevance, and impact regulate the social roles of disciplines. These external criteria matter for the allocation of resources. Internally, much is about the allocation of resources 


\section{Box 3.1 Securitization in medicine. Danger replacement and politically productive dreams of safety}

\section{Klaus Hoeyer}

What are the attitudes to danger and the modes of securitization characterising medical practice? It seems quite impossible to answer this question in any meaningful manner and yet it is obvious that medicine is all about danger. Treatment always poses a risk to the body. Medical practice is therefore not about installing security where there used to be risk, but about replacing one form of danger, disease, with another, treatment. Even in cases of prevention there are no absolutely safe strategies: you might do more harm than good and often only realise in tragic hindsight. Medical practice is also about danger replacement in a more profound and discomforting sense: if one treatment works and saves your life (e.g. treatment of a heart attack), it basically means that you survive long enough to encounter another and perhaps more painful death (such as cancer). There is no enduring security in medicine; just continuous danger replacement.

How do medical institutions organise to cope with this form of danger replacement? From a legal and organisational perspective, the preferred method has for years been to delegate maximum authority to a responsible medical professional with the ability to exert individual professional judgment in each singular case. The system has traditionally been organised so that it would hold people responsible according to rank and familiarity with best available evidence. The law would never tell a doctor what to do, but doctors could lose their authorisation if acting in ways deemed unreasonable by other doctors.

This approach was engrained in traditional medical training. In a classic study of medical training, Charles Bosk turned the proverb "forgive and forget" around and stated that the training of doctors centres on the ambition to "forgive and remember" (Bosk 1979). Doctors learn to administer danger by performing risky procedures and learning from their mistakes. To learn to practice medicine is not only to learn to apply medical insight but also to administer danger replacement in an accountable manner. This is achieved by way of a set of sanctions holding doctors responsible to their seniors and peers. Bosk classifies the different forms of mistake and points out how mistakes stemming purely from lacking technical know-how are used for teaching purposes but encouraged and unproblematic. However, if junior doctors do things 
unauthorised by senior doctors, it is heavily sanctioned and they potentially lose their position.

The life and death decisions that doctors must make impose great psychological demands on them. There probably are some similarities between the combination of strict lines of authority and autonomy in medical training and what we find in military training. It is training designed to cope with the moral challenges faced by those having to make life and death decisions. Of course the training of doctors is different in the sense that they are mostly trained to save life, while military staff should learn to dispense with it.

This traditional model of paradoxically mixing autonomy with systems of strict obedience has undergone significant changes. First from within the medical field, where a demand for systematic evidence gradually from the 1950s onwards complemented the experience-based ideal described above. Then, during the past decades a new set of transformations stems from strengthened pressures from patients wanting greater influence, and politicians and the public wanting to control priorities and govern the health services according to politically determined goals. Data-driven health service is the new mantra, leaving much less room for clinical judgement. It has also become a matter of public accountability to demonstrate proof of security, or to use a more common term in medicine, "safety." As a consequence, the medical professions now have to document safety. Today, documentation demands have thoroughly changed medical practice. In effect Michael Power's Audit Society has transformed the clinic (Power 1997).

The aim of safety holds a great legitimising potential. The potential makes it politically productive. It is used to install procedures which are now curtailing the medical autonomy which used to be so central to danger management at the clinical level. Of course, safety and danger are always just matters of degree: there is no absolutely safe procedure in medicine. Hence, safety is not an actual state that can be achieved; rather promises of safety serve as unreachable mirages projected into the future in order to restructure organisational actors in the present.

Other challenges to the traditional mode of dealing with danger stem from an increasing politicisation of the demands imposed on the health services, including the patient rights movement, as well as increased awareness of the volatility of health and disease. New and sudden viral threats such as Bird's Flue, Ebola, or, most pertinently, COVID-19, catastrophes such as Fukushima, and terrorism-induced risk scenarios such as anthrax dissemination, are all seen as potential dangers that the 
health care system must be prepared to deal with. It is, however, a very different set of skills which are in demand here than what Bosk described. It is work performed at the desk, not the bedside, and it is about producing scenarios of the unknown, rather than deciding what to do with the concrete case right in front of you. It is about resources and organisational decisions, not about treatment or prevention in a medical sense.

What I have been able to outline here is only a sketchy set of thoughts about what characterises the ways in which the medical profession deals with danger and strives for "security." Furthermore, medicine is much more than doctoring - it involves a whole range of professions working. These caveats aside, it is still fair to say that training in medicine is also training in danger replacement, and the courage that health professionals exhibit on an everyday basis is essential to the trust and gratitude most patients express after visits to medical institutions.

\section{Notes and References}

Bosk, Charles L. 1979. Forgive and Remember: Managing Medical Failure. Chicago:University of Chicago Press.

Power, Michael. 1997. 'Expertise and the Construction of Relevance: Accountants and Environmental Audit'. Accounting, Organizations and Society 22: 123-146, 10.1016/s0361-3682(96)00037-2.

\section{Box 3.2 "It is difficult to look busy while thinking": Translation Advice for Human Terrain Teams (HTTs)}

\section{Maja Zehfuss ${ }^{a}$}

The 2003 invasion of Iraq by the United States and its allies did not go quite as planned. "Shock and Awe" failed to deliver the desired quick resolution and the allies they found had created a situation that was undesirable all round. They were occupying the country and yet unable to ensure basic levels of security, either for themselves or for the population. They found themselves exactly where they did not want to be: involved in counterinsurgency warfare.

In this type of warfare, as Marine Major General Mattis put it succinctly, the "people are the prize" (Ricks 2006). Ways had to be found to win the people over. Making sure they would not be killed by insurgents or indeed by the occupiers would have been a good start, but this was easier said than done and it would not have been enough. "Hearts and minds" would have to be won. 
Western militaries had long counted on their technological superiority, but you cannot bomb your way to people's support. To generate support you have to understand the people. This is not what soldiers are typically best at. Anthropologist Montgomery McFate had argued for some time that her discipline had something to offer to the military, that it should remember its promising beginnings as a "warfighting discipline" and contribute to national security by working more closely with the military (McFate 2005: 24). The military needed to understand the local culture and anthropologists had that expertise: a perfect match, as far as McFate was concerned.

She and others were able to persuade military leaders and so by 2005 the US Army was establishing the so-called Human Terrain System (HTS) in order to address its "cultural knowledge needs" (McFate \& Jackson 2005: 18-21). HTS would establish HTTs, which would deploy social scientists to combat zones in order to use their knowledge and skills to facilitate winning the war. They would do research to support commanders.

The programme received some very favourable press coverage early on. Anthropologists were called a "crucial new weapon" (Rohde 2007). It all seemed to make perfect sense. Yet HTS quickly ran into problems. Most disturbingly, a number of social scientists were killed on deployment. As she was trying to interview an Afghan, Paula Loyd was doused in petrol by him and set alight. She died a slow and painful death. One of her teammates killed the Afghan in retaliation.

These casualties were only one aspect of the problem. HTS became the subject of much wider controversy. For one thing, the programme seems to have been mismanaged at the highest level (Lamb et al. 2013). For another, the anthropologists whose expertise was celebrated as a solution to the security problems in Iraq and Afghanistan objected to the programme. Many argued that participation would mean violating their professional ethics. Providing information to the military would put the local population, who would be the anthropologists' research subjects, into harm's way. They could be killed as a direct consequence of participating in the research. It is difficult to imagine a more flagrant violation of the principle that research subjects must not be harmed (Zehfuss 2012: 175-190). So anthropologists were not as keen to save the day as McFate wanted them to be and the programme was not sufficiently well run to allow even those who were willing to do what the military thought was needed.

This story has been told before, but somehow in telling this story of controversies, scandals and deaths, the story of how HTS actually 
works or is, for that matter, meant to work, has been obscured (Lamb et al. 2013). The declassified Human Terrain Team Handbook, compiled in response to problems some HTTs experienced in providing useful support to commanders, tells us this story. It tells us what the teams are meant to do, how they are to conduct research and how they are to communicate with the military. The handbook tells a story of what social science research is and a story of what the military does. The moral of the story is translation advice: HTS only works if the two spheres can be made to speak to each other successfully.

The handbook tells us that HTTs do academic research. This involves the following research design: Like all well-planned research, these designs will be based on research problems phrased in terms of a thesis. The problems themselves will refer to a particular social theory. These problems are tested through hypotheses which enable the researcher to test their explanatory force. The data that result are used to validate or refute hypotheses, and by doing so affirm the overarching social theory's utility as a way of understanding the social world (Finney 2008: 55).

On the other hand, the handbook tells us how crucial it is that any insights are made accessible for and relevant to commanders. It is crucial to make "the gathered data operationally relevant"; for if the information is not "distributed and briefed in a relevant manner, it is worthless data." The HTT leader must "couch" the information "in terms familiar to a military audience, making it not significantly timeconsuming, and insure it is operationally-relevant to the unit's operations and problem-set" (Finney 2008: 4).

What we are being told, therefore, is that, ironically, the challenge lies in translating between two cultures: not between the US culture and the culture of the local population, but between the culture of the social scientist and that of the military. The supposed experts in culture are being given advice on how to navigate the culture divide. This is beautifully captured in an assertion that reflects the values of military culture: "Critical thinking is perhaps the most underrated aspect of analysis. Because it is difficult to look busy while thinking, those that do engage in this activity are seen as lazy or spacey" (Finney 2008: 19). This observation would make no sense in the context of an academic research culture. In attempting to resolve the lack of cultural understanding between local populations and occupying forces another culture gap that requires translation has been produced. 
The military is looking to the social sciences to provide "valid and objective information" that will assist them in mission accomplishment, which is thought to deliver security. Social scientists might question that supposed causality and understand security differently. Yet what emerges as interesting is not so much any translation of the content or location of security, but the production of the encounter. This is a story of appropriating not just social science knowledge but social scientists themselves. Despite the gap between a culture that values analysis and one that values action social scientists were considered useful.

It is not the distance between the two cultures that is uncomfortable, but the resonance between them. Research and reconnaissance are not as different as we might like to think; knowledge, as anthropologists of course are well aware, is useful. In the candid words of a commander explaining what he expects from his HTT: "I need to know if I give [the village elders I am meeting] a handshake or a hand grenade" (Burke 2010: 29). The problem that emerges from the story of HTS is only superficially one of the gap between military needs and scientific protocols or of their different understandings of security. More fundamentally, the problem is the reverse: that the gap is not as large as the social scientists would like.

\section{Notes and References}

a The themes and ideas that inform this tale are elaborated in Maja Zehfuss (2012); Maja Zehfuss (2013); and Maja Zehfuss (2018).

Burke, Carol. 2010. 'Combat Ethnography', in Douglas Higbee (ed.) MilitaryCulture and Education. Farnham: Ashgate: 29-37.

Finney, Nathan (2008). Human Terrain Team Handbook. Fort Leavenworth, KS:Human Terrain System.

Lamb, Christopher J., James Douglas Orton, Michael C., Davis, Theodore T., \& Pikulsky (2013). Human Terrain Teams: An Organizational Innovation for Sociocultural Knowledge in Irregular Warfare. Washington DC, US: Institute ofWorld Politics Press.

McFate, Montgomery. 2005. 'Anthropology and Counterinsurgency: The StrangeStory of Their Curious Relationship'. Military Review 85: 24-38.

McFate, Montgomery, \& Jackson, Andrea (2005). 'An Organizational Solution for DODasCultural Knowledge Needs' Small Wars Journal. Military Review, July-August, 2005, 18-21.

Ricks, Thomas E. 2006. ,Fiasco: The American Military Adventure in Iraq. New York:Penguin.

Rohde, David. 2007, october 5. 'Army Enlists Anthropology in War Zones'. New YorkTimes, s. 1. 
Zehfuss, Maja. 2012. Culturally sensitive war? The Human Terrain System and the seduction of ethics. Security Dialogue 43: 175-190 10.1177/ 0967010612438431.

Zehfuss, Maja. 2013. Staging war as cultural encounter, in Jenny Edkins and Adrian Kear (eds.) International Politics and Performance: Critical Aesthetics and Creative Practice. Abingdon: Routledge: 221-233.

Zehfuss, Maja. 2018. War and the Politics of Ethics. Oxford: Oxford University Press.

too (including research grants, hiring, etc.) but also about shaping the future architecture of its body of knowledge, which includes struggles over the control of the academic institutions proper, i.e. scholarly journals. Thus, struggles inside a discipline are over what constitutes its centre (explains and regulates the whole), what is a specialisation, and what should really not count at all. For two entirely different takes on security, see Vigh's box 3.9 where he explains the anthropological take on security and Hahnemann's box 3.5 on Economics.

Although, as we have noticed earlier, the relationship across disciplines and professions is a continuum there is, at least ideal typically, a difference as to how clashes should be expected to play out. With disciplines, immediate incompatibilities when collaborating with others likely show up in the form of different conceptual universes and thus different intellectual structures. For a profession in contrast, emphasis will be at least as much on how things are done practically.

In meetings with non-members, the professional will typically be keen to instigate procedures that symbolise the importance of their particular skills. In intelligence, the regulatory skill (defining its professional ethos) is secret knowledge; for the military officer, it is war; in journalism it is communication; in medicine, it is cure, and so forth. All these skills are different and distinct from the skills that define other professions. The focus on skills to carry out a task is present in Klaus Hoeyer's tale (in Box 3.1) on the professional identity of medicine, which he characterises as based on the ability to "replace disease with treatment." This process, he argues, involves difficult decisions on life and death and a psychological strength similar to the one found in the military profession; and documentation similar to the one found in auditing.

Just as professions work alongside one another to be useful to society (the usefulness of engaging many skill to solve a particular problem), academic disciplines have increasingly accepted inter disciplinarity as a particular and necessary challenge (Gibbons et al. 1994; Messer-Davidow et al. 1993; Nowotny, Scott \& Gibbons 2002). In these debates research frontiers are located at the site where collaborating teams address particular challenges deemed significant by society. The context of application and the usefulness of its concepts thereby becomes the privileged point for pursuing the research that matters - also to basic science. As such, task-defined research 
agendas have become a major focus of funding (cf. most clearly the funding practices of the EU; Friedrichs \& Wæver 2009). This is highly relevant in the present context of translations among disciplines and professions.

To sum up, the identity of and the space between these professional identities can be described through the categories in Table 3.1. Where the first two columns describe the main distinctions and identity markers of professions and disciplines (practical utility and analytical ability), the two following columns - the intersecting zone of translation - describe the defining "space across" these disciplines and professions and the means for translation typically employed in each. The space between disciplines is mainly defined by the possibility for interdisciplinarity and the means for translation is "analytical concepts." Across professions, the space is primarily defined as solutions to problems - a space negotiated and defined by the idea of "skills." By zooming in on and understanding the negotiations going on in these spaces across disciplines and across professions - the analytical concepts and skills defined, redefined, or invented - we come to identify the new meanings of unwanted futures and the practices for handling them. These spaces are thus "zones of translations."

Table 3.1 Translation zone between functionally differentiated expertise - disciplines and professions

\begin{tabular}{|c|c|c|c|c|c|}
\hline Functional unit & Distinction & $\begin{array}{l}\text { Basis of } \\
\text { authority }\end{array}$ & $\begin{array}{l}\text { Means of } \\
\text { translation }\end{array}$ & $\begin{array}{l}\text { Relation } \\
\text { to state }\end{array}$ & $\begin{array}{l}\text { Relation to } \\
\text { knowledge }\end{array}$ \\
\hline $\begin{array}{l}\text { Discipline: } \\
\text { distinct from } \\
\text { other } \\
\text { disciplines }\end{array}$ & $\begin{array}{l}\text { Domain of } \\
\text { theore- } \\
\text { tical } \\
\text { expertise }\end{array}$ & $\begin{array}{l}\text { Analytical } \\
\text { ability }\end{array}$ & $\begin{array}{l}\text { Interdisciplinary } \\
\text { collaboration; } \\
\text { Disciplinary } \\
\text { concepts; } \\
\text { Degrees }\end{array}$ & $\begin{array}{l}\text { Transcen- } \\
\text { ds state }\end{array}$ & $\begin{array}{l}\text { Produces } \\
\text { knowledge }\end{array}$ \\
\hline $\begin{array}{l}\text { Profession: } \\
\text { distinct from } \\
\text { other } \\
\text { professions }\end{array}$ & $\begin{array}{l}\text { Domain of } \\
\text { practical } \\
\text { expertise }\end{array}$ & $\begin{array}{c}\text { Practical } \\
\text { utility }\end{array}$ & $\begin{array}{l}\text { Skills; } \\
\quad \text { Certificates; } \\
\text { Practical } \\
\text { problem- } \\
\text { solving }\end{array}$ & $\begin{array}{c}\text { Authorized } \\
\text { by state }\end{array}$ & $\begin{array}{l}\text { Applies } \\
\text { knowledge }\end{array}$ \\
\hline
\end{tabular}

While these differences between professions and disciplines are important for understanding the translations currently happening in the fields of security, the divisions are of course, in reality, not always as clear. First, one could argue that some professions largely followed disciplines. For instance, the discipline of economics was assumed to be at the bottom of everything economists do including e.g. how financial risks are managed; insurance mathematicians were seen as the key to insurance practices; and, for instance, climate science as central for what goes on in climate policies. Second, some professions are not professions in a "state certified" fashion - like intelligence, corporate security management or disaster management. Third, some professions have an 
academic discipline closely accompanying it (e.g. medicine or law). Last, a particular practice field is often made up "from the start" so to say by a collaboration among disciplines, as for instance public administration in Denmark mixing lawyers, economists and political scientists (where in some other countries like France, they are trained as a profession with a specialised training). A very different example of this type is the field of climate change expertise, which is really a large interdisciplinary cooperation (as witnessed by the number of participants in IPCC) that operates as separate disciplines academically, but jointly as a body of expertise informing policy. Yet, and despite these overlaps between the functional logics of disciplines and professions, they each work to establish certain kinds of professionalism, which again work to make different authoritative claims on reality (cf. Table 3.1).

\subsubsection{Translations across professionalisms}

Often, the push for translation across professionalisms mostly comes from a "third party," pointing to those who have then to translate amongst the professions in question. Decision makers ask for input on "how to regulate intellectual property internationally" (Porsdam's tale, Box 4.4) that takes into account more dimensions than in the past (e.g. in the health system; See Klaus Hoeyer's tale in Box 3.1). As a consequence, lawyers, humanists, and tech experts have to talk to each other; and medical doctors and lawyers have to adjust the system regulating the medical profession. In other instances, a problem or issue is transferred from one professional domain to another - in effect being translated into being about an entirely different unwanted future: Jonna Nyman (Box 3.3) tells us how "energy security" during the Obama administration might have been about averting the unwanted future of climate change when discussed as part of an environmentalist agenda. When taken over by the Department of Energy, it, however, became about the unwanted future of energy supply problems,

\section{Box 3.3 Translating energy security in the United States: What happened to climate change?}

\section{Jonna Nyman}

Energy security is in many ways a peculiar concept: the label travels internationally and across institutions and fields of practice, but its meaning changes. As a result, it is often considered notoriously "fuzzy" as a concept (Valentine 2010), and it can be difficult to pin down. My tale of translation explores energy security in the United States during the Obama administration. It shows how the White House defined 
energy security and set the agenda; and then how this notion of energy security was translated into practice in the Department of Energy and the State Department, and how the concept changed during this process. The tale is based on interviews with policy officials at different levels in these departments, undertaken in 2012.

While the White House defined the broader agenda when it came to energy security, different institutions were then tasked with the policy implementation of this agenda: here the Department of Energy and the State Department played an important role. In some ways Obama took quite a traditional approach to energy security, emphasising the need for security and diversity in energy supply; this also included a focus on energy independence. He defined his approach to energy security as an "all out, all of the above" approach, to indicate that all sources of energy were acceptable. However, he had also been a vocal proponent of the need to move to cleaner energy sources. He explicitly labelled climate change an issue of "national security," and repeatedly linked his energy security agenda with climate change, noting that "our continued dependence on fossil fuels will jeopardise our national security" (Obama 2010). However, as energy security travelled and was translated into different government departments, the climate focus largely disappeared.

\section{How was energy security translated?}

Once Obama had set out his policy agenda and his interpretation of energy security, different departments were tasked with achieving the various targets and goals. However, each department also has its own agenda(s), based on the individual personalities of the people involved, as well as the preconceived, and often institutionalised, ideas about what that department's "role" was. The departments also tended to use very particular languages when they were talking about energy security.

The Department of Energy had generally been a department doing research and development on energy rather than one setting policy. Its officials tended to use technocratic or scientific language, and they had a practical strategy that was focused on research and deployment of different technologies. The department's mission had been seen as being one of "science and energy." In a discussion about Obama's approach to energy one interviewee said, "everything is on the table. Nuclear is on the table, clean coal is on the table, better uses of oil are on the table. You've got to do everything, you can't just rely on solar to solve the problem." In many ways, this statement was quite closely aligned with Obama's notion of energy security. 
However, in the discourse of most officials interviewed, the renewables, climate-focused part of Obama's energy agenda largely disappeared. One interviewee noted that the climate agenda was something largely "done in other departments." Another interviewee, when asked about the relationship between energy security and climate change, said that when you were dealing with energy security, because of the politics that were involved, "you're not allowed to say climate change anymore'. In the everyday life of Department of Energy officials, climate change was off the energy security agenda and it was assumed that it will...get dealt with along the way to new energy technologies."

When it came to the State Department, energy security had grown more institutionalised since 2011, with the creation of a new Bureau of Energy Resources inside the department, though energy security had long been a factor in the department's operations. The language used by State Department officials was one of strategy and geopolitics. According to one interviewee, energy security was understood in traditional, geopolitical terms, as "the ability of a country to access the energy it needs to maintain national power."

There was a focus on ensuring the stability of energy suppliers (internationally), in terms of political stability and markets, and interviewees noted that "using diplomacy to protect global [oil] supply" was a key part of energy security. Oil supply was seen as central, with some discussion of gas/coal, but again clean energy largely disappeared. When one interviewee was asked about the division between energy and climate change, they noted that "there were...some significant hard policy choices where those two were in tension... but those issues were not really resolved at a senior level." The same interviewee then went onto say that there was also an institutional division within the department between people who were working on energy security and people working on climate change.

\section{What had changed and why?}

As energy security travelled and translated into different government departments, Obama's climate focus largely disappeared. As it was translated, a much more traditional notion of energy security prevailed, and the climate agenda was largely lost. This did not necessarily mean that climate change was completely ignored: while it had disappeared in the everyday conversations in these institutions, it sometimes reappeared in external policy reports or discourse. However, it was clear that within these departments there was a discomfort with the link between 
energy security and climate change. Things were changing somewhat, but it was not a comfortable process. For example, when asking interviewees in both departments about energy security, climate change never came up spontaneously or without explicit prompting.

A number of different reasons could explain this (mis)translation. Firstly, departments understood security, risk, and threat very differently: Whereas the State Department relied on a traditional notion of national security, the Department of Energy focused on safety and domestic supply. The two departments hence used very particular security languages, which also affected how they could talk about energy security. In comparison, climate change is a global threat that crosses national borders, which doesn't fit easily within these understandings and vocabularies of energy security. Lastly, institutional culture likely played a role. Climate change was not traditionally dealt with in these departments, and that's difficult to change overnight.

To conclude, while the concept of energy security was translated, the meaning changed, but the actors involved rarely acknowledged this. These different meanings often worked (even unacknowledged) alongside each other. They presented different unwanted futures, using different vocabularies, and these different notions of energy security opened up different political possibilities and policy choices.

\section{Notes and References}

Obama, Barack (2010). Remarks by the President on the Economy atCarnegie Mellon University. https://obamawhitehouse.archives.gov/ the-press-of!ce/remarks-president-economy-carnegie-mellon-university accessed June 6, 2021

Valentine, S. V. (2010) The fuzzy nature of energy security. in B. K. Sovacool (ed.) The Routledge Handbook of Energy Security. Routledge: 56.

whereas the State Department worked to avert the unwanted future of depending on potential enemies as energy suppliers.

Seen from the inside of a given field, the motivation for engaging with another can be import or export oriented. It can be the functional demand from one discipline, profession, or functional system for knowledge that is believed to reside in another. A clear case is in Maja Zehfuss's box on HTTs (Box 3.2), where the military asks for help from anthropologists. Also Jeppe Strandsbjerg's analysis (Box 3.4) where cartographers are put to work for lawyers and foreign offices is a good example 


\section{Box 3.4 Translating nature, law, and sovereignty in the Arctic: a question of security?}

\section{Jeppe Strandsbjerg}

The relationship between geography and law plays a significant though not always appreciated - role for the conduct of international relations. International Law in general and Maritime Law in particular refers frequently to features of "nature"; that is, the material environment, when defining the conditions for the distribution of sovereignty. Though, while law refers to geography as if it is an unproblematic and static presence, the material world of rocks, continental shelves, and low tide elevations is always more ambiguous. Therefore, scientists and technicians - what I prefer to call cartographers - play an essential role in determining a spatial, or cartographic, reality within which sovereign claims are negotiated. In the following I will present a story about continental shelves, the Arctic Sea, states, scientists, and lawyers. In the described process three moments of translation (of security, of "nature," and between disciplines) take place. While all three are important I will emphasise the process of translation that invariably takes place not only between different professions or "codes and particular social factions" (as described in the introduction chapter) but between science, law, and geography in the attempt to practice international politics proper.

The first moment of translation occurs when a series of events and conditions are interpreted in a particular fashion. When the Russian Arktika expedition submerged a Russian flag on the seabed of the North Pole in 2007 it came to symbolise a fanciful end emerging popular interest in the Arctic. News media and commentators around the world did not hesitate to reinvigorate colonial imaginaries of the lone white explorer (now in the shape of a submarine) raising a European flag on a landscape marker to claim the said space for his native sovereign. In combination with realist geopolitical outlooks emphasising the presence of large oil and gas reserves, unsettled maritime boundaries, and increased accessibility due to diminishing ice cover, Arctic politics were widely described in terms of competition and potential security issues. That is, the future of Arctic politics was seen as at least potentially unwanted. This can be seen as a securitisation process driven by commentators and media. In reaction, we witnessed a desecuritising translation by the littoral states of the Arctic Ocean. In 2008 they signed the Ilulissat Declaration where they confirmed that 
they would follow international law and established diplomatic practice when dealing with issues of sovereignty and Arctic governance. As such they translated Arctic affairs as being "normal" rather than "exceptional."

A successful translation of the Arctic as being peaceful and nonexceptional rests however on a particular relationship between law and geography. It requires a legal-technical translation of the environment; what I call stabilising nature. The origins of the, then, frequently discussed sovereignty issues derive from the United Nations Convention of the Law of the Sea (UNCLOS) and the way it codifies states' rights to the seabed. The continental shelf is described as having both a legal and a geological existence. All states can claim a 200 nautical miles (NM) continental shelf. But where the "real" continental shelf extends beyond the $200 \mathrm{NM}$ a state can claim rights over what is called the Outer Continental Shelf. The principle is simple but when you are in the field it is incredibly complicated. All the Arctic States spend vast amounts on scientific expeditions that survey the seabed in incredibly harsh conditions in order to determine the presence and contour of the continental shelf; as they are defined within geology but also as they are described in the legal text. In other words, the cartographers deployed on the continental shelf missions work to translate an ambiguous material environment into a stabilised geology that corresponds with scientific practice as well as law.

The third moment of translation occurs when claims are to be submitted to the UN body - the Commission on the Limits of the Continental Shelf (CLCS) - that assesses the claims made by coastal states. Having completed data collection, a task force is established with cartographers, diplomats, and lawyers that have to translate the data, the law, and the political aspirations of states into a single claim. The different professions, or disciplines, engaged all talk about the same phenomenon but do it from very different perspectives. Cartographers refer to the geomorphological features and data, the lawyers refer to the legal text, and the diplomats to the interest of states and the desire to expand rights. There are, thus, disciplinary translations of the continental shelf which have to be interpreted into one. The cartographers are well aware that their discipline has been overtly politicised but the response varies from calls for better science to a realisation that the mandate is to interpret the data in a way that is as beneficial as possible for extended Continental Shelf claims while staying within what is scientifically credible.

The processes surrounding continental shelf claims in the Arctic are illustrative, I believe, of security issues more generally. The first moment 
concerns whether a particular scenario is being cast as an unwanted future or a normal situation. While securitisation theory has traditionally emphasised political elites as securitising actors, we have seen a reverse situation where elites aimed to desecuritise the question of demarcating sovereign rights. This move, however, depends on two further moments of translation. First, a process where the material environment is translated by cartographers who, in effect, assemble a stabilised spatial reality that can serve as a basis for sovereign claims. Subsequently lawyers, diplomats, and cartographers pass through a moment where three different conceptions of the continental shelf have to be translated into one coherent document that satisfies both legal, technical, and political aspirations driving the continental shelf process. While the second moment of translation in this tale speaks directly to the rationale behind this book, we should be cautious not to downplay the significance of cartographers that continuously work through processes of translation which stabilise nature in a manner that makes it compatible with international law.

of this. Both are discussed in more detail below. But the motivation can also stem from a wish to communicate meaning from one's own system to another. A striking case here is climate science where the scientists in (classical) climate studies strive to both communicate to decision-makers and to enrol specialists in other fields. This is done not least in relation to the social sciences and humanities in order to strengthen both the total body of knowledge and not least the ability to link up to citizens and decision- makers (see also the discussion below as well as Richardson, Carruthers \& Hui 2011; Wæver \& Rasmussen 2013).

A different kind of dynamic involves the situation where a field that previously worked in its own niche is exposed to the pressure of having to compare itself to other fields, i.e. the pressure from prioritisation imposes a linking to other fields. A clear example of this also relates to climate change, where an attempt to level out the climate threat was sought through a comparison to other pertinent problems on economic grounds (How cheap is adjustment contra the development of climate friendly technologies?). These types of arguments can be found in Bjørn Lomborg's publication The Skeptical Environmentalist: Measuring the Real State of the World (2001). Another example of this can be found in Hahnemann's tale in Box 3.5, 


\section{Box 3.5 Beyond control. The economic translation of security}

Niels Peter Hahnemann

Economics is essentially about trying to plan social outcomes so that they become, as we would want them to be. Economics is very much about obtaining security. When events are according to plan they are as you want. That feels safe. However, you cannot have security without the fear of loosing it. So what economics wants to do is to think about prediction and forecasting. Does that mean control?

You may say that economics is a guide to social decision-making. We want to get prices and quantities right using computation, numbers, and mathematics. Homo economicus is usually portrayed as egotistical. You should rather see it as decision-making opposed to coercion. The basis is enlightenment philosophy and the idea of self-determination and freedom, where the power of the sovereign needs to answer to the people. The people should decide by itself for itself. Economics is an instrument in democracy.

But things can go wrong. So an important point in economics is expectation formation and the risk of error and how to hedge against this. Examples of hedges are financial market instruments and public policies. Flexible prices are in principle the best hedge you've got. The problem with enlightenment philosophy and politics is, however, that we need error to correct error in a sort of learning process. In enlightenment there was only one valid answer: control through the nation state and free markets. But what comes after attempts to control, when these projects falter: that's the problem.

The ambition of control such as expressed by economic policies is represented in science such as the science of economics, but the key point in science is that a statement may be wrong. Science is theory confronted with observation. The history of science is marked by a lot of wrong assumptions. Science must renounce on the ambition of control to be science; it strives for knowledge rather than power.

Chart 1 illustrates the approach of conventional economics. A model in price and quantity $(x, y)$ is projected in exogenous time $z$. The projection does not change the properties of the model. Thus, from an endpoint in time one can calculate the error and feed it back into the model as error correction. This captures the role of policy, technology, and so forth. 


\section{Chart 1}

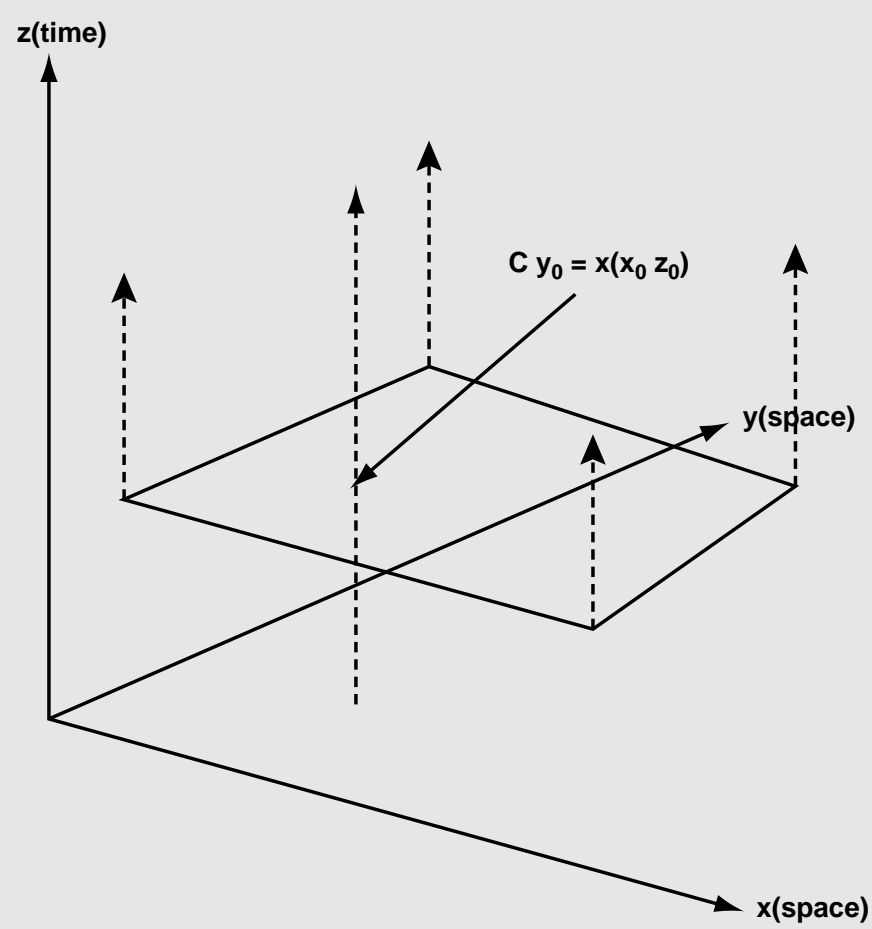

But the point of ecological economics is, I think: you cannot control! If you look at economics more deeply then I think it can be seen as being more about coping with diversity, giving something up for having something else. You can't always get what you want. There is this dream of security, but then it turns out not to be the case. Economics reveals this. My idea about ecology is in social science terms: you must cope with diversity and hedge against risk.

I see the world as a very risky place indeed. But according to standard economic theory, this is no problem really. If we are clever enough, we can turn the economy into an efficient and optimal environment by supplementing markets with public policies. But we can't. The answer is not more control, but rather to cope with error, market failure, and conflict.

The real model is much more like in Chart 2. Time is here part of the model; there is no endpoint from which we can assess error. Technology and policy become endogenous. This is what I call the economics of spacetime. 


\section{Chart 2}

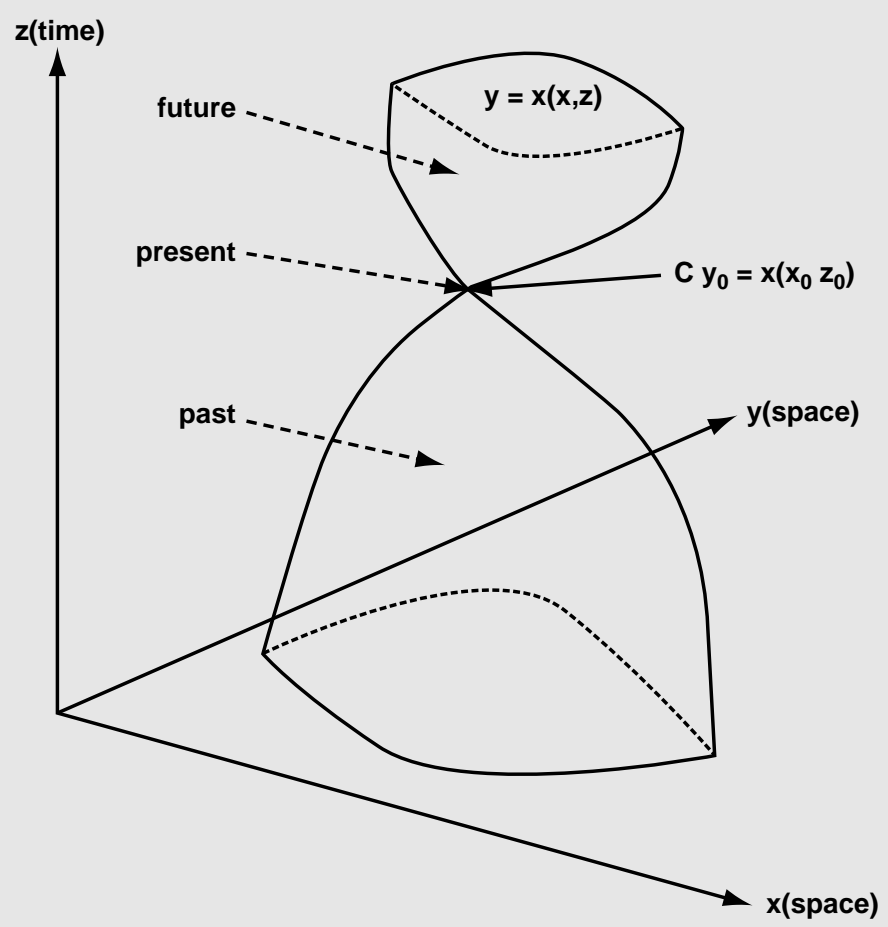

I think the idea about ecology is appealing to the whole of the economy, not just a separate compartment of society. Ecology means diversity, risk sharing, and the use of markets in this respect. The idea of "free markets" is not useful because it is basically just a new government idea. I'm not saying that you must not regulate. That's the free market ideology. If you could, then fine, but you can't. It doesn't work. Government cannot do the job, I think, but what I am talking about is of course a new form of government that does certain things.

Basically, economic theory is an outline of equilibrium, that is, it describes that there is an independent adjustment process going on that runs according to some laws. You can develop your understanding of these laws, and you can then use the laws to organise society. But if laws are laws, you must observe them and respect them and act accordingly. That means that laws may actually lead to outcomes that are not really desirable.

Unwanted futures is a state of society that you cannot alter even though you may want to because it seems undesirable. The problem is 
then how to cope with this situation. Economics is a political instrument, yes, but it is more than that and it is here that the whole challenge rests. We tend to think about economics in political terms, but we should not do that. Uncertainty can be calculated. The future is determined. It comes with a probability. It cannot be decided at will.

So we need a theory of what comes after control - after the failure of markets and government policies. And we do not, I'm afraid, have such a theory yet. But the globalised interconnected world is also as far as I see it a novelty. It is new that man has been capable of altering the natural, biological, environmental basis for its existence in a way that threatens man's own existence from a more long-term sustainability perspective.

The idea of sovereign power is dead, if you ask me, and it is only in economic theory that you really find, and only if you look hard enough, an understanding of this. But the death of sovereignty causes a security problem. What I call ecological economics is, I think, the appropriate reply to the security threats of the 21 st century, but we do not know yet the basic principles of this theory.

where economy is put forward as the "gold standard" on which all unwanted futures can be calculated.

To go into more detail, the translations involving different forms of professionalism include the example put forward by Maja Zehfuss in Box 3.2. She argues that in the HTS of the US military the meeting between a powerful profession - the military - and the academic discipline of anthropology produced a number of telling dynamics. A struggle to make anthropological concepts useful for military practice hit the discipline of anthropology on a soft spot. When asked to assist the military in identifying and mapping the human terrain in Afghanistan and making that knowledge actionable in real-time ("operationally relevant"), a clash was inevitable. In gathering knowledge about a specific terrain, anthropologists talk to people and observe their ordinary sayings and doings. This normally takes time. But in the military, time is of the essence. And one military commander explained that what he needed to know was just whether to greet people with a "handshake" or a "hand grenade" (Box 3.2). But anthropology is about trust. The professional code of anthropologists states that a primary responsibility is to "do no harm" to research objects. How was the practice of identifying dangerous individuals compatible with this foundational professional impulse? The discipline of anthropology ended up reinforcing its own boundary and a public debate ensued (Gusterson 2007, 2009, 2010).

Another good example of translations involving professions and disciplines is Jeppe Strandsbjerg's tale in Box 3.4. Strandsbjerg takes us to the Arctic, where a Russian expedition submerged a flag on the seabed of the 
North Pole in 2007, spurring international conflict dynamics. The melting ice cap had made the area more interesting for the exploration of oil and gas reserves in the area, and unsettled/disputed international boundaries made a scramble for the North Pole a potentially dangerous development. The translation of this situation was first clearly in securitization mode, but a diplomatic process overtook this and deemed the situation "non-exceptional." This nonexceptionality, however, rested on a particular understanding of the relation between law and geography. The task seemed straightforward: determine the reach of the continental shelf and extend the boundary beyond the standard 200 nautical miles following that. But nature turned out not to be a willing partner for such a schematic demand. The conditions for determining the contours of the continental shelf were harsh. And oftentimes, the precise limit of the shelf required judgment rather than precise measurement to determine. The end result, where cartographers passed their knowledge to lawyers and diplomats in an attempt to produce a document that both satisfied legal, technical, and political aspirations, is a clear-cut example of the translation processes involving professions and disciplines.

If we look at the case of climate science, translations across professionalisms are key to understanding the processes that have been set up to deal with this issue. The Intergovernmental Panel on Climate Change (IPCC) was created in 1988. It was set up by the World Meteorological Organisation (WMO) and the United Nations Environment Program (UNEP) to prepare, based on available scientific information, assessments on all aspects of climate change and its impacts, with a view to formulating realistic response strategies. The initial task for the IPCC was to prepare a comprehensive review and recommendations with respect to the state of knowledge of the science of climate change; the social and economic impact of climate change, and possible response strategies and elements for inclusion in a possible future international convention on climate (UN General Assembly Resolution 43/53 of 6 December 1988). So, the task was broad and spoke to many different forms of professionalism. In the process following the 1988 resolution, the UN Framework Convention on Climate Change (UNFCCC) was adopted and the IPCC science thereafter had to produce knowledge which could feed into this largely political process, making disciplinary translations mandatory.

\subsection{Translations beyond disciplines and professions: the role of amateurs}

Another zone of translation that professions and disciplines take part in is situated across these professionalisms and what we normally refer to as amateurism. Although certifications, formal education, and academic titles help to create a hierarchy between experts and amateurs - demarking a line - what particular expertise counts in a specific context is often regulated by "largely tacit theories that underpin rule by experts" (Jasanoff 2012: 11). How to define experts thus varies from culture to culture and sometimes what one culture 
deems amateurish is valued by another. But relatedly, a push for change comes from the more general process of a changing relationship across expert and lay, as most dramatically in the case of medicine: between the doctor and patient. We discuss both issues in the text below.

\subsubsection{Dynamics of the amateur}

Today, public policy is almost always linked to some kind of expertise. In the areas of security, risk, and danger, no less than in most other fields, the processes of problem analysis, articulation of responses as well as popular justification draw on actors claimed to be particularly knowledgeable about the subject at hand (Berling \& Bueger 2015; Collins, Evans \& Gorman 2007; Jasanoff 2012; Leander \& Wæver 2018). Yet, it "is less clear, however, how states recognise who is an expert, mediate conflicts among experts, or persuade publics that they have enrolled the best available expertise into the tasks of governance" (Jasanoff 2012: 11). What matters to decision makers, publics, and other consumers of the output of some process is often the performance - that something fills the role of expertise, as long as it can be ascribed the relevant competences well enough that it is not doubted by society. ${ }^{4}$

Another way to approach the question of expertise and its constitution of authority vis-à-vis the amateur is to study the way in which expertise is communicated. In the literature on risk communication, it is argued, that the popular use of experts can serve at least three public functions: one is to correct behaviour, another is to create debate for the sake of pluralist representation, and the third is to create resistance (Fischhoff 1995; Jasanoff 1998; Leiss 2006). Where the first expresses a realist and instrumental vision of communication; it is about communicating the right information, including the right stakeholders and avoiding misunderstandings; the two other rest on a more constructivist vision of expert knowledge and a clear political vision of the need for democratic inclusion of the public in this construction.

In some literatures, this is discussed in terms of "lay expertise." In similar terms, Gubrium and Holstein (2003) characterise "the interview society" as a society where the traditional distinction between interviewer (the expert) and the interviewed (amateur/layman) breaks down in postmodern interviewing - or in a society where we commonly tend to agree and recognise that knowledge is co-produced. The conventional understanding of "expertise" is thus challenged, as it is no longer reserved for professions and disciplines; knowledge claims can have all kinds of sources from practical experience to local access. Collins and Evans (2002), for example, meticulously seek to draw lines between a "core group" of experts and an audience, including in the group of experts what they call "experience-based expertise" (see also Evans 2015 for an application of this idea to the security domain). However, in the current analytical set-up it makes more sense to retain the 
more conventional terminology of "experts" as those with generalisable, formal knowledge claims - the professionalisms - vis-à-vis lay actors as those that challenge the historically sedimented structures.

\subsubsection{Translations across disciplines/professions and amateurs}

The tale by Anna Leander, in Box 3.6, is a good example of an attempt by central NGOs and state officials to communicate the need for ethical security practices among private military and security companies (PMSCs) to important stakeholders (states, NGOs, and companies). Populated by diplomats from signatory and non-signatory states, legal experts, NGO representatives, security company representatives, and academic experts such as Leander herself, the meeting in question was set up to celebrate the fiveyear anniversary of the Montreux document (2008). As Leander tells us, regulation of this area was traditionally done by mobilising legal experts and diplomats, but in the Montreux +5 meeting of Leander's tale, this hierarchy is broken down as a host of different actors have been invited to take part in debates. Oblivious of hierarchies, the process folds and unfolds as different themes are taken to be central by different participants. The rooms echoes with contradictory translations of how and whom to regulate PMSCs. It echoes with security translations. Leander's tale thus shows us how the concept of security, in this process of reviewing the Montreux +5 document, was negotiated, re-negotiated and resisted by the different parties, and how, as a consequence, the meeting worked to destabilise rather than settle the meaning of expertise, responsibility, and authority, in order to obtain the short-term gain of collecting all into one performed unity. The tale shows

\section{Box 3.6 Talking Curves at Montreux +5}

Anna Leander

Montreux+5

This tale is drawn from fieldwork I did at the Montreux +5 Conference in (yes!) Montreux, 11-13 December 2013. The conference was organised by those who initiated, sponsored, and promoted the Montreux Document on Pertinent International Legal Obligations and Good Practices for States related to Operations of Private Military and Security Companies during Armed Conflict (henceforth the MD) namely Democratic Control of the Armed Forces (DCAF), the Swiss Government and the International Committee of the Red Cross (ICRC). This document is "an intergovernmental document intended to 
promote respect for international humanitarian law and human rights law whenever PMSCs are present in armed conflicts." To this end the MD spells out "pertinent legal obligations" (on four pages and a small paragraph) but also "best practices" (on eleven full pages). The Montreux +5 Conference celebrated the document's fifth anniversary. The party was held to review the MD but also to promote it. Invited were the signatory states, non-signatory states, as well as assorted companies, NGOs and academics (including myself) susceptible of having a view on the topic. I want to tell the political tale of how talking in curves around the MD at the Montreux+5 "translated" security in plural, nonhierarchized, proliferating, future-oriented ways folding the MD and security into each other but also triggering resistance against that folding.

\section{Security translations in plural}

Montreux +5 was not about security, but about the regulation of those involved in producing it. However, the nature of it is no minor matter. It sets the boundaries of the discussion. What exactly is it that the MD is, or should be, relevant for? Once upon (a no doubt idealised) time, this question would have been settled among diplomats and their legal experts who could have disagreed expertly in ways reflecting the powers authorising them to speak and constituting them as speakers; i.e. the legal system of their home states. This would make for an orderly discussion carried out in the language of international law. However, Montreux +5 , and the many other flourishing "multi-stakeholder" fora developing the codes of conduct, standards, best practices, and benchmarks have more in common with the cacophony that meets Michel Serre's updated account of the life of $\mathrm{HC}$ Andersen's Thumbelina's. Petite Poucette, as she is called in French, struggles to learn from the heterogeneous voices that speak to her on any given topic. Traditional learned authorities (perhaps even the teacher), but also entrepreneurs, grandma, classmates, YouTube, Wikipedia, and her own experience are all chipping in. There is not one interpretation of the security it of regulation but infinitely many.

\section{Weakening the hierarchies of translations}

In Petite Poucette's classroom the teacher is still (at least sometimes) physically in front of the class, speaking to it, and organising its day. Similarly, at the MD celebration the room is arranged in hierarchical fashion: signatory states (in alphabetical order in front), followed by non- 
signatory states, followed by international organisations, followed by everyone else. But the regimented hierarchy cannot even survive the room organisation. It fades towards the back of the room. NGOs, consultants, company organisations, academics, legal networks, and assorted individuals have been seated partly in alphabetical order but towards the back of the room free seating prevails. The participants move around, link up with each-other, and make constant cross references in the session, oblivious of hierarchies. No one seems overly worried. In spite of recurring recalls to order in the form of strict agendas, hierarchically organised questions ("does any signatory state wish to comment?" opens all discussions), breakout sessions for signatory states only, and micro-managed placement and dinners, the hierarchy is fragile. So is the hierarchy of its - of MDs - the order of the conference tries to impose.

\section{Proliferating of Contradictions}

The its seem to multiply, mix, and recur as the discussion proceeds. Some suggest that it is currently appropriate, others would like to see it extended to for example maritime and cyber, women, the employees in security companies, and specific subgroups such as those recruited from former developing countries. Others suggest that it is harmed by the MD in its current version. The MD has to be more closely tied to other agreements including the voluntary "International Code of Conduct" for companies, a binding UN instrument still to be developed, or arrangements to support the work of associations trying to bring cases and ensuring accountability. These diverse but also contradictory and incompatible understandings of it are all aired; not in neat hierarchically ordered fashion. Each it meanders around the meetingroom, the dinner tables, the coffee breaks as the participants take hold of it, provide a translation, bring it somewhere else, change their minds and free it. It recurs in its different guises repeatedly. Sometimes someone's it is contested. But mostly it is stated and then left as the next speaker seizes it and continues to provide their own translation. At the end of three days the room is filled with echoes of contradictory its; security translations.

\section{Generating Potential}

The Montreux+5 meeting is not intended to settle on a single translation of it as the right one. It does not even seem to be interested in establishing a hierarchy among them or to signpost diffuse 
boundaries around the permissible it translations. Instead the organisers of the meeting seem to welcome-no, they encourage-as many it translations as possible. The more the merrier. In the concluding session, Philip Spoerri (from the ICRC) and Valentin Zellweger (from the Swiss department of Foreign Affairs) both congratulate themselves and the audience on the productive conference. But productive of what exactly? More its no doubt; a proliferation of "co-created" its. The its have been heard, understood, distorted, and ignored. They can be mobilised, used, and abused as need be. They have been set free. Even if this is a matter of uncertain becoming, of immanence, Montreux +5 has been a birthday celebration in a dual sense; it celebrates the five years of the MD but also the "heterogenesis" of its to be potentially realised in the future. This achievement could suffice to justify the way concluding speakers are lauding the achievements of the meeting. However, this is probably not what they have in mind.

\section{Triggering Resistance}

As the audience leaves the room, the echoes of three days' worth of security translations die out; they live on as potential becomings. But this is not all that is left of Montreux +5 ! Even if the MD remains untouched, the Montreux +5 has already rewritten the its the MD pertains to. The meandering discussions have folded MD and security into each other, consolidating a topography, inhospitable to those trying to delink companies from armed conflicts generally or from voluntary best practices such as those of the MD specifically. This redrawing of topographies triggers resistance. This began already at Montreux +5 . Invited guests argued for delinking and unfolding. South Africa (a nonsignatory state with a strong national legislation banning PMSCs), Gabor Rona (of the UN working group) and Patricia Feeney (of Rights and Accountability in Development) all for different reasons suggested that focussing on the MD was a mistake. As the child who, when told the story of the big bad wolf and the three little piglets, asks if one might imagine something else than a brick house to deal with the wolf (other relations to the wolf or another wolf), they were asking for something else than the MD to deal with companies in armed conflict. Invited guests were resisting the politics of talking curves at Montreux +5 . The echoes of this resistance will fade as they leave but also live on as potential becomings beyond the room. 
Table 3.2 Translation zone between expertise and non-expertise

\begin{tabular}{|c|c|c|c|c|c|}
\hline Unit & Distinction & $\begin{array}{l}\text { Basis of } \\
\text { authority }\end{array}$ & $\begin{array}{l}\text { Means of } \\
\text { translation }\end{array}$ & $\begin{array}{l}\text { Relation to } \\
\text { state }\end{array}$ & $\begin{array}{l}\text { Relation to } \\
\text { knowledge }\end{array}$ \\
\hline $\begin{array}{l}\text { Amateur: } \\
\text { distinct } \\
\text { from } \\
\text { expert }\end{array}$ & $\begin{array}{c}\text { Formalization } \\
\text { of expertise }\end{array}$ & $\begin{array}{l}\text { Formal } \\
\text { education } \\
\text { vs. } \\
\text { Experience }\end{array}$ & $\begin{array}{l}\text { Instruction; } \\
\text { Generalized } \\
\text { knowledge vs. } \\
\text { Representati- } \\
\text { on; } \\
\text { Resistance; } \\
\text { Particular } \\
\text { knowledge }\end{array}$ & $\begin{array}{l}\text { Undermines } \\
\text { state } \\
\text { authority }\end{array}$ & $\begin{array}{c}\text { Undermines } \\
\text { expert } \\
\text { authority }\end{array}$ \\
\hline
\end{tabular}

the pull of establishing cross-cutting forms of expertise - even at the price of producing internal tensions.

Table 3.2 describes this second zone of translation that we identify is important to understanding changing meanings of professions and disciplines, namely the one across the external divide between experts and amateurs. Whether the distinction is based on formal education, representation in society, or experience.

\subsection{Translations by what means?}

In the zone of translations across different professionalisms a number of means have been defining for the evolving translations. Generally speaking, technology and digitalisation have been major important means used to mobilize and support concepts of unwanted futures. Big data and datamining are good examples of this. It focuses on the possibility of gaining more knowledge, not only to gain better effects or to explain more (utility and ability) but also, and maybe more importantly, to "bridge" different professional knowledge spheres. Technology is somehow that which makes dialogue possible across and beyond professionalisms. Climate change is again an excellent example, where geology, engineering, and social behaviour increasingly are seen as one analytical object because they can all be approached by only one means, namely data technology. Where we normally in science considered causality as important to any explanation (social or technical), this is no longer the only criteria for validity. Rather, causality has been substituted by what Louise Amoore (2015) calls "an ontology of association": a search for patterns of associations rather than patterns of causality. This exactly makes it possible to bridge disciplines and spheres of professionalism, as it breaks with the idea of disciplinary independence and theoretically informed interdependence between the analytical concepts in different disciplines (Chandler 2014). Although the actual performance of new big data based practices like "predictive policing" often fail to live up to the hype and actually operate on "old style ontologies," the image of their 
novel nature anchored in big data ontology already now has authority effects both vis-à-vis other professions, citizens, and decision makers. Techniques are implemented as if they followed the new logic where data speaks on its own and (especially with the addition of Artificial Intelligence (AI)) self-improve in inscrutable ways.

This trend seems to promise an easy diffusion or translation of results from one professional sphere to the other. However, as Vogel shows us in her tale, tacit knowledge - the unspoken, unwritten knowhow that goes into highly specialised science - may actually hinder this frictionless transport of results. It installs a topography of knowledge which speaks directly against the flattening effects of big data. We discuss this in more detail in section 3.4.

Another important means for the translations across and beyond professions involves new institutional platforms. These have become a physical place for translation; public private partnerships (PPPs) are probably the best example of institutional innovations that serve as a platform for translation across professions. As forcefully argued by Niels Åkerstøm Andersen these partnerships are increasingly seen as an alternative to law and the contract (which is another site of translation; see also Chapter 5), and that designates a possible "unity of interest." In terms of professions, the PPPs have become a new hybrid actor, the place where new skills and actions are developed (Andersen 2004; Petersen 2014). The call for cyber security partnerships is a good example of how governments, in setting up new PPPs, seek to create a sense of community across national security services (the police and intelligence services) and the corporate sphere (tech giants and other companies) (Christensen and Petersen 2017). The nature of the threat simply forces the hitherto closed police and intelligence profession to rely on technical expertise from the outside. Another example is critical infrastructure protection, where we also see attempts to bring together security intelligence and corporate professionals. As large parts of critical infrastructure are privately owned, the security-corporation link almost inevitable.

Where PPPs are often thought of as formalised, we also see this kind of hybrid activities in less formalised settings. Anna Leander's tale, in Box 3.6, is an excellent example of this: of how states initiate the Montreux +5 meeting with a clear agenda to bridge professional interests. Yet, she shows us how these rather clearly expressed intentions get more and more blurred when translated into the context of the Montreux +5 meeting and thus when other actors engage in the formation of the meaning of security. Jeppe Strandsbjerg (Box 3.4) does not have the same focus on one meeting or document but shows us how many different actors, with more or less settled agendas, struggle to make their understanding of nature and security in the Artic useful for decision-makers. At one level this illustrates a more "harmonious" interdisciplinary division of labour because different disciplines primarily come in at different stages. It initially generates a sequential translation process where the products of one discipline have to be made 
sense of within another discipline. However, at the final stage, cartographers, lawyers, and diplomats have to act jointly to produce a common understanding.

In terms of the rise of the amateur, the development of the internet has worked as probably the most important factor to empower lay people. This has confronted the meaning of the expert, e.g. in medicine, ${ }^{5}$ where the patient consults the internet and meets the doctor with (uncertified) knowledge, which the doctor then has to compete with.

Also in conflict situations, lay people are obtaining a voice through the internet. Rune Saugmann Andersen (2016), for example, explains how digital media bestows upon citizens "a right to look," and Leander (2014) shows how a cacophony of voices were deemed relevant expert voices in the determination of who was responsible for the sarin gas attacks in Syria in 2013. One notable example was that for a time, a nun was held as the expert on these attacks, based on her analysis of YouTube clips. However, later she lost her expert status as a tech-expert intervened and spoke about the timing of YouTube vis-à-vis real-time.

The examples show an important new phenomenon which empowers lay people and challenges traditional expert status. In many of the traditional security professions (military and intelligence), secrecy remains a prevailing paradigm that seeks to hinder this kind of empowerment. Here, as a direct contradiction to the abovementioned processes, ordinary peoples' use of the internet and social media is used by intelligence services to gather new data. Tourist photos shared on, e.g. Facebook are used to determine rising water levels in rivers to pre-empt flooding, and people claiming to not have been in a conflict region are contradicted by having been tagged in their friends' photos online.

\subsection{What concepts of security emerge this way?}

This chapter has looked at the dynamics of translations of security across and beyond professionalisms: What triggers them and through what means do they take place? We have also established how professionalism is defined by their formal and functional characteristics as well as by an establishment of hierarchy across the expert and the amateur. Yet, we still need to ask how these modes of thinking about professionalism shape, confront, or dismantle our practices and concepts of unwanted futures themselves. We have argued from the start that the present approach brings new light on the evolution in security in the broad sense of concepts for unwanted futures, variably termed risks, danger, threats, and so forth. Situations of translation lead to change sometimes among these different concepts - security and risk, for instance - and sometimes under the same rubric, say "security."

This section teases out three examples of how such new conceptual meanings have emerged. We first discuss the discipline of economics as an 
example of a situation in which a threat is met by reactions of denial, redefinition, and surrender. Secondly, we survey a situation in which different professionalisms - in this case: intelligence, science, and health - meet, leading to a redefinition of central established concepts of security and professionalism. Thirdly, we discuss a situation in which a threat confronts the idea of professionalism by challenging its limit, and in the process produces a new form of hybrid concept and practice of expertise, not amenable to one, exclusive profession or discipline; here we use the field of cyber security as an example.

\subsubsection{Translations of uncertainty: new categories of risk}

Our first example is - appropriately - one where a discipline has a distinct, strict and almost discipline-constitutive conception of how to go about unwanted futures. In Box 3.5 by Niels Peter Hahnemann, we meet the discipline of economics where the mainstream conception has clearly defined concepts of risk and uncertainty and systematically excluded a securitization-like concept of security. Risk is a foundational concept with operational status. Uncertainty was originally introduced as its opposite: the everyday unpredictable, incalculable in contrast to what was in principle calculable and meaningfully approximated in predictions (Keynes) and at first mostly as a horizon of impossibility. However, uncertainty also grew into an operational category during the 1960s (Best 2009; Knight 1921) because variation in the information basis for decisions could be modelled and had explanatory power. It became possible to move uncertainty into the category of risk and in that move make uncertainties manageable. Securitization, in turn, was outside the perspective because the whole world of economics is - economistic. That means: it is all about agents calculating and optimising, balancing various payoffs gradually against each other, whereas securitization is about existential threats that have to be prevented and therefore overrule the normal balancing of one gain against another. As Niels Peter Hahnemann shows in Box 3.5, both risk and uncertainty are still lodged in a rationality of control. Catastrophic scenarios like terrorism, climate change, and to some extent even a "discipline internal" issue like systemic crisis, confront the discipline with an external limit. That is intellectually unsatisfactory but scientifically manageable.

When economists move out of their university department to work concretely on a specific issue like climate change, the dominant approach will at first be one where the external is translated into the internal, the extreme events modelled and calculated in terms of probability and impact. Economists end in big debates amongst themselves over the discount rate (Nordhaus 2007; Stern et al., 2006), which in practice ironically determines the conclusion, given that it is ultimately outside the researchable and a decision of a deeply political 
nature. The next phase, however, has been that economists of the environment have tried to enlarge the concept of economics in an ecological direction, which in turn implies a shifting concept of risk often re-organised around the concept of sustainability (Martinez Alier et al., 2010). This constitutes a fundamental change in the conceptual landscape of unwanted futures, because the calculable and optimising unit-focused/micro concept of risk gives way to a limit concept at the macro level. Also, the time-horizon changes from a forward looking one of optimisation towards one that "counts backwards" from a guard rail around advisable futures.

Another place where economic thinking has de facto innovated its conception of risk and uncertainty is in the business world, where decisionmakers wearing an economic hat - i.e. basically Chief Executive Officers and Chief Financial Officers - have to interact with Corporate Security Officers and other security or risk oriented leaders. This entails constant negotiation of how to translate "security" into the economic bottom line of profitability. At first, this happens mostly within the classical economic language in terms of optimising security investments in a probability-times-damage calculus. However, gradually the interaction produces more complex considerations about the value added of security, including brand and resilience in a crisis (Petersen 2014). The resulting concept of unwanted futures and their role in business decisions has evolved.

\subsubsection{Different professionalisms}

Our second example is brought out in Box 3.7 by Kathleen Vogel. Artificial virus produces novel challenges to the world of science, the intelligence systems and health professionals. Science is - ironically - under-supplied as to any concept of risk or danger in relation to its own work. It is deeply entrenched in the institutions and ethos of science that it is in some sense a self-optimising system: if we allow the free competition of the best scholarly efforts, truth will prevail and it is good. Openness is a central part of the institutional machinery of science (Merton 1973), so basically you are doing your job for the best of mankind if you push forward with your research and make it publicly available. The dominance of this conception explains how tortured were the personal reactions and reflections of the scientists involved in the Manhattan project - being responsible for the bomb led the different individuals (Bohr, Oppenheimer, Teller et al.) in very different directions. However, their reaction was still predominantly to ask for even more openness, to make insights shared and monitored (Bohr 1950). The crisis over artificial virus took a novel path, where journals stopped publication of otherwise publishable research because it would potentially be dangerous. The strategy applied by the journals, Science and Nature especially, in these cases was reluctant. It included a mix of accepting the social reality that an intelligence and national security perspective took a different view, and it 
was better for science to exert an element of self-regulation before it was regulated from the outside, and on the other hand, attempts to formulate an own rationale for what is scientifically sound practices. This is a case of a see-no-risk conception starting to incorporate concepts of risk and danger. On the side of the intelligence community, the challenge was - as Kathleen Vogel chronicles in the box - that the intelligence community had to work with new kinds of experts. In this regard, Vogel points especially to the organisational and procedural problems raised and specifically the issue of the replication of tacit knowledge. Informed by experts from science and technology studies, the pivotal question for the intelligence community became: How easy would it be for an individual with malevolent intentions to imitate the unwritten elements of the laboratory procedures? This went to the very heart of scientific practice and clashed with intelligence-gathering protocol. Would an intelligence officer have to spend hours on end observing how the production of the virus in the laboratory was carried out for the intelligence service to have full information of the potential threat? And would the officer even be able to understand what he or she was observing? This challenged the time-sensitive workings of the intelligence community and at the same time forced scientists to "open the black box" of how science is done. Both are integral parts of the functional logics of the different professionalisms. On top of that, the concepts of threat and risk were challenged. In the world of intelligence, most attention is usually directed at those with malign intentions and possibly excessive capabilities. In the case of virus research, the main danger actually comes from "good guys" who do their job, are not really reckless about the security and safety of their own operations, but spread dangerous knowledge intentionally and as part of their job. Here the challenge to concepts of risk and insecurity is partly - as in the above case of the economists - between different basic concepts. But it runs deeper as well. Agency and intentionality were involved as were the different functional logics of science and security professionals.

\section{Box 3.7 Interventions into Intelligence: Some Early Observations}

Kathleen M. Vogel

Since the end of the Cold War, U.S. intelligence analysts have been struggling to anticipate and assess a diverse array of threats involving state and non-state actors. With the noted intelligence failures contributing to September $11^{\text {th }}$ attacks and the 2003 Iraq War, the U.S. intelligence community has recognised the need to acquire new outside expertise to mitigate future intelligence failures. In 2008, the U.S. Intelligence Community Directive 205, "Analytic Outreach" was released which charges intelligence analysts with leveraging "outside expertise 
as part of their work" in order to "explore ideas and alternative perspectives, gain new insights, generate new knowledge, or obtain new information." (U.S.I.C. 2008) In this context, I have started exploring ways to interject and translate analytic perspectives from the social science field of science and technology studies (S\&TS) into the U.S. intelligence community in order to generate new understandings of threats involving weapons of mass destruction and then to study how intelligence analysts absorb these S\&TS perspectives to make sense of these threats (Vogel \& Dennis 2018). Therefore, my current efforts are as follows: (1) descriptive, with the aim of creating new knowledge and understanding about how intelligence analysts acquire, process, and respond to ideas from the science and technology studies field; and (2) interventionist, with the aim of improving and changing the way intelligence analysis is conducted in order to improve U.S. national security policymaking. This tale describes one "translation experiment" in which I was a participant observer in meetings with intelligence analysts assessing a contemporary bioweapons threat: the 2011-2012 H5N1 avian influenza experimental controversy. ${ }^{a}$

In September 2011, scientists from the Netherlands and Japan announced publically that they had created mutations of the H5N1 avian influenza virus that made the virus more transmissible through the air. ${ }^{b}$ These results raised public and government concerns about the various future dangers that this new artificial virus posed_for public health and security. There were calls to restrict publication of the experiment so that someone with ill intentions would not be able to replicate the virus and cause havoc. In this particular case, the key issues for translation revolved around the intelligence question: How easy would it be for terrorists to replicate this experiment for harm? Answering this question would involve translating academic S\&TS research about tacit knowledge for application by intelligence analysts to assess the possibility of terrorist replication of this experiment.

One benefit of this translation experiment was that all information discussed was open source information. There was no classified information that would pose barriers for discussion with these intelligence analysts because the $\mathrm{H} 5 \mathrm{~N} 1$ experiments were all unclassified experiments conducted in academic laboratories. At the initial meeting that I had with these intelligence analysts there were four bioweapons intelligence analysts (one senior level analyst and three junior level analysts), and one intelligence official. After this initial meeting I 
subsequently followed up with them by email, as well as individual meetings.

To date, the existing policy discussions about the H5N1 experiments had focused on the scientific manuscripts and the explicit, written knowledge present in those manuscripts. According to literature in the S\&TS field, it is not possible to evaluate tacit knowledge merely by reading the manuscript or only talking to the principal investigators, which seemed to be the common approach that most analysts and officials were using at the time to assess the threat from the mutated virus. In talking with the intelligence analysts, we discussed that to truly investigate tacit knowledge one needs to go beyond the published manuscript and conduct an in-depth analysis of "what went on in the lab" in the $\mathrm{H} 5 \mathrm{~N} 1$ experiments. This would require talking to the graduate students and postdocs who actually did the hands-on work. We explained to the analysts that to analyse "what went on in the lab" would require using ethnographic research methods for in-depth, descriptive, systematic study of the laboratory work.

Once we shared these insights with the intelligence practitioners, we asked them: How feasible would it be for intelligence analysts to do this kind of analysis? Their response was insightful. They mentioned that there are three issues that pose challenges. First, they described how there are different types of workers and responsibilities involved in collecting and analysing intelligence information. The intelligence analyst would provide questions to the intelligence "collector." The collector, who often does not have subject matter expertise, does the actual collecting of information in the field (or, in this case, the laboratory). But, this analyst noted that this can lead to problems because the collector often does not have the expertise to evaluate the information they are gathering or to evaluate on-site what the results mean. Also, the collectors often don't know how to ask follow on questions. Second, the analysts stated that it would also be difficult for them to contract out this work to academics. Tasking academics to do this type work would be seen as "collection" and could create the impression that academics would be conducting espionage. Also, they mentioned that they would be hard pressed to find an academic subject matter expert who could assist them because the existing academic science advisors all have institutional and personal agendas that bias their advice. Finally, the analysts noted that intelligence analysts wouldn't do this kind of ethnographic research and analysis because, "they have too many other things to do." It was puzzling to hear that 
analysts do not have time to conduct primary research on an active case.

The preliminary conclusions from this translation experiment were revealing. They revealed that there is a need for more fundamental development and understanding of tacit knowledge as a concept for analysis in intelligence. This signals a need for the use of more social science expertise and methodologies within intelligence. Also, intelligence practitioners themselves indicated that they would be interested in looking at more detailed case studies (historical and contemporary) to better understand tacit knowledge. The comments by intelligence practitioners also revealed that they encounter problems with identifying, acquiring, and using available expert knowledge. This signals that there is a need for more financial and managerial commitment in intelligence to outreach. This could involve the creation of new institutional structures and practices within intelligence analytic units for evaluating and using expert knowledge

This translation tale reveals the practical, working-level, and institutional constraints in academic-intelligence engagements and translations. It also reveals insights about intelligence culture and practices that need to be taken into consideration for successful translations to occur. Finally, concepts like tacit knowledge were found to be a bit "academic" for some of the practitioners. This indicates a need to translate S\&TS ideas to practitioners in a very basic idiom. This "experiment" in translation reveals that there is a critical need for more substantive and extended discussions between academic scholars and intelligence practitioners. This could be done with more targeted outreach efforts to individual intelligence practitioners, as well as through more formal means via intelligence universities and training schools.

\section{Notes and References}

a Parts of this tale is based on Vogel's work on Bioterrorism published in 2013/ 2014. For more details on this case, see: Kathleen M. Vogel, (2013/14).

b For an overview of the H5N1 controversy, see: Kwik-Gronvall, Gigi (2013).

Kwik-Gronvall, Gigi. 2013. 'H5N1: 'A Case Study for Dual-Use Research', Working Paper (Washington, DC: Council on Foreign Relations, July 2013). http://www.upmchealthsecurity.org/our-work/pubs_archive/ pubs-pdfs/2013/2013-07-15-h5n1_dual-use_research.pdf.

U.S. Intelligence Community (U.S.IC). 2008. The U.S. Intelligence CommunityDirective 205, Accessed at https://www.dni.gov/!les/ documents/ICD/ICD_205.pdf. June 7th 2021. 
Vogel, Kathleen M. and Michael A. Dennis. (February 2018). 'Tacit Knowledge, Secrecy, and Intelligence Assessments: STS Interventions by Two Participant-Observers' Science, Technology, and Human Values 45(5): 834-63.

Vogel, Kathleen M. 2013/14. Expert Knowledge in Intelligence Assessments: Bird Flu and Bioterrorism. International Security 38: 39-71 10.1162/ isec_a_00150.

\subsubsection{A Hybrid professional: the example of cyber security}

Our third and final example of a process of translations that has led to identifiable and observable innovations in the functionally sedimented concepts of security and other unwanted futures can be found in the domain of cyber security, where corporate, governmental, and civil actors increasingly interact. In this case, the traditional logic of national security, closely tied to the function of the state apparatus' ability to protect its citizens, is confronted with its own impossibility. The cyber domain is simultaneously considered an individualised matter of privacy ("the internet of things"), an economic matter of profit ("tech giants"), a national matter of civil protection and wealth, and an international matter of peace. It is, in other words, a field that can hardly be fitted into one or two categories of professions.

While scholars do discuss how these many actors, working in this domain of cyber security, should be allowed to define national and international security and the actions taken by states in the name of cybercrimes and wars (cf. Carr 2016; Dunn Cavelty \& Suter 2009), it is commonly acknowledged that today's concept of national security is up for negotiation in the (shared) practices of cyber security (Christensen 2018). In the work of the intelligence services and the police private tech companies are constantly asked to contribute to national security by providing information, defining needs, and ensuring their own safety and risk practices.

One can go as far as arguing that the concept of cyber security has provided for new hybrid forms of organisations, of networks and partnerships, and even a new kind of professional. All produced and defined by these different actors, having to take each other's concepts, practices, and interests into account. Such hybrid forms may not be introducing an entirely new concept of security but is constantly exposing and confronting the established norms and practices of security, risk, and safety.

\subsection{Stakes and consequences: new complexities, new security professionals, new concepts of security?}

As argued in the introduction, the field of security politics is shifting. Western politicians and intelligence agencies increasingly appeal to civil 
society institutions and actors to manage security, and there is a strong public appeal for scientists to collaborate to solve some of the world's burning issues (climate change, cybercrimes, counterterrorism, nuclear proliferation, humanitarian catastrophes, etc.). In the wake of this development, scholars also observe a "diffusion" of security knowledge - a diffusion, which has called for new academic collaborations (interdisciplinarity) and cooperation across professions. In this broader field, we are, as argued earlier, witnessing a variety of struggles over the meaning of the most defining disciplinary concepts of unwanted futures: security, uncertainty, risk, and safety. In this environment, security is translated on a daily basis with an effect that must not be underestimated. As social workers now have to consider radicalisation as a key concern in their daily practice, the meaning of social welfare changes. As cyber security is now to be handled by a wide range of corporate actors, e.g. Google and Microsoft, new concepts of corporate risk and enterprise risk management occur and engage in a zone of translating security. Similar in the area of climate change we witness a current appeal for interdisciplinary collaboration to help mitigate the effect of human disaster or, as we see in the Arctic (Box 3.4 by Strandsbjerg) to solve more problems of authority and responsibility (the issue of sovereignty).

These societal practices are formative for the intellectual and social structure of disciplines. The production of risk or vulnerability assessments no longer takes place in isolation within separate spheres; they occur as meetings in which different academic and practical rationalities of security intermingle. Consequently, deep ontologies in different disciplines and professions both condition and are challenged by changing organisational patterns in security practices. An example of this is described in the tale by Strandsbjerg, where he shows how the meaning of "nature" itself is contested in the work of lawyers and cartographers when they are confronted with international security issues concerning sovereignty and territory as discussed earlier in this chapter. Another example is how fundamental assumptions in modern economics come under pressure when forced to deal with novel issues such as climate change and terrorism. Further, the replacement of the secrecy-beats-secrecy-to-get-at-the-truth rationality that used to regulate intelligence agencies with probabilities and risk thinking constitutes an example of this.

What we see, however, is not only the emergence of new concepts and meetings across disciplines and professions. Two developments or stakes are worth mentioning here: one is upcoming of new forms of professionals, not sanctioned by the state, in communities of practice that in many ways have made practical experience the benchmark of professionalism. Another stake is how a changing understanding of the 
university in society has reconfigured the idea of security research and thus the meaning of security.

\subsubsection{Communities of practice: the professional practitioner}

The whole idea of professionalism within the field of security, which before rested upon professional state security agencies to certify or acknowledge, is today up for grabs as more and more issues are handled by actors which before were considered "amateurs" in this field. As shown in an analysis of the management practices considered in the field of corporate security, a security manager whose task is to unite corporate and national security aims have become central to corporate management (Petersen 2014). Amy Zegart describes this phenomenon as "a quiet intelligence revolution inside America's leading companies," observing how "hotel chains, cruise lines, airlines, theme parks, banks, chemical companies, consumer product manufacturers, pharmaceutical companies, and even tech giants have been developing in-house intelligence units" (Zegard 2012). Thus, today we are not only witnessing how former amateurs on security are constituted as (semi)professionals. With these new transnational professional identities, new visions of knowledge have also emerged: knowledge as something embedded in established contextual practices, more than in truths established through research. The authority of the profession thus lies in its worth for practice rather than in its relation to the state. Etienne Wenger, for example, observes how the state in some instances has lost its defining authority, as new and informal "communities of practice" emerge. Where Weber and Parsons saw education as the seeds of a "profession" - functionally linked to state bureaucratisation and specialisation (Ritzer 1975; Weber 1968) - Wenger argues that the coherence of the "profession" is increasingly relying on an informal "community of practice" (Wenger 1998). In similar terms, and directly linked to globalisation, Seabrooke talks about new professional ecologies based on "epistemic arbitrage"; on self-identified professional relationships that draw on a common pool of knowledge. These networks, he argues, are based on new transnational relations across professionals and are distinct from the domestic professions that rely on state-acceptance and possible penalty. These, more loosely defined networks, are held together by "shared understandings of how issues should be governed, tasks allocated, and who knows well enough to do the work" (Seabrooke 2014: 50). The general learning is that the existence of a "community of practice" often is part of a process of professionalisation: a process or attempt to transform amateurism into professionalism. This development has created a new kind of authority, a new kind of professionalism, that does not get its legitimacy from being approved 
(formally or informally) by the state or citizens of states but from references to socio-political and economic practices.

\subsubsection{Science in society: science as innovation?}

Another and related stake in the developments of professionalism can be observed in development of a "mode 2 " kind of thinking about the role of science in society: A kind of thinking that stresses the need for disciplines to engage in complex processes of application-driven knowledge also to develop itself as a discipline. The production of knowledge is increasingly, since the mid-90s, considered a shared endeavour and not something residing in the academic sphere alone. This shift has larger implications as societal change today is increasingly seen as something happening in the economic and political sphere outside universities - as economic and technical innovations. Accordingly, we are witnessing an erosion of the classical Humboltian understanding of science as something that naturally creates value (Floud 2003; Floud 2013; Horst \& Irwin 2018; Slaughter \& Leslie 1997). Scholars instead talk about a shift towards the Entrepreneurial University (Edquist 2001), which sees itself as "problem solver," with an aim "to create new value for the stakeholders of university" (Cai 2017: 603). Others again talks about a shift from "science and society" to "science in society" (Floud 2003: 3). As the conceptual historian Benoit Godin writes in his historical analysis of the concept of innovation, inventions, which historically were closely linked to thinking at universities (cf. Francis Bacon), are increasingly considered as something that should be "commercialised," and thereby as something that should "support" the actions taking place in the economic and political realm of social life (Godin 2015).

How does this impact the way we think about security? One can argue that this demand for economic or political actionability has put security research under pressure and thereby also worked to alter the meaning of security altogether. Before, the provision of national security was considered a common good that was hard to measure in terms of societal needs, as the problem needed to be solved would be unknown to society or the general public. Today, security research (like all kinds of research) increasingly has to be sellable and be commercialised to satisfy a clearly stated societal need for protection (Friedrichs \& Wæver 2009). While this development forces research to rethink their own position in society, in the case of security the fact that research has to be useful for someone, risks losing sight of not only long-term perspectives and needs, but also the idea of the common good. 


\section{Box 3.8 I see dead people}

Nisha Shah ${ }^{\mathrm{a}}$

War without corpses?

At a recent visit to the Canadian War Museum, a curator concluded the tour with the following factoid: of the 13000 works of art (primarily paintings) in the museum's collection, only 64 display dead bodies. This absence of dead bodies in a war museum is puzzling. War is a "bloody affair" and war museums often commemorate the dead. On this particular day I was confounded because we had just come from the Le Breton Gallery, displaying "the way human ingenuity has been applied to the science of war, creating weapons and other devices to attack, protect, and kill." The irony here between the way that the depiction of death is considered illicit in visual imagery portraying war and the way that war's weaponry can elicit them, being explicitly designed with destructive objectives, is obvious. It results in a dilemma whereby despite looking down the barrels of guns, you can leave the museum with a sense that war does not produce corpses - or, at least not very many of them.

\section{Productive deaths?}

As an indelible part of war, dead bodies is an "unwanted future": they are fated and foreseeable. Death is something to be minimised. But, as the story goes, it is unavoidable. What responsibility then do war museums have to display death? The immediate response might be that museums have a duty to demonstrate war's violent consequences without indulging a voyeurism that glorifies its gory details. Indeed, the emphasis on ruined landscapes in war art, as stated in one of the museum's exhibits, is intended to be a "gentler means of conveying ... the enormous human costs of war." But given this human cost it also seems that war museums have an ethical responsibility to show that dead bodies in war are often normal - even intended. Killing in war is not always an unfortunate side effect, and neither is it necessarily an egregious crime against humanity; in certain circumstances it is sanctioned by international law and within the moral parameters of just war theory.

This tale describes my journey to dig up the dead at the Canadian War Museum - and returning to the weapons gallery seemed to be an obvious place to start. Weapons are often explicitly designed to translate directly into death. But how does the encounter with death 
translate when weapons shift from the theatre of war - where they are objects of destruction - to the museum's exhibition space - where they become objects on display?

\section{Becoming a weapon}

The Le Breton Gallery is an impressive space showcasing guns, tanks, and bombs. Following the practice of other kinds of museums, the visitor's experience is organised through the use of neatly arranged labels that order weapons in a kind of taxonomy of destruction. They are classified as objects designed for "Land," "Sea," or "Air" warfare, and categorised according to their use as "field artillery," "armoured fighting vehicles," "cannons and mortars," and so forth.

At first sight, dead bodies appear to be missing due to the sanitising effect of technological language. The emphasis on technical descriptions seemingly evades the brutality of war: for example, we are told that the Vulcan Cannon, a "revolutionary advance in aerial firepower" furnishes the "ability to fire 6000 rounds per minute." And, "Did you know?" (as a special descriptive section is titled) that because the Vulcan cannon "permits a much higher rate of fire than a gun with a single barrel," the "wear on gun barrels" or "problems caused by gun barrels heating up when they are fired" are significantly reduced. Conducting a detailed survey of the exhibited armaments, you can learn a great deal how various weapons work. But little appears to be said about what these tools of combat have done and can do in terms of the human cost of war. The effect seems to be that moving weapons from the battlefield to the museum space seemingly defuses them: there is a taxonomy of destruction without a consideration of its consequences.

Yet when you face a three meter high and 60 tonne Leopard C2 tank or touch a field-gun or mortar, the ramifications of these (often very large) pieces of machinery for human life and death are hard to ignore. Indeed, a different story comes to the fore when reading the nitty-gritty details of the neatly arranged labels in search of the casualties of war. The Vulcan Cannon, we are told, has been used to "attack enemy targets on the ground," specifically in "strafing attacks against vehicles and personnel." Considering the capacities enabled by various military technologies, dead bodies suddenly appear through the means that make them disappear. Far from absent in the museum space, dead bodies are actively produced within it. 
But there is something troubling about the simplicity of literally reducing weapons' technical capacities to dead bodies. Despite arguments that death in war, even with its legal and moral authorisations, should be seen as an act of atrocity, the museum's weapons' display reveals a history of violent objects that over time have become part of the mainstay of modern military arsenals - as the class of conventional weapons, they are tools of combat that states are sanctioned to use. Some weapons might be outdated or updated, but their descriptions provide a narrative of tools of combat whose form, function, and at times lethal consequences are expected and accepted.

\section{Desirable destruction}

Of course, international warfare does not involve the unbridled use of force. Over time, some weapons have been deemed inappropriate (such as chemical, biological, and nuclear weapons). But the visit to the weapons gallery suggests that there is an equally long history of the development of weapons that are considered appropriate to use.

After leaving the museum in search of death, I am left pondering how the museum's display of weapons sheds light on how and why certain forms of destruction have been deemed desirable, even when they can have deadly effects.

\section{Notes and References}

a For an expanded and elaborated version of this tale, see: Shah, Nisha. 2017.

Shah, Nisha. 2017. Death in the details: Finding dead bodies at the Canadian War Museum. Organization 24: 549-569.

\section{Box 3.9 Security and the anthropology of potentiality}

\section{Henrik Vigh}

The anthropological approach to "security" starts with the inverted commas (Paraphrasing Bachelard's view of science (Lianos, 2007:1.2)). The very point of departure is a questioning of what security is ethnographically and politically. We focus on what security looks like from below, anchored in life-worlds and experience, and how security concerns connect and conflict across social environments and scale. The anthropological focus on "security" has, as such, been on what Bubandt has termed "vernacular security" (2005). Whether researching 
high-ranking politicians or local residents, we approach the concept in terms of how it is understood by the people who think, feel, and practice it. Yet the inverted commas equally entail not taking the concept for given and looking at "security" in a critical perspective. Tracing the concept in its multiple actualizations - from the social to the political and back - thereby destabilizes and unsettles it. It illuminates the situatedness and negotiated character of "security" and clarifies the power and resistance at play in securitizing practices and positions.

\section{Potentiality and politics}

At its most basic, issues of security and insecurity can be seen as part of "the anthropology of potentiality" (Gammeltoft 2013; Vigh 2011; Vigh 2018). Potentiality is, in this respect, simply conceptualized, in Batesonian terms, as the possible actualisation of a hidden capacity (Bateson 2000 [1972]: 401). In a political anthropological perspective this entails that figures and forces are seen as containing hidden state (s) that are dormant or immaterialized, but which may actualize their alter states in dangerous manners. Potentiality comes to inhabit the situation as a detrimental yet "absent presence" (Agamben 1999: 178).

The above may seem overly theoretical, yet the fact that social and political worlds can be seen to have a perilous depth and dimensionality that encompasses more than its manifest representation is neither novel nor surprising. Life is experienced as "embedded in an intricate network of visible and invisible forces" (Hecht \& Simone 1994: 77), merely because the complexity and simultaneity of relations and associations are simply too dense for full overviews to be gained and clarity achieved, making uncertainty and opacity a foundational aspect of the social condition (Vigh 2011: 94). The point is that looking at security through the lens of potentiality allows us to see how the present may be experienced as a state that is pregnant with negative figures and forces, and hence to make sense of the way that people anticipate and seek to counteract the impact of these (Vigh \& Turner 2007). It allows us to grasp issues of suspicion and preemption as social phenomena rather than merely policy concerns.

\section{Spectral and spectacular}

Anthropologically, security issues may, thus, be seen as specific political figurations of potentiality. When the stakes are high, uncertainty creates an engagement with the world, which is radically attentive to ulterior movements and motives. A "hyper-hermeneutics," as an 
"anticipatory practice" attuned to insecure circumstance (Spyer 2002: 35). Our political bearing becomes vigilant, causing people to read danger into a broad range of social processes and positions. What constitutes security is, thus, culturally specific and socially diverse (Holbraad et al.). Yet, looking ethnographically at security, equally allows us to clarify connections and highlight, for example, how global figures are played out in local contexts and how the local concerns play into global figures or fear. Anthropologies of security are commonly, as Goldstein phrases it, simultaneously "ethnographically sensitive and attuned to contemporary global interconnections" (2010: 487). A particularly salient instance of this may be elucidated by focusing on the way that a critical event can instate itself as a critical continuity (Vigh 2008), which moves from the local to the global and from the minor to the massive. Unsurprisingly, the $9 / 11$ bombings of the World Trade Centre in 2001 provide an interesting case. The bombing of the World Trade Centre stands as a "security moment" (Ibid.), a critical event, which triggered and changed a political imaginary that was to have drastic effects on practice and policies. In terms of potentiality, we may say that the event instated an understanding of a negative force in our midst, a "spectral presence" that revealed itself in a "spectacular manner." It unsettled us as a revelation of the fact that global fault lines and conflicts are present amongst us in what is seen to be a camouflaged form. In social terms, contemporary multicultural societies developed in this way in an almost paranoid schizoid manner (Cash 2009). They became fearful societies, in which the minority parts are perceived, by the dominant majority, as malevolent and harmful to the whole. The consequence has been, that the particular instance of insecurity expanded across scales in attempts to engage it and the potential enemy within.

\section{Pre-emption}

Attempts to neutralise threats and stabilise order through security measures may add to the instability that is sought counteracted. In the almost two decades since the $9 / 11$ bombings the US and EU have witnessed relatively few deaths from Islamist terror in comparison to the amount of deaths instigated by the response. In terms of proportionality, the war on terror that followed $9 / 11$ is an example of how a critical event has installed itself as a critical continuity that transgresses scale and space. Besides the enormous expenditure, it has spawned the deaths of 
hundreds of thousands in the global South and laid whole countries barren in terms of the safety and security it aims to provide elsewhere.

The exceptional response is a primary example of the power of potentiality in social and political life. Negative potentiality is commonly reacted upon pre-emptively as the imagined future unfolding of a detrimental condition or process is sought neutralised before it materialises. It is, as such, not the amounts of $9 / 11$ deaths or the spectacular event that causes the intensity of the reaction, but the fact that it instated an imaginary of a spectral presence and future attacks. An underlying threat that the West has struggled to fathom and react to with preemptive extremes ever since.

The problem is exacerbated by the fact that our reactions create more of the problem that they seek to avoid or control. The lawlessness of the war on terror has been prolonged into the tactics of drone attacks, signature strikes, and homeland security. These practices of preemption work through a predefined idea of possible culprits and perpetrators, expanding accountability to whole populations, religious groups, and regions. From drones in the Levant to "visitation zones" in Northern European cities, the pre-emptive practices in question carry the risk of causing the marginalization, lack of protection, and Othering that may very well be part of the reasons that people turn toward radical political movements, including Islamism, in the first place. Our aporic acts add to the threat we are seeking to protect ourselves against.

\section{Notes and References}

Agamben, Georgio. 1999. Potentialities: Collected Essays in Philosophy. Stanford, CA: Stanford University Press.

Bateson, Gregory. 2000[1972]. Steps to an Ecology of Mind: Collected Essays in Anthropology, Psychiatry, Evolution, and Epistemology. San Francisco, CA: Chandler Publishing Company.

Bubandt, Nils. 2005. Vernacular security: The politics of feeling safe in global, national and local worlds. Security Dialogue 36(3): 275-96.

Cash, John D. 2009. 'Negotiating Insecurity: Law, Psychoanalytic Social Theory and the Dilemmas of the World Risk Society'. Australian Feminist Law Journa/30(1): 87-107.

Fraser, Nancy. 1995. From redistribution to recognition? Dilemmas of justice in a 'Postsocialist' age. New Left Review 212 (July-August): 68-93.

Fraser, Nancy. 2005. Mapping the feminist imagination: from redistribution to recognition to representation. Constellations 12(3), 295-308.

Gammeltoft, Tine M. 2013. Potentiality and Human Temporality. Current Anthropology 54(7), 159-S171. 
Goldstein, Daniel M. 2010. Toward a critical anthropology of security. Current Anthropology 51(4), 487-517.

Hecht, David, \& Simone, Maliqualim (1994). Invisible Governance: The Art of African Micropolitics.New York: Autonomedia.

Holbraad, Martin \& Morten Axel Pedersen. 2013. (eds.) Times of Security: Ethnographies of Fear, Protest and the Future, London \& New York: Routledge.

Keane, Webb. 2014. Affordances and reflexivity in ethical life: An ethnographic stance. Anthropological Theory 14(1), 3-26.

Lianos, Michalis. 2007. Pierre Bourdieu: Episteme, Polity and Critique. Sociological Research Online12(6): 8.

Spyer, Patricia. 2002. 'Fire without smoke and other phantoms of Ambon's violence: media effects, agency, and the work of imagination'. Indonesia 74: 21-36.

Vigh, Henrik and Steffen Bo Jensen. 2005. The Violent Mobilisation of Political Youth. Unpub. Manus. RCT, Copenhagen.

Vigh, Henrik. 2008. Crisis and chronicity: Anthropological perspectives on continuous conflict and decline. Ethnos 73(1): 5-24.

Vigh, Henrik. 2011. Vigilance: on conflict, social invisibility, and negative potentiality. Social Analysis 55(3): 93-114.

Vigh, Henrik. 2018. Lives Opposed: perceptivity and tacticality in conflict and crime. Social Anthropology - Anthropologie Sociale 26(4): 487-501.

\section{Notes}

1 Even if war is an age-old social activity, professionalization of the military profession only happened in the 19th century (Huntington 1957: 19).

2 Harold Laswell described the skill as "the management of violence" and Huntington (1957: 11) calls it "successful armed combat."

3 Think about the Status Angst of political scientists wanting to be like economists wanting to be like natural scientists.

4 According to Jasanoff (2012) some national cultures are more dependent on standpoint-independent scientific evidence (e.g. the U.S.); some focus on institutional and political representation in the construction of expertise (e.g. Germany); and some again focus on individual experience and competent judgement as a main feature in the constitution of the expert (e.g. the UK). Similarly, these expressions of expertise may vary along lines other than the national, i.a., organisational culture (cf. Douglas \& Wildavsky, 1982). We pursue the question of translations across and beyond these kinds or cultures in Chapter 4.

5 The role of the internet in undermining fixed hierarchies of scale is discussed in Chapter 5 .

\section{References}

Abbott, Andrew D. 2001. Chaos of Disciplines. University of Chicago Press.

Abbott, Andrew D. 1988. The System of Professions: An Essay on the Division of Expert Labor. Chicago: University of Chicago Press. 
Adam, David. 2010. 'Climate: The Hottest Year'. Nature 468: 362-64. https://doi. org/doi:10.1038/468362a

Agamben, Georgio. 1999. Potentialities: Collected Essays in Philosophy. Stanford, CA: Stanford University Press.

Amoore, Louise. 2015. 'Life Beyond Big Data: Governing with Little Analytics'. Economy and Society 44(3): 341-66.

Andersen, Rune Saugmann. 2016. 'Video, Algorithms and Security: How Digital Video Platforms Produce Post-Sovereign Security Articulations'. Security Dialogue 48(4): 354-72.

Andersen, Niels Åkerstrøm. 2004. 'Supervisionsstaten og den politiske virksomhed. I C. Frankel (ed.), Virksomhedens Politisering (s. 231-260). Copenhagen: Samfundslitteratur.

Bar-Joseph, Uri. 2010. Intelligence Intervention in the Politics of Democratic States: the United States, Israel, and Britain. Pennsylvania: Penn State Press.

Berling, Trine Villumsen and Christian, Bueger. 2015. 'Capturing Security Expertise - an introduction', in T.V. Berling and C. Bueger (eds.) Capturing Security Expertise: Practice, Power, Responsibility. London: Routledge.

Best, Roger J. 2009. Market-Based Management: Strategies for Growing Customer Value and Profitability. Upper Saddle River, NJ: Pearson/Prentice-Hall.

Bohr, N. 1950. 'On the Notions of Causality and Complementarity'. Science 111: 51-54. 10.1126/science.111.2873.51.

Bourdieu, Pierre 1998. The State Nobility. Cambridge \& Oxford: Polity Press.

Cai, Yuzhuo. 2017. 'From an Analytical Framework for Understanding the Innovation Process in Higher Education to an Emerging Research Field of Innovations in Higher Education. forthcoming'. The Review of Higher Education. https://doi.org/10.1353/rhe.2017.0023.

Carr, M. 2016. Public-Private Partnerships in National Cyber-Security Strategies. International Affairs, 92(1), 43-62. https://doi.org/10.1111/1468-2346.12504

Chandler, D. 2014. Resilience: The Governance of Complexity. Routledge.

Christensen, Kristoffer Kjærgaard. 2018. Corporate Zones of Cyber Security. University of Copenhagen.

Christensen, Kristoffer Kjærgaard and Karen Lund Petersen. 2017. 'Public-Private Partnerships on Cyber Security: A Practice of Loyalty'. Report, Copenhagen.

Collins, Harry M., Robert Evans, and Mike Gorman. 2007. 'Trading Zones and Interactional Expertise'. Studies in History and Philosophy of Science 38(4): 657-66.

Collins, Harry M. and Robert, Evans 2002. 'The Third Wave of Science Studies: Studies of Expertise and Experience'. Social Studies of Science 32(2), 235-96.

Dingwall, Robert and Philip Lewis. 2014. The Sociology of the Professions: Lawyers, Doctors and Others. Quid Pro Books.

Douglas, Mary and Aaron Wildavsky. 1984. Risk and Culture: an Essay on Technological and Environmental Dangers. California, US: University of California Press.

Dunn Cavelty, Myriam and Manuel Suter. 2009. 'Public-Private Partnerships are no Silver Bullet: An Expanded Governance Model For Critical Infrastructure Protection'. International Journal of Critical Infrastructure Protection2: 179-87.

Edquist, Charles. 2001. The Systems of Innovation Approach and Innovation Policy: An account of the state of the art. Paper presented at the DRUID Conference. 
Evans, Robert. 2015. 'What Is Expertise? Technical Knowledge and Political Judgement.' in T.V. Berling, and C. Bueger (eds.) Security Expertise. Practice, Power, Responsibility. London: Routledge: 19-37.

Fischhoff, Baruch. 1995. 'Risk Perception and Communication Unplugged: Twenty Years of Process'. Risk Analysis, 15(2): 137-45.

Floud, Sir Roderick. 2003. 'Science in Society: Caring for Our Futures in Turbulent Times'. European Science Foundation - Science Policy Briefing, 1-36.

Floud, Roderick. 2013. Introduction to Quantitative Methods for Historians. Taylor and Francis.

Fraser, Nancy. 1995. 'From redistribution to recognition? Dilemmas of justice in a 'Postsocialist' age'. New Left Review 212(July/August), 68/93.

Friedrichs, Jörg and Ole Wæver. 2009. 'Western Europe: structure and strategy at the national and regional levels', in Arlene B. Tickner and Ole Wæver (eds.), International Relations Scholarship Around the World (s. 261-86). London \& New York: Routledge.

Gibbons, Michael, Camille Limoges, Helga Nowotny, Simon Schwartzmann, Peter Scott, and Martin Trow. 1994. The New Production of Knowledge: The Dynamics of Science and Research in Contemporary Societies. Los Angeles and London: Sage Publications.

Gieskes, Edward. 2006. Representing the Professions. Newark, DE: University of Delaware Press.

Godin, Benoit. 2015. Innovation Contested: The Idea of Innovation Over the Centuries. New York: Rouledge.

Gubrium, Jaber F. and James A. Holstein. 2003. Postmodern Interviewing. London: Sage.

Gusterson, Hugh. 2007. 'Anthropology and Militarism.' Annual Review of Anthropology 36: 155-75.

Gusterson, Hugh. 2009. 'Project Minerva and the Militarization of Anthropology'. Radical Teacher 86: 4-16.

Gusterson, Hugh. 2010. 'The Cultural Turn in the War on Terror'. in I.J. Kelly, B. Jaurequi, S. Mitchell, and J. Walton (eds.) Anthropology and Global Counterinsurgency. Chicago: University of Chicago Press: 279-296.

Horst, Maja and Alan Irwin. 2018. Hvad vil vi med universiteterne?. Copenhagen, Denmark: Informations Forlag.

Huber, Michael. 2002. Managing the Unknown Future: Different Rationales for Insuring against Terrorism. World Trade Bulletin, No. 10.

Huntington, Samuel P. 1957. The Soldier and the State: The Theory and Politics of Civil-Military Relations. Cambridge: The Belknap Press.

Jasanoff, Sheila. 1998. 'The Political Science of Risk Perception'. Reliability Engineering \& System Safety 59(1): 91-99.

Jasanoff, Sheila. 2012. Science and Public Reason. Routledge.

Keane, Webb. 2014. Affordances and Reflexivity in Ethical Life: An Ethnographic Stance. Anthropological Theory 14(1): 3/26.

Knight, Frank H. 1921. Risk, Uncertainty and Profit. Boston and New York: Houghton Mifflin Company. 
Kuhn, Thomas. 1996. The Structure of Scientific Revolutions. Chicago: University of Chicago Press.

Leander, Anna. 2014. 'Essential and Embattled Expertise: Knowledge/Expert/Policy Nexus around the Sarin Gas attack in Syria'. Politik 17: 26-37.

Leander, Anna. and Ole, Wæver. (eds.) 2018. Assembling Exclusive Expertise: Knowledge, Ignorance and Conflict Resolution in the Global South. London: Routledge.

Leiss, William. 2006. 'Three Phases in the Evolution of Risk Communication Practice'. Annals of the American Academy of Political and Social Science 545(1): 85-94.

Lomborg, Bjørn. 2001. The Skeptical Environmentalist: Measuring the Real State of the World. Cambridge: Cambridge University Press.

Martnez-Alier, Joan, Unai Pascual, Franck-Dominique Vivien, and Edwin Zaccai. 2010. 'Sustainable De-Growth: Mapping the Context, Criticisms and Future Prospects of an Emergent Paradigm'. Ecological Economics 69(9): 1741-47.

Merton, Robert K. 1973. The Sociology of Science: Theoretical and Empirical Investigations. University of Chicago Press.

Messer-Davidow, Ellen, David R, Shumway. and David, Sylvan (eds.) 1993. Knowledges: Historical and Critical Studies in Disciplinarity. University Press of Virginia.

Nordhaus, William D. 2007. 'A Review of the Stern Review on the Economics of Climate'. Journal of Economic Literature 45(3): 686-702.

Nørgaard, Katrine. 2010. Den politiske kriger: Arbejdshafte til Militar etik og ledelse ipraksis. Copenhagen, DK: Forsvarsakademiets Forlag.

Nature. 2010. 'Closing the Climategate'. Nature, 468-345. https://doi.org/10.1038/ $468345 \mathrm{a}$.

Nowotny, Helga, Peter Scott, and Michael Gibbons. 2002. Re-Thinking Science. Knowledge and the Public in an Age of Uncertainty. Cambridge: Polity Press.

Petersen, Karen Lund. 2014. 'The Politics of Corporate Security and the Translation of National Security'. in Kevin Walby and Randy Lippert (eds.) Corporate Security in the 21st Century: Theory and Practice in International Perspective. Basingstoke: Palgrave Macmillan: 78-94.

Richardson, David M., Jane Carruthers, and Cang Hui. 2011. 'Humanmediated introductions of Australian acacias - a global experiment in biogeography'. Divers Distrib 17, 771-87.

Ritzer, George. 1975. 'Professionalization, Bureaucratization and Rationalization: The Views of Max Weber.' Social Forces 53(4), 627-34. https://doi.org/doi:10. $2307 / 2576478$

Saks, Mike. 2010. 'Analyzing the Professions: The Case for the Neo-Weberian Approach' Comparative Sociology 9(6), 887-915.

Saks, Mike. 2012. 'Defining the Role of Knowledge and Expertise'. Professions and Professionals, 2(1), 1-10.

Seabrooke, Leanard. 2014. 'Epistemic Arbitrage: Transnational Professional Knowledge in Action'. Journal of Professions and Organization 1: 49-64.

Slaughter, Sheila. and Larry L. Leslie 1997. Academic Capitalism, Politics, Policies, and the Entrepreneurial University. Baltimore, MD: Johns Hopkins University Press.

Smetters, Kent. 2004. Insuring Against Terrorism: The Policy Challenge. BrookingWharton Financial Papers. 
Stern, N.H., S. Peters, V. Bakhshi, A. Bowen, C. Cameron, S. Catovsky, D. Crane, S. Cruickshank, S. Dietz, N. Edmonson, S.-L. Garbett, L. Hamid, G. Hoffman, D. Ingram, B. Jones, N. Patmore, H. Radcliffe, R. Sathiyarajah, M. Stock, C. Taylor, T. Vernon, H. Wanjie, and D. Zenghelis. 2006. Stern Review: The Economics of Climate Change. Cambridge, UK: Cambridge University Press.

Taylor, Elizabeth. 1995. 'The Globalization of Higher Education and the Professions'. Canadian Journal of Occupational Therapy 62: 59-61. 10.1177/ 000841749506200201.

Wæver, Ole and Kjeld Rasmussen. 2013. 'Klimaændring, ørkendannelse og konflikt i Sahel'. Udenrigs 68(2): 69-77.

Weber, Max. 1968. Economy and Society. Totowa, NJ: Bedminster.

Wenger, Etienne. 1998. Communities of Practice: Learning, Meaning, and Identity. New York, US: Cambridge University Press.

Whitley, Richard. 2000. The Intellectual and Social Organization of the Sciences. Oxford: Oxford University Press.

Zegart, Amy. 2012. 'Spooks, Incorporated'. Foreign Policy Dec. 5. 


\section{Translations across cultures}

While understanding translations of security, recall that we start our observations from a number of sedimented structures of meanings or organisational logics that have developed over time. As argued in chapter 1, we find the structures most pertinent for our purpose to be constituted by distinctions based on function, segmentation, and stratification. Following this line of thought, these constitute important translation zones when aiming to capture translations of unwanted futures. The previous chapter revolved around the functional differentiation between disciplines and professions. In this chapter, we tend to the segmentational differentiation between cultures. The next chapter will move on to scales as stratification.

Security issues, risks, and other conceptualisations of unwanted futures appear differently in and, in particular, shapes different cultures, yet sometimes one organisational or national culture imports notions of unwanted futures from another. In all these cases, unwanted futures are translated. Nations may seek inspiration on how to understand or handle an unwanted future in other nations. Organisations may look to neighbouring organisations that have the same kind of goals but pursue them in a different way. For instance, the conceptualisation of terrorism and counterterrorism are often inspired by or imported from one political culture to another. Likewise, counter-intelligence strategies developed in one organisational setting are often translated to an alltogether different national and organisational culture. This chapter sets out to answer the basic question what happens to unwanted futures, security issues, risk concerns, or understandings of threats, when attempts are made to translate them across cultures?

Culture is a term employed to convey a host of different meanings. Leaving aside a number of the complexities, this chapter focuses on one of them: The concept of culture denotes collective "ways of life": Insiders understand why "we" do stuff in "our" way; outsiders may need to be instructed, need to study, or they even need to assimilate, to really understand this culture, at first foreign to them. This idea of distinct little boxes of meaning often works in uneasy tandem with the idea of one universal process of cultivation towards human perfection, towards civilisation.

A division of labour between the concepts of culture and civilisation often

DOI: $10.4324 / 9781003175247-4$ 
facilitates the co-existence of these two ideas. Particularly, since national cultures acquired their own states (or states took upon them to cultivate each a nation), the concept of civilisation is used to re-inscribe and formalise a hierarchy between cultures. A similar hierarchy may also be observed among organisations - sanctioned by the state or the market-as a competition over which organisational culture performs most effectively. At each of their scales, nations and organisations select what kind of knowledge is suitable and employable, not just in relation to a goal or problematique at hand, but also in relation to their respective cultures.

Our investigation starts out by identifying translation that draws on and challenge past logics of organisation associated with "culture" understood in this way. To do so we ask: What is the main form of organisation and ordering principle? Which conceptual meanings are invoked and what kind of sedimented structures do they rely on? This chapter finds that two main distinctions are fundamental for understanding the translation zone between cultures. The one is horizontal and revolves around translations between different cultures of (in principle) equal status-be they national or organisational. We ask how one culture differentiates itself from other cultures? The other cuts across this distinction vertically and present an alternative: The universalising and civilising mode on the one hand against individual cultures on the other. Here, we ask how one can identify translations of unwanted futures in relation to cultures attempting to universalise themselves? These sections draw on a number of empirical tales and observations by scholars who claim that we are currently witnessing renegotiations not only of individual cultures (inspired or under pressure from other cultures) but also the relation between cultures (e.g. the understandings of hierarchies).

The two main distinctions in this translation zone are negotiated with various means and mobilise a range of authority claims (cultural heritage, civilisational superiority, etc.) They will, we claim, help us to grasp analytically the different forms of culture, and the negotiations of new meanings going on in the everyday translations of unwanted futures. In its attempt to create new meanings, a translation will, it is argued, always entail a negotiation of one or more of these distinctions. Towards the end of the chapter, we argue that the translations on unwanted futures have fostered a number of new conceptual developments and forms of governance.

We observe that modern distinctions and understandings of culture are being challenged in at least two ways. First, the role of the nation state and national identity is being challenged by a global civil society and business networks. These governance networks are not replacing governments but are increasingly relevant as social groups and corporate units outside the immediate jurisdiction of the nation state. They are acknowledged as communities with international and global importance to the management of unwanted futures. Secondly, we observe an increasing pressure on, and a general disbelief in, the possibility of purposeful rational action in the management of unwanted futures. We argue that the entire idea of 
"learning" as the key to translations across cultures is challenged as the idea of purposefulness has come under pressure in today's threat discourse, characterised by dispersed and possible catastrophic threats. In this discourse on uncertainty, the means/ends rationality, the possibility of control, and the possibility of purposefully steering through a refinement of tools are fundamentally questioned.

\subsection{The translation zones across cultures on the same scale: Negotiating difference}

When outlining our theoretical approach in chapter 2, we conceived of translation as something that takes place when different conceptual expressions meet and is negotiated. In chapter 3, we analysed translations across professions and disciplines as functionally differentiated social structures each organised in the same way around a structure of knowledge (i.e. a sedimented constellation of meaning). Translation processes were somehow shaped by these sedimented bodies of meaning as the urge to import knowledge on unwanted futures had to either fit, confront, or dismantle these past disciplinary structures of meaning. Thus, the negotiation of the delimitation of professional/disciplinary sovereignty over different functions of society was important.

In this chapter, we analyse the translation across cultures - understood as different structures of meaning found in what appear to be functionally like units. We ask how knowledge on new security, risk, and threat issues are imported from "colleagues" or "neighbours" who are found to be in seemingly similar roles or situations and translated into the sedimented codes of one's own (national or organisational) culture.

However, all the while each organisation or nation claims sovereignty over their own culture, some of the translation processes are marked by the way in which some cultures simultaneously claim - or are apprehended - to be superior to others. Hierarchies are produced, whether heralded or not. The latter phenomenon is the focus of section 4.2. Section 4.1 tends to translations across cultures on the same scale-after having first further dissected the concept of culture in order to understand the ordering mechanisms and claims to authority made in the translation zones.

\subsubsection{What concept of culture?}

Culture has been characterised as a "hyper-complex" concept (Fink 1988: 22), signifying how it is not just complex but carries with it contradictory meanings and paradoxes no matter how it is employed. In this chapter, we unpack a few of the key complexities to better understand the profoundness of current and past translations as well as to prepare the reader for why some of these complexities and paradoxes nevertheless sneak back into our analysis (Bauman 1999: 13-29; Valbjørn 2008: 34). After dealing with these complexities, we leave 
a concept of culture standing, which has been dubbed the "differential version of the anthropological concept of culture" (Bauman 1999: 13-29; Valbjørn 2008: 38): The idea that culture is plural; that distinct cultures exist as clusters of meaning differentiating members of one culture from another; cutting off transparent communication and spurring the need for translations.

In terms of etymology, culture comes from cultivation: Originally used to characterise the way in which humans could develop their worshipping of gods (as in a cult), the word was later employed to denote the perfection of human life in general (the idea that all spheres of life were relevant to the gods serving as a bridge). Empirically, if not normatively, it was possible to honour the gods in different ways, hence to articulate the idea of cult(ure)s in the plural.

In Herder, culture was conceived of in a way that made a lasting impression - not only on academic discourse (Fink 1988: 17-18) but also on everyday life and practical discourse. On the one hand, culture is that which distinguishes human kind from animals; we all have culture. On the other hand, humans also have different cultures. So culture is generically human, but it is also differential as it divides humans into groups. Moreover, Herder takes the concept to extremes in two ways: First, he expands the concept to encompass all aspects of human life, spiritual and material. Secondly, he conceived of all cultures as equal - consistently striving to avoid the implication of hierarchy between different cultures.

Roughly speaking, the idea of culture as a process of perfection was taken over gradually by another concept, namely that of civilisation. During the 17th and 18th centuries, the elite took off, cultivating or civilising itself, leaving the masses behind (Bauman 1999: xxxii). This connotation lives on in the aesthetic distinction between "high" and "mass culture" (Hauge 1988: 39). However, the nationalist "awakening" in the 18th and 19th centuries insisted that this vertical distinction was secondary by insisting that the elites needed to educate their masses and assimilate and elevate them to what were already their true national cultures (Bauman 1999: xxxiii; Gellner 1983: 34). The coupling of nation and state made the outer boundaries of European cultures more relevant and internal distinctions less so (Barth 1969: 14-15; Bauman 1999: xxx-xxxi, xxxix; Gellner 1983: 48-49). The main task of civilisation was, then, pushed outwards from Europe to the receiving end of imperialism. Here, individual anthropologists armed with the idea of a plurality of self-containing cultures could from their elevated civilisational position - identify and describe entire cultures (1999: 1, 25-26), and in effect produce the knowledge necessary for the Empire to embark on the White man's burden of civilising the coloured races. In anthropology, culture thus became the name for that which produced social order at the scale of a nation or ethnic group-leaving "culture" as an obvious metaphor for sociological studies of how organisations create order (Meadows 1967; Smircich 1983: 341).

Social and cultural anthropology for long parted ways over what was to be the relevant unit of study; culture or society (Bauman 1999: 1), while occasionally debating what was the difference and relation between these two ways 
of conceptualising human collective units. Certain iterations reduced culture to the immaterial superstructure to a material base of productive and reproductive structures. Similarly, some of the many foci taken up by what has been summarised as a "Cultural Turn" in International Relations have been on culture as immaterial aspects in contrast to materiality (Katzenstein 1996; Valbjørn 2008: 35). Likewise, in organisation theory, the concept of culture has been employed to denote that effervescent supplement which explains what cannot be read from formal organisational charts (Schein 1990).

These distinctions between culture and society or material and immaterial are not immediately relevant to the analyses of this chapter. Rather, the concept of culture in focus here is the idea that human interaction is shaped by and shapes "cultures," and therefore that objects and ideas may be translated from one culture to another. Long ago, anthropology gave up the idea of selfcontaining cultures. However, the general consensus remains that there are indeed cultural differences-describing ways of acting and interacting-which are both clustered and sustained in practice over time, and therefore lend themselves easily to identificatory processes (Eriksen 2000: 10, 13, 16; 2002: 4, 7-9; Vermeulen \& Govers 1994: 1-4). Moreover, the empirical world has taken up the concept of culture; people understand themselves as if they form part of more or less closed clusters of cultural traits (Hastrup 2004: 77). Hence, cultures - understood as repetitive ways of doing things - come to delimit the reach of cosmologies: to provide basic orientational values and to function as criteria for selecting risk and dangers (Douglas 1996; Douglas \& Wildavsky 1984). Thus, culture serves as criteria for informing decision, action, and interaction in specific settings (Hastrup 2004: 97-116).

Boundary maintenance mechanisms and social demarcations serve to distinguish culture at different scales (Bourdieu 1979). Just as national culture has been promoted by the institutional apparatus of the nation state, and to a certain degree homogenised as a result, cultures of organisations at smaller scales are also distinct. In organisational studies, the debate over the meaning of culture attracted significant attention in the 1980s as a debate on how distinct cultures affect human behaviour and organisational performance. For the main part, culture has been considered an important force behind organisational and individual performance as well as something that can be created for the sake of improvement (Smircich 1983). Despite the many approaches to organisational culture, it is commonly agreed that historically different kinds of organisations can be characterised by their distinct identification processes (cultures), which, in turn, provides for different managerial solutions. A distinction is often made between bureaucratic cultures, corporate cultures, and voluntary organisational cultures: NGOs and voluntary organisations being loosely organised and tied together by visions of a common purpose or enemy, private companies being based on principles of profit and self-governance (the invisible hand), and the western state celebrating a democratic elitist and hierarchical bureaucratic order (Douglas 1992: 167-187; Al-Najjar 1996). In defining the boundary of the organisation, these different institutions rely on 
different socio-cultural dynamics and logics of decision-making. These management cultures might, as argued by Hofstede (2001), however, interfere with or be influenced by other cultures, e.g. national cultures, thus being exposed to translations across scales.

Present dynamics involving culture may be identified along a spectrum stretched out between national to organisational cultures (including state bureaucracies) as ideal types: Nations are legitimised by their very particularity and by the value and loyalty that their members ascribe towards this particularity. In contrast, the particularity of an organisational culture is legitimised by its goal achievement. Accordingly, organisational membership is also not primarily a question of identity or belonging but a question of contribution to goal achievement. "Nations" and "organisations" are in this sense ideal types, as we recognise that most modern cases of both nations and organisations are "polluted" by the other type: When becoming or acquiring a state, a nation organises itself to be able to pursue goals. Likewise, all management 101 courses tell you that one important way of orienting member actions towards your preferred goals is to make them identify with the values of your organisation.

\subsubsection{Translations across cultures}

Translations across cultures often involve the selection of what a specific culture deems suitable and useful knowledge. Self-reflective cultures, represented and oriented towards goals by their organisational structure (whether states, NGOs, or companies) encounter unwanted futures and seek inspiration in other cultures for how to manage them. Or they encounter other cultures as potentially threatening and the relation as in need of management. Both situations involve seeking knowledge across cultural borders. Crossing borders, however, is not necessarily unproblematic, peaceful, and cooperative but might also be conflictual.

Which concepts might we then argue are translated in the translation zone and with what means? Most basic is the question of whether crosscultural "understanding," and cultural "import," is at all possible. An extreme version of the idea of cultural difference was famously dubbed the Sapir-Whorf hypothesis: It holds that linguistic categories - uniquely combined in each language - influence perception and cognition to such a degree that it is not possible to transport meaning across languages (and hence, across cultures) without changing it. If you say something in a different language, you will say something different (Wigen 2018: 51). Likewise, functionalist system theoretical understandings of organisational culture emphasise the particularity of the organisation (structure, size, technology, and leadership patterns) and thus its self-sustained order (Luhmann 1977; Meyer 1981).

Yet, despite the different positions on this (chapter 2), scholars agree on the empirical observation that there, in any modern organisation, exists an urge 
for progress. Whether this urge for improvement, learning or control, creates new or different cultures is a matter of analytical perspective. Maja Zehfuss' tale (discussed in chapter 3) exemplifies this: The whole basis for having the US Army employ anthropologists in Afghanistan is an idea that "we" can actually understand the Other (provided that we are trained adequately). Likewise, in Jonathan Austin's tale (Box 4.1) of how torture was translated as part of the Global War on Terror, US officials believed that they could acquire culturally specific knowledge from inviting interrogators from Middle East countries to explain or show how they managed the unwanted future embodied in suspected terrorists of that cultural background.

\section{Box 4.1 Hot Tea with Sugar and the Translation(s) of Torture}

Jonathan L. Austin

In January 2002, the United States asked itself whether it should continue letting detainees at Guantanamo Bay "think they are being taken to shot" or, alternatively, whether they should get them some "hot tea with sugar." This question, of whether to be benign or brutal, was resolved with a call to acquire "expert[s] in their culture to help us with issues such as this." ${ }^{1}$ While the names of the experts who eventually answered this call are unknown, their nationalities are: Egyptians, Jordanians, Syrians, Libyans, and other regional neighbours (Open Society Foundation, 2013). Security agencies from these states offered their staff to assist US, British, and other forces in the "interrogation" of prisoners. As is well known, then, the United States ultimately chose to import a global expertise in brutality. The logic underlying this decision revolved around the claim that the present bad of torture should be embraced in order to pre-empt an unwanted future (a "ticking [terrorist] time bomb"). Against this, critics immediately countered, torture would deleteriously introduce an additional consequence [?!] to that causal chain: the present bad, nay evil of torture, intended to prevent an unwanted future, would also instantiate a worse-unwanted future by "changing us" or "our" democratic constitution (For notable versions of the argument and the critique, in dialectical form, see Dershowitz (2002) and Scarry (2004)). What this changing-of-"us" refers to, concretely, has never quite been specified, however. Here, I suggest it relates to the intimate entanglement of different security cultures or cosmologies in the joint enaction of violence and, as the old saying goes, the betrayals that the translations in practices, hierarchies, and ontologies these entanglements ultimately provoked. 
To return to Guantanamo Bay, we can see the brutality of those translations in the testimony of Mohamedou Ould Slahi, one of the socalled "high-value" detainees held there, and his following autoethnographic record of a conversation between American, Jordanian, and Egyptian torturers:

"We appreciate everybody who works with us, thanks gentlemen," said [the US interrogator].

"We happy for zat. Maybe we take him to Egypt, he say everything," said an Arab guy whose voice l'd never heard, with a thick Egyptian accent. (...)

"Somebody like this coward, it takes us only one hour in Jordan until he spits everything," said the Jordanian [interrogator].

While competing over the relative efficacy of their violence work, this trio of "interrogators" was inflicting a method of torture that Slahi describes as "ice cubes and smashing" upon his body (Slahi 2013). This particular practice of pain was introduced to Guantanamo Bay by these two external security cultures, before later being rearticulated in Iraq and elsewhere by US Special Forces. Indeed, US Department of Defense inquiries into the torture techniques used in Abu Ghraib later described how they had "migrated" from Guantanamo. This trade and transfer of torture practices moves us to the first element translated by these intercultural relations: the morphologies of practices themselves. Practices are not simply collected "as is" but are, rather, fused, bonded, and recombined so as to translate repertoires of action significantly. Thus, an earlier Cold War shift in interrogation practices towards "clean" psychological techniques - inspired by scientific experimentation and the mimicking of Soviet practices - shifted again post-9/11 by combining psychological and physical coercion: a clean and brutal torture in which the ice of this "ice cubes and smashing" erased "sovereign" signs of pain. For a discussion of the Cold War-era evolutions, see Rejali (2007).

These morphological translations in torture practices were mediated through human bodies like Slahi's and he himself describes these experiences of spatial multiplicity - in which the violences of multiple security cultures were enmeshed and enacted in the same space - as just another abduction inside the abduction of his rendition (Slahi 2013). The violence unleashed at Guantanamo, and elsewhere, related thus to the specific expertise imported into this field of action and not simply any aberrant Schmittian exception. Indeed, once torture became, in the words of the Open Society Foundation, globalised in this way at least two further forms of translation were set in motion: of the hierarchies of world politics and of the ontologies of actors. To turn to hierarchies, material assistance in the 
"detainee programme" was not provided in subservient terms. Jordan, Egypt, and other states were not mere clients. They could make demands, and they did. To show this, we can turn to another disappeared detainee, Sami al-Saadi. Al-Saadi was a Libyan dissident living in exile until, in February 2004, he was arrested in China, transferred to Hong Kong, and then "rendered" by the CIA and MI6 to Tripoli, where he was placed in the custody of the Libyan state, which imprisoned, tortured, and sentenced him to death (Human Rights Watch 2012). Importantly, the CIA and MI6 were unconcerned with Al-Saadi and he was abducted solely at the whim of the Libyan authorities in return for intelligence cooperation. Indeed, there are many other instances in which authoritarian states demanded and received assistance from democratic states in such a way as to invert the traditional view of counter-terrorist "cooperation" as hierarchically directed by a metropolitan centre (or "Empire") of world political violence (ibid.).

To move finally to ontologies, however, upon Al-Saadi's release and the discovery of documents in post-Gaddafi Libya detailing MI6 involvement in his torture he began legal proceedings against the British government. The British refused, on national security grounds, however, to try his case openly and instantiated, instead, a trial in the secret court system it had established soon after 9/11. In response, Al-Saadi gave up his quest for justice with the words that, "I went through a secret trial once before, in Gaddafi's Libya. In many ways, it was as bad as the torture." Secret courts, a post-9/11 adoption of authoritarian practices, were necessitated to mask complicity in torture, just as they are in classically understood autocratic or despotic states. This is what I mean by the translation of ontologies: the inertia produced by the entangling of an actor in a hybrid assemblage that necessitates substantial changes in its identity. This ontological translation can be traced back to the enmeshing of security cultures in the same space of violence at Guantanamo Bay, to the consequent translation of the morphologies of torture practices, and the resultant reassembling of the hierarchies of world politics. It is here then that the concrete meaning behind the injunction that torture "changes us" can be located and, moreover, where we also find the genesis of emerging homologies or "unforeseen convergences" between democratic and autocratic states (Agamben 1998: 13). Indeed, to end back with Slahi in Cuba, he also described the moment at which his body was beaten there as marking a "thick line between my past and my future." It was then that he felt his self being "broken" but it was also, perhaps, one forgotten moment in which contingencies between being benign and being brutal were definitively translated into the betrayals of that forewarned worse-unwanted future. And it is thus that another of Slahi's remarks hints, finally, at how the 
consequences of these painful translations for own body echoed back on his assailants: "It is not me anymore, and I will never be the same as before" (Slahi 2013).

\section{Notes and References}

Agamben, Giorgio. 1998. Homo Sacer: Sovereign Power and Bare Life. Stanford: Stanford University Press, 13.

Dershowitz, Alan. 2002. Why Terrorism Works. Yale: Yale University Press. Human Rights Watch. 2012. Delivered into Enemy Hands. London: Human Rights Watch, 102-110.

Open Society Foundation. 2013. Globalizing Torture: CIA Secret Detention and Extraordinary Rendition. New York: Open Society Foundation.

Rejali, Darius. 2007. Torture and Democracy. Princeton: Princeton University Press.

Scarry, Elaine. 2004. 'Five errors in the reasoning of Alan Dershowitz', in Sanford Levinson (ed.) Torture: A Collection. Oxford: Oxford University Press.

Slahi, Mohamedou Ould. 2013. The Guantánamo Memoirs of Mohamedou Ould Slahi. 30 April 2013, Slate.com.

US Department of Defense. 2002. 'Initial Observations from the ICRC Concerning Treatment of Detainees', Available at: http://www. washingtonpost.com/wp-srv/nation/documents/GitmoMemo01-21-02. pdf Accessed 30 June 2014.

US Department of Defense. 2004. 'Final Report of the Independent Panel to Review DoD Detention Operations [The Schlesinger Report]'. http://www. defense.gov/news/aug 2004/d20040824!nalreport.pdf. Accessed 30 June 2014.

In both Zehfuss' and Austin's tale, the motivation for understanding the cultural Other was ultimately to better fight the enemy who is hiding among the cultural Other; perhaps even incarnating a particularly threatening version of the Other culture. This is how the motivation for a "cultural translation" looks from a national security perspective. A supplemental motivation for the very same engagement may be found when looking at these particular cases from the perspective of a performance-oriented bureaucratic organisation. Particularly Austin's tale lays out how the selection of knowledge and the learning of technologies is done in order to appear useful from one organisational point of view (Wigen 2018: 3), even if this might compromise the values signifying the larger identity of which the organisation is also a part. What seems useful within one organisational rationality (a bureaucratic one) might not be so in the context of another (broader cultural identity). For cultures, hence, the selection of knowledge across cultural boundaries is a negotiation at many levels. 
When, in instances like these, a translation of an unwanted future occurs from a will to engage the other, to know about, or learn from the "other" culture, the extraction of knowledge is dependent on mediators (Wigen 2018: 9): We need "them" to educate "us" about their culture, or we need some of "us" to educate ourselves in their culture. In Austin's tale (Box 4.1), practitioners were imported by the United States to explain, show or even instruct their practical expertise in torture; an expertise deemed culturally specific both in the sense that the victims react in culturally specific ways, but also in the sense that the torturer builds his practical expertise on knowing these culturally specific reactions from experience. The discipline of anthropology has institutionalised the extended fieldwork as a practice for how to immerse oneself in a foreign culture as a privileged way to get to know and understand it. However, as Martin Holbraad's tale from Cuba (Box 4.2) exemplifies, the fieldwork engagement with the other culture is in current anthropology utilised also - or even primarily - as a touchstone for observing and critiquing one's own culture (Jasanoff 1986). Hence, when importing culturally "other" experts or when deploying our own experts in knowledge about "the other," the loyalty of these intermediaries may be put in question. "Traduttore, traditore!", as exclaimed in an Italian saying: "Translator, you are a traitor!" (Wigen 2018: 9). In Zehfuss' tale (Box 3.2 in chapter 3), the US Army summons anthropologists, supposedly trained in seeking knowledge about/across cultures, only to see that they resist to engage due to a lack of trust in the way in which "their own" culture will utilise the acquired knowledge in its future management of insurgency. Ulrik Pram Gad's tale (Box 5.5 in chapter 5) takes as its point of departure how Danish soldiers apprehended as Muslims are repeatedly met as cultural interlopers and in some instances as a potential fifth column - by broader societal discourses and in some instances by immediate colleagues and superiors. Even if they communicate adherence to an ideal of dialogue (Gad 2011) their honesty may be challenged. Likewise, anthropologists and other social scientists employed in Afghanistan as part of the Human Terrain patrols were killed as some Afghans did not accept the legitimacy of the aim of their

\section{Box 4.2 "In this house we're revolutionaries, damn it!". A visceral translation to Cuba}

\section{Martin Holbraad}

One of the things that strikes even casual visitors to Cuba since the opening of the island to western tourism is the startling ease with which local people, particularly in Havana and other parts accustomed to the flow of foreigners since the 1990s, voice their many dissatisfactions with the now so obviously ailing state of their socialist Revolution. ${ }^{a}$ Complaining about - indeed lamenting - sundry indices of what even 
the state media sometimes call the "moral crisis" of recent years is so common among Cuban citizens that it has come to acquire the character of a kind of social lubricant, akin to British people's habitual exchanges about the weather. The phrase "no es facil" (it isn't easy), which can follow any manner of complaint - from state-sanctioned electricity interruptions due to lack of petrol, to interminable programmes of staged political debate on state television, to the rise of delinquency, alcoholism, prostitution, and so on - functions almost as a sign of punctuation: a sentence's temporary pause in resigned desperation.

Quickly accustomed to my own friends' daily litanies of this kind in the first months of my PhD fieldwork in 1998, a time in which the Cuban Revolution's future prospects seemed no less uncertain than they do today, I tended rather quickly to take these as signs of people's basic exhaustion with their government's relentless pursuit of a socialist path since the revolution of 1959. Certainly, western commentators on Cuban society (CNN, BBC, assorted bloggers, etc.) as well as dissident voices speaking to their foreign publics from the island typically offer just such interpretations: Cubans, oppressed for more than five decades in the name of socialism, are fed up, and, since they can't say so on pain of punishment by the authorities, they grumble quietly to each other and to any foreigner who may care to listen.

During the course of my fieldwork and in the years since, however, I have come to have serious doubts about this manner of understanding - or, if you like, translating - the situation in Cuba. A first inkling that something might be amiss with the liberal democratic fantasy of Cuba finally in popular ferment against an exhausted totalitarian "regime" came to me one night when, rather unguardedly due to the effects of the rum we were drinking, and a little fed up myself with my closest friends' constant litanies of complaint, I let my own libertarian colours show by suggesting that, if they were so dissatisfied, they should perhaps do something about changing their government. "That's what we did in 1973 in Greece" (where I come from), I said in risqué tone. Instantly sobering the atmosphere, and cooling it considerably, my good friend Manolo $^{2}$ (a state-trained playwright in his late 40s) cut my banter off: "This is not Miami and we are not worms!" (gusanos, the term used popularly and in earlier times officially to refer to the revolution's defectors in the US and elsewhere). "This is our country and if we have to fight for it and for all this shit that you see around you, we will!"

It has to be said that at the time I took my friend's seemingly knee-jerk and rather macho reprimand as a natural reaction to a foreigner's 
presumptions. Coming from Greece, I am very used to my own chauvinistic responses when it comes to sundry Northern Europeans and IMFers lecturing me on all of my country's failings - the "how dare you!" retort. But other poignant episodes that took place as my fieldwork continued showed me that such an interpretation too is inadequate on its own. As I began to realise, my working assumption that people's complaints with the current state of their version of revolutionary socialism must imply a nascent anti-revolutionary impulse was misplaced. If anything, it was often because people were committed to their Revolution that they were so expressly dejected with its current ailing state. To see how visceral - indeed violent - this apparently contradictory commitment can get, consider another example.

This took place in 2004, in the home of another good friend, Rogelio, a music-school trained brass player who these days earned dollars by teaching foreigners to play Cuban percussion. Gathered in his front room for an informal drinking party with friends, we were chatting about music when another friend of mine, Jose Luis, whom Rogelio had met through me a few times before, arrived quite drunk and in a vile mood. Quite imposing in character, Jose Luis was a Leningrad-trained academic with a keen interest in current affairs. Soon, as was his want when he was drinking, he started to dominate the conversation, on this occasion with a string of comments, in turns bitter and indignant, about all manner of controversies regarding current government policies. Noting that our host Rogelio was getting quietly agitated by this, I tried to steer the conversation onto other topics, but to no avail. At some point, Jose Luis indicated the large photographs of Camilo Cienfuegos, Ché Guevara, and Fidel himself that Rogelio, like so many other Cubans, kept in prominent positions on his walls. "Look at these shameless sons of bitches! Ok, these two may have been different (pointing at the photos of Camilo and Ché), they're gone. But this guy (Fidel)! What a piece of work he is!" What I had failed to notice at this point is that Rogelio had in the meantime disappeared into his bedroom. As we were all reeling at Jose Luis's outrageous remarks, Rogelio came storming back into the living-room wielding a huge rusty machete, shouting in total paroxysm: "Get the fuck out! In this house we are revolutionaries, fuuuuuuck!!!!" and lurched at Jose Luis who beat a quick retreat out onto the street, shouting that the incident would not end there, which, as a matter of fact, it did (the two men never spoke again).

These tales' heady mix of late socialist dejection and apparently visceral and chauvinistic revolutionary fervour raises at least two questions in 
relation to the notion of securitization in particular. First, there is the question of how far the model of securitization itself tends to ratify the BBC image of peoples oppressed by the arbitrary power of totalitarian states. How does the basic Copenhagen School distinction between ordinary politics, say, and states of emergency, tally with a situation in which, as my tales would indicate, the two are viscerally imagined as coterminous? Indeed, as I have argued elsewhere, the commitment to self-sacrificial violence that underpins the cry "in this house we are revolutionaries!" concertedly collapses the basic distinction between people and state, so that the very idea of a "state of emergency" becomes blurred (Holbraad \& Pedersen 2012, 2013). Secondly, I would note the complexities introduced also by the apparently self-contradictory nature of people's stances to revolution in Cuba today. What l've tried to drive home by emphasising the visceral character of people's against-the-odds revolutionary commitment is that the BBC-style temptation here not to take this seriously, demoting it to a veneer of appearance underlain by a presumably more real sense of dejection, should be resisted. But if so, then we seem to be left with subjectivities that are somehow split down the middle - people, if you like, that in some sense are talking past themselves. People, then, not so much as political units, subject externally to the vagaries of states of exception, but as complex, internally variegated political landscapes in their own right. Perhaps what we need here is some kind of securitization theory of the soul itself. ${ }^{\text {b }}$

\section{Notes and References}

a These tales have previously been presented as part of a larger attempt to understand what I call the "ontology" of revolutionary commitment in Cuba (Holbraad 2014).

b All personal names and some identifying details are fictitious.

Holbraad, Martin. 2014. 'Revolución o Muerte: The Political Ontology of Cuban Revolution'. Ethnos 79(3): 365-387.

Holbraad, Martin and Morten A. Pedersen. 2012. 'Revolutionary Securitization: An Anthropological Extension of Securitization Theory'. International Theory 4(2): 165-197.

knowledge seeking (Gusterson 2007). Fluency - real or imagined - in more than one culture brings dual identities with it. Dual or hybrid identities open up questions about loyalty. And loyalty is seen as imminent in the current Western programmes for the management of unwanted futures like terrorism and insurgency, portrayed as rising from cultural Otherness. 
In sum, translation zones across cultures consist in meetings with the culturally defining Other. These meetings involve an attempt of "perspectivetaking" (Tomasello et al. 1993) by either imitating or collaboratively learning (Wigen 2018) new ways of handling unwanted futures or by being instructed to take on other's perspective by force, law, or informally.

Historically, some means have become institutionalised in the translation zones across cultures. Nation meets nation in conflict, sometimes defined by the institution of war. Nations attempt to negotiate with other nations, whether to collaborate or just to keep conflict from getting lethal, via $d i-$ plomacy. Companies and organisations are subject to regulations and laws but engage in contracting or collaborate more informally through partnerships. Thus, many of today's cultural translation zones are institutionalised, some institutions being more collaborative, others more conflictual.

Yet, the means might not be as institutionalised as the examples here indicate. States, organisations, and companies continuously look to others to learn and find inspiration in order to optimise or improve their own managerial or democratic practices. Corporate business turns to intelligence seeking against their competitors; criminal organisations go to war against each other and against other organisations including the state; and inter-state engagement increasingly takes the form of contracting-in formal treaties or (as in Austin's tale) in clandestine exchanges. Thus, for any organisation (state, voluntary or corporate) to seek knowledge, to analyse the situation and improve practice, is considered crucial to the definition of success. These goal-oriented cultures and practices, however, stand in contrast to a national culture, which is basically based on an idea of belonging, culture as that which people/citizens are born into.

Although the impulse to translate across cultures often departs from inside one of these cultures, it might not be so. The vision of indigenous culture is of course mainly an imaginary construct. As Frank Sejersen's tale (Box 5.2 in chapter 5) is witnessing, even cultural "belonging" cannot be sedimented. His tale begins when the prospect of an unwanted future materialises: In the small Alaskan settlement of Kivalina, climate change is no longer just a theoretical prognosis - changing weather literally undermines the community. The immediate physical disappearance of their settlement dislocates the community's cosmology, in turn forcing its members to engage in a re-invention of their future, which cannot but translate themselves out of what they and others counted as their indigenous culture.

The identities of and the spaces between these culturally defined units can be summarised through the categories in Table 4.1. The first column identifies "culture" as the main identity markers, i.a. the criteria for what distinguishes one nation or organisation from the next one. The second column lists the basis of legitimacy of cultural particularity - and here is what distinguishes a national and an organisational culture: Nations are legitimised by their very cultural particularity and by the value and loyalty that their members ascribe towards this particularity. The particularity of an organisational culture is legitimised by its goal achievement-and membership is 
Table 4.1 Translation zones across cultures - spectrum from national to organisational

\begin{tabular}{|c|c|c|c|c|c|}
\hline Unit & Distinction & $\begin{array}{l}\text { Basis of } \\
\text { authority }\end{array}$ & $\begin{array}{l}\text { Means of } \\
\text { translation }\end{array}$ & $\begin{array}{l}\text { Relation to } \\
\text { state }\end{array}$ & $\begin{array}{l}\text { Relation to } \\
\text { knowledge }\end{array}$ \\
\hline $\begin{array}{l}\text { Nation } \\
\text { distinct } \\
\text { from other } \\
\text { nations }\end{array}$ & $\begin{array}{l}\text { Uniqueness } \\
\text { of culture }\end{array}$ & $\begin{array}{l}\text { Sovereignty; } \\
\text { Loyalty; } \\
\text { Belonging; } \\
\text { Diversity }\end{array}$ & $\begin{array}{l}\text { Diplomacy; } \\
\text { Intelligence; } \\
\text { War; } \\
\text { Regulation } \\
\text { and Law; } \\
\text { Assimilation }\end{array}$ & $\begin{array}{l}\text { State } \\
\text { claims to } \\
\text { represent }\end{array}$ & $\begin{array}{l}\text { Selects } \\
\text { suitable } \\
\text { knowle- } \\
\text { dge }\end{array}$ \\
\hline $\begin{array}{l}\text { Organisation } \\
\text { distinct } \\
\text { from other } \\
\text { organisa- } \\
\text { tions }\end{array}$ & $\begin{array}{l}\text { Value of } \\
\text { culture }\end{array}$ & $\begin{array}{l}\text { Goal } \\
\text { achieve- } \\
\text { ment; } \\
\text { Utility; } \\
\text { Market } \\
\text { Competiti- } \\
\text { on }\end{array}$ & $\begin{array}{l}\text { Contract; } \\
\text { Handshakes; } \\
\text { Partnerships; } \\
\text { Instruction; } \\
\text { Assimilation; } \\
\text { Acquisition; } \\
\text { Imitation }\end{array}$ & $\begin{array}{l}\text { Sanctioned } \\
\text { by law or } \\
\text { utility }\end{array}$ & $\begin{array}{l}\text { Employs } \\
\text { useful } \\
\text { knowle- } \\
\text { dge }\end{array}$ \\
\hline
\end{tabular}

primarily a question contribution to goal achievement. This reflects in the ideal typical difference of raison d'être and in the respective means of communication listed in the fourth column: A nation seeks to assimilate members internally, while asserting sovereignty externally. An organisation values its members' contribution to goal achievement (in pecuniary or other forms), while promising rationality in goal achievement to the outside world by communicating symbols of organisation.

The third column summarises the contours of the space between cultures; the zones in which difference is negotiated; where the value of the particularities distinguishing culture from culture is determined. The fourth column exemplify traditional means for translating across nations including intelligence seeking, diplomacy, and war - whereas organisations ideal typically translate by contracting at the market. The final columns characterize the relation between, on the one hand, national and organizational cultures, and on the other hand, the state and knowledge. By zooming in on and understanding the negotiations going on in these spaces across national and organisational cultures - the loyalties and rationalities defined, redefined, or invented - we seek to identify new meanings and practices of managing unwanted futures.

\subsection{Translation zones beyond culture: Particularities claiming universality}

In the same way as the meaning of expertise relies on a distinction to the amateur (cf. chapter 3), the above-described concept of "culture" is fundamentally based on versions of particularism and thus universality (cf. the 
discussion on civilisation). Following the conceptual developments outlined previously, the ideal type relation between two cultures is, thus, one of equality. The fact that cultures are substantially different legitimises a division of the world into sovereign nations. However, nations tend not to

Table 4.2 Translation zone between cultures and universalisation

\begin{tabular}{|c|c|c|c|c|c|}
\hline $\begin{array}{l}\text { Challenge to } \\
\text { cultural unit }\end{array}$ & Distinction & $\begin{array}{l}\text { Basis of } \\
\text { authority }\end{array}$ & $\begin{array}{l}\text { Means of } \\
\text { translation }\end{array}$ & $\begin{array}{l}\text { Relation to } \\
\text { state }\end{array}$ & $\begin{array}{l}\text { Relation to } \\
\text { knowledge }\end{array}$ \\
\hline $\begin{array}{l}\text { Universality } \\
\text { distinct from } \\
\text { particularity }\end{array}$ & $\begin{array}{l}\text { Intrinsic } \\
\text { valuation }\end{array}$ & $\begin{array}{l}\text { Diversity vs. } \\
\text { Intrinsic } \\
\text { universality }\end{array}$ & $\begin{array}{l}\text { Narratives of } \\
\text { distinction } \\
\text { vs. } \\
\text { Narratives } \\
\text { of } \\
\text { universal } \\
\text { identity }\end{array}$ & $\begin{array}{l}\text { Undermines } \\
\text { state } \\
\text { sover- } \\
\text { eignty } \\
\text { (except } \\
\text { possibly } \\
\text { of } \\
\text { hegemon) }\end{array}$ & $\begin{array}{l}\text { Undermines } \\
\text { culturally } \\
\text { distinct } \\
\text { knowl- } \\
\text { edges }\end{array}$ \\
\hline
\end{tabular}

respect this, their own founding principle. Rather particular nation states routinely insist that their culture in some sense embody values of a universal validity. Hence, they are even sometimes - from their own perspective justified in seeking to promote them abroad (cf. the debates on morality and human rights) (see Table 4.2).

More generally, Modernity may be read as one grand ordering project, seeking control over insecurities, potential threats (Bauman 1991) - in short: over unwanted futures. While Modernity may have a diverse genealogy, it remains one among other ways of going about the human condition. Contrary to other ways, Modernity's urge to know, fixate and manage the future imbues it with an expansionist, even universalist impulse. And like one of its central incarnations, Liberalism, it often approaches cultural Others with the idea that they are really identical with us - potentially or right below the surface. This brings us to the second ordering distinction in the translation zone on cultures. The one that cuts across the horizontal division into equal units and posits some as "more universal than others". One example is provided in Martin Holbraad's tale (Box 4.2) of his own (over-)interpretation of Cubans' dissatisfaction with the state of their revolution as a symptom of their hidden Liberal subjectivities. As Holbraad's tale also hints at, such universal pretension of particular positions may spur a dynamic of reactions and counter-reactions - or, in other words, a dynamics of translating programmes for interpreting and managing unwanted futures back and forth across cultures. In our chapter, this second universalising distinction inserts tension and grounds for the evolving of novel concepts and practices. 


\subsubsection{Dynamics of universalisation}

Universalisation takes many forms. While we might accept the market as an ideal type of organisation, somewhat different from the universal pretensions of Liberalism, market competition and diversity still presuppose some higher moral order and a liberal version of universality, namely that of the invisible hand. This means, on the one hand, that aggressive marketing of culturally produced - products are in line with the logic; that cultural selfassimilation as a result of seeking inspiration across cultural borders are legitimate (as long as intellectual property rights are respected); and that no organisation is in and of itself is a legitimate referent object of securitization in the sense of being protected with extraordinary means (Buzan et al.'s (1998) chapter on economic sector). On the other hand, whereas the market logic is expected to self-reproduce its cultural diversity - as new units should challenge old ones to re-invent themselves - this logic needs protection from the unwanted future of undue abuse of a (ideally temporary) monopoly position (to illegitimately perpetuate itself). Although the situation of individual companies in the market is unlike nations in the international system, the market logic appears as one culturally particular principle of organisation with universal pretension.

When national cultures are invaded by outsiders attempting to homogenise them to a model of supposed universal validity, cultural change may be interpreted as an existential threat against which extraordinary means are warranted: Identity is threatened - security measures are called for (Buzan et al.'s (1998) chapter on societal security). French laws against Hollywood movies, and Icelandic linguistic purification drives are basic examples of such "cultural security politics." However, the attempts to protect "Asian values" against supposedly universal human rights raises the stakes as the negotiations move beyond the economic and cultural spheres and directly into questions of state authority. In Africa, Western development aid was made conditional on promotion of not just human rights but also a series of liberal institutions promoting a market economy. Later, conditionality was extended to include cooperation on security reform aiming to control and eradicate religious and ideological groups and programmes deemed a threat to Western states and ways of life. In other words, depending on the form, which these security measures take, the imperial culture may in turn interpret them as a threat to the universal validity of its values and thereby to its identity. In places like Afghanistan, Iraq, and parts of Northern Africa, the result has been an - asymmetrical - conflict spiral of governmentality and counter-insurgency strategies met by resistance.

However, like companies learning from successful competitors, cultures may alternatively - as mentioned - also seek to self-assimilate to imperialist cultures by translating as many substantial or diacritical traits as possible. By accepting the label "developing," third world countries have identified themselves as lesser versions aiming to catch up with the "developed" world. 
The unwanted future of losing out to the Other is translated into a bright future by joining the winners. However, such submissive strategies may be thwarted by top-down interpretion of the attempt as a threat of pollution or invasion threatening the purity of their culture and therefore dismissing the copy-cat as an imposter: Turkey might for a brief moment in time around the turn of the millennia have thought of themselves as eligible for membership of the European Union. But soon, it was clear to all parties involved, that a European consensus was forming that Turkey would never really catch up because as a Muslim country they were essentially different (Gad 2005, 2010; Pieterse 2000). The result is mis-recognition - denial of recognition in spite of honest attempts to identify - which is likely to backfire in the form of counter-identification (Gad 2010; Hage 2008). This brings us back to the main scenario of resistance and governmentality: excluded minority youth appearing "radicalized" is governed back towards the acceptable, liberal mainstream, and simultaneously interpellated as irredeemably beyond reach ( $\mathrm{Gad}$ 2012a, 2012b; Kühle \& Lindekilde 2009; Lindekilde 2012).

Finally, of course, one culture's programme for managing an unwanted future may be translated into other cultures without sparking (enough) resistance to feed such spiralling dynamics. We will return to an example of such a "smooth" top-down chain of translations below, after delving into a few mechanisms and dynamics of "bandwagoning" and resistance.

\subsubsection{Translations across particular but universalising cultures and cultures of resistance}

When a "lesser" culture embarks on translating the way in which a dominant culture handles a particular unwanted future, specific cultural scripts and practices may become iconic: Certain ways of doing things are deemed important to translate into one's own practice if one hopes to be counted as successful. Austin's tale (Box 4.1) is an example of how even a culture both self-evaluating and seen by others as leading (the United States is supposed to be the lone military superpower) may find a need to import techniques (torture) from "lesser" cultures (Middle Eastern ones) - simply because the unwanted future in question (terrorism) is managed in a securitized mode.

Both resistance to universal projects and the governmentality and counterinsurgency strategies responding to resistance need as input knowledge of (rather than import of) the Other culture. What sets off Zehfuss', Austin's, and Gad's tales is the need of the US-led universal project of liberal peacebuilding to know Afghan and Arab cultures in order to manage the unwanted future of terrorism. Intelligence is necessary for building better strategies for averting the short-term unwanted futures of terrorism - and for averting the long-term unwanted future of having the universal value of your particular culture denied by insurgents. 


\subsection{Translations by what means?}

As discussed previously, a number of means in the translation zone across cultures have been institutionalised: War, diplomacy, contracting, and partnerships were mentioned. A number of physical objects, technologies, and concepts are, however, also involved in the translations across and beyond cultures as what we call means: documents, meetings, surveillance equipment, violence, and Nature itself.

To take an example, Jonathan Austin's tale relays how voices claim that an organisational translation of torturing techniques from an "other" culture translates into a threat against "our" true identity. Or in other words: How the identity of the "we" is co-translated in the process of translating unwanted futures. Such co-translations may produce new means to counter an unwanted future such as torture and interrogation techniques. In this way, a translation or co-translation may produce new risks or security problems while at the same time legitimising new means. Another good example of this is found in Elida Jacobsen's work on biometrics (2015). Jacobsen shows how a biometric technology can redistribute unwanted futures across time when translated into a more fragile, postcolonial political and social culture. The biometric system, imported to secure the nation against non-citizens tapping into social benefits, places the protagonist at risk: not only a risk of losing his economic entitlements but also his liberty. Stritzel (2014), on the other hand, follows how the concept of "organised crime" is translated across organisational and national cultures with diverse effects at each turn: First, the concept was translated from domestic US law enforcement agencies to a foreign policy context allowing what was once police tasks to merge with military means. Later, the concept was translated into the European Union's technocratic cooperation placing it in a risk management logic. Taken together, specific vocabularies and concepts (Stritzel 2011) and practices, bodies, and technologies (Austin, this volume; Jacobsen 2015) were translated across cultures. But the "receiving" culture is often co-translated as their ontologies, cosmologies, discourses, and selves are altered.

Lack of control over the import of culturally "other" knowledge is easily securitized in the context of a securitized programme for the management of an unwanted future. Nevertheless, self-reflection and self-reinvention may alternatively be the result of a translation of an unwanted future. As mentioned, Frank Sejersen's tale reflects an example of such a translation in which the unwanted future is conceived of as un-refutable because appearing in the form of a non-human, material fact: Rising sea level and harsher storms. (There might be human targets to blame and to turn to for assistance. We return to this in our discussion of the tale in chapter 5.) Even when an unwanted future materialised in the form of a human other, the reaction need not follow a threat/defence logic: The history of imperialism includes (rare) examples where a community translates an intruder into its 
cosmology as undeniably superior, prompting a strategy of self-assimilation, submission or even self-destruction (Gad 2010, 2005; Todorov 1982).

A more common means of translating an unwanted future, however, is to embed its management in hard-to-negotiate materiality: Roman and Chinese empires of yesterday built walls to keep out Barbarians; today, European nation-states re-erect barbed wire border fences and vigilante patrols are patrolling the Rio Grande while until recently cheering on former president of the United States Donald Trump to build a higher wall. But as the Israeli wall in the Palestinian territories reminds us, the distinction between defence and offense is never clear cut; and, as we will discuss later, one translation of security may set in motion a whole cascade of translations.

The ultimate means of translating an unwanted future as part of a civilising mission involves physical violence. A particular vision of how the world should be and how it should become so is exported across cultural boundaries. If not in the sense that its substance is imported and accepted by the receiving culture, then in the sense that the prerequisites of its implementation within the world view of the dominant culture are imposed upon a dominated culture. The exportation of a world view can then be driven to the point where a number of those holding opposing world views are being terminated in the process. But such export-driven translations may be achieved or attempted with less draconian side-effects depending on the posture and means available to the receiving culture. A growing literature interprets Western practices in engaging the Global South - development aid, conditionality, peace building, security sector reform, etc. - as governmentality in the Foucauldian sense: As efforts - once removed to conduct the conduct of conduct; as attempts to shape the capability and intention of formally sovereign states to shape the subjectivity of their citizens in ways that do not translate into futures deemed unwanted by the West. We read such practices through the lens of means of translations.

If the receiving culture is sympathetically inclined, of course, the translation may be conducted in an altogether different mode and with different means. At a societal scale, the revision of primary school curricula, the reform of social benefits, the easing of taxes for certain industries and classes may be analysed as a means for implementing a certain neo-liberal programme of managing an unwanted future of a potential decline in national competitiveness vis-à-vis other nation states. At both scales, coincidental misunderstandings, deliberate mis-translations, and outright hypocrisy may be functional for the translation, for the domestic and international interpretation of the translation, and/or, hence, for the relation between the exporting and the importing culture.

Between these two extreme scenarios of war and reluctant acceptance, a translation of an unwanted future from one culture may set in motion a whole cascade of different translations. An instructive example of such cascading can be found at Thule, a rather desolate location in the North West of Greenland, as recounted in Gad's tale (Box 4.3). Probably, such 


\section{Box 4.3 Translations of Security Cascading at Thule}

\section{Ulrik Pram Gad ${ }^{a}$}

In the very first rounds of the Cold War, the United States found itself facing the unwanted future of a Soviet nuclear attack. Military planners felt an immediate need to devise a strategy for managing this unwanted future. Looking at a globe and calculating the shortest missile and airplane trajectories between Russia and North America pointed to a need for an air base ideally placed somewhere in the North of Greenland (Ross \& Ancker 1977), a Danish colony which the United States had taken into custody during WWI when Denmark was occupied by Nazi Germany. As a 1947 letter from the US consulate in Godthåb to Washington exclaimed: "We need Thule ... . Look at Thule on the map. It makes Alaska look sick. It is one of the very few places in Greenland where it is possible to construct a large airfield. It is also accessible to large ships" (quoted in DUPI 1997: 68). Consequently, a request was made to Denmark to buy the whole island. A Danish diplomat, technically gone rogue, had already during WWII granted the US unlimited military rights on the island (Lidegaard 1999). This arrangement had retroactively been confirmed by the Danish government seeking allied status, eager to distance itself from its rather ambiguous collaboration with the German occupants.

In Denmark, a select foreign policy circle translated the US offer to buy the island into a potential unwanted future of losing both what was left of imperial grandeur and what was apprehended to be the most important argument for allowing Denmark into the NATO alliance providing security against Soviet aggression (Lidegaard 1999). The prospect of allowing new US bases and installations (on top of those already established as part of the WWII efforts) also emerged as an unwanted future - both because it would explicate the loss of national pride to the electorate, but also because it was expected to provoke the Soviets (Lidegaard 1999). Hence, the Danish government translated the US base request into an expansion of a weather station already established by the tiny settlement of Thule in the very North West of Greenland.

In the early summer of 1951, this government decision translated into a very manifest change of the living conditions for the couple of hundred persons strong semi-nomadic Inughuit hunting population of the district. 10.000 US construction workers and soldiers invaded the Pituffik plains across the bay from the Thule settlement (Malaurie 1956). The troops established airstrips, a gigantic pier, a Modern town, and a host of military installations (Taagholt 2002). Inughuit's interpretation of their new future as neighbours of a US military base was not clear in the first instance 
(Brøsted \& Fægteborg 1987; Malaurie 1956). The establishment of the base itself translated into a radical change in the economy of the hunting community. On the one hand, the base shut the hunters out from their main source of monetary income; hitherto, they had been hunting fox on the Pituffik plains, markets in Europe and America valued highly their skins (Petersen 1996). On the other hand, foods and a lot of other goods were suddenly available for free at the dump of the base (Gilberg 1964).

However, the Danish colonial administrators translated the presence of the base into their own pre-established narrative. This, their favourite narrative presented Denmark as the protectors of indigenous Greenlandic culture. Faced with the presence of a modern city - and its all too attractive dump (Gilberg 1964) - as next-door neighbours to what was counted as the most pristine, traditional Inuit community, the paradoxical continuation of this Danish narrative chosen was the decision (in 1953) to relocate the Thule settlement. Most of the inhabitants were to move to Qaanaaq, a summer settlement some $100 \mathrm{~km}$ to the North, not in use at the time. This relocation of the central settlement - combined with the way the base closed sleigh-routes connecting hunting grounds - translated into increasingly difficult conditions for upholding life based on hunting (Brøsted \& Fægteborg 1987).

Today, some 60 years later, the hunters at Thule translate their experience with the US base - including particularly with the alleged nuclear pollution of their hunting grounds from a 1968 crash of a B52 bomber - into an unwanted future already realised (Hastrup 2015). Meanwhile, the rationale in US security strategy for upholding the base has changed. Now, a couple of huge radars at the base is a central tool in the US program for averting the unwanted future of missile attacks from "rogue states" as well as the traditional Russian foe (Taagholt 2002). Notably, the territorial Government of Greenland has succeeded in translating this new US programme into enhanced autonomy vis-à-vis the Danish government. Pointing to the price paid by the Inughuit at Thule for Danish colonial facilitation of American military needs, the Government of Greenland negotiated enhanced foreign policy influence (Kristensen 2005). The process culminated in Greenland co-signing an amended version of the Danish-American agreement on the defense of Greenland. Increasingly, Greenlandic politicians have mobilised past colonial wrongs like those at Thule to narratively support and legitimise scenarios involving Greenlandic independence. Scenarios which, however, appear as unwanted futures in Danish discourse (Gad 2016). 
Nevertheless, the increased standing of the Government of Greenland in questions of international security has arguably not translated into better futures for the Inughuit at Thule. The radars still make for an obvious target in the event of a nuclear conflict involving the United States. The base still cuts the hunting grounds in two. And for security reasons, the facilities, communication infrastructure, and air connections of the base are largely off limits to the locals. Even if, as one qaanaarmioq exclaims, "We are not terrorists!" Only the weekly helicopter from the base brings a box of fresh fruit otherwise a rare and expensive treat in this farthest corner of the Danish kingdom. And every Christmas, an outreach/charity drive at the base helps Santa bring presents from the soldiers to the community (Gad 2017a, 2017b).

\section{Notes and References}

a This tale translates empirical material first presented in Gad, 2017a and $2017 \mathrm{~b}$ into the analytical framework of this volume. The research project was supported by the Carlsberg Foundation and fieldwork in Qaanaaq and at Thule Air Base was sponsored by Aase \& Jørgen Münter's Foundation and the US Embassy in Copenhagen.

Brøsted Jens. and Mads Fægteborg. 1987. Thule. Fangerfolk og militæranlæg, 2nd ed., Copenhagen: Akademisk.

DUPI. 1997. Grønland under den kolde krig: Dansk og amerikansk sikkerhedspolitik 1945-68. København: Dansk Udenrigspolitisk Institut.

Gad, Ulrik Pram. 2016. National Identity Politics and Postcolonial Sovereignty Games: Greenland in the margins of Europe. Copenhagen: Museum Tusculanum Publishers (Monographs on Greenland 353 [Man \& Society 43] series).

Gad, Ulrik Pram. 2017a. 'Pituffik i Praksis: Nationale reskaleringer i Avanersuaq'. Tidsskriftet Grønland 65(2): 151-169.

Gad, Ulrik Pram. 2017b. 'Sex, Løgn og Landingsbaner: Thule set relationelt'. Tidsskriftet Grønland 65(3): 216-241.

Gilberg, Aage. 1964. 'Thule - 25 år efter'. Tidsskriftet Grønland 12(6): 201-216.

Hastrup, Kirsten. 2015. Thule på Tidens Rand. Copenhagen: Lindhardt \& Ringhof.

Kristensen, Kristian Søby. 2005. 'Negotiating base rights for missile defence: The case of Thule Air Base in Greenland', in B. Heurlin and S. Rynning (eds.) Missile Defense: International, Regional and National Implications. London: Routledge.

Lidegaard, Bo. 1999. I Kongens Navn. Henrik Kaufmann i dansk diplomati 1919-58, 2nd ed., Copenhagen: Samleren.

Malaurie, Jean. 1956. The Last Kings of Thule. A Year Among the Polar Eskimos of Greenland. New York: Thomas Y. Crowell Company. 
Petersen, Klaus. 1996. 'Handelsstationen i Thule'. Tidsskriftet Grønland 44(6): 222-250.

Ross, Fredric S. and Ancker, Paul E. 1977. 'Thule Air Base'. Tidsskriftet Grønland 25(9-10): 268-278.

Taagholt, Jørgen 2002. 'Thule Air Base 50 år'. Tidsskriftet Grønland 50(2-3): 41-112.

cascading is a standard phenomenon, provided that the analyst traces the processes across continents and decades.

\subsection{What concepts of security emerge this way?}

This chapter has looked at the dynamics of translations of security across and beyond cultures. What triggers them and through what means do they take place? We have also established that the cultural mode of translations gave us two entry points: The particularistic mode, which stresses territorial separation and uniqueness; and the universalising mode, which focuses on the possibilities for improvement, progress, and future advancement. What remains is to ask what the implications are of these modes for our social and political concepts and for the practices associated with these concepts of unwanted futures?

Like in the previous chapter, this section will provide the reader with three examples of how translations of culture have given rise to new conceptual meanings of security. The first example is one of a situation in which a threat is perceived as external to an organisational culture and is met by attempts to stabilise established meanings and practices of security. The second example is a situation in which one culture meets another culture - parked by the introduction of GMOs in foodstuff - leading to negotiations and redefinitions of the core political concepts and practices of unwanted futures. Thirdly, we discuss a situation in which a culture is confronted with the impossibility of "itself": with that which seemingly renders the existence of "a culture" impossible. In this case on human rights, the example shows how universalising tendencies and, to some extent globalisation, both stabilise and destabilise a territorial and national understanding of culture in international relations.

\subsubsection{Relating to external threats}

In their famous book Cultures of Risk, Douglas and Wildawsky (1992) describe how risk perceptions of voluntary organisations rest on the existence of an outside threat, which members voluntarily gather around in order to confront. It is a culture where "security truths" are based on necessities to resist an outside, often catastrophic, threat. The examples are environmental organisations working against the destruction of the planet; religious groups 
preparing for doomsday, aid organisations fighting human disasters (famine, intrastate wars, etc.). These types of organisations are often contrasted to the hierarchical state bureaucracies, as discussed in Jonna Nyman's tale (Box 3.3). In state bureaucracies, the selection of risks to be managed are, according to Douglas and Wildavsky, not based on truisms but on a Weberian rule-based logic of rules and procedures.

Jonna Nyman's tale on energy security (Box 3.3) is a good example of the difficulties involved in using a discourse on catastrophe to change the behaviour of an established bureaucracy. In her tale, she describes how the Obama administration's concept of energy security, closely linked to the threat of climate change, did not resonate very much with the normal practices of the bureaucratic organisations involved (the US Department of Energy and State Department). Historically, bureaucracy defined security as matter of energy security, supply and energy independence and not about climate change. The issue of climate change, she shows, was difficult to unite with such traditional understandings of energy security, and the focus on climate change largely disappeared in that process of bureaucratisation. The traditional bureaucratic understandings of energy security, she argues, were preserved.

One way to read this tale is to see it as a description of an attempt to use a logic of catastrophe (climate change) to govern an issue that traditionally was defined within the logic of normal politics. In other words, the Obama call for necessity did not translate well into a rule-based organisation defined by past patterns and procedures.

\subsubsection{Clashing cultures of risk: GMOs and the meaning of precaution}

The term "cultures of risk" has become an established term in debates on risk communication and risk expertise, evoked to describe how expert traditions in different societies inflict upon the possibilities of politics. The popular examples are the many different cultural understandings of the risk of nuclear energy, of genetically modified organisms, of environmental dangers (Rayner 1992) and climate change (Kahan et al. 2010). These studies not only point to the different risk perceptions of lay people versus experts, as described in chapter 3, but also to the cultural differences between nations (Jasanoff 1993; Stirling 2007; Vogel 2012).

While most of these studies use a comparative perspective in order to expose the limits of certain cultural habits and national political systems, some also look at how differences in national cultures and risk perceptions create international political tensions due to difficulties of translation across cultures. The example of WTO and the EU-US collaboration on tariffs related to GMO crops is a striking one, as it exposes a disagreement on what can and should form the basis for risk regulation at the international level (Lee et al. 2009; Stirling 2007; Vogel 2012). One side (the United States) has consistently accused 
the EU of using the principle of precaution as a strategic weapon to reduce imports of US crops, while the EU generally sees the dispute as a matter of culturally different approaches to risk and thus an American lack of sensibility to scientific uncertainty and potential unwanted futures.

For most scholars, this debate is a prime example of how the precautionary principle has come to change the meaning of free trade. In the Rio Declaration, precautionary action was established as an approach to risk mitigation, because "where there are threats of serious or irreversible damage, lack of full scientific certainty shall not be used as a reason for postponing such measures" (UN 1992, principle 15). The emphasis on a lack of scientific evidence (uncertainty), as well as a stress on the possible catastrophic character of the threat, defined the meaning of precaution. Precaution came to request a special kind of decision-making, a macro-political planning that is based on the unknown future. In trade policies, this means that free trade can no longer be considered an exclusive political position, as scientific uncertainty about unwanted futures (precaution) became something that legitimately could override a wellestablished liberal convention.

\subsubsection{The impossibility of cultural identity: Cultural human rights}

The human rights agenda, and with that the struggle for universalised rights to privacy and individual protection, provides a good example of how the limits of culture are constantly confronted and negotiated by universalising tendencies. While this is not exactly a new debate, current concerns about data protection and surveillance have renewed its relevance in a Western context. Today's debates on privacy protection of data have, among other things, triggered a new kind of nationalism that is expected to affect the future exchange of information as well as commerce. Helle Porsdam's tale on Human Rights (Box 4.4) shows how the concept of cultural rights, as a universal human right, gets subsumed under a pluralistic understanding of culture. Rather than confronting the particularity of the international territorial order of sovereign states, the UN concept of cultural rights works to manifest the universal in the particular. As Porsdam writes, cultural rights are usually understood as universal "rights to education, to participate in cultural life, and to benefit from scientific progress," yet they are also closely linked to local cultures of origin and national identity and security. While Porsdam recognises the effect of such rights discourse, she points out how globalisation and global corporate interests might undermine such particularistic "culturification" of universal human rights. This is a good example of how the universal and the particular modes of thinking in relation to culture and security are in constant flux. The concept of cultural rights is at once universal and particular - tied to either individual or to national security - as well as constantly confronted by globalising tendencies that might after all make the concept entirely useless. 


\section{Box 4.4 The Security of Cultural Rights}

\section{Helle Porsdam}

Roughly speaking (and grossly simplifying), the historical approach means working with sources, both empirical and theoretical, which may validate or refute hypotheses about the past. It furthermore entails gathering, selecting, and analysing relevant information along with verifying the authenticity and veracity of this information and of the most pertinent collected evidence. And finally, very importantly, it means understanding ideas and cultural concepts as something that are themselves historically conditioned rather than eternally fixed. Some historians (e.g. economic historians) work empirically and quantitatively - especially in this digital age where there's more and more big data to make use of. Others (such as political historians, historians of ideas, or cultural historians such as myself) work more theoretically and qualitatively-so as to get a more detailed understanding of people's beliefs, attitudes, and values.

What does this mean for security studies? The historical approach, I argue, can work as a de-securitization instrument by clarifying difficult issues. Let me offer an example from my own research on human rights (HR). Whether we like it or not, HR has become one of the most dominant international discourses and that part of HR, which concerns cultural rights, is currently emerging as the new frontier of human rights (please see the list of referenced literature). In a globalising world, identity-related questions inherently linked to human dignity and self-respect are frequently at the root of violence and peace issues, and whereas "culture" used to come last, it is now seen as a basic component (even pillar) of political and economic development.

The right to culture in human rights law essentially concerns the celebration and protection of human creativity and knowledge. At the universal level, cultural rights are recognised in the rights to education, to participate in cultural life, and to benefit from scientific progress. Most importantly, we are talking about Article 27 of the Universal Declaration of Human Rights (1948), repeated almost verbatim in Article 15 of the International Covenant on Economic, Social and Cultural Rights (ICESCR, 1966), whose first part recognises the right of everyone:

"To take part in cultural life;

To enjoy the benefits of scientific progress and its applications;

To benefit from the protection of the moral and material interests 
resulting from any scientific, literary or artistic production of which he is the author".

Article 13 of the ICESCR, which provides for the right to education, is closely related to the right to participate in one's culture as cultural life is one of the elements that ensure the total development of the human being.

Nothing speaks more to the emerging importance of cultural rights than the 2009 appointment of a Special Rapporteur in the field of cultural rights. The areas highlighted by first Special Rapporteur Farida Shaheed as especially important are:

"The right of access to and enjoyment of cultural heritage (2011)"

"The right to enjoy the benefits of scientific progress and its applications (2012)"

"Cultural rights of women on an equal basis with men (2012)"

"The right to freedom of artistic expression and creativity (2013)"

"The writing and teaching of history-history textbooks (2013)"

"History and memory (2014)"

"Intellectual property regimes (2015)".

Among the themes that Shaheed's successor, Karima Bennoune, has focused on are these:

"The intentional destruction of cultural heritage (2016)"

"The rise of fundamentalism and extremism, in diverse forms, and their grave impact on the enjoyment of cultural rights (2017)"

"The cultural rights approach to the universality of human rights (2018)"

"The importance of public spaces for the exercise of cultural rights (2019)" 
"The situation of cultural rights defenders, human rights defenders who defend cultural rights in accordance with international standards (2020)".

UNESCO has also taken an interest in the normative content of the right to the benefits of scientific progress. One example is the 2009 Venice Statement addressing food production, advances in medicine, and IT and directly confronting intellectual property issues. Most recently, during the COVID-19 epidemic, the Committee on Economic, Social and Cultural Rights (the monitoring body of the ICESCR) issued General Comment No. 25 on Science and economic, social, and cultural rights. The General Comment opens by saying that, "the intense and rapid development of science and technology has had many benefits for the enjoyment of economic, social and cultural rights. At the same time, the risks-and the unequal distribution of these benefits and risks-have prompted a rich and growing discussion on the relationship between science and economic, social and cultural rights."

How do we make sure that people benefit from advances in medicine and information technology, and that culture becomes an enabler and driver for development? In terms of the right to enjoy the benefits of scientific progress, the global acceleration of the production of knowledge has increased the effects on human rights in both positive and negative ways. Advances in information and communication technologies have expanded opportunities for education, free speech, and trade, but have also widened the digital gap; and the relationship between human rights and science is complicated by the fact that private and non-State actors are increasingly the principal producers of scientific progress and technological advances.

Also, are cultural rights individual or collective? How do we reconcile claims of access to knowledge and culture (think of the Access-toKnowledge [A2K], open access or "free culture" movements) with the fights of indigenous groups for culture as empowerment-and both with digital responsibility? Over the past few years, intellectual property has become a major forum for discussions on identity politics - cf. that part of Article 15 of the ICESCR which talks about the "benefit from the protection of the moral and material interests resulting from any scientific, literary or artistic production of which he is the author." New claims for intellectual property are voiced in terms of identity politics, cultural survival, and human rights and these new claims for intellectual property reflect an understanding of rights not merely as incentives-for-creation, but also as tools for 
both recognition and redistribution. Something new/different is at stake here-something which is not covered by and indeed at times even conflicts with the objectives of the $\mathrm{A} 2 \mathrm{~K}$ movement: the distinctive rights of indigenous peoples and other minorities to their intangible cultural heritage.

This is truly a minefield! Activist and highly politicised efforts are underway to protect culture and cultural heritage (just think of the Greeks wanting the Elgin Marbles back from the British Museum). Many of these are insufficiently theorised and highly contested. A more scholarly approach needs to be developed to assist scholars, policymakers and civil society groups in conceptualising the place of cultural rights within the human rights system. What historians can contribute is a laying bare of empirical facts and historical contexts, of arguments and points of view what is at stake here, what are the issues, why are they so contested, and who said, thought, argued, and wrote what, when? In the best of all possible worlds, as a result of this process of working with both empirical and theoretical sources the historical approach/method can help question received truths and narratives. It can help clarify muddled issues-can work, that is, as a de-securitization instrument.

We should never forget, as the UNESCO Constitution of 1945 so forcefully reminds us that, "since wars begin in the minds of men, it is in the minds of men that the defenses of peace must be constructed; ... Ignorance of each other's ways and lives has been a common cause, throughout the history of mankind, of that suspicion and mistrust between the peoples of the world through which their differences have all too often broken into war."

\section{Notes and References}

Belder, L. and H. Porsdam (eds.) 2017. Negotiating Cultural Rights: Issues at Stake, Challenges and Recommendations. Cheltenham, UK: Edward Elgar.

Committee on Economic, Social and Cultural Rights. 2020. General comment no. 25 on science and economic, social and cultural rights (article 15 (1) (b), (2), (3) and (4) of the International Covenant on Economic, Social and Cultural Rights, E/C.12/GC/25.

Casciani, Dominic. 2012. UK pays £2.2m to settle Libyan rendition claim. BBC News, 13th December 2012. Available at: http://www.bbc.com/ news/uk-20715507. Accessed 30 June 2014

Porsdam, H. 2019. The Transforming Power of Cultural Rights: A Promising Law and Humanities Approach. New York: Cambridge University Press.

Porsdam, H. 2020. 'Linking research and human rights: The right to science', in J. Lother (ed.), Research and Human Rights. Oslo: Novus Press. 
Porsdam, H. and S. Porsdam Mann (eds.) 2021. The Right to Science: Then and Now. New York: Cambridge University Press. Forthcoming.

Porsdam Mann, S., Y. Donders, and H. Porsdam. 2020. 'Sleeping Beauty: The Right to Science as a Global Ethical Discourse'. Human Rights Quarterly, March 2020.

Porsdam Mann, S., Y. Donders, and H. Porsdam. 2021. 'The right to science in practice: A proposed test in four stages', in H. Porsdam and S. Porsdam Mann (eds.) The Right to Science: Then and Now. Cambridge and New York: Cambridge University Press. Forthcoming.

UNESCO. 2009. 'Venice statement on the right to enjoy the benefits of scientific progress and its applications'. UNESCO Experts' Meeting on the Right to Enjoy the Benefits of Scientific Progress and Its Applications, 3rd Meeting, Venice, Italy, 16-17 July 2009.

\subsection{Stakes and consequences: A negotiated rationality?}

Can we observe dissolutions of the modern distinctions that define the translation zone on culture? We can observe at least two ways in which these modern distinctions are being challenged. One is the role of the nation state and national identity, largely being challenged by a global civil society and business networks. These governance networks are not replacing governments but are increasingly relevant as social groups and corporate units outside the immediate jurisdiction of the nation state and are acknowledged as communities with international and global importance to the management of unwanted futures (see also chapter 5). Secondly, we can observe an increasing pressure on and a general disbelief in the possibility of purposeful rational action in the management of unwanted futures. As we will argue later, the entire idea of "learning" as the key to translations across cultures is challenged as the idea of purposefulness has come under pressure in today's threat discourse, characterised by dispersed and possible catastrophic threats. In this discourse on uncertainty, the means/ends rationality, the possibility of control, and the possibility of purposefully steering through a refinement of tools are fundamentally questioned.

\subsubsection{National identity - concepts of globalisation and networks}

Many political scientists have been concerned with what they see as a shift from government to governance. They not only question a future organisation based on nation states, but they observe how important policies are made outside the jurisdiction of nation state bureaucracies, in a fragmented public and private sphere (Rhodes 1996). The emphasis is on social networks, professional networks, economic and even criminal networks (Sørensen \& Torfing 2005), tightly or loosely organised policy communities. 
From the perspective of international networks, it is increasingly acknowledged that globalisation has challenged the classical understanding of civil society as tied to national cultures (Beck 2006; Castells 2008). As Beck and Castells observe, more and more civil society groups and global business have an almost paradoxical relation to the state, state governance, and policy-making. These groups and companies often draw their legitimacy by claiming to be beyond the state (in fact often by opposing or resisting state policies), constructed around global rather than national communication networks. Yet, each citizen or company is still a citizen somewhere. The term "global civil society" is an attempt to overcome the statist bias present in the concept of civil society (Bartelson 2003; Castells 2008; Kaldor 2003).

Accordingly, these global civil society groups seek their legitimacy to speak "on behalf" of some kind of (global) public ethics, and not just as part of a Western democratic order. As Corry concludes, "'global' in global civil society relates to the emergence of a global consciousness, espousing the nonparticularity or worldwide interests" (2006: 322). Thus, environmental NGOs speak on behalf of "nature," development NGO's on behalf of the "weak" and Anonymous on behalf of "privacy," and in doing so they transcend that the classical version of national belonging. In these attempts to manage unwanted futures, cultural meaning is thus not defined in terms of nation states.

Identity and culture is therefore, in these matters, no longer a matter of belonging to a nation state because you are born into it. Instead, it reaches beyond the conventional meaning of "political organisation." Castells talks about a "crisis of identity," as autonomy is no longer defined by the political identity as citizens but rather on a cultural identity detached from the state (Castells 2008: 82). Beck and Sznaider (2006) talk about new "transnational spaces and cultures of memories" (2006: 15); arguing that "Cultural perceptions and definitions at the same time draw new boundaries. Those groups, countries, cultures and states which share the same definition of a threat may be said to 'belong to it'; they form the 'inside' of a transnational risk community" (Ibid: 11). Thus, while the perception that unwanted futures are becoming global, it is not doing away with culture and organisation, nor with the particularism/ universalism distinction on which it relies. Rather, it challenges the vision of culture as something nationally, and maybe even spatially, bound.

It is in this context that we increasingly talk about hybrid actors: Those actors that are neither fully global nor entirely national. Some NGOs and large businesses are "national" in the sense that they individually refer to national law and attempt to influence state policies through lobbying (Smith \& Guarnizo 1998). On the other hand, they are also not exclusively national as their actions affect and are affected by global level interactions independently of their national affiliation, in their choices of communication, corporate policies, in choices of grassroots' activities, civil action, etc.

This development not only challenges or redefines the means associated with translations across nation states (e.g. war, intelligence, and diplomacy) but also the "cultural" means of organisations (e.g. the role of the contract sanctioned 
by law). War or diplomacy are good examples of how "negotiations on meaning" no longer take place only between nations but: as we see in, e.g. cyber security, hybrid warfare involves private actors with a different cultural and purposeful orientation than the state, e.g. social movements, organised criminals, and hacker groups. Likewise, the privatisation of intelligence might increasingly create a commercialised intelligence culture.

\subsubsection{Learning}

A second challenge to translations across cultures, defined by the differences between like organisations, is an increasing disbelief and distrust in the possibility of "learning" for the sake of progress or improvement. An increasing awareness of an uncertain, complex, and unpredictable threat environment has created a new understanding of the relation between the organisation and its environment (i.e. other organisations). Or rather, a disbelief in the ability to control, and thereby advance, through learning. As both Beck and Giddens have described, today's "risk society" or "late modernity" are characterised by an increasing "ambiguity of knowing" (Beck, 1992, 1999; Giddens 1992) or what one could see as a distrust in conventional consequentialist risk thinking. In terms of culture, we observe a doubt in the possibility of seeing cultural learning as an instrument to the management of unwanted futures. One can see that development in the current changes in risk management practices: where past approaches were based on the possibility of control and perfection through cultural learning (consequentialism), we see today an increasing focus on decision-making structures that aim to cope with uncertainty and unavoidable failures by norms of resilience (Berling \& Petersen 2020; Bourbeau 2018; Chandler 2014; Petersen 2016; Power 2007).

As a management tool, resilience accepts uncertainty, with internal control systems and emergency management being the practices mainly associated with this idea. As explained by David Chandler in his work on the concept of resilience, resilience is the acceptance of the inevitable failure and a management solution that relies on local micro managerial practices only, deifying macro (political) planning (Chandler 2014). In more concrete terms, but with similar conclusions, Michael Power argues how business contingency planning is the best available risk management alternative in a world of uncertainty, as it relies on an acceptance of uncertainty and defies the illusion of control implied in conventional approaches to enterprise risk management (Power 2009).

\section{References}

Al-Najjar, Nabil. 1996. 'Aggregation and the Law of Large Numbers in Economies with a Continuum of Agents', Discussion Paper, No. 1160, Northwestern 
University, Kellogg School of Management, Center for Mathematical Studies in Economics and Management Science, Evanston, IL.

Bartelson, Jens. 2003. 'On the redundancy of civil society', in Jan Hallenberg, Bertil Nygren and Alexa Robertson (eds.) Transitions: In Honour of Kjell Goldmann. Stockholm: Department of Political Science: 111-122.

Barth, Fredrik. 1969. 'Introduction', in Ethnic Groups and Boundaries. The Social Organization of Culture Difference. Oslo: Universitetsforlaget: 9-38.

Bauman, Zygmunt. 1991. Modernity and Ambivalence. Ithaca, NY: Cornell University Press.

Bauman, Zygmunt. 1999. Culture as Praxis. 2nd ed. London: Sage.

Beck, Ulrich. 1999. World Risk Society. Cambridge: Polity.

Beck, Ulrich. 1992. Risk Society: Towards a New Modernity. New Delhi: Sage.

Beck, Ulrich. 2006. Power in a Global Age. Cambridge: Polity.

Beck, Ulrick and Natan Sznaider. 2006. 'Unpacking Cosmopolitanism for the Social Sciences: A Research Agenda'. The British Journal of Sociology 57(1): 1-23.

Berling, Trine Villumsen and Karen Lund Petersen. 2020. 'Designing resilience for security in the Nordic region Implications for strategy', in Sebastian Larsson and Mark Rhinard (eds.) Nordic Societal Security: Convergence and Divergence. London: Routledge: 131-153.

Bourdieu, Pierre. 1979. Distinction. A Social Critique of the Judgement of Taste. New York and London: Routledge.

Bourbeau, Philippe. 2018. On Resilience: Genealogy, Logics, and World Politics. Cambridge: Cambridge University Press.

Buzan, Barry, Ole Wæver, and Jaap de Wilde. 1998. Security: A New Framework for Analysis. Boulder, CO: Lynne Rienner.

Campbell, David. 1992. Writing Security: United States Foreign Policy and the Policy of Identity. Manchester: Manchester University Press.

Castells, Manuel. 2008. 'The New Public Sphere: Global Civil Society, Communication Networks and Global Governance'. The Annals of the American Academy of Political and Social Science 616(1): 78-93.

Chandler, David. 2014. Resilience: The Governance of Complexity. New York, US: Routledge.

Corry, Olaf. 2006. 'Global Civil Society and Its Discontents'. Voluntas: International Journal of Voluntary and Nonprofit Organizations 17(4): 303-324.

Derrida, Jacques. 1982 [1972]. 'Différance', in Margins of Philosophy. Chicargo, US: University of Chicago Press, 1-28.

Douglas, Mary. 1992. Risk and Blame. New York: Routledge.

Douglas, Mary. 1996. Natural Symbols: Explorations in Cosmology. 2nd ed. London: Routledge.

Douglas, Mary and Aaron Wildavsky. 1984. Risk and Culture; an Essay on Technological and Environmental Dangers. California, US: University of California Press.

Eriksen, Thomas Hylland. 2000. 'Ethnicity and Culture: Aa Second Look', in H. Roodenburg and R. Bendix (eds.) Managing Ethnicity. Amsterdam: Het Spinhuis.

Eriksen, Thomas Hylland. 2002. 'Confessions of a Useful Idiot, or Why Culture Should Be Brought Back In'. Uppsala University. LBC Newsletter (blog). October 2002. http://folk.uio.no/geirthe/Confessions.html.

Fink, Hans. 1988. 'Et Hyperkomplekst Begreb. Kultur, Kulturbegreb Og 
Kulturrelativisme I', in H. Fink and H. Horsbøl (eds.) Kulturbegrebets Kulturhistorie. Kulturstudier, Aarhus: Aarhus Universitetsforlag, 9-23.

Gad, Ulrik Pram. 2005. Dansksprogede Grønlanderes Plads i et Grønland under Grønlandisering Og Modernisering.

Gad, Ulrik Pram. 2010. '(How) Can They Become like Us? Danish Identity Politics and the Conflicts of "Muslim Relations"'. PhD dissertation, University of Copenhagen.

Gad, Ulrik Pram. 2011. "Muslims as a Security Problem in Danish Integration Discourse: Peace, Welfare, Culture". NordEuropaForum 1: 41-72.

Gad, Ulrik Pram. 2012a. 'Concepts of Dialogue as Counterterrorism. Narrating the Self-reform of the Muslim Other'. Critical Studies on Terrorism 5(2): 159-178.

Gad, Ulrik Pram. 2012b. 'Preventing Radicalisation through Dialogue? SelfSecuritising Narratives Vs. Reflexive Conflict Dynamics'. Critical Studies on Terrorism 5(3): 391-407.

Gellner, Ernst. 1983. Nations and Nationalism. London: Basil Blackwell.

Giddens, A. 1992. 'Risk, trust, reflexivity'. in U. Beck (ed.).Risk Society: Towards a New Modernity. New Delhi: Sage.

Gusterson, Hugh. 2007. 'Anthropology and Militarism'. Annual Review of Anthropology 36: 155-175.

Hage, Ghassan 2008. 'Analysing multiculturalism today', in T. Bennett and J. Frow (eds.) The SAGE Handbook of Cultural Analysis. London: Sage.

Hansen, R.B., Ulrik Pram Gad, and Christian Madsbjerg. 1998. 'Værdien af værdier', DJØF-bladet, 16: 4-6.

Hastrup, Kirsten. 2004. Kultur. Det Fleksible Fallesskab. Aarhus: Aarhus Universitetsforlag.

Hauge, Hans. 1988. 'Begrebet culture. Fra Coleridges Kirke Til Hillis Millers Dekonstruktion', in H. Fink and H. Horsbøl (eds.) Kulturbegrebets Kulturhistorie. Kulturstudier, Aarhus: Aarhus Universitetsforlag: $24-47$.

Hofstede, Gert. 2001. Culture's Consequences: Comparing Values, Behaviors, Institutions and Organizations across Nations. 2nd ed. London: Sage Publications.

Holbraad, Martin and Morten Axel Pedersen. 2012. 'Revolutionary Securitization: An Anthropological Extension of Securitization Theory'. International Theory. https://doi.org/10.1017/S1752971912000061.

Holbraad, Martin and Morten Axel Pedersen (eds.) 2013a. Times of Security: Ethnographies of Fear, Protest and the Future. London: Routledge.

Holbraad, Martin and Morten Axel Pedersen. 2013b. 'Revolución o muerte: Selfsacrifice and the Ontology of Cuban Revolution'. Ethnos: Journal of Anthropology. http://dx.doi.org/10.1080/00141844.2013.794149

Jacobsen, Elida K. U. 2015. Unique Biometric IDs: Governmentality and Appropriation in a Digital India. Sweden: University of Gothenburg.

Jasanoff, Sheila. 1986. Risk Management and Political Culture. New York: Russell Sage Foundation.

Jasanoff, Sheila. 1993. 'Bridging the two cultures of risk analysis'. Risk Analysis 13: 123-129.

Kahan, Dan M., Hank Jenkins-Smith, and Donald Braman (2011). 'Cultural cognition of scientific consensus'. Journal of Risk Research 14: 147-174.

Kaldor, Mary. 2003. 'The Idea of Global Civil Society'. International Affairs 79(3): 583-593. 
Katzenstein, Peter J. 1996. The Culture of National Security: Norms and Identity in World Politics. New York: Columbia University Press.

Kølln, Troels. 2017. 'Frygt', Magisterbladet. 10 February, Copenhagen.

Kühle, Lene and Lasse Lindekilde. 2009. Radicalization among Young Muslims in Aarhus. Aarhus: Center for Studies in Islamism and Radicalisation.

Lee, Kelley, Devi Sridhar, and Mayur Patel. 2009. 'Bridging the divide: global governance of trade and health'. The Lancet 373: 416-422.

Lindekilde, Lasse. 2012. 'Neo-Liberal Governing of 'Radicals': Danish Radicalization Prevention Policies and Potential Iatrogenic Effects'. International Journal of Conflict and Violence 6(1): 109-125.

Luhmann, Niklas. 1977. 'Differentiation of Society'. Canadian Journal of Sociology 2(1): 29-53.

Mazover, Mark. 2008. 'Paved Intentions: Civilization and Imperialism'. World Affairs 171(2): 72-85.

Meadows, Paul. 1967. 'The metaphors of order: Towards a taxonomy of organization theory', in Llewellyn Gross (eds.) Sociological Theory: Inquiries and Paradigms. New York: Harper \& Row: 77-103.

Meyer, John W. 1981. 'Kings or People'. American Journal of Sociology 86(4): 895-899.

Petersen, Karen Lund. 2016. 'Risk and Security', in Myryam Dunn Cavelty (ed.) Routledge Handbook on Security Studies. Routledge.

Petersen, Karen Lund. 2019. 'Three Concepts of Intelligence Communication: Awareness, Advice and Co-Production'. Intelligence and National Security 34(3): 317-328.

Pieterse, Jan Nederveen. 2000. 'Europe and its others', in Luisa Passerini and Marina Nordera (eds.) Images of Europe. Working Paper (HEC 2000/5). Florence: European University Institute: 35-45.

Power, Michael. 2007. Organized Uncertainty: Designing a World of Risk Management. Oxford, New York: Oxford University Press. http://www.loc.gov/ catdir/toc/ecip0711/2007006181.html.

Power, Michael. 2009. 'The Risk Management of Nothing'. Accounting, Organizations and Society 34: 6-7.

Prince, Ruth J. 2016. 'Anthropology and empire', in John M. MacKenzie (ed.) The Encyclopedia of Empire. Chichester, UK: Wiley.

Rayner, Steve. 1992. Cultural theory and risk analysis, in Sheldon Krimsky and Dominic Golding (eds.) Social Theories of Risk. London: Praeger: 83-116.

Rhodes, Roderick A.W. 1996. 'The New Governance: Governing without Government'. Political Studies 44: 652-667.

Schein, Edgar Henry. 1990. 'Organizational Culture'. American Psychologist 45(2): 109-119.

Smircich, Linda. 1983. 'Concepts of Culture and Organizational Analysis'. Administrative Science Quarterly 28(3): 339-358.

Smith, Michael Peter and Luis Eduardo Guarnizo (eds.) 1998. Transnationalism from Below. New Brunswick, NJ: Transaction Publishers.

Sørensen, Eva and Jacob Torfing. 2005. 'Network Governance and Post-Liberal Democracy'. Administrative Theory \& Praxis 27(2): 197-237.

Stirling, Andrew. 2007. 'Risk, precaution and science: towards a more constructive policy debate'. EMBO Reports 8: 309-315.

Stritzel, Holger. 2011. 'Security: The Translation'. Security Dialogue 42(4-5): 343-355. 
Stritzel, Holger. 2014. Security in Translation: Securitization Theory and the Localization of Threat. New York: Palgrave Macmillan.

Taleb, N. N. 2007. The Black Swan: The Impact of the Highly Improbable. New York: Random House

Todorov, Tzvetan. 1982. The Conquest of America. The Question of the Other. Norman: University of Oklahoma Press.

Tomasello, Michael, et al. 1993. 'Cultural Learning'. Behavioral and Brain Sciences 16(3): 495-511.

UN. 1992. Report of the United Nations Conference on Environment and Development (Rio de Janeiro 3-14 June 1992) at https://www.un.org/en/ development/desa/population/migration/generalassembly/docs/globalcompact/A_ CONF.151_26_Vol.I_Declaration.pdf. Accessed 7th June 2021.

Valbjørn, Morten. 2008. A 'Baedeker' to IR's Cultural Journey Before, During and After the Cultural Turn - Explorations into the (Ir)Relevance of Cultural Diversity, the IR/Area Studies Nexus and Politics in an (Un)Exceptional Middle East. Aarhus: Forlaget Politica.

Vermeulen, Hans and Cora Govers. 1994. The Anthropology of Ethnicity, beyond 'Ethnic Groups and Boundaries'. Amsterdam: Het Spinhuis.

Verdery, Katherine. 1994. 'Ethnicity, nationalism, and state-making: ethnic groups and boundaries: past and future', in Vermeulen, Hans, Govers, Cora, (eds.) The Anthropology of Ethnicity: Beyond 'Ethnic Groups and Boundaries'. Amsterdam: Het Spinhuis: 33-58.

Vogel, D. (2012). 'The transatlantic shift in regulatory stringency', in The Politics of Precaution: Regulating Health, Safety, and Environmental Risks in Europe and the United States. Princeton: Princeton University Press: 1-21.

Wigen, Einar. 2018. State of Translation. Turkey in Interlingual Relations. Ann Arbor: University of Michigan Press. 


\section{Translations across scales}

When understanding translations of security, recall that we start our observations from a number of sedimented structures and organisational logics developed over time. As argued in chapter 1 we find the structures most pertinent for our purpose to be constituted by discintions based on function, segmentation, and stratification. Following this line of thought, the previous two chapters revolved around the functional differentiation between disciplines and professions, and the segmentational differentiation between cultures. In this chapter, we delve into the stratificational mode by focusing on translations across scales.

Unwanted futures appear in particular shapes in relation to distinct scales. As part of the management of an unwanted future at one scale, other scales are inscribed. In this process, the unwanted future is translated across scales. For instance, when a government find its state sovereignty threatened by an invading army, this securitization routinely translates into particularly bleak prospects for cohorts of young individuals (mostly men) drafted to serve in trenches or vehicles, more or less armoured. Such translations - whether top-down or attempts to expand a particular program for managing an unwanted future to larger scales - may succeed seamlessly; they may be accepted grudgingly; or they may meet outright resistance. Because no scales are given: Rather they are constructed. Moreover, scales are co-constructed in attempts to fixate them in specific relations to other scales. The translation of unwanted futures across scales is one important technique of fixating scalar hierarchies. This chapter thus set out to answer the basic question what happens to conceptualisations of unwanted futures when attempts are made to translate programmes for their management across scales?

As a concept, scale basically carries two distinct meanings. It is the articulation of these two meanings that makes for the concept of scale - and for the politics of scale: First, scale may refer to scope in the sense of more or less expansive spaces of encompassment; spaces of different size. The global scale is larger than the national scale which encompasses the individual scale. Second, scale may refer to hierarchy in the sense that scales order a series of levels relative to each other. The individual scale refers to the nation, not just because it is something bigger in which the individual is

DOI: $10.4324 / 9781003175247-5$ 
situated - but also because a relation of authority is upheld. Likewise, the state may be subjected to dynamics at regional or global scales, which it seems unable to escape. So what makes a scale a scale - at least in our use is that it is inscribed in partially successful projects for fixating a series of scales in relation to each other. Scales, hence, are sedimented as the result of hegemonic struggles over the fixation of meaning. Scales are co-produced in the production of knowledge, whether this knowledge presents itself as academic or governmental.

One particular scale - the one of the state - stands out in our analysis for a couple of reasons. First of all, in most parts of the world popular imagination places particular authority with the state: In states approximating the nation state ideal, many individuals identify with the state. In other states with only feeble claim to embodying one nation, the state nevertheless imposes itself on individuals inhabiting a defined territory - propped up by an international society of states bestowing the privileges and responsibilities of sovereignty on the state. Second, to some academic disciplines, this sedimented scale of authority has become pivotal for analysis: Most pertinently, international relations is founded on the very idea that states constitute the central scale of agency. In contrast, Marxist Economics - which still frame problematiques important for, i.a., human geography and international political economy - has tracked a particular conception of state (understood as particular functions in relation to capitalism) across scales. Anthropology, having arrived relatively late to the study of the state, has perhaps been able to approach the state with the least preconceived opinion. The point is that due to the sedimented discourses reproducing the scale of the sovereign state, many translations of unwanted futures depart from or are aimed at the state. And involving the state in a translation raises the stakes and makes for potential conflicts, as these translations necessarily involve the acceptance of and resistance against an authority posing as ultimate.

Our investigation starts by identifying the translation zone that draws on and challenges past logics of organisation associated with scales. What is the main form of organisation and ordering principle? Which conceptual meanings are invoked and what kind of sedimented structures do they rely on? The chapter finds that two main distinctions are fundamental for understanding the translation zone across scales. The one is vertical and revolves around translations between different higher and lower scales in terms of hierarchy. The other distinction collapses the vertical distinction and presents an alternative: The networking mode that exists independently of the hierarchical, scalar understanding. These sections draw on a number of empirical tales and observations by scholars who claim that we are currently witnessing renegotiations not just of hierarchy, but also of territoriality and belonging.

This chapter thus discusses what is at stake when an unwanted future is and it necessarily is - translated across scales as part of its management. As 
in earlier chapters, we proceed in three steps: As argued in chapter 2, a translation always entails a negotiation of certain central distinctions in its attempt to create new meanings. In relation to scale, a first major distinction defining for how new meanings are negotiated is the distinction between higher and lower scales in terms of hierarchy. Hence, the first section discusses how the sedimented structures of meaning producing these scalar practices are both challenged and upheld in today's translations of unwanted futures. Our discussion proceeds from a theoretical clarification of the concept of scale to empirical examples of translations of unwanted futures across scales, drawing - as in previous chapters - on a series of "boxed tales." Particularly, we proceed by asking: What is translated - by what means? The other defining distinction is the one between sedimented scales on the one hand, and networks defying scale and hierarchy on the other hand. In the second section, we, therefore, analyse how change and new developments can be identified as translations of unwanted futures in relation to networks "out of scale," and as dynamics resulting from such translations. This section also draws on the empirical tales submitted, and on observations by scholars who claim that we are currently witnessing the renegotiations of not just scales from the global via the national to the individual but also the relation between, on the one hand, this sedimented hierarchy of scales and, on the other, networks which seem to connect in ways defying or annulling sedimented scales. Again we ask, what is translated and by what means? Before concluding the chapter by restating the political stakes of these negotiations, we touch upon which concepts of security emerge in this negation across and beyond scales.

Overall, we observe at least two ways in which modern distinctions are being challenged in this chapter. One is the modern understanding of the individual as an easily identifiable and essential unit of analysis and legal category. From being understood as a homogeneous and sovereign unit, the individual is increasingly split in two by technological and political developments. Secondly, we observe how the territorial reach and segmentation of the scalar model is challenged by the rise of super-empowered individuals who depend on networks to be powerful.

\subsection{Negotiating hierarchies of scale}

When outlining our theoretical approach in chapter 2, we conceived of translation as something that takes place between structures of meaning. In chapter 3 , we analysed translations across professions and disciplines as functionally differentiated social structures each organised in the same way around a structure of knowledge (i.e. a sedimented constellation of meaning). Hence, translation processes were - at least partially - shaped by these sedimented bodies of meaning (e.g. by the urge to import knowledge on unwanted futures which did not fit with disciplinary structures of meaning). But at the same time, the negotiation of the delimitation of 
professional/disciplinary sovereignty over different functions of society was important. In chapter 4, we analysed the translation across cultures - understood as different structures of meaning found in functionally like units in the same vein: Knowledge on new unwanted futures were imported from "colleagues" or "neighbours" found to be in similar roles or situations and translated into the sedimented codes of one's own (national or organisational) culture. Or knowledge deemed necessary for managing on an unwanted future was sought translated from the culture of a competing or even enemy Other. All the while each organisation or nation claimed priority for their culture within their organisation or nation, some of the translation processes were marked by the way in which some cultures simultaneously claim - or were seen - to be superior to others. Hierarchies were produced, whether heralded or not.

The translation zones studied in this chapter - involving scales - are structured somewhat differently than the zone across professions and disciplines and as well as the one across cultures, in at least two ways: First and foremost, when looking for "professions" and "disciplines" as well as "cultures," one could in principle find social entities and sedimented structures of meaning which either conceive of each other as equal or even structures which the neutral observer could by some external standard conclude to be equal. In contrast, "scales" is an inherently hierarchical form of social organisation: Most basically, being a unit encompassed by something larger entails being in the lower end of a logical hierarchy: A unit is an instance of a more general phenomenon, supposedly held together by an identical relation to phenomena at other scales. However, on top of this basic hierarchy of scope, a political negotiation of the hierarchy of authority across different scales takes place: What scale is and should be the most important in terms of normative value, causal influence, and/or agency.

Second, professions, disciplines and cultures may - since based on "distinct" structures of meaning - to a certain degree understand and present themselves as self-relying and closed off to the outside. In contrast, the relation between a scale and a sedimented structure of meaning is different: Scales are produced and re-produced by what Anthropologist Anna Tsing calls "scaling projects" and "scalar ideologies." And, notably, each project and ideology - while promoting one scale as relevant - necessarily explicitly co-produces other scales and orders these different scales in hierarchies of authority. Some of these scales have - even if contingent - sedimented into relatively stable platforms for agency; most pertinently the individual, the state and the global. They are, however, constantly under pressure not only in translations across scales but also in translations beyond the most prevalent scalar sedimentation. The latter situation is the topic of section 5.2. This section 5.1 tends to translations across scales. We start with a discussion tracing the main form of organisation and ordering principles in this particular zone. 


\subsubsection{What is scale?}

Scale, as discussed in this context, comes out of physical geography, in which the concept denotes "[a] level of representation; in cartography, the ratio between map distance and distance on the ground. Geographical difference is expressed at all scales, from the inter-personal to the institutional, and from the national to the international" (Mayhew 2009). The choice of a scale in which to represent the world involves political choices and effects. As an authoritative disciplinary dictionary warns:

[P]lotting geographical information on too small a scale can conceal information which only becomes apparent at smaller scales and higher resolutions. The map of US persistent poverty purports to show poverty at county level; and shows no poverty in Oregon. The map of Oregon, beneath it, also at county level, tells a different story. (Ibid.)

However, real trouble begins when certain scales take on a life of their own. cultural anthropologist Sari Wastell has, inspired by Marilyn Strathern, explained why. Her basic observation is that the scale global:local depends upon a certain presumed but impossible meta-position, which tells us that "local really is more specific and atomistic than the impersonal and allencompassing global" (Wastell 2001: 186). The scale insists that we accept each manifestation of a local context as a constituent element of a global whole - as a subjective position in an objective reality. This insistence that the global is empirically evident makes it possible to measure it - even if this possibility only arises from an "inaccessible God's-eye view" (ibid.). Moreover, to encompass the units assigned to a scale, this scale necessarily essentialises and harmonises "its units," beginning with the individual. In a Western and uniquely modern formulation, scale imagines the individual as "a coherent and isolable whole" (ibid: 193) which takes on different roles at different, stratified scales. This essentialised and holistic individual is the starting point of the scale of social measurement which works upward through various aggregates (i.e. community to society) until it arrives at the global (ibid.).

Importantly, essentialism is not just a bi-product of scale-making; rather "[t]he essentialisms are the inevitable product of scale insofar as any act of measurement requires proportionality and ratio." (Wastell 2001: 194) Discussing the distinction between formal rule of law and informal common law, she observes that "[w]hat is the state and what is non-state must be imagined as a unified type in order to locate other similar types elsewhere in the world" at a comparable scale (Wastell 2001: 194). Finally, her claim is that essentialised constructs of difference cannot help but create hierarchies. That is to say, different units, once concretised and imagined as discrete, bounded entities, must necessarily be perceived as better or worse, more or less valuable, dominating or in need of domination. These are the requisites 
of scale: "Measurement is never simply noting difference, because the difference is not 'out there' to be noticed" (Wastell 2001: 200). Rather, difference is called into being via scale. The unity of each type of units comes not just from the units being assigned to this or that particular type. The stabilisation of each type comes from the inscription of all its units in an identical relation to one or more types of units comprising different scales.

Thus, when theorising, various social sciences have allocated some mechanisms to be active at some scale, while positioning some entities to work at some other scale. Economists practice a division of labour between microand macro; sociologists discuss how to weigh and integrate these two levels (Jepperson \& Meyer 2011; Ritzer \& Stepnisky 2014: ch. 13). Foundational to the political science discipline (including international relations as a subdiscipline) has been the division between three levels: the individual, the domestic, and the international system (Checkel 1998; Singer 1961; Waltz 1959). Within IR, a critique of this levels scheme was born in the early 1990s. An inside/outside logic permeated IR scholarship (Walker 1993) and also IR practitioners (Ashley 1984, 1988). At the domestic level, some notion of development had been conceived of as possible, whereas at the international ("system") level, change was not seen as an option. Instead, recurring patterns of enmity seemed irreversible, the argument went. This basically reproduced a world view, which excluded alternative forms of organisation and practices. While Waltz, Singer and others were correct in observing mechanisms and units at three sedimented scales, they naturalised and essentialised their existence rather than facilitating the study of their genesis and reproduction.

In human geography, a meticulous debate departing from the attempts to pinpoint the strongholds and weak spots of capitalism has gradually unravelled the social construction of scale and, thereby, identified a politics of scale (Smith 1990). A basic contribution consists in the disentanglement of three aspects of scale as employed in geography and related social sciences (Howitt 1998): Scale may refer to size or scope: Some phenomena encompass more volume than others. Scale may refer to a hierarchy of levels: Some phenomena "add up" with neighbour phenomena to contribute to something of a higher order - or in reverse: Lower order phenomena are constituted by "superior" mechanisms. Finally, and most pertinently, scale may refer to the very ordering of phenomena at distinct scales by being related to each other in terms of encompassment and hierarchy (Brenner 2001; Howitt 1998; Leitner \& Miller 2006). In this latter understanding, "multiple spatialities of scale" are produced in parallel (Brenner 2001: 606) ${ }^{1}$. Even so, "[p]rocesses of scalar structuration may crystalise into scalar fixes" which "may constrain the subsequent evolution of scalar configurations" (Brenner 2001: 606-607). We basically concur with this image: Scales are socially constituted and reconstructed with significant political effects. Certain scales have acquired significant durability in our minds and in our practices as they are sedimented along with bodies of meaning. However, scale - as all aspects 
of producing space - is "transductive", i.e. a "never-ending prospective operation" (Lefebvre 2002: 118). In other words; though scale is produced it cannot be counted on to do what it was intended to do. ${ }^{2}$ Scales, hence, remain an important analytical lens through which to observe the social world - because the social world employs scale as a way to structure and understand itself. Whether these scales have a degree of durability or show themselves to be ephemeral is in principle an empirical question (Leitner \& Miller 2006: 121-122).

Rejecting à priori assumptions about the immutability of any scale and about the primacy of one scale, our ontology of scale is akin to current projects in anthropology and sociology: First of all, scale is something you mobilise - and most often something you mobilise in the plural:

if there is one thing you cannot do in the actor's stead it is to decide where they stand on a scale going from small to big, because at every turn of their many attempts at justifying behaviour they may suddenly mobilise the whole of humanity, France, capitalism, and reason while, a minute later, they might settle for a local compromise. (Latour 2005: 184-185 quoting Boltanski \& Thevenot 2006)

In parallel, Anna Tsing lays out how globalist, regionalist, and nationalist "projects come into being as... articulations among partially hegemonic imagined different scales" (Tsing 2000: 121). Hence, "Scalar positions are self-chosen and outside imposed historically traceable projects grounded in ideologies of how to live one's life" (Neveling \& Wergin 2009: 323). However,

[n]ot all claims and commitments about scale are particularly effective. Links among varied scale-making project, can bring each project vitality and power. The specificity of these articulations and collaborations also limits the spread and play of scale-making projects, promising them only a tentative moment in a particular history. (Tsing 2000: 120)

\subsubsection{Translations across scales: from global to individual}

In this scheme, levels of different size may be articulated ranging from the planetary, the universal, the global, via the supranational, the civilisational, the continental, the (transnational) regional, the national, the state, the (subnational) regional, the "culture," the metropolitan, the urban, the local, the neighbourhood, the household, the family, and the couple to the body. But what is important is to follow how - on top of this basic hierarchy of size - a political negotiation takes place of the hierarchy of authority and causality across different scales: Each scalar project and ideology - while promoting one scale as relevant - necessarily explicitly co-produces other 
scales and orders these different scales in hierarchies of authority; in levels. In important ways, this approach is in line with the premises of securitization theory as presented in Buzan et al. (1998) and Buzan and Wæver (2009):

In principle, securitizing actors can attempt to construct anything as a referent object. In practice, however, the constraints of facilitating conditions [not least, but not only, discursive sedimentations] mean that... middle-scaled 'limited collectivities' have proved the most amenable to securitisation as durable referent-objects. (Buzan \& Wæver 2009: 255)

However, this prioritisation - well-documented empirically, backed by important yet non-determining theoretical considerations (Ibid.) - extends only to security "proper." Whether they extend to other modes of managing unwanted futures - risk, uncertainty, unsustainability, and so forth - is an empirical question. Our basic point in this chapter is that an important element in these processes of relating and prioritising of scales consist of the distribution and reinterpretation of unwanted futures: Securitizations at one scale are translated into risk calculations at another scale; attempts to make unsustainable relations sustainable at one scale translates into uncertainty about the future at another scale.

On the one hand, the translation of unwanted futures across scales is part of everyday politics: When narratives proceed from the presentation of a specific danger, risk, threat, uncertainty, or unsustainability to laying out what "we" have to do to manage the unwanted future in question, bads and goods, tasks and opportunities are necessarily distributed to units, fora and processes at various scales. On the other hand, when the distribution promoted provokes resistance, stakes are raised: What was originally promoted as a peaceful, reasonable, just, and ordinary way of managing this particular unwanted future may suddenly need firmer back-up. The scalar ordering project may find itself challenged and react by re-translating the management strategy into security-mode. Conversely, resistance might attempt to find ways to translate itself into less-securitizable modes. The result may be a hide-and-seek-like game, rather than outright confrontation. In a variety of ways, not only specific unwanted futures are translated - but also their scope may be translated - and most explosively; authority is translated across scales.

In terms of politics and security, the national scale - aka. the state level has claimed primacy in important ways which may serve as our point of departure when unfolding the translation of unwanted futures across scales. First and foremost, the state has claimed sovereignty over lesser scales, most pertinently by subjecting individuals: The Hobbesian solution to the problem of order fixed the rational individual as subject in relation to sovereignty at the state level (Edkins \& Pin-Fat 1999, Walker 1999). Foucault's analyses of discipline and governmentality can be read as accounts of how 


\section{Box 5.1 "To live on the edge is not the same as to live on the margins"}

leva Jusionyte

"Vivir al límite [to live on the edge] is not the same as vivir en el límite [to live on the margins]. Maybe a few dedicate themselves to the former. Millions of Paraguayans, Brazilians, and Argentines everyday do the latter." With this line Argentine newspaper columnist finished his opinion piece about Kathryn Bigelow's plans to make a movie about organised crime in this tri-border area of South America. Contrasting two modes of being-in-the-world, the quote complicates the translation of security from the global to the local milieu. There is a difference between the dangerous and adventurous lifestyle on the edge - Vivir al límite is the Spanish title of Hollywood director's 2008 thriller The Hurt Locker, which depicts technicians of a bomb squad working in Iraq - and the precarious existence on the margins, where those cast into social and economic periphery are haunted by the spectral presence of the neoliberal state. ${ }^{b}$ The author called his piece "The Other Triple Frontier," arguing against political and media discourses that criminalise the border region.

This article was published on 31 March 2011, on the last day of my extended fieldwork in Puerto Iguazú, a northern Argentine town, situated in the notorious "frontera caliente," the "hot border," with Brazil and Paraguay. In global and national imaginaries this region has been known as a haven of organised crime, where porous borders enable drug and human trafficking, contraband, money laundering, and other illicit activities. Since the bombing of two Israeli institutions in Buenos Aires in the 1990s, the Triple Frontier has also been linked to terrorist training and financing. After 9/11 the US government designated the region as a threat to security, including it into its global strategies and practices of "the war on terror." Official documents, such as the International Narcotics Control Strategy Report and Country Reports on Terrorism, annually prepared by the Department of State, repeatedly assert that the tri-border area is "an important regional nexus" of arms, narcotics, and human trafficking, counterfeiting, pirated goods, and money laundering - "all potential funding sources for terrorist organisations." Included in the global security regime, the region became the target of militarisation and surveillance, and, under pressure from the US, the Argentine government began implementing rigorous migration control and customs inspection, thereby limiting informal cross-border exchanges, traditional source of livelihood for the local community. 
Between 2008 and 2014 I conducted ethnographic research in the Triple Frontier, trying to understand what role journalists, embedded within particular social settings, play in translating - mediating, reinterpreting, and adapting - global security to make it meaningful on the local scale. Rather than copying and pasting the security paradigm, centred on global threats of international organised crime and terrorism, the media in the triborder region tactically used parody and conspiracy theories to challenge it. For example, when the US media networks talked about an alleged Osama Bin Laden's visit to the Triple Frontier, a local Brazilian newspaper ridiculed these accusations by turning Bin Laden into a poster boy in a series of advertisements promoting tourism to the waterfalls: "If Bin Laden risked his neck to visit Foz de Iguazú, it must be worth it." In 2010, to discuss the popular vilification of the region, Argentine, Brazilian, and Paraguayan journalist associations organised a tri-national meeting. Calling terrorism threat in the border area nothing more than a myth, they challenged the geography of blame, re-locating responsibility for trafficking and contraband on state policies that disadvantage the remote region and discriminate against its residents. Journalists even argued for a redefinition of the term "terrorism," invoking the memory of state terrorism under Plan Condor and suggesting the concept of "social terrorism," to emphasise the structural quality of violence on the border. Off the record, conspiracy theories were also widespread: Many accused the US government of securitizing the region in order to take control of the Guaraní Aquifer, one of the largest fresh water reservoirs in the world. ${ }^{e}$

A young reporter, when I asked whether she felt safe in the Triple Frontier, said: "I live in Iguazú and I see that people here are peaceful. I don't see armed traffickers around the corner, as everyone imagines. They think that here, in Iguazú, we live in trenches." Journalists emphasise that Iguazú is a safe place, which they chose to be their home after experiencing violent crime, from robberies to assaults, in metropolitan areas. Iguazúenses often use the heavy presence of law enforcement national gendarmerie, naval prefecture, army, federal and provincial police, and even armed park rangers - as evidence of security. But they also acknowledge that "pueblo chico" can be "infierno grande" [small town, big hell]. By means of corruption and impunity, organised crime is so well "organised" that it rarely affects residents randomly. To further minimise risks to their individual safety, journalists do not report on many illegal activities, which are protected by the law of silence, thus becoming complicit with contraband and corruption. Despite their jobs in newsmaking, journalists are also residents of their communities; therefore, their 
media stories are shaped by their daily experiences of living in a marginalised corner of the state. For them, security has a different meaning, which one Iguazúense articulated in the following way:

Robberies or problems with drugs are not the only means to measure security. Insecurity means people don't have a home, their basic needs are not met, people don't have what to eat, people don't have access to education. ... They think that a hundred thousand more soldiers [and] more forces in the streets will make me feel more secure. No. If I continue to have no power [and] no water, what security are we talking about? ... I feel secure when my neighbour feels secure.

On the local scale, the discourse of terror threat is juxtaposed to people's experiences of structural inequality, poverty, and corruption that characterise their daily lives on the margins of the state, where security is tightly linked to economic and social well-being. Local journalists act as intermediaries between different scales of making security, using news tactically to reinterpret and reconstitute spectacular narratives of global threats within the local setting of a small border town, where people are equally concerned with governmental neglect and invested in protecting the image of their hometown as a safe place.

\section{Notes and References}

a Martín Granovsky, "La otra Triple Frontera." Página/12, March 31, 2011.

b Here I am referring to Daniel Goldstein's concept of the "phantom state" and his discussion of its spectral presence in communities situated on the margins of the law. See Outlawed: Between Security and Rights in a Bolivian City (Duke University Press, 2012).

c Country Reports on Terrorism 2013. U.S. Department of State. April 2014. [http://www.state.gov/documents/organization/225045.pdf].

d Osama en las cataratas? BBC Mundo, April 16, 2004. [http:// news.bbc.co.uk/hi/spanish/misc/newsid_3632000/3632283.stm] See also John Tofik Karam, "Crossing the Americas: The U.S. War on Terror and Arab Cross-Border Mobilisations in a South American Frontier Region" (Comparative Studies of South Asia, Africa and the Middle East 31(2): 251-266, 2011).

e For more on conspiracy theories regarding U.S. interests in the aquifer, see Carmen Ferradás, "Environment, Security, and Terrorism in the Trinational Frontier of the Southern Cone" (Identities-Global Studies in Culture and Power 11(3): 417-442, 2004).

Country Reports on Terrorism. 2013. US Department of State. April 2014. http://www.state.gov/documents/organisation/225045.pdf.

Ferradás, Carmen. 2004. 'Environment, Security, and Terrorism in the Trinational Frontier of the Southern Cone'. Identities-Global Studies in Culture and Power, 11: 417-442 10.1080/10702890490493563. 
Granovsky, Martín. March 2011. 'La otra Triple Frontera'. Página/12. http:// www.pagina12.com.ar/diario/elpais/1-165237-2011-03-31.html

Goldstein, Daniel. 2012. Outlawed: Between Security and Rights in a Bolivian City. Duke University Press.

Karam, John Tofik. 2011. 'Crossing the Americas: The U.S. War on Terror and Arab Cross-Border Mobilizations in a South American Frontier Region'. Comparative Studies of South Asia, Africa and the Middle East 31: 251-266.

unwanted futures identified at/by a societal/national/state scale are translated to individuals. Eugene Weber analysed how specific institutions primary education; military draft - of the embryonic nation state turned "Peasants into Frenchmen" and hence translated unwanted futures envisioned for the state (disloyal subjects; attacks from neighbouring massarmies) into futures not attractive to individuals (potential for those who did not comply with compulsory education; realised for those who did comply with mandatory soldiering).

Another way in which this nationalist project is visible today is in the translation of state-level security to local scale insecurity. Jusionyte begins her account (in Box 5.1) of translations of security in the Triborder area by describing how Argentina, Brasil, and Paraguay create security for their respective state sovereignties by rescaling the threats of organised crime and terrorism to the local level in a way which is typical: By pushing insecurity to

\section{Box 5.2 Translating emergency in Alaska}

\section{Frank Sejersen}

The last decades, the Arctic has been brought into our attention in new ways. It has become a place of extreme physical transformation set in motion by rising temperatures. This transformation has produced a new landscape of risk. One could say that, due to climate change, the Arctic has become an intense and compact scene of translation and for scaling local-global relations and to conceptualise causalities of complex systems and the concept of risk itself. Consequently, the region has also increasingly become a scene or arena for meetings of different systems of meaning where the "unwanted future" is negotiated. These meetings may be structured on different ways of understanding time and risk. In some cases, the focus of meetings is on long-term security 
issues and based on the invocation of scenarios while in other cases, the emergency is immanent. But even in the latter cases, the problems of translation place parties in situations of predicament. For the Inuit in general, the melting and transforming Arctic is a complex matter. For some groups the changing weather and ice-scape hinder safe access to resources and reliable forecasting. Seen from the point of view of Inuit, the states' conceptions of security do not always match their concerns related to community priorities, well-being and development. And "the environment" may have a totally different meaning in Inuit thinking about security when compared to dominant state discourses. The security claims of Inuit is a constant reminder that any security talk is political and ideologically saturated. Inuit are, for example, still struggling to have their particular experiences of environmental insecurity understood (Harrington \& Lecavalier 2011: 111) and in fact some of the state's security programs may destabilise Inuit communities. For other Inuit groups, the environmental changes have offered them possibilities to pursue new opportunities. In Greenland, for example, the regional authorities see climate change as facilitating new economic opportunities in the shape of mining, oil and gas development.

The problems of Kivalina, a small Alaskan village, are illustrative of some of the problems related to translations of security. The Inuit inhabitants are fighting a particular climate change-related problem and have become known world-wide due the predicament they find themselves in. Kivalina is a small community of around 400 Inuit. Their village is located on a slim peninsular. It was established by the state authorities, more than hundred years ago. Today, destructive storms and waves coming in from the Chukchi Sea are devouring the coastline, and with an accelerating force, because the protective sea ice has disappeared due to global warming. Studies warn that the village could submerge within a couple of decades. Kivalina thus exists in a state of imminent danger and risk. Seen from Kivalina, the risk posed by erosion is a security issue for the community. For the state of Alaska the situation is also troublesome. It has been estimated that a relocation of Kivalina may cost as much as $\$ 100$ million. In Alaska 184 out of 213 native villages are affected by flooding and coastal erosion. Therefore, the economic, political, and technical burden put on the shoulders of the authorities are enormous. This may be one of the reasons why the authorities are reluctant to initiate relocation of Kivalina. Instead, the military has tried their best to protect the village by installing constructions to guard the houses from the sea. But the solution cannot be 
permanent. The village has to move. So apart from the obvious but difficult questions that follow in the wake of such a move like how to talk about it, how to find funding, where to move, who to coordinate it and when to do it, a more important question emerges: Whom to become? However, this question has little place in the arenas set up for negotiating the solutions.

The authorities primarily translate the risk and disaster in technical terms which is also reflected in the suggested solutions centred on the construction of barriers of sandbags and stones. Furthermore, most disaster and emergency programs are handled by military contractors, which according to Christine Shearer (2011) is fuelled by the "disaster myth." This myth subscribes to a particular understanding of a disaster, where citizens are believed to act in panic and social order will break down. Top-down authoritarian intervention and control is perceived to be the solution, leaving community-driven initiatives in the shadow. When Kivalina was officially declared a disaster area, federal emergency programs provided funding for sandbags and stonewalls. Since the village voted in favour of relocation in 1992, the inhabitants have been struggling to find government assistance and funds and are struggling to find their way around state bureaucracy in order to get relocated. The URS corporation which was contracted to relocate the village suggested Tatchim Isau as a suitable place for a new village because it was considered cheap and good for construction. For the inhabitants of Kivalina it was a place bad for living and far away from the areas they use for hunting. A controversy over whose knowledge and priorities emerged as the technical paradigm dominated the site for translation of security. In order to create a new arena suitable for translation their security concerns, Kivalina and a group of lawyers filed a public nuisance lawsuit against fossil fuel companies because Kivalina was of the opinion that the industry was doing public harm caused by their products. Not only did this lawsuit translate and scale the problem in a totally new direction, it also showed that the "unwanted future" could not be considered a result of a natural disaster but rather by a socionatural event, where problems and solutions were deeply enmeshed in politics and colonial legacies.

For inhabitants of Kivalina the usual question of "how to deal with the risks of climate change" is exchanged with the question of "whom to become when dealing with the risks of climate change" (Sejersen 2012). The point of departure is that the question "whom to become" is 
tantamount to thinking of communities on another scale and to creating new images of social life. The reports, programs, and strategies which constitute the primary arena for this difficult process of translation of how to perceive, approach, and deal with the "unwanted future" seem to be inadequate to embrace the community's own security interpretations. When they filed a lawsuit is was a way to carve out a new arena for translation.

\section{Notes and References}

Harrington, Cameron and Emma Lecavalier. 2011. 'The environment and emancipation in critical security studies: the case of the Canadian Arctic'. Critical Studies on Security 2(1): 105-19.

Sejersen, Frank. 2012. 'Mobility, climate change, and social dynamics in the Arctic: The creation of new horizons of expectation and the role of community'. In Hastrup and Olwig (eds.) Climate Change and Human Mobility. Global Challenges to the Social Sciences. Cambridge: Cambridge University Press: 190-213.

Shearer, Christine. 2011. Kivalina: A Climate Change Story. Chicago: Haymarket Books.

the borders. The means of translation are also typical: Deployment of heavily armed manpower. This, moreover, translates into unwanted futures for the locals, however in Jusionyte's account, the locals do not portray the presence of neither criminals nor security personnel as security threats as such. Rather they protest the bleak prospects of economic prosperity stemming from the area being depicted as insecure and threatening, and from such a huge proportion of the sparse resources allocated to the area channelled into measures meant to produce security for the state (rather than for the locals). In contrast, Sejersen's tale about Kivalina (included in Box 5.2) is - in the first instance - about the troubles of a village facing the unwanted future of being eradicated by erosion caused by climate change; the troubles of translating this very bad, but also very local future: Translating it into something which actors at other scales are willing to act upon - in a way which translates back into a future which the community may interpret as less un-inhabitable.

The privilege placed on the nation/state scale is not just affirmed in relation to scales re-produced as smaller and lower-leveled. Nation state programmes for managing unwanted futures are also projected to larger, "higher-leveled" scales. Wæver and Buzan (in Box 5.3) exemplify how universalist ideologies may be presented as threatened when not adhered to beyond the confines of their promoters. This tale also explains the conflictual side-effects involved in a project for expansive re-scaling of a 


\section{Box 5.3 Conflicting universalisms}

\section{Ole Wæver and Barry Buzan ${ }^{\text {a }}$}

The Crusades as well as the opposition between monarchy and republicanism are examples of universalist beliefs that created macrosecuritizations extending beyond the nation state scale.

However, the Cold War represents one of the clearest examples of how nation state programmes for managing unwanted futures are projected to larger and "higher-leveled" scales. In the Cold War constellation, both the US and the Soviet Union promoted universalist ideologies that were both inclusive in nature. As such they were ideological beliefs about the best way to optimise the human condition, universalist in the sense that they claimed to be directly and immediately applicable to all of humankind. The ideologies were pitted against each other in a zero-sum competition for dominance on the global scale. The Cold War constellation was upheld through a mutual macrosecuritization of the Other, where each ideology was presented as threatened because it was not adhered to universally. The securitizations thus defended each superpower's claim to own the future of humankind. Each universalism posited a deep similarity within its sphere and deep difference with the Other.

Key to understanding the stability of the Cold War constellation is how the universalist ideologies spoke not only to the core identities of the two nation states but also found resonance on a larger scale with elites as well as masses in the wider audiences of the West and the socialist world. Watchwords like "democracy," "freedom," and "socialism" were played not only to the domestic audiences in the nation state but also to a much wider international audience. The values connected to these watchwords facilitated an intersubjective sense of threat and the fact that the values were articulated as mutually exclusive meant that a strength and depth of securitization, comparable to national security, could be created across a wider scale.

The Cold War was notable for being a clash between two inclusive universalisms. However, history is replete with examples of imperial exclusivisms making claims to superior rights and status for one group over the rest. The French and British empires, the US doctrine of manifest destiny, the Japanese drive for a "Greater East-Asia Co-Prosperity Sphere" as well as the Nazi theories of the master race all rested on exclusive claims. However, even without such an explicit vision of superiority, a position can develop where the needs of the Self are articulated as overriding the rights of Others. Germany (or France or Russia or...) could 
only be secure if they could gain hegemony over Europe; the US can only be secure if the world is safe for its version of democracy and capitalism; Israel can only be secure when it has killed all "terrorists," and so forth.

The $20^{\text {th }}$ century is an illustrative example of how conflictual it is to posit expansionist or universalist claims on a global scale. The First World War played out as a clash amongst a set of exclusive hierarchical great power identities battling for hegemony. Likewise, the Second World War featured another range of hierarchical exclusivist identities (Britain, France, Germany, Italy, Japan) along with two inclusive universalist ones (American liberalism and Soviet communism) that later played out in rivalry during the Cold War. Expansive re-scalings such as these are thus likely to meet resistance when confronted with alternative expansionist or universalist projects, a recipe ripe for mutual macrosecuritizations and creation of large-scale constellations such as the Cold War.

The only way for expansionist or universalist claims to reach stability is if they succeed in dominating the whole of the international system. There are a few examples of such occurrences in the ancient and classical times; the Roman and Chinese empires as well as the Incas, where a single polity and culture came to rule a known world over a substantial period. Such a level of stability has not been achieved in modern times. Even the closest contestant, in the form of the liberal market democracy projected by the West, remains heavily contested in the Global South. It has even resulted in a counter-securitization, where a unipolar world order led by the US is constructed as a threat to other great power and to smaller powers fearing to become the object of such a project.

While the re-scaling can involve universalist claims, it does not necessarily mean that they are universal in terms of participation. If the claim requires an earthly Other as a threat, there is an inherent self-limiting quality to the claim that means that such beliefs cannot reach a planetary scale. Centrally, inclusive and exclusive universalisms are challenged because they generate a threat too like themselves (ideology against ideology, superpower against superpower). It is, however, possible for some universalisms to achieve stability if the threat is a different entity from themselves. For physical threat universalisms such as the ones designating global warming, diseases or the planetary impact of asteroids as threats to the entire humankind, it is possible to reach a universal scale. This is also more likely for existing order universalisms such as the Global War on Terror. This war generates a constellation where $99.9 \%$ of the global population organised in sovereign nation states is pitted against the non-state terrorists, making stability on the global scale much more likely. 
History presents us with a wealth of examples, from the realm of the Incas to the Global War on Terror, of how nation state programmes for managing unwanted futures have undergone an expansive re-scaling in making universalist claims, more often than not resulting in conflictual constellations on the global scene when confronted with alternative expansionist or universalist projects.

\section{Notes and References}

a Based on Buzan and Wæver, 2009

Buzan, Barry and Ole Wæver. 2009. 'Macrosecuritisation and Security Constellations: Reconsidering Scale in Securitisation Theory'. Review of International Studies 35(2): 253-76. https://doi.org/10.1017/S02602105 09008511.

programme for managing an unwanted future is likely to meet resistance when confronted with alternative expansionist (or even universalist projects), spiralling into escalation. With this in mind, Holbraad's tale in Box 4.2 can be re-read as a matter of scale-making rather than a clash of culture: The liberal anthropologist going to revolutionary Cuba ends in rough and tumble, not just because two different cultures meet. Conflict arises mainly because one of the ideologies involved - the liberal - is universalist. As discussed in chapter 4, liberalism understands itself to be the yardstick against which other ideologies should be measured - and the goal towards which all would strive, if not dominated, distracted, or blindfolded into preferring other values. Communism, of course, has a long and glorious history, ending abruptly in 1989, as the main challenger to liberalism for universal validity. Cuba, famously, employed Che Guevarra to support its claim in anti-colonialist struggles on three continents. But from Holbraad's tale, it seems that the Cuban revolution has relinquished its universalist even its expansive - pretensions and retracted to a defensive position.

Interestingly in this regard, in line with Chakrabarty's call for a "provincialization of Europe" (2000), anthropologists (Holbraad \& Pedersen 2008) abstract from Strathern's work an ambition of comparing - i.a., between Melanesian and European ways - without elevating one of the two to a universally valid, "neutral" scale: Whereas "for scales to be able to measure things they have to be more abstract than them." (Holbraad \& Pedersen 2008: 378). They advocate that "the very distinction between scales and things is obliterated" (Holbraad \& Pedersen 2008: 378), with a view to allowing "comparisons [to be] things that act as their own scales - things that scale and thus compare themselves" (Holbraad \& Pedersen 2008: 375). This line of reasoning 
makes a lot of sense for a research strategy guided by a normative aim of denaturalizing one's own mode of being. In that sense, it would be applicable to the International Relations discipline. However, it would not necessarily assist our attempt to understand current translations of unwanted futures. We observe trends in the translations across scales (and cultures - in chapter 4) and find that some scales and universalising projects indeed pose as yardsticks for others to follow.

Unwanted futures envisioned at one scale may also be used to promote the priority of wholly new scales. The very attention given to scale in human geography has turned from efforts to identify the scales on which central, objective mechanisms of capitalism (threatening the livelihood of the masses) are situated, to the ideological production of threats to national economies promoting the global as the decisive (and irrefutable) scale determining that: there is no alternative. Likewise, climate change and its consequences in the Arctic are generally interpreted as an unwanted future in relation to most scales (global climate, regional species, local stocks, household livelihood). But as noted by Sejersen (in Box 5.2), a proto-national Greenlandic scale is being carved out as a possible winner when the thaw comes: When the prospects of ice melting - in the Arctic Ocean, on the Greenland Ice Cap, on the thin rim of land along the shores of the great island - are translated to the national narrative, it is used to conjure up new possibilities for resource extraction, cultivation, hydro-electric industries and, ultimately, sovereign independence ( $\mathrm{Gad} \&$ Strandsbjerg 2019). Table 5.1 summarizes our characteristique of the translation zone across scales in terms parallel to the tables in chapter 3 and 4 summarizing translation zones across disciplines and cultures.

Table 5.1 Translations across scales

\begin{tabular}{|c|c|c|c|c|}
\hline Unit & Distinction & Basis of authority & $\begin{array}{l}\text { Means of } \\
\text { translation }\end{array}$ & $\begin{array}{l}\text { Relation to } \\
\text { state }\end{array}$ \\
\hline $\begin{array}{l}\text { Scale: distinct } \\
\text { from other } \\
\text { scales }\end{array}$ & $\begin{array}{c}\text { Reach or } \\
\text { depth }\end{array}$ & $\begin{array}{l}\text { Causal } \\
\text { significance; } \\
\text { Authority; } \\
\text { Order }\end{array}$ & $\begin{array}{l}\text { Equality; } \\
\text { Implementatio- } \\
\text { n; Narration of } \\
\text { hierarchy; } \\
\text { Dependence; } \\
\text { Derivation }\end{array}$ & $\begin{array}{l}\text { Produces/ } \\
\text { privileges } \\
\text { state }\end{array}$ \\
\hline
\end{tabular}

\subsection{Translations beyond scales: the power of networks}

Today, the authority of institutions at the individual, the national, and the supranational scale is challenged - not just by projects for prioritising other scales but even more challenging: By social structures and phenomena not easily analysed (let alone governed!) at any known, sedimented scale. To take an example, the existence of technologically empowered cyber networks and 
internet-based social networks constantly challenges the neat demarcation between the individual level, the state level and the transnational/international level, thereby imploding both the meaning of scale understood as encompassment or scope and the material translation of a scale into territory. The traditionally tight connection demarcating a certain territory as falling under the jurisdiction of a particular state (the sovereign state as both an authoritative political level and a territorial container) is fundamentally challenged by these de-territorialised networks which spread unevenly through geographical and hierarchical terrain. The image of a Russian doll of scales - one encapsulating the other - is replaced with a web of relations crisscrossing and encircling the hierarchised and territorial sedimentation of scales.

\subsubsection{Dynamics of re-scaling networks}

The "folds" and "twists" (Allen 2011: 295) which these networks insert into the sedimented, scaled social reality challenge the different scales as geometrical, vertical, and topographical by inserting more fluid concepts of intensity and compression (Allen 2011), dispersion and connectivity (Brenner 2001: 597). That which is far away becomes near; that which seems weak becomes powerful. This world cannot be "subsumed under a spatial geometry that assumes a world of scalar integrity, measured connections and effortless reach. The spatial metrics no longer, if they ever did, simply add up" (Allen 2011: 294).

The workings of social networks are not captured by us as analysts nor by the projects trying to discipline the networks in practice if we insist on scales as the primary way of addressing and countering them.

[W] hat comes to the fore is less the extension of power "upwards," "downwards" or "sideways" and rather more of an interplay between all the different institutional interests and authorities involved where agendas are mediated for specific political ends through a mix of distanciated and proximate actors. (Allen 2011: 291)

Some authors have concluded that the concept of scale should be eliminated from analysis since it is both theoretically unclear beyond repair and inherently harbours politically conservative effects. Rather, they suggest that one employ a "flat ontology" arguing that they follow Latour on this (Marston, Jones \& Woodward 2005). However, according to Latour, flatness "is not a description of the world" (Leitner \& Miller 2006: 121, quoting Holifield 2006: 15-16). Rather, flatness is the default position of the observer, not identical to the claim that the world of the actors has been flattened out. The image of flatness was merely a way for ANT observers to clearly distinguish their job from the labour of "those they follow around" (Latour 2005: 220). Faced with the sudden shifts of scale and connections spanning not only hierarchically across scales but also horizontally within scales, the only possible solution for the analyst is, therefore, to turn to the 
empirical data - "letting society be ahead of us instead of behind us" (ibid: 108). Methodologically and epistemologically speaking, this means that the world is flat until we study it and determine the topography and sedimentation of it. This new topography will allow us to understand how networks essentially challenge/negate/render obsolete scalar disciplining.

Importantly, this plasticity of the networks should not be mistaken for a lack of power. By working outside of/across/crisscrossing the received wisdom of how to perceive of the social, social networks act as the negation of these and thereby as an issue which escapes normal routines for handling them, and for handling the unwanted futures they might bring about. Social movement strategies draw on and are interleaved with diverse spatialities - networks of spatial connectivity, mobility, place, as well as scale - which means that they prevent contestations from being contained spatially (Leitner \& Miller 2006: 122). In other words, while the unwanted futures, which sedimented, scaled identities face in the form of cyber networks, production chains, and intelligence (and other knowledge producing) networks might be conceived of only as being of the "global" or transnational scale this does not capture the issue in its entirety. Instead, their uneven spread across the globe - and across any territory or social entity delimited at a lesser scale - challenges the scalar analysis in itself and makes the pinpointing of the right level next to impossible. Relatedly, scalar government/disciplining becomes increasingly difficult, and tougher measures to counter the networks are set up as a result. Simply because they exercise powers of reach that enable them to be more or less present within and across structures, regardless of their actual physical location or distance from each other (Allen 2011: 286). In Austin's tale in Box 4.1, you might say that the networked phenomenon of torture had implications at all levels and at the same time produces even worse unwanted futures with an impact on future policies, torture expertise, and the international system. This makes networks a specific challenge for the classical actors. By largely embodying scale-jumping and de-territorialised practices, the networks are immensely difficult to grasp, fixate, and discipline.

\subsubsection{Translations across scales and networks}

Terrorist networks may be mobilised by involving an unwanted future understood at one scale (threats against the holy land, against a certain identity or religion (Buzan \& Wæver 2003; 2009: 255-256) or against the commerce or "way of life" of a metropole) but are translated not only to an aggregate international level nor only to an individual level but to an essentially multi-scalar phenomenon. By knitting together, e.g. individuals, transnational companies, armed forces, and identities (at a middle scale between state and the global level, e.g. civilisation, ideology) the network functions in particular ways which essentially defy scalar disciplining. It builds its own topography, so to speak. From our perspective, then, the networks that produce, constitute, or protest against a perceived unwanted future challenge not only scales understood as 
scope and hierarchy but also the very demarcation of the state as a container of territory and authority and thereby the scalar view of the world in its entirety.

Jonathan Austin (Box 4.1) describes a networked unwanted future - "a ticking terrorist threat" - which was translated from being an American issue of counterterrorism in Guantanamo Bay to being a matter of transnational state cooperation (on torture expertise) with Middle Eastern countries and later an even "worse unwanted future" by changing the self-understanding of the democratic "us" and "our democratic constitution" through an "intimate entanglement of different security cultures or cosmologies." In the process, individual bodies were inscribed and changed through pain, unclear jurisdiction practices and the enrolment of amorphous physical space (where was I taken, who is charging me of what?) and hierarchies of world politics were transformed: The cooperating Middle Eastern states were not just clients: "They could make demands, and they did." The unwanted future was thereby not only addressed as a matter at the state level but inscribed both lower and higher levels while at the same time drawing new lines between professionals and amateurs of torture. The end result was a change in - or at least a challenge to 1) the understanding of Western ideals, 2) individual lives and bodies (the interrogated terrorists), and 3) the configuration of the international system. So, the terrorist network had remarkable effects beyond its own reach on a series of scales, on identity-related aspects, and also on the configuration of certain forms of expertise. The network thus defies the classical prisms for understanding scales exactly by mixing them and destroying them, thereby making "that which is without definite contours" (Allen 2011: 20; Latham 2011) a more adequate description of "the crosscutting mix of distanciated and proximate actions" (Coleman 2011: 309) which make up networks. ${ }^{3}$

At the same time, however, to take another example, social movements target scales through an analysis of a scaled reality in order to determine what is the most effective scale for organising resistance, and often reach the conclusion that a coordinated multi-scalar politics is the most effective response (Leitner \& Miller 2006: 121). For instance, studies of social movements working against neoliberal governance have argued that the movements trace neoliberal structures to a variety of scales, and connections to extra-local sources, channels and agents of neoliberalisation, and use this analysis to seek out terrains and targets for effective resistance (Leitner et al. 2007). Neoliberalism - producing futures not wanted by these resistance movements - is thus sought countered by strategically mapping the scales on which its presence and effects are most felt, and subsequently tailoring resistance based on this mapping. The analysis of the different levels involved and the workings of the networks in response to this are thus important for understanding unwanted futures across scales and networks. In the process, a number of threats are countered, created, and circumvented, whether it be the threat of terrorism, or the networked attempts to resist neoliberal market control of civil society and individuals by social movements such as "Occupy" activists. Table 5.2 summarizes our characteristique of the translation zone between scales and networks out of scale. 
Table 5.2 Translation zone between scales and networks

\begin{tabular}{|c|c|c|c|c|c|}
\hline $\begin{array}{l}\text { Challenge to } \\
\text { scalar unit }\end{array}$ & Distinction & $\begin{array}{l}\text { Basis of } \\
\text { authority }\end{array}$ & $\begin{array}{l}\text { Means of } \\
\text { translation }\end{array}$ & $\begin{array}{l}\text { Relation to } \\
\text { state }\end{array}$ & $\begin{array}{l}\text { Relation to } \\
\text { knowledge }\end{array}$ \\
\hline $\begin{array}{l}\text { Network: } \\
\quad \text { distinct } \\
\text { from } \\
\text { scaling }\end{array}$ & $\begin{array}{l}\text { Orientation: } \\
\text { (hierarch- } \\
\text { ical vs. } \\
\text { lateral) }\end{array}$ & $\begin{array}{l}\text { Causal } \\
\text { signifi- } \\
\text { cance; } \\
\text { Normative } \\
\text { valuation }\end{array}$ & $\begin{array}{l}\text { Law; } \\
\text { Discipline; } \\
\text { Intelligenc- } \\
\text { e; Policing } \\
\text { vs. } \\
\text { Resistance } \\
\text { (voicing, } \\
\text { hiding); } \\
\text { Digitalisati- } \\
\text { on; } \\
\text { Globalisati- } \\
\text { on; } \\
\text { Terrorism }\end{array}$ & $\begin{array}{l}\text { Undermines } \\
\text { state } \\
\text { sovereignty }\end{array}$ & $\begin{array}{c}\text { Undermines } \\
\text { authorised } \\
\text { expertise }\end{array}$ \\
\hline
\end{tabular}

\subsection{Translations by what means?}

A number of means in the translation zone across scales revolve around lawmaking at the local, the state, and the international level. Some of the means we saw in the chapter on cultures also apply: War and diplomacy would act as means to keeping the state at its privileged position on the scalar hierarchy. A number of physical objects, technologies and concepts are, however, also involved in the translations across and beyond scales as what we call means: Physical objects, $\mathrm{CO}_{2}$, official text, identity politics, parody, images, algorithms, and more.

Physical objects may play an important role in translating unwanted futures across scales. Fridlund (in Box 5.4) provides a cookbook example of the successful assertion of an official, national interpretation of an unwanted future on individuals and families: When preparing for what would be known as the Second World War, the British authorities distributed gasmasks to all metropolitan citizens. Carrying around - or suddenly realising that one had forgotten - the little cardboard box containing the mask, worked as a constant, bodily reminder of the (official interpretation of an) immediate security threat.

Somewhat similar, Nisha Shah shows (box 3.8) how physical objects, displayed in a war museum, come to create certain understandings of appropriateness in war. 


\section{Box 5.4 Securitizing things: Recovering a lost material history of the fear of the next war}

\section{Mats Fridlund ${ }^{a}$}

This thing history recovers a lost - but in the interwar years widely present - security sensibility: The fear that the next war would come as a sudden and intense air assault with gas bombs on big cities (Titmuss 1950, 10, 21). Will Irwin's book The Next War: An Appeal to Common Sense (1921) summarised it:

Here is a projectile - the bomb-carrying aeroplane - of unprecedented size and almost unlimited range; here is a killing instrument - gas - of a power beyond the dream of a madman; here is a scheme of warfare which inevitably draws those who were hitherto regarded as non-combatants into the category of fair game.... In "the next war," this gas-bombardment of capitals and great towns is not only a possibility but a strong probability - almost a certainty (Irwin 1921: 43, 45-46).

This fear bred an "air-raid phobia" among British authorities who during the 1938 Munich Crisis began offering gas masks to all civilians (Lee 2003/ 04). The previously specialised military technology became a mundane civilian materiality (Fritzsche 1992; 1993). The masks were more than passive symbols. The "masses" were, according to a wartime analyst, to be

helped to feel that if this was a new kind of war, it was their war too. The gas mask was, for a time, the best of any propaganda to uplift civilian morale. It gave the led a feeling of equality with their leaders, a participation between the YOU and the US, the civilian and the soldier. Everybody was armed (MOA a 1940: 111).

The mask's presence, even its box, visceralised security and fear making the next war ever-present. To one man war, from

being a remote possibility, became almost overnight an immediate danger. I can remember at my boarding school, where the wireless was banned and interest in politics discouraged, how suddenly one evening, soon after the start of the Christmas term, the lights began to dim in a trial black-out, and how, when they were raised again, the staff hurried in with armfuls of small cardboard boxes and 
one by one we were outfitted with a gas mask. This was what brought home to most people the real meaning of the crisis (Longmate 1971).

Similarly, a London neighbourhood's distribution of masks "was the last straw" to another man: "They thought about gas, and that frightened all these average working-class ladies. It was a fear which was generated by our own air-raid precautions, if you like" (Arthur 2004). Another woman discovered fear:

As I looked through the lounge doors, I saw a sight which frightened me. The whole family and all the guests were standing in the lounge, on the table there were a lot of square boxes marked 'Small' 'Medium' and 'Large' Each contained a gas mask. A man was fitting my mother, he asked her to breathe and he held a piece of paper against the end of the hideous contraption. Is it really as bad as all that?

This viscerally present fear made her "too frightened to notice" her fiancé's kiss (Hurford-Veazey 1938).

In July 1939 with some 50 million masks issued the leaflet Your Gas Mask reassuringly broadcasted "TAKE CARE OF YOUR GAS MASK AND YOUR GAS MASK WILL TAKE CARE OF YOU.” (McCutcheon 2007) This wartime caretaking came on September 3 when Prime Minister Neville Chamberlain on BBC declared that "this country is at war with Germany" (quoted in McCutcheon, 2007). Shortly thereafter London's first air-raid siren went off. Many seemed to believe "that, immediately on the outbreak of war, the sky would be filled with German bombers raining down high explosive bombs and poison gas." (IWML a) A typical reaction was a teenager who 50 years later could "clearly recollect the feeling of fear and anxiety" that Chamberlain's words generated:

This was the real thing! My stomach churned, were we going to be inundated with a torrent of bombs? Was the air around us soon to be polluted by gas? All these thought revolved in my head as, grabbing our gas masks, we scampered for the cupboard under the stairs. (IMWL b)

Another teenager's "mind jumped erratically from vivid memory to fearsome thought and back again at great speed," instantly recollecting "having my gas mask issued, fitted and tested," and "attending First Aid 
classes with my Aunts to be shown how to deal with mustard and chlorine gas poisoning in a gas attack." (IWML c) One woman sat securely sheltered when

suddenly Grandma said 'Where are your gas masks?' In our hurry to leave home we had completely forgotten about our little cardboard boxes. With visions of our being gassed Grandma hastily produced large pads of wet flannel that we were to hold over our nose and mouth. We then departed from Islington very quickly to get away from vulnerable London... heading west with our wet pads at the ready waiting for the first gas warning. With great relief we heard the'All Clear'. We never went without our cardboard boxes for a very long time after that. (IWML d)

Although this was a false alarm, the following day the mask had transformed Londoners: "That Monday morning, everywhere you went people were carrying their masks. It was almost like an army with those brown cardboard boxes over their arms." (Haining 1989: 60) The war normalised the mask and its fear: A worried secretary "answered the phone in it too. It still leaks as it always has done. I have been officially told they are sorry, but can do nothing about it. I am afraid of gas." (MOA b) A mother still worried in 1944 what a German attack would do to her two children and their masks:

Then again, I keep worrying, suppose they was to drop gas, then what would I do? Charlie knows about his gas mask and that of course, they have it at school, but what would I do with Billy? He'd scream himself silly if I was to try and put anything over his face. It doesn't make you want to have kids does it? There is so much worry to it nowadays. (Quoted in Sheridan 2000)

The future bad of gas never totally evaporated except in our histories. There it was eclipsed by the realised bads of cities bombed and burned.

\section{Notes and References}

a Parts of this argument were published in Fridlund, Mats. 2020. 'Keep calm and carry one: The civilian gas mask case and its containment of British emotions', in Susanne Bauer, Maria Rentetzi, and Martina Schlünder (eds.) Boxes: A Field Guide. Manchester: Mattering Press: 424-440.

Arthur, Max. 2004. Forgotten Voices of the Second World War. London: Ebury Press: 9. 
Fritzsche, Peter. 1992. A Nation of Fliers: German Aviation and the Popular Imagination. Cambridge: Harvard University Press.

Fritzsche, Peter. 1993. 'Machine Dreams: Airmindedness and the Reinvention of Germany'. The American Historical Review 98: 685-709.

Hurford-Veazey, Joan. 1938. 'Love and War; An Autobiographical study of the years 1939-1945: Covering the Second Great War'. September 15, 1938.

Haining, Peter. 1989. The Day War Broke Out 3 September 1939, London: WH Allen: 30.

IWML a, unpublished material from the Imperial War Museum London archives, Misc: BBC Radio, 67/278/1-2 (2), Folder "Waterlines 5/6th August”, Mrs. Jean Herbert 150988 (78) in Brighton.

IWML b, unpublished material from the Imperial War Museum London archives, Beswetherick M L. 01/10/1.

IWML c, unpublished material from the Imperial War Museum London archives, Misc: BBC Radio, 67/278/1-2 (1), Folder 'Day War Broke Out. 3', Kathleen M Goodman 101088 (123).

IWML d, unpublished material from the Imperial War Museum London archives. Misc: BBC Radio, 67/278/1-2 (1), Folder "Sunday 16th July. Waterlings", A[nthony]. W. Payne 111188 (461) in Islington.

Irwin, Will. 1921. "The Next War": An Appeal to Common Sense. New York: E.P. Dutton: 45-46.

Lee, Gerald. 2003. "I see dead people”: Air-raid phobia and Britain's behavior in the munich crisis'. Security Studies 13: 230-272.

Longmate, Norman. 1971. How We Lived Then: A History of Everyday Life During the Second World War. London: Hutchinson of London.

MOA a. Mass Observation Arhive, "War begins at home" (London: Chatto \& Windus, 1940).

MOA b. Mass-Observation Archive, Replies to Directive June-September 1940 - air raids (2-239), DR1364.

McCutcheon, Campbell (ed.). 2007. Public Information Leaflet No. 2, reproduced in Air Raid Precautions. Stroud: Tempus.

Sheridan, Dorothy (ed.). 2000. Wartime Women: A Mass Observation Anthology 1937-45. London: Phoenix: 208.

Titmuss, Richard M. 1950. Problems of Social Policy. London: HMSO: 10, 21, 111.

Physical objects may also be deployed to re-translate unwanted futures across scales in immediately de-securitizing ways: When the authorities (in Sejersen's account, Box 5.2) organise sandbags, stone, and concrete to delay the sea's erosion of the foundation of the Alaskan village, the immediate impossibility of existence of Kivalina is translated into a longer-term scenario - deferring in turn the responsibility of the authorities to conclude on a costly solution. 


\section{Box 5.5 Translating national threats to individual se- curity: Muslims in the Danish Armed Forces}

\section{Ulrik Pram Gad ${ }^{a}$}

When signing up with Western armies, Muslim citizens enter organizations particularly charged in the nexus of security and identity politics. Dominant Western discourses have posed Islam and Muslims as a threat to cultural identity, economic welfare, and physical security (Gad 2010; Huysmans 2006). The literature on the nexus between security and identity would lead us to expect that security close down the possibility of affirming hybridity, when national security is translated to the individual scale ( $\mathrm{Gad} 2012$ ). The touting of existential threats is most often accompanied by a digital ordering of the social universe as, according to a leading security practitioner "Either you are with us, or you are with the terrorists" (Bush 2001). As the basic categories distinguishing Us from Them are solidified and radicalised in public discourse, questions of loyalty and identity are inescapable for Muslims in the Danish Armed Forces (DAF). Public debate on Muslims in the military repeatedly activate stereotypes of a disloyal fifth column. Nevertheless, Muslims in DAF insist on carving out a room for diversity and hybridity.

\section{Integration machine or nurturing a fifth column}

In 1997, a leaked Defence Intelligence threat assessment report discussed risks related to new cohorts of "second generation immigrants" entering DAF via conscription. The Social Democratic Minister for Defence concluded the ensuing debate by characterising DAF as "an excellent integration machine." In 2002, DAF prepared amending an internal regulation on uniforms to allow religious headgear (such as turbans, skullcaps, and headscarves). However, the parliamentary base of the centre-right government new in office at the time, nationalist Danish People's Party, derailed the plan as its spokesperson protested that "the Danish Defense has to be a 100 pct loyal example of Danishness ... I fear a fifth column[;] it will have an amputating effect on the defense effort, if some Muslim soldiers have a loyalty problem." Hence, in 2009, Maria Mawla was catapulted into national debate, when the Home Guard's personnel magazine presented her as a cover story of successful integration. Her defendants insisted that her combination of the uniform with a headscarf was an emblem of integration: "What could be more sublime than a young Muslim woman with Dannebrog 
[the Danish flag] on her shoulders," one editorial rhetorically asked. But this narrative, claiming that her symbolic difference could be upheld when integrated in the national defence forces, was unacceptable to the governing alliance between promoters of the fifth column narrative and the integration motor narrative. In effect, she could not stay part of the defence of the state: Insisting on the headscarf, she was threatening national identity. The figure of the Muslim as a fifth column live on: It is a fixture of Islamophobic fringe fora on the internet, fed by the 2009 Fort Hood incident in which an army psychiatrist killed 13 and injured 31 at a US Air Force Base. In Danish broadcast drama - globally acclaimed, and uniquely effective as one of the few things that "unites the nation" in a time of fragmented media - even Muslims cast as security providers are nevertheless narrated into plots involving them with stereotypes of violence and treason. Moreover, beyond its original reference to infiltrators in the armed forces, "fifth column" has become widespread as a general metaphor for the presence of Muslims in the West.

\section{Fifth columned to your face}

These societal discourses casting Muslim citizens as instigators of unwanted futures translate into the organisational reality of everyday life in the armed forces. One soldier, whom I intervieweed, recalled how a colleague once told him; "'Radwan, in the event of war, I won't trust you", and reflected on the experience: "That sticks out a mile - but feelings are mutual, like; he doesn't trust me, and I don't trust him" [Interview 8]. In parallel, Adil reports a rather public and loud clash with another recruit very early after enlisting, during which he was categorised as part of an invasion: "What are you doing here? And what are all of you doing here?' and then she kind of escalated into 'But you shouldn't be here... you are taking over everything." [Interview 10]

As disturbing as such individual confrontations can be, the stakes are raised significantly when it is the army organisation that treats you with suspicion. Kareem reported such an experience he had as an interpreter officer on a sharp mission abroad: "[T]hey found some morters and a letter... and simply told the chief interpreter that... I should not be part of doing this job: I should not be allowed to see these things." Rotbøll (2009) reports a similar incident and the following exchange between Jamal, an interpreter, and an intelligence officer over whether he could take on a sensitive assignment: "Well, I am just like the other 
interpreters; like Christian, Kristian and Christine," Jamal explained. "But you are not," the officer replied.

\section{Adding nuance to stereotypes}

Nevertheless, ambitions to change the identity positions available in Danish national discourse are explicit in a number of the interviews. One of the most prevalent identity political projects is the rather basic urge to nuance dominant negative stereotypes. Hassan, along with other interviewees, explained to me:

I am tired of seeing how you only talk about foreigners who do not behave... [so I want to] show the Danes that there are also the likes of me, who can be of assistance to Danish society.... 'Hello! We are here too; we can behave; we can do something good.' [Interview 1]

This motivation has been the impetus behind some taking up more or less formalised external roles as "ambassadors" for the armed forces related, i.a. to recruitment efforts. But even mundane routines may become significant when performed "while brown": Kareem explains the joy of wearing his uniform on the way home from the barracks: "[l]t was... a personal thing; something I did for myself... [it was] fun to follow all the facial expressions and reactions, which you... saw and felt, when you did that." [Interview 7].

However, negotiating dominant stereotypical images is not an optional, external PR job. It is a daily task internally in the army, which you may take upon you more or less willingly. Hassan makes the point, repeated by others, in this way:

Just here in this house, for instance, there is not a lot of ethnic background.... If I can show both this house and broader society, that I can do good - then maybe it will cause someone to say; 'well, even if I saw all that [bad] stuff on the news, we do have this guy too... and he has done this and that [good stuff]'; so maybe we will get another picture. [Interview 1]

Insisting on showing - in personal interaction or by merely appearing in public in uniform - that there are "good Muslims" too, constitutes a performative denial of security political narratives associating Muslims in general with threats to welfare, culture, and peaceful coexistence. Samir recollected the predicament, in which he found himself, like this: 
The Danes won't accept you because they are different.... The immigrants hate you because they feel that you are a traitor. So... you won't be accepted by the pale group; you won't be accepted by the darker group.... And I think 'no, I just want there to be some kind of bridge between us.' [Interview 3]

\section{Notes and References}

a The interviews which form the base of this tale was conducted as part of a post doc.project sponsored by the Center for Advanced Security Theory as part of a University of Copenhagen excellence program. Names and certain biographic details have been changed to secure anonymity. The background paragraph draws on Gad (2017), Gad (2020) and Gad (forthcoming) in which empirical references can be found.

Bush, George W. 2001. President Bush Addresses the Nation, The Washington Post. Accessed at: https://www.washingtonpost.com/wp-srv/ nation/specials/attacked/transcripts/bushaddress_092001.html

Gad, Ulrik Pram. 2010. (How) can They become like Us? Danish identity politics and the conflicts of 'Muslim relations, $\mathrm{PhD}$ dissertation, Department of Political Science, University of Copenhagen.

Gad, Ulrik Pram. 2011. 'Muslims as a Security Problem in Danish Integration Discourse: Peace, Welfare, Culture'. NordEuropaForum 2011(1):41-72.

Gad, Ulrik Pram. 2012. 'Concepts of dialogue as counterterrorism. Narrating the self-reform of the Muslim Other'. Critical Studies on Terrorism5(2): 159-78.

Gad, Ulrik Pram. 2017. 'From Flip-Flopping Stereotypes to Desecuritizing Hybridity. Muslims as Threats and Security Providers in Danish Broadcast Drama Series'. European Journal of Cultural Studies 20(4): 433-448.

Gad, Ulrik Pram. 2020. 'Under krydspres mellem stat og nation: Mangfoldighedsledelse og muslimer i det danske forsvar', in Henrik R. Christensen, Brian A. Jacobsen and Signe E. Larsen (eds.) Religion i det offentlige rum. Et dansk perspektiv, Aarhus: Aarhus UP

Gad, Ulrik Pram. (forthcoming) 'Identity Politics between State and National Security. Muslim Soldiers in the Danish Armed Forces'

Huysmans, Jef 2006. The Politics of Insecurity. Fear, Migration, and Asylum in the EU. London: Routledge.

Rotbøll, Emil. 2009 'Er jeg en forrædder?'. Information 23 December

However, the Kivalina villagers attempted to reach a solution by filing a lawsuit against polluters - inserting an element of global scale $\left(\mathrm{CO}_{2}\right.$ vs. climate) in the local causal chain (sea vs. village). More generally, the potency of law as a means for resistance at the local or individual scale against top-down translations of unwanted futures varies a lot, even in societies with some credible claim 
to the rule of law: Some legal traditions empower certain individuals in relation to certain authorities under some circumstances, thereby making law a means for countering unwanted futures imposed on or relegated to the individual level.

Official text in general also constitutes a tangible technique for upholding a specific way of translating unwanted futures across scales - particularly topdown in sedimented hierarchies of authority. To be efficient, however, they need to resonate at least to some degree with broader social discourses. Nevertheless, taken together, official and informal discourses will provide a variety of repertoires available to actors at the individual and interpersonal level trying to re-translate and re-distribute the unwanted future. Gad (in Box 5.5) provides examples of such negotiations from a study of the identity politics taking place within the institutional framework of the Danish Armed Forces as they increasingly enrol sons and daughters of Muslim immigrants in an organisation recently mainly deployed to fight enemies defined as Muslim.

Governance standards and procedures is a top-down measure that seeks to translate a programme for managing unwanted futures across scales while seeking to re-instate a hierarchy of scales. Philipsen's account (in Box 5.6) provides a mundane example: To be eligible for funding from the $\mathrm{UN}$, what begins as a bottom up business development and social inclusion project needs to be translated into a security project by adding urgency and potential danger to the marginalisation of war-amputees. The funding, which appears important to upholding the UN at the top of the hierarchy, was almost derailed by the amputees resistance to being re-cast as uncapable (let alone dangerous). In this case, part of the legitimacy of keeping the UN at the top of the relation comes from a two-way relation to "lesser" scales: UN policies prescribed local ownership of projects - so the UN actually needed local partners to provide some measure of acceptance for it to stay on top of the hierarchy.

\section{Box 5.6 How the single Leg Amputee Sports Club Became a Matter of Peacebuilding}

Lise Philipsen $^{a}$

During UN Secretary-General Ban Ki Moon's visit to Sierra Leone in June 2010, the Single Leg Amputee Sports Club (SLASC) played a football match. The Secretary-General was so impressed by the team's energy and performance that he promised the club 100.000 USD from the UN Peacebuilding Fund. Following this, it became the task of the United Nations Integrated Peacebuilding Office in Sierra Leone (UNIPSIL) to pass the proposal through the UN system.

Highly concerned with the ideal of local ownership, the SLASC was invited to the UNIPSIL compound for training on how to formulate the 
proposal, and within a few days received the first draft proposal from the SLASC. In the proposal the sports club had set down an extensive business scheme enabling the club to become self-sustainable by renting out sound systems, establishing an internet café and a sports cinema hall, and driving "poda podas"b (SLASC 2010: 7). Yet, this proved to be a far cry from what was considered sufficient to allow a UN peacebuilding project to pass through the system.

As the document shifted from the hands of the SLASC to the hands of UN bureaucrats, the tricky task became making this project look like a convincing and accountable case of peacebuilding. Also, it had to be fitted into the right UN matrixes and aligned with the bureaucratic and normative lingo of the UN. This was done by framing the proposal under Peacebuilding Fund Priority Area 2 as an endeavour to further the: "promotion of coexistence and social acceptance ofmarginalised groups that are still affected by the legacy of the civil war, inparticular access to resources for socio-economic integration in the social fabricof Sierra Leone." (SLASC 2010) Among other things, the project template included the criteria of "direct and immediate relevance to peacebuilding, time-critical nature of the project and the unavailability of timely alternative funding; the lack of available funding for specific peacebuilding activities, and catalytic effect of the project on the engagement of stakeholders in the peacebuilding process" (UNPBF 2009: 4-5). In parallel with making a case for how the project was in this way both urgent and relevant for peacebuilding, measurable indicators/ targets, means of verification and important assumptions had to be established (UNPBF 2009: 7-8). The original project from the SLASC had to be edited to unrecognisability.

At the same time the SLASC did not see why their original proposal needed such heavy editing. This resulted in fierce discussions. In particular, the SLASC objected to the condition that $30 \%$ of the promised amount had to be allocated to the International Organisation for Migration (IOM) for procurement and management. They found it more accurate for the proposal to state that the reason for this was the extensive bureaucratic rules of the UN. At the same time the inclusion of the IOM as procurement partner suggested to them that the UN did not trust their ability to make good use of the money. However, the involvement of the IOM was beyond discussion, as every UN peacebuilding project has to have a UN procurement partner (UNPBF 2009). As the IOM explained to the representatives of SLASC: "Money from PBF comes with aprocess you have to follow, with specific criteria you 
have to follow." From the perspective of the SLASC, however, the only argument they felt was needed was that the Secretary General had promised them the money.

Having finally agreed on a version of the proposal UNIPSIL was eager to get it off the table and pass it through the application process. They felt little reason to go into deliberations about the logical and practical consistency of the project, because to their mind, it "had never made sense and never would." ${ }^{\mathrm{d}}$ Yet, the larger UN system was not going to let this happen so easily. The proposal kept coming back from the UN offices in New York with a number of comments and questions to be answered: Was the project implementable? Could one really be sure of the planned outcomes? Who was the poda poda driver? Did he have the right driver's license? What would his salary be? Did the SLASC have the sufficient insurance and commercial license? Had a market assessment of the income generating activities taken place? Would it take place? Had there been an institutional capacity assessment? And, what resources and mechanism existed for SLASC to ensure transparent, efficient and cost effective implementation? ${ }^{e}$

As another version of the proposal was made, taking the above questions into account, it did not go down well with the SLASC. Logically, in order to gain funding for capacity building, a clear case for a lack of capacity had to be made. Yet in the eyes of SLASC, who in the end had to sign the proposal as its authors, even calling the project a capacity-building project was seen as an unacceptable insult, as this suggested that they had a somehow limited capacity. To prove that this was certainly not the case, they provided the UN with official organisation certificates, invited them to their headquarters, training sessions, matches on the beach, and even to church. At the same time negotiating with the SLASC to make the document fit UN requirements was nearly impossible given that they had very little reason to alter the proposal. Their argument for why the UN Peacebuilding Fund should approve the proposal was simply that the Secretary General had already promised them the 100.000 USD. As they said: "The Secretary General will bless us again." $f$

This story about how an amputee sports club became a matter of peacebuilding reveals how the ideals of the UN are negotiated when they meet a concrete context. In this context, the peacebuilding aim of "Promoting coexistence and peaceful conflict resolution" became an exercise in turning the SLASC project into a sellable and passable project in the UN. And indeed, in the end, the SLASC proposal was seen 
as a success story of peacebuilding. As a UN officer told me towards the final editing stages: "My UN colleagues like this proposal - they say it's very innovative."g

\section{Notes and References}

a This tale is based on the fieldwork conducted for a PhD project reported in: Philipsen, L. (2013). Liberalism Lost in Translation: Practices of Human Security, Peacebuilding and Liberal Insecurity in Sierra Leone. Department of Political Science. Copenhagen: University of Copenhagen; Philipsen, L. (2016). Escaping friction: Practices of creating non-frictional space in Sierra Leone. In: Björkdahl, A. (ed). Peacebuilding and friction, global and local encounters in post-conflict societies. New York: Routledge, 64-83; Philipsen, L. (2020). Pioneers of Peace, Implementers of Humanitarianism: Learning from the Ambivalence of Peacebuilders. Journal of Intervention and Statebuilding: 1-22.

b "Colourful, customized, converted mini-buses can be seen all over the country and provide the main, cheapest form of transport for the vast majority of people. Essentially they are mini-buses that have been converted to hold up to about 20 people (although in reality there is often almost twice this many people on them!). They drive a particular route and collect and drop-off people on the way for a standard fee set by the Government" (SLASC 2010). Project Proposal to the UN Peacebuilding Fund (original project proposal). Freetown: Single Leg Amputee Sports Club - Sierra Leone. p. 6).

c Meeting notes SLASC, IOM meeting, IOM, Freetown, 19 July 2010

d Personal communication, UNIPSIL, Freetown, 13 July 2010.

e E-mail communication, UNIPSIL, Freetown, 19 July-30 September 2010.

f Meeting notes SLASC, IOM meeting, IOM, Freetown, 19 July 2010.

9 Field notes, IOM, Freetown, 9 August 2010.

SLASC. 2010. Project Proposal to the UN Peacebuilding Fund (original project proposal). Freetown: Single Leg Amputee Sports Club - Sierra Leone.

UNPBF. 2009. Guidelines for Applying to the United Nations Peacebuilding Fund.

Means for non-violent bottom-up resistance to a top-down translation of an unwanted future features in Jusionyte's tale (in Box 5.1) from the Triborder area: Here parody and the aggravation of conspiracy theories to satirical effect were meant to defuse the imposition of "terrorism" as a localised threat. More generally, images are often apprehended to be a particularly efficient means of both top-down propaganda and bottom-up resistance. However, as Hansen discusses (in Box 5.7), while the immediacy 
and visceral capacity of visual communication may often provoke more emotions than written or even spoken words, the direction and valence of the emotions cannot be taken for granted. Effects may vary diametrically with time and cultural context.

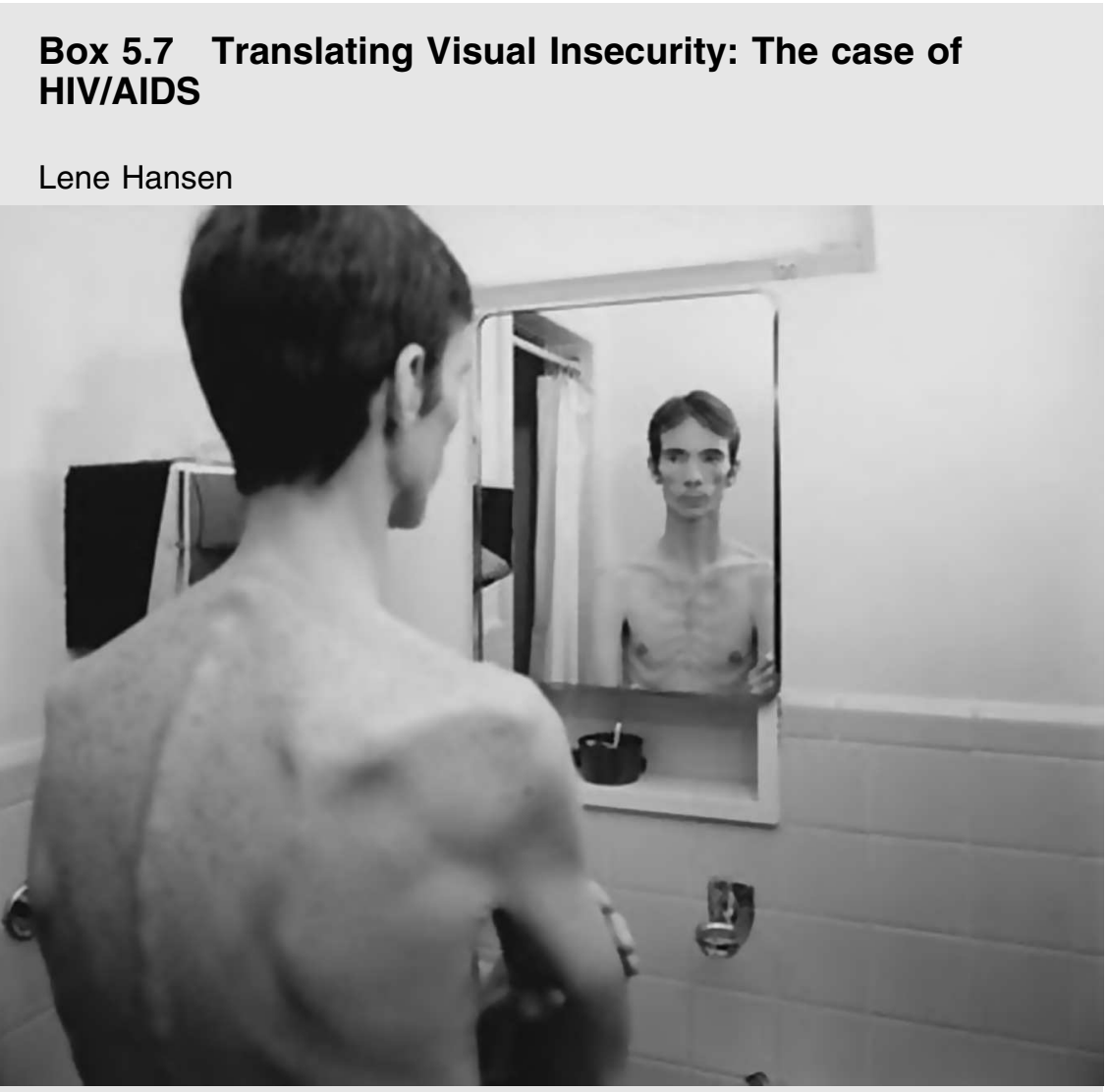

Nicholas Nixon: Tom Moran, October 1987, from the People with AIDS series xiv (C) 2021. Digital image, The Museum of Modern Art, New York/Scala, Florence

Images play a central role for how threats and insecurity are communicated. The attacks on the United States of American on September 11 were brought instantaneously to audiences worldwide who watched in disbelief as planes hit the World Trade Centre and the twin towers collapsed. The photographs from Abu Ghraib provided visual proof that abuse - possibly torture - was taking place, yet the effect of the images was not simply to verify but to activate deeply emotional responses to what was being shown. 
The field of Security Studies was late to embrace the study of how images evoke and "translate" insecurity. As a consequence, it was disciplines like Art History, English Language and Literature, and Cultural Studies that first asked how security images should be interpreted and their impact on politics be understood. To ask how images "speak" security from within the field of Security Studies therefore involves an engagement with how other disciplines have theorised the visual. Not only because translating the knowledge - and debates - produced elsewhere might prevent security scholar from reinventing the wheel, but because such an engagement provides a valuable basis for contemplating the specific contribution that Security Studies might make.

Photographs of people suffering from HIV/AIDS provide a powerful illustration of how images may securitize (Bleiker and Kay 2007). From the discovery of the illness in the 1980s to the present, HIV/AIDS has been constituted as a threat to societal security, to regional stability, to Human Security, and to the globe itself. Back in the early years of the epidemic, the disease was largely addressed as a North American and Western European phenomenon and the politics of threats and insecurity linked with the widespread constitution of this as a "gay illness." Today, HIV/AIDS is predominantly seen as predicament of the Global South and parts of Africa as most strongly affected. As HIV/AIDS has migrated from one geopolitical location to another, so has the way in which it has been securitized. Referent objects, threats, and appropriate policies have changed, but images that visualise the threat posed by the disease, most strikingly by showing the impact on deteriorating human bodies, have been central throughout.

Take the example of "Tom Moran, October 1987," a photography by renown art photographer Nicholas Nixon. This photograph is part of a series "People with AIDS" that Nixon composed in the early days of the HIV/AIDS epidemic, that is prior to the medication that decades later allow many with an HIV status to live with the disease. In 1987, however, the prospect for people like Tom Moran was the ultimate insecurity: Imminent death. Nixon documented the stages of physical decay following individuals - who had volunteered to be part of his project - by taking photographs of them every month.

At the time, these images were met with severe criticism from activists in organisations such as ACT-UP (the AIDS Coalition to Unleash Power). Looking back, professor of Art History Douglas Crimp reflected on the interpretation of images like Nixon's: 
The people who circulated these images often claimed that it was helpful to see such images because the viewer could sympathize with them and see the terrible effects of the disease. I recognized that the effect of the images could be just the opposite. That is, they could produce a phobic effect in which the last thing one would ever want to do would be to identify with their subjects. A viewer could see them neither as human nor as possible self-images, but rather as images of abjection and otherness. (Takemoto 2003)

Yet, such a phobic response may not be the only possible emotional effect on the viewer. As prominent visual theorist Mieke Bal wrote in response to "Tom Moran, October 1987."

When looking at a man looking at his mirror image showing his body devastated by disease and with an undefined look resignation, assessment, or shock? - I feel overwhelmed by a turbulence of contradictory emotions ... Given the date of the photograph (1987) and the man's young, beautiful, but skeletal face and emaciated chest, the association with AIDS is inevitable, and I feel grief, compassion, and anger. (Bal 2006)

How should we translate these conflicting responses to "Tom Moran" into Security Studies? First, they show that images may trigger emotional responses, but that such responses are not unequivocal but vary according to time, place, and perhaps individual, experiential factors. Second, the goal of Security Studies should not be to determine which emotional response is right or wrong, that is, how the image "really" speaks but to analyse which interpretations are offered and the role such interpretations play in public debate and policy making (Hansen 2011). Security discourses on HIV/AIDS were markedly different in 1987 than in the 2000s and the constitution of "Tom Moran" is not situated outside of these, but within them. The image, in short, is never reducible to a particular, universal "security emotionality," but made to speak in time and place.

\section{Notes and References}

Bal, Mieke. 2006. 'The Pain of Images', in Mark Reinhardt, Holly Edwards, and Erina Duganne (ed.) Beautiful Suffering: Photography and the Traffic in Pain.Chicago: The University of Chicago Press: 93-115.

Bleiker, Roland, and Kay, Amy. 2007. 'Representing HIV/AIDS in Africa: Pluralist Photography And Local Empowerment'. International Studies Quarterly 51: 139-163. 
Hansen, Lene. 2011. 'Theorizing the image for Security Studies'. European Journal of International Relations 17: 51-74.

Takemoto, Tina. 2003. 'The Melancholia of AIDS: Interview with Douglas Crimp'. Art Journal 62: 84.

If we turn to the relation across scales and networks, a number of physical objects and technological developments also plays into the translations. Perhaps most importantly, the development of the internet, algorithms, surveillance equipment, and communications technologies have made the network if not possible in the first place, then increasingly able to gather, communicate, and exploit the gaps outside of scales. At the same time, these technologies have made it increasingly difficult to hide from government control. We all leave a digital footprint, which can be harvested, analysed, and used against a perceived threat by authoritative actors.

The spectacle surrounding Edward Snowden can be regarded as relying on exactly these types of technologies. Edward Snowden became the symbol of global civil society/citizens rising against state-controlled surveillance and the harvesting of data. After having had access to data from the NSA, Snowden chose to disclose what he considered illegitimate practices targeted at individuals. But at the same time, the leaks told a story of the US secretly tapping information from allies and adversaries (i.e., states). In that sense, through the use of technology - the internet, access to databases, electronic copying of classified information - Snowden (an individual person) materialised as a threat to US security by disclosing a set of state practices targeted at both the state level and the individual level (in order to capture a networked unwanted future of terrorism) and spreading that information through the internet. The establishment of Snowden as a threat was both triggered by a networked phenomenon - the terrorism threat, which had set the harvesting of data in motion in the first place - and also resulted in yet another networked future not wanted by the state - the threat of a social movement materialising around Snowden spreading ever more information from the US secret intelligence archives through different individual home pages and servers. As such, the challenge of networks seems tied to new technologies to a very great extent. It allows social movements to set in motion a spiralling effect in which the attempt to discipline one threat leads to the creation of another.

Another individual who made himself powerful through the use of new technologies is Anders Breivik, a Norwegian middle class man in his thirties. He has been called a lone wolf, but basically he used the networked electronic society to both feed his extreme right-wing sentiments about the wrongdoings of the Norwegian Labour Party and his Islamophobia, to learn how to cook up bombs, and to get in touch with weapons dealers and fertilizer web-shops (fertilizer was used in the bomb he set off in the centre of 
Oslo on 22 July 2011). By combining these elements (and a list of other things, such as obtaining a legal permit to carry a Glock pistol and other hand guns) through an internet connection in the remote countryside in Norway, Breivik managed to carry out a terrorist attack against both the central administration in Oslo and a gathering of labour party youths on the island of Utøya. Breivik claimed 77 lives. He was hailed a hero amongst an amorphous network of far-right wing enthusiasts all over the western world and condemned by governments and citizens in the same part of the world. His acts could not have been carried out without the use of and belonging to de-territorialised, technological networks, and without physical objects.

The attempt to bring Breivik back in scale by the Norwegian government included first the mental health system and then (when he was considered fit for normal justice procedures) the legal system in Norway. His network of followers was sought controlled by denying him the opportunity to make his own defence in court in a televised address. He now serves a prison sentence in a high security prison in Norway, where his rights of communication have been restricted, thereby preventing him from upholding and inspiring his network of followers.

Like in the translations around professions where amateurs may (immediately) seem empowered by technological development but professions (especially if state-backed) find themselves empowered to get back control by more technological development, the existence of the internet and telecommunication systems seem to work both as a trigger empowering networks, but at the same time as an electronic field to be harvested by actors seeking to tackle unwanted futures - both scalar and networked.

\subsection{What concepts of security emerge this way?}

The scalar mode of interrogating translations of security gave us two entry points: The hierarchical and territorial, and the networked and deterritorialised. What remains for this chapter is to distil the implications for our social and political concepts of unwanted futures and thus for the practices associated with the core concepts of risks, dangers, security issues, unsustainability, and so forth. This section will tease out three examples of how such new conceptual meanings have emerged. The first example is an example of a situation in which a threat, pre-packaged from the outside, is met, and where the scale is attempted to be "saved" either by denial, by redefinition, or by surrender. Secondly, we survey a situation in which one scale meets another scale, leading to a redefinition of the hierarchical relation, and thus of the established concepts of security. Thirdly, we discuss a situation in which a scale is confronted with its own impossibility, a networked phenomenon, and how securitization is used to help re-territorialise and thereby manage the threat. 


\section{Box 5.8 Voices of Data Doubles}

\section{Didier Bigo}

We are in a computer. We are in a data base. We are in a watch list, black or grey, public or private. We are false positive. We are called data doubles, and we don't understand how and why we are there. Could you help?

We are surprised to be there. Except from Bruno Latour and its ants, nobody said that we will be translated and that we will shift our identity and subjectivity. We are all European or Canadian citizen. We are bankers, we are artists, we are in humanitarian NGO's. We live in the first circle of e-Dante Inferno. And, oh I forget, we are not religious, but we have Muslim names.

As data doubles we are now notorious. Courts have given us fame, especially European courts, the last resorts of a series of lost national causes as they say. We are still in the list, we have not been delisted, fame continue. Our physical bodies had a different fate. It was harder for them; deprivation, torture, bad treatments, no money, no work, no social security, but now they are alive. Not yet free as we are still in the list, but they have a limited mobility, they could have been dead. They are half happy.

Who are we? You want the list? You are curious, aren't you? You do not believe that we are just innocent. We are still suspect despite innocence proven in courts, we may be indefinitely in a list now, a public or a private one. Once in a list, always in a list, said an intelligent service officer, thinking maybe of himself. Let us present ourselves.

This is not Maher Arar. And the Data double. A long story. But you don't care anyway about my story. My data double story.

This is not Abu Omar. An even longer story. You care a little bit more maybe? Only because I changed the game with my Italian judge friend Spataro. Who would have thought?

Sabrina and Nicolo remember well now who I am. Sabrina DeSousa, CIA officer, broke the law and we are paying for the mistakes right now by five years prison. Nicolò Pollari, director of SISMI more lucky? he has been acquitted by the court.

We have a name but not a body, we are the second circle of e-Dante Inferno. We are companies; we are NGO's. We are multiple bodies created after the abolition of slavery. We are what they call moral persons. We are mostly NGOs, the most moral or charitable persons of 
the moral persons, but we share the watch list as false positives. Do you know us? Cordaid. Building Flourishing Communities.

Interpol. Humanitarian NGO's complicities translated onto starvation.

Global Fund for Women in Sudan. How freezing of assets are transformed from women's equality in to certain masculinity.

We are sorry we have no name, we are $\mathrm{X}$ or statistics or biometrics portraits, your new identity. Do you love your portraits? Put it in you're bedroom, your next on the list. We are the other e-Dante circles, more and more anonymous. We are collateral effects of diminution of health, of food, of humanitarian aid due to counter - terrorism. Never heard of us? I am father $\mathrm{X}$, killed because I was working in Sri Lanka helping Tamil Communities, not LTTE, but Sri Lankan soldiers well trained in Israel and the US have considered that I will help them in the future. We were the Moro NGO bureau in Philippines. We were burnt in our office after death threats. Not located by a drone, just a human informant calling us terrorist supporters. A communication error.

We are from SUDO in Sudan, specialised in food distribution, we have all been put under surveillance. Our 16 bureaus have been destroyed. We are from India, from Colombia, from Uganda. No incidence of a database, just small inconveniences at the airport? Certainly, an error of translation in your world.

We are overpopulated, duplicated, "worldcheck(ed)." We get by millions nowadays. How we get there? Because of your experts on profiling, their great capacity on big data, their capacity to collect data, to exploit statistics. We are happy to know it is not a direct racist discrimination done by a human being, that we are there because of "artificial intelligence," in a form of dissociated bodies recomposing data doubles that travel through time, back and forth, as forward memories, to find out how guilty we will be. A perfect future or a future perfect? A french saying: Futur anterieur. Because of your politics of numbers and statistics, of your statistical normalisation of behaviours. No state of exception here, no big emergency, no threat, just a lot of very nice routine, job as usual. As they say: Nothing personal.

Why are we there? Because you believe in science, in prediction, in prevention. Because you believe in unknown unknowns that you will nevertheless know through prevention. Because you accept the $1 \%$ doctrine. Because you practice myth in science by densifying it that it cannot be expurged, purified. Because you love sacrificial astrology? I know finally who you are: Aztec Priests, aren't you? 


\subsubsection{Rescaling responsibility in the face of a threat}

Frank Sejersen's tale (Box 5.2) about the Kivalina Inuit population gives us a good example of the first type of meeting: When a scale meets "the world" and reacts. Kivalina is a village located on a slim peninsula that risks submerging due to the melting of protective sea ice. Climate change is the cause of this situation and the security threat to the village is considered immanent and existential to a significant degree by various actors at different scales. In this situation, where a local scale meets "the world" a number of different scalar activities surrounding concepts of unwanted futures could be identified. Cast as a small local scale in a meeting with a large global natural disaster the Kivalina Inuits were subjected to state-level policies of mitigation. Sandbags and stone walls were the technical instruments to counter or at least defer the threat, as relocation opened a very expensive and encompassing problematique, which would potentially be relevant for more than 180 villages in Alaska in total. However, the Kivalina population did not feel that the threat to their territory, which these measures could protect, was the biggest threat. While of course essential, for them, as Frank Sejersen tells us, "Whom to become without the land" was a much more pressing issue. In defence of their identity and in an attempt to mobilise themselves as more than victims of the forces of nature, the Kivalina villagers sought to counter the dominant mitigation strategies. They voted for relocation of the whole village and filed a lawsuit against oil companies to underline the human component of the security threat - and hence the responsibility for the unsustainable situation. In the process, they made the issue of climate change relevant for more than just one state (the US, let alone Alaska), but at the same time made the responsibility at the state level more complex as the public/private divide was blurred. In effect, the response of the people in Kivalina re-scaled responsibility for their (in)security from the state's responsibility for the social security of its individual citizens to, first, the state's responsibility for their communal identity and, second, to inscribe a global responsibility flowing from the "corporate citizenship" of multinational companies. The security threat became a political rather than a technical issue as identity and territory were combined with socio-natural causes. What we see is therefore a reformulation of a territorial concept of security in this specific case. What would normally fall under the responsibility of the state (safeguarding the territory) becomes an issue open to action by a number of agents spanning different scales and organisational forms. At the same time, national authorities are inscribed with the task of maintaining and sustaining communal identities.

\subsubsection{Reconceptualising security to renegotiate scalar hierarchy}

In Ieva Jusionyte's tale (Box 5.1) about the triple frontier area between Brazil, Argentina, and Paraguay, scale is used in imaginative and transformative ways 
to translate a global threat of terrorism and local and national risks of poverty and gun violence into a "safe place" for locals. Through a mobilisation of a "geography of blame," local journalists countered the dominant definition of the small piece of land by the Iguazu falls. The US global war on terror and drugs had led to pressure on Argentina to install immigration control and surveillance to counter the global threat at the local level. This had produced a space cast by outsiders as a safe haven for all kinds of bad people with shady intents, including - ostensibly - terrorists such as Osama Bin Laden. An image of a "hot border" was the result. But, Jusionyte describes, how by countering this image through parody and by a "law of silence" (whereby local journalists did not report on, e.g corruption and contraband) the triborder area was sought constituted as a "safe place" in contrast to metropolitan areas plagued by robberies and assaults and far from a reality dominated by international terrorism. Further, the meaning of security was translated from the global meaning of a threat from terrorism best countered with military and security guards to a human security perspective of housing, poverty, and infrastructure. The global scale was ridiculed and problematised as the most relevant one for defining security for the region. The nation-states involved were blamed for their neglect of border regions, and the local level was held up as a strong community in which security was produced not by the state, nor by the global level, but by a feeling of security produced in micro-relations "when my neighbor feels secure." Despite expectations about the dominance of the national scale, this tale tells a story of the national level being caught in-between. The global super power pressures the Argentinian state to react in its border region - while the regional/local scale fights back through both parody (to global discourse) and through indignation about poverty and neglect (to the state authorities). The concept of security is translated and anchored solidly in the local context and is disconnected from the global/national securitized scale. In the process, security comes to be related to mundane issues of water and electricity supply instead of soldiers and border control. In terms of securitization theory, the locals attempt to de-securitize by making their regional security a matter of everyday concerns. The responsibility remains at the state level, however, as the state is blamed for neglect of its border region. But the solution is not military. It is economic development of the local level.

\subsubsection{Re-territorialising a network: operation successful-patient died}

Establishing the Guantanamo camp was part of the US response to the networked threat of Al Qaeda in the name of both national and global security. Withholding and interrogating combatants, Guantanamo was an emergency measure performed by the US state to tame the immediate threat by fixating individuals supporting the terrorist Al Qaeda network, which could have harmed US territory, citizens or troops. But in the process, this 
emergency measure and the securitization and disciplining of the networked Al Qaeda threat translated the referent object to be defended to the US nation as a beacon for a liberal project with global pretensions. By letting experts from illiberal regimes teach western practitioners how to excel in their interrogations, and by holding combatants without a trial for more than a decade, the referent object - that which was supposed to be defended was damaged. This, arguably, played a part in the unwanted future of networked terrorism morphing - temporarily, at least - into the territorialised Islamic State. More pertinently, it also accelerated the loss of credibility of the referent-object-to-be-defended. Hence, the unwanted future of networked terrorism was translated into a different unwanted future of a self-eroding universalizable identity for the US in particular, and the Western world in general. From the perspective of civil rights, measures in the name of security translated into threats. In terms of changes in concepts of security we see two related conceptual issues at play. First, a conceptual change is arising as risks that were formerly dealt with as police matters become threats to national security and thereby eligible to be dealt with and acted upon under that heading. More and more risks are now thought of as security threats, but even though the trend in that direction is tangible the conceptual battle is not settled. The second concept under pressure here is the classical concept of national security. The legitimacy of employing emergency measures to protect national security is held as a foundational principle. However, this clearly backfired in this example as threats to the very core of the nation - the liberal principles - were eroding as a consequence of these very emergency measures. The concept of national security, therefore, did not seem to be a useful frame for grasping the new reality of networked terrorism but rather started a negative spiral to the detriment of the American superpower.

\subsection{Stakes and consequences: re-territorialisation and super- empowered individuals}

This chapter has looked at the dynamics of translations of security across and beyond scales, what triggers them and through what means do they take place. We have also established that the scalar mode of translations gave us two entry points: The hierarchical mode, which stresses territoriality and authority, and the networked mode, which collapses the scalar focus. What remains is to ask what the implications are of these modes for our social and political concepts and for the practices associated with these concepts of unwanted futures? Can we observe dissolutions of the modern distinctions defined by the translation zone across and beyond scales? Or are the examples given in the book just re-articulations of conventional meaning?

We observe at least two ways in which these modern distinctions are being challenged. One is the modern understanding of the individual as an easily 
identifiable and essential unit of analysis and legal category. From being understood as a homogeneous and sovereign unit, the individual is increasingly split in two by technological and political developments. Secondly, we observe how the territorial reach and segmentation of the scalar model is challenged by the rise of super-empowered individuals who depend on networks to be powerful. We turn to each of these developments below.

\subsubsection{Controlling and dividing individuals}

In the tale of Didier Bigo (Box 5.8), the story of "the one network effect" is captured eloquently. Once again, the unknown and unwanted future of terrorism plays a central role in triggering the harvesting of electronic data from flight manifests, phone records, and credit card transactions in order to draw out patterns which can identify the "bad elements" amongst individuals. The "data double," which results as a bi-product from the attempt to discipline the networked unwanted future by state actors (intelligence services), effectively splits the individual in two (or more) - making the term "dividual" a better term than "individual" (Critchley 2013). In similar terms, other scholars speak about a changing meaning of subjectivity, as privacy can no longer be linked to individuals' intentional doings but, in today's digitalised networked society, to the existence of personal data itself (Andrejevic \& Gates 2014; Pasquale 2015). The integrity of the individual as a legal and physical entity is challenged and real-world consequences on the individual might follow: You may not be allowed to travel to the US because of suspicious patterns in your previous travels, or you may be put in custody until the status of your data double has been screened and cleared. All because mundane activities were marked suspicious in a state algorithm, trying to detect a de-territorialised, networked threat. In this case, both the individual level and the state level are challenged. The state is challenged by the threat of networked terrorism, but at the same time attaches itself to network technologies in an attempt to get terrorism back in scale. The individual is submitted to extensive control and is split in the process, leading to unforeseen consequences.

\subsubsection{De-territorialisation and re-territorialisation}

The second observation of change related to scales concerns territoriality. Analytically speaking, in the world of networks, we are no longer in a landscape where the lines of control can simply be understood in terms of scope and hierarchy (Allen 2011: 290). But while this seems fluid, intangible and essentially de-territorialised and completely outside of scales, the networks are still to some extent territorial andspatial and present unevenly on 
classical scales. The flat world of networks still manifests itself as reterritorialisations in the physical world and in the world of scales. In other words, some nodes in the web of the network are more important than others. Cyber networks still depend on physical servers and access points, terrorist networks depend on communication which has to be transported either physically or electronically, weapons storage requires a physical location and access routes, and human bodies are required to carry out the attacks or set them in motion. So, networks are not ephemeral and living simply in a world awash in fluidities. There are entry points from where the networks can be attacked and disciplined in attempts to regain authority by more classical actors on different scales. In Guantanamo Bay (see Austin Box 4.1), the terrorist threat was translated into captured terrorists who were gathered and attacked body by body in a meeting between the state and the individual in order to eradicate or discipline the unwanted future of terrorism by obtaining information about their network. Edward Snowden was banned from travelling and threatened with severe penalties, should he show up on US soil or in countries with an extradition deal with the US - and the wikileaks website, trading in similar leaks, was put under severe attack from US government agencies. The possible, physical and virtual space in which Snowden's biological body and data double could be present was thereby restricted. This did, however, not stop him from giving interviews and disclosing ever more information in other parts of the internet. So, he was there, but he was not there. The threat was sought disciplined but seemed to spiral out of control, nonetheless. The case illustrates how we continuously see a play between de-territorialisation and re-territorialisation when networks challenge scales. The individuals who have arisen on the basis of the networked challenge to the scaled reality have been referred to as "super-empowered individuals" (Friedman 1998): Individuals who by playing a central role in a networked phenomenon - rise to become threats to established authority. Edward Snowden was such a superempowered individual, as was Anders Breivik and in certain senses Osama Bin Laden. All rose to threat status by occupying or creating a central node in a network threatening to destabilise sedimented authority relations. But rather than this meaning a re-introduction of the individual level in a scaled universe this installs a hybrid form in which the superempowered individuals depend on networks spanning territories, people, and things to be powerful. Even more so since becoming a central node in a network might be th consequence of happenstance rather than willful intervention. Rune Saugmann Andersen's tale (in Box 5.9) illustrates how such a position may even be produced by the very powers attempting to avoid exactly that outcome. 


\section{Box 5.9 Visual translations of (in)security}

\section{Rune Saugmann Andersen}

In 2009 an image circled the news, showing a woman lying on the road, seemingly receiving a blow from a police baton. This woman was not a central person in the 2009 protests that took place at Copenhagen's Brorson Church when police arrested asylum seekers who had taken refuge in the church for weeks. She was not a core organiser in the activist network that had pledged to do everything possible to save the refugees from the deportations to Iraq that were likely to follow their arrest. She was not one of the Iraqi asylum seekers that the confrontations were supposedly all about. Yet the day after the confrontations, it was her image that was all over the news, and she was the one journalists wanted to speak to. Rather than this being due to her role in the political movement around the refugee issue, it was due to a spectacular instance of filmed police violence, performed on her body.

The morning after the Brorson confrontations, a video was widely circulated online and quickly spread to mass media. It showed a young woman being struck with a police baton while pulling back from the confrontation, receiving eight beatings in total - the last one, from behind and dangerously close to her neck, occurring while she was clearly following police orders to leave the scene.

With her spectacular suffering filmed and thus able to enter new contexts, the woman seen suffering in the video immediately became the most sought-after topic of interviews, news, and other media products seeking to leverage the attention to her, such as online opinion polls asking news consumers to judge the appropriateness of the police conduct in the light of the video. The woman was the most sought-after interviewee of the day, questioned about how her suffering felt, about her experience of police brutality, live on current affairs TV. While news and current affairs programming on TV focused on the female protagonist in a spectacle of gendered suffering, tabloid newspapers soon followed up by attributing gendered and sexualised connotations to the spectacular violence, e.g., naming her "the baton girl" (Harder 2009). The recording of the violence performed by the police onto her body transformed the young woman into the unlikely, unwilling, and unprepared spokesperson for those resisting the forced repatriation of Iraqi asylum seekers. Her statements, such as that "I think it is a far more serious crime to deport people to a country in which they risk being killed" (Hansen \& TV2 News 2009: 2'15") show her 
struggling, mostly in vain, to steer the discussion towards the violence of forced repatriations rather than filmed protest violence. The massive focus on this single, random episode - a young woman with a distinctively Danish look becoming the main character in a debate about forced repatriation of Iraqi refugee seekers - is a view of the confrontation encouraged by the translation of the camera, and by the media networks in which the translated protest flourishes.

When digital cameras are used to film political conflicts involving political violence, the protest is translated, rather than simply recorded or captured even if this is how we usually describe it. The camera substantially translates and transforms political conflicts, introducing new dynamics that arise from the protest-as-image, not from the protest-as-streetconfrontation. As we have just seen, this transforms the cast of a political confrontation, away from organisers and towards those caught in spectacular images. The temporality of the confrontation also changes, with the aftermath - the retrospective witnessing of insecurity - becoming an important parameter in a visual security argument.

By doing this, protest filming reconfigures the conditions that make possible effective political protest or effective responses to political protest, tying such effectiveness to the online and mass media remediation of the visual media content produced by the filmed protest. That these media dynamics favour spectacular suffering of feminised victims is visible not only in the Brorson protests but also in the way in which Neda became the face of the 2009 Iran uprising after her video-filmed death (Andersen 2012), or how the image of tear-gas sprayed towards a "lady in red" (Ms. Ceyda Sungur) became the iconic image of the 2013 Gezi Park protests in Turkey despite the protagonist's "reluctance" (Williams 2013).

There is another interesting dynamic at work when protests are filmed, a kind of Heisenberg principle that the presence of cameras that observes a conflict changes the behaviour of conflict participants. This dynamic, in its essence, is an anticipation of the dynamic described earlier, where (often feminised) victims of violence become important pivots in after-conflict security debate. In the Brorson confrontation this is visible in the preparations made by both protesters and police. Protesters pledge to be in the church with the refugee seekers, and with cameras and media equipment, at all times. Police, on their side, not only film the confrontations, and later make their surveillance film public for the first time ever in order to influence the post-confrontation debate (Andersen 2013). The 
Copenhagen police also decides in advance of the operation to only arrest the able-bodied men taking refuge in the church, even if women and children there were also sought for deportation. This decision ensured that the images of refugees being handcuffed matched the stereotypes of dangerous and/or angry 'Middle Eastern men' prevalent in contemporary Danish debates about refugees, the Global War on Terror (GWoT), and the war in Iraq.

It is perhaps no coincidence that in the GWoT-related conflicts ablebodied men were systematically denied designation as civilians, and by extension both the protections offered to civilians and the privilege of having their deaths counted as civilian collateral rather than enemy casualty. Preventing images of arrested women and children primes the visual imprint of the Brorson conflict towards angry Iraqi men struggling with police, and participates in securitizing the refugee issue, depicting refugee seekers as a threat rather than as in need of protection.

The translation done by the camera - rendering a political confrontation as a digital visual artefact - is by no means a passive recording. Rather we can see the camera as the central inscription device that transforms political confrontations, translating the corporeal, spatially and temporally situated materiality of political confrontation to a fluid mediatised conflict with different dynamics and logics. Here "an inscription device is any item of apparatus or particular configuration of such items which can transform a material substance into a figure or a diagram" (Latour \& Woolgar 1979: 51).

\section{Notes and References}

Andersen, Rune Saugmann. 2012. 'REMEDIATING \#IRANELECTION: Journalistic Strategies for Positioning Citizen-Made Snapshots and Text Bites from the 2009 Iranian Post-Election Conflict'. Journalism Practice 6: 317-336.

Andersen, Rune Saugmann. 2013. 'Citizen "Micro-Journalism": How \#IranElection was exploited in politics and newspaper stories'. in R. Berenger (ed.) Social Media Go To War: Rage, Rebellion and Revolution in the Age of Twitter. Spokane, WA: Marquette Books: 335-353.

Hansen, J. L. and TV2 News. 2009. 'Kirkerydning: Vil klage over slag'. TV2 News.

Harder, T. 2009. 'Knippel-Pigen Meldt til Politiet', Ekstra Bladet. Accessed at: https://ekstrabladet.dk/nationen/article4165808.ece

Latour, Bruno and Steve Woolgar. 1979. Laboratory Life: The Social Construction of Scientific Facts. Beverly Hills, CA: Sage. 


\section{Notes}

1 Some scales may be dominant in some sector of society, while others scales are dominant in other sectors. Versions of Marxism found scalar domination in the economy - and, therefore in regulatory state institutions - to be generated by capital (Collinge 1999: 569). In scientist approaches to natural geography, scales are seen to become dominant due to objective features of natural systems (Manson 2008). To reverse epistemological flattening à la Latour, Manson suggests an 'epistemological scale-continuum' relegating 'constructionist scales' to the 'human' end of 'human geography', allowing 'realist' and 'hierarchical' concepts of scale jurisdiction over the natural geography (Manson 2006).

2 We thank Matthew Coleman for this fortunate formulation.

3 The distinction between topography and topology has been used to capture this distinction in human/cultural geography (see, e.g., Allen, 2011; Elden, 2011; Coleman, 2011).

\section{References}

Allen, John. 2011. 'Topological Twists: Power's Shifting Geographies'. Dialogues in Human Geography 1(3): 283-98.

Andrejevic, Mark and Gates, Kelly. 2014. 'Big data surveillance: Introduction'. Surveillance \& Society 12(2): 185-96.

Ashley, Richard K. 1984. 'The Poverty of Neorealism'. International Organization. 38: 225-286.

Ashley, Richard K. 1988. 'Untying the Sovereign State: A Double Reading of the Anarchy Problematique'. Millennium: Journal of International Studies 17: 227-262.

Boltanski Luc and Laurent Thévenot. 2006. On Justification: Economies of Worth.Princeton, NJ: Princeton University Press.

Brenner, Neil. 2001. 'The Limits to Scale? Methodological Reflections on Scalar Reconstruction'. Progress in Human Geography 25(4): 591-614.

Buzan, Barry and Ole Wæver. 2003. Regions and Powers. Cambridge: Cambridge University Press.

Buzan, Barry and Ole Wæver. 2009. 'Macrosecuritisation and Security Constellations: Reconsidering Scale in Securitisation Theory'. Review of International Studies 35(2): 253-76.

Buzan, Barry, Ole Wæver and Jaap de Wilde 1998. Security: A New Framework for Analysis. London, UK: Lynne Rienner Publishers.

Chakrabarty, Dipesh. 2000. Provincializing Europe: Postcolonial Thought and Historical Difference. Princeton, US: Princeton UP.

Checkel, Jeffrey T. 1998. 'Review: The Constructivist Turn in International Relations Theory'. World Politics 50(2): 324 48.

Coleman, Matt. 2011 'Topologies of practice'. Dialogues in Human Geography 1(3): 308-11.

Collinge, Chris 1999. 'Self-Organisation of Society by Scale: A Spatial Reworking of Regulation Theory'. Environment and Planning D: Society and Space 17(5): 557-74.

Critchley, Simon. 2013. Infinitely Demanding, Ethics of Commitment, Politics of Resistance (Radical Thinkers). 1st ed.London: Verso.

Elbe, Stefan. 2006. 'Should HIV/AIDS Be Securitized? The Ethical Dilemmas of Linking HIV/AIDS and Security'. International Studies Quarterly 50: 119-144. 
Edkins, Jenny and Véronique Pin-Fat. 1999. 'The Subject of the Political', ch. 1, in Jenny Edkins, Nalini Persram, and Véronique Pin-Fat (eds.) Sovereignty and Subjectivity. Boulder: Lynne Rienner: 1-20.

Elden, Stuart. 2011. 'What's Shifting?'. Dialogues in Human Geography 1(3): 304-307.

Friedman, Thomas L. 1998. Foreign Affairs; Angry, Wierd and Deadly. The New York Times. Accessed at: https://www.nytimes.com/1998/08/22/opinion/foreign-affairsangry-wired-and-deadly.html

Gad, Ulrik Pram and Jeppe Strandsbjerg (eds). 2019. The Politics of Sustainability in the Arctic. Reconfiguring Identity, Space, and Time. London, UK: Routledge.

Holbraad, Martin and Morten Axel Pedersen. 2008/09. 'Planet M: The intense abstraction of Marilyn Strathern'. Cambridge Anthropology 28(3): 43-65.

Holifield, Ryan. 2006. Spaces of risk, spaces of difference: environmental justice and science in Indian country, unpublished doctoral dissertation, Department of Geography, University of Minnesota.

Howitt, Richard. 1998. 'Scale as relation: musical metaphors of geographical scale'. Area 30: 49-58.

Jepperson, Ronald and John W. Meyer. 2011. 'Multiple Levels of Analysis and the Limitations of Methodological Individualisms'. Sociological Theory 29(1): 54-73.

Latham, Alan. 2011. 'Topologies and multiplicities in space-time'. Dialogues in Human Geography 1(3): 312-15.

Latour, Bruno. 2005. Reassembling the Social: An Introduction to Actor-NetworkTheory. New York City, US: Oxford UP.

Lefebvre, Henri. 2002. [1961] Critique of Everyday Life: Foundations for a Sociology of the Everyday (Volume 2). London: Verso.

Leitner, Helga and Byron Miller. 2006. 'Scale and the Limitations of Ontological Debate: A Commentary on Marston, Jones and Woodward'. Transactions of the British Geographical Society New Series 32: 116-25.

Leitner, Helga, Kristin M. Sziarto, Eric Sheppard, and Anant Maringanti. 2007. 'Contesting urban futures: decentering neoliberalism' in Helga Leitner, Jamie Peck, and Eric Sheppard (eds.) Contesting Neoliberalism: Urban Frontiers. New York City: Guilford: 1-25.

Mayhew, Susan. 2009. A Dictionary of Geography, entry on 'Scale'. Oxford UP.

Manson, Steven M. 2008. 'Does Scale Exist? An Epistemological Scale Continuum for Complex Human-Environmental Sytems'. Geoforum 39: 776-88.

Marston, Sallie A., John Paul Jones II, and Keith Woodward 2005. 'Human geography without scale'. Transactions of the British Geographical Society New Series 30: 416-32.

Neveling, Patrick and Carsten Wergin. 2009. 'Projects of Scale-Making: New Perspectives for the Anthropology of Tourism'. Etnográfica 13(2): 315-42.

Pasquale, Frank 2015. Black Box Society: The Secret Algorithms That Control Money and Information. Cambridge, MA: Harvard University Press.

Ritzer, George and Jeffrey Stepnisky. 2014. Sociological Theory. McGraw-Hill.

Singer, J. David. 1961. 'The Level-of-Analysis Problem in International Relations'. World Politics 14(1):77-92.

Smith, Neil. 1990. 'Afterword: The Beginning of Geography', in Uneven Development, 2nd ed. Cambridge, MA: Blackwell: 160-178.

Tsing, Anna Lowenhaupt. 2000. 'Inside the Economy of Appearances'. Public Culture 12(1):115-44. 


\section{Translations across scales}

Walker, Robert B.J. 1993. InsidelOutside: International Relations as Political Theory. Cambridge: Cambridge University Press.

Walker, R.B.J. (Rob) 1999. 'Foreword', in Jenny Edkins, Nalini Persram and Véronique Pin-Fat (eds) Sovereignty and Subjectivity, Boulder: Lynne Rienner.

Wastell, Sari 2001. 'Presuming Scale, Making Diversity: On the Mischiefs of Measurement and the Global:Local Metonomy in Theories of Law and Culture'. Critique of Anthropology 21(2): 185-210.

Waltz, Kenneth 1959 Man, the State and War: A Theoretical Analysis. Columbia University Press.

Williams, Holly. 2013. Massive, violent crowds protest Turkish leader as policies'. CBS News.1 June. Retrieved 2 June 2013 


\section{Conclusion: analysing translations of security}

When the Danish Prime Minister Mette Frederiksen appeared on national TV on 11 March 2020 to announce the lockdown of large parts of Danish society she was flanked by different forms of expertise and authority with each their specific conceptualisation of what the unwanted future of the corona pandemic entailed. The following months can be seen as an example of a (televised) translation zone in which hybrid forms of governance arose and new concepts were born. This book has been about understanding exactly such translations. They take place between different conceptions of unwanted futures and are often approached from different disciplines or professions, national or organisational cultures, or across different scales.

The relevance of this approach emerged at a particular time and place. It is a response to a specific situation in which "security" has simultaneously come to assume a new centrality in public and private policy-making, while it increasingly takes many different forms. There are, in other words, not just one specific security mode of addressing unwanted futures - and then more and more of that one practice - but instead several competing styles and codifications of how to manage unwanted futures. Several different practices are gaining wider circulation and importantly, they increasingly intersect. With issues such as the corona pandemic - but also terrorism, climate change, information security, and migration - high on the political agenda, security has to a much larger extent become an integral part of everyday life. Security is no longer preserved for the security specialists to handle: the military, the police, or the emergency agencies. Instead, doctors, scientists, civil society, private companies, and global organisations are called upon to manage new threats. As the corona pandemic has so clearly shown, none of this happens in siloed spaces but in interactions where actors are forced to transcend their traditional modus and engage with styles that used to be alien to them. Doctors are asked to take a stand on the closing of borders. Politicians are forced to speak in the language of scientific certainty instead of values, citizens are called upon to police themselves.

These changes in the security landscape call for a rethinking of the disciplinary and practical boundaries that hinder us from understanding the possible impact of and the opportunities that arise from these developments. 
Therefore, the book - and the research project behind it - is a deliberate effort to provincialise "the security way" of approaching an unwanted future. Different forms of securitizations, dangerifications, or risikifications exist among a wider family of concepts and policies that share the feature of prescribing how to go about an unwanted future in the present. In order to capture this, we have suggested a general framework for understanding along which lines the conceptual changes are taking place. While paying close attention to the methodological problems involved in framing an analysis in terms of prefixed concepts and actors, we introduced a framework for analysis that aims to grasp how different conceptualisations meet and potentially transform existing practices, structures, and historically constituted structures of meaning. This framework has "translations" as its core analytical concept, pointing to the conceptual changes that happen in meetings between functionally differentiated professions and disciplines, across cultures, and scales. We keep this concept of translation open; allowing a focus on all kinds of meetings between sedimented structures of meaning - including distortions, articulations, and attempts at perfection. This framework for analysis helps us to highlight actual practices of translations and to reveal the politics of security, risk, and danger today. Moreover, we claim that the way in which the framework has facilitated our mapping of security translations is an important finding in its own right: looking at contemporary societies through this lens, we claim to have identified the main lines along and across which translations happen today. This is of potential relevance for other research agendas.

\subsection{A framework for analysis: translation zones, concepts, and time}

We are aware of the methodological dangers of taking our point of departure in any fixed structure and initially wanted to focus our analysis on an open understanding of translations. However, instead of leaving this as a totally free-floating "activity," we found it pivotal to introduce a set-up that could grasp how conceptions with roots in entirely different conceptual universes meet. Basically, our one, very modest, yet "un-fashionable" and (in the current critical security studies climate) controversial, claim is that everything is not happening in one shapeless space - there are zones of meaning-making, and therefore when translations happen, they often cross boundaries between meaning-spaces. These spaces cannot be named and mapped in a positive and definitive sense, because that would demand a total theory of society of a kind that is no longer possible in our age. It is important to leave the nature of these spaces analytically open to emerge through analysis, but so more important it then is to have a general metamap that exactly enables an analysis that spots potentially transformative conceptual translations and political innovations. 
The main structure of the book followed the triad of functions, cultures, and scales, each of which constitutes a zone of translations. They are, in other words, points of observation from where we can study translations of unwanted futures. In chapter 3, we looked at professions and disciplines that correspond to some field or function of society. They constitute professionalised knowledge-based organisations that draw legitimacy from the functional differentiation of society. Chapter 4 then shifted to a differentiation along a different principle. Cultures do not claim to do one specific kind of thing (as functionally differentiated ones do), they each claim to do the same thing, but in a particular way: their way. Nations claim cultural uniqueness; organisations cultivate unique organisational cultures. In chapter 5 then the organising distinction was the one of scale. In a more or less explicitly territorial format, translations grapple with systems of space and hierarchy. Table 6.1 summarises the relations between the state and knowledge production and each of these functional, segmentational, and stratificatory differentiations.

Table 6.1 Translation zones negotiating support of state and knowledge

\begin{tabular}{|c|c|c|c|}
\hline $\begin{array}{l}\text { Unit } \\
\text { differentiated by... }\end{array}$ & & Relation to state & $\begin{array}{l}\text { Relation to } \\
\text { knowledge }\end{array}$ \\
\hline \multirow[t]{2}{*}{ Functional expertise } & Disciplines & Transcends state & Produces knowledge \\
\hline & Professions & Authorised by state & Applies knowledge \\
\hline \multirow[t]{2}{*}{ Culture } & Nations & $\begin{array}{l}\text { State claims to } \\
\text { represent }\end{array}$ & $\begin{array}{l}\text { Selects suitable } \\
\text { knowledge }\end{array}$ \\
\hline & Organisations & Sanctioned by state & $\begin{array}{l}\text { Employs useful } \\
\text { knowledge }\end{array}$ \\
\hline Scale & & $\begin{array}{l}\text { Produces/privileges } \\
\text { state }\end{array}$ & $\begin{array}{l}\text { Prioritises } \\
\text { knowledge }\end{array}$ \\
\hline
\end{tabular}

Each chapter was subdivided into two parts, where the first looked at what happened when two different manifestations of the chapter's type met each other, profession to profession, culture to culture or scale to scale. The second then studied translations that happen between the organising principle of the chapter and its opposite: professions meeting lay knowledge, cultures confronting universalisation, and scale opposed to de-territorialisation. This our basic analytical grid for identification of translation zones is summarised in Table 6.2.

Table 6.2 Our analytical grid pointing out potential and potent translation zones

\begin{tabular}{lll}
\hline $\begin{array}{l}\text { Logic of } \\
\text { differentiation }\end{array}$ & $\begin{array}{l}\text { Differentiations according to } \\
\text { logic }\end{array}$ & $\begin{array}{l}\text { Differentiations } \\
\text { challenging logic }\end{array}$ \\
\hline Functional & $\begin{array}{l}\text { Discipline vs. Discipline } \\
\text { Profession vs. Profession }\end{array}$ & Expertise vs. Amateur \\
Segmentational & $\begin{array}{l}\text { State vs. State } \\
\text { Organisation vs. Organisation }\end{array}$ & $\begin{array}{l}\text { Culture vs. Universalism } \\
\text { Stratificatory }\end{array}$ \\
\hline
\end{tabular}


The nature of this framework and grid for analysis not only helps us to reveal the politics of the actual practices of security, risk, or danger, it also reveals our own academic practice. We have argued against seeing meaning as radically emergent but rather as historically and contextually bound: Actors speak from the communities they hail from. Therefore, we find it productive to highlight actual practices of translations and cases that disclose the intersections between different conceptual universes. Our analytical grid claims that two types of translations are bound to happen. First, translations are bound to happen across distinctions within a particular logic: across the borders of functional differentiations like two competing professions; across the borders of two segmentational differentiations like two neighbouring nation states; or across two scales organised in a hierarchy. Second, translations are bound to happen across the distinctions marking the end of any of these three basic logics of differentiation, which have been defining for our modern view of threats and security. What happens when the amateur (e.g. the public) suddenly becomes a security expert? What happens when that which before was considered "outside" to the state (e.g. threats to national security) are now considered part of the internal? What happens when a hierarchical order is challenged by a network organisation? These translation zones are the places where differentiations sedimented in modernity can no longer be kept separate; the place where concepts, programmes, and practice meet. Often, these are the spaces for studying the newness of the practices we observe as it marks both the possibility and the impossibility of these ruling distinctions or systems of meaning. For example, it might seem paradoxical to be both an amateur and an expert at the same time and then still uphold the distinction. Yet, this is what can be observed in today's debates on co-production of security-knowledge where traditional meanings of security expertise, as something that resides in the state, are being challenged. As society has generally evolved beyond most of the classical comprehensive models from social science, this multi-dimensional picture of simultaneous variations of different kinds is an unusually inclusive way to travel through contemporary social life and identify spaces and transitions between them. In our case, this grid emerged out of an attempt to follow security translations through society, but the grid is more general. We suggest that it is likely to have applicability for quite different research interests than those in the present book.

What have we looked for, when we zoomed in on these translation zones to study how social and political concepts change? How does one analyse change and understand the magnitude and meaning of current security practices? First, we have argued that translations draw on different means: the powerful discursive or physical means that mobilise these translations and make them possible. As shown in this book, these means can range from everything from laws, instructions, and formal certificates over imitation and assimilation to physical artefacts. Secondly, each translation makes authority visible in different ways, and thirdly, each translation involves different stakes and produces different consequences.

Table 6.3 sums up our definition of where to look and what to look for when analysing the translation of unwanted futures. 
Table 6.3 Our definitions and examples of where to look and what to look for when analysing the translation of unwanted futures

\begin{tabular}{|c|c|c|c|c|}
\hline & Translation zone & Authority & $\begin{array}{l}\text { Means of } \\
\text { translation }\end{array}$ & $\begin{array}{l}\text { Stakes and } \\
\text { consequences }\end{array}$ \\
\hline Definition & $\begin{array}{l}\text { The meeting-place } \\
\text { between } \\
\text { different } \\
\text { conceptual } \\
\text { expressions of } \\
\text { how to handle } \\
\text { unwanted } \\
\text { futures }\end{array}$ & $\begin{array}{l}\text { The claims that } \\
\text { make the } \\
\text { translation } \\
\text { powerful and } \\
\text { legitimate }\end{array}$ & $\begin{array}{l}\text { The means by } \\
\text { which the } \\
\text { conceptual } \\
\text { negotiations } \\
\text { take place. }\end{array}$ & $\begin{array}{l}\text { What comes } \\
\text { out of the } \\
\text { conceptual } \\
\text { negotiation } \\
\text { (e.g., new } \\
\text { concepts; } \\
\text { new forms of } \\
\text { authority; } \\
\text { hybrids) }\end{array}$ \\
\hline Examples & $\begin{array}{l}\text { Disciplines; } \\
\text { Professions; } \\
\text { Cultures } \\
\text { (nations and } \\
\text { organisations); } \\
\text { Scales }\end{array}$ & $\begin{array}{l}\text { Utility; analytical } \\
\text { ability; } \\
\text { authority; } \\
\text { experience; } \\
\text { loyalty; } \\
\text { diversity; goal- } \\
\text { achievement; } \\
\text { competition; } \\
\text { universality; } \\
\text { causal } \\
\text { significance; } \\
\text { normative } \\
\text { valuation }\end{array}$ & $\begin{array}{l}\text { Degrees; skills; } \\
\text { certificates; } \\
\text { instruction; } \\
\text { resistance; war; } \\
\text { assimilation; } \\
\text { sovereignty; } \\
\text { salary; } \\
\text { acquisition; } \\
\text { publicity; } \\
\text { collaboration; } \\
\text { law; regulation; } \\
\text { certification; } \\
\text { imitation; } \\
\text { weapons; } \\
\text { digitalisation; } \\
\text { terrorism }\end{array}$ & $\begin{array}{l}\text { Universalisatio- } \\
\text { n; networks; } \\
\text { repressions; } \\
\text { liberation; } \\
\text { emancipa- } \\
\text { tion; } \\
\text { torture; war }\end{array}$ \\
\hline
\end{tabular}

If you want to frame your analysis of a security translation as we suggest, you should go through at least the four steps shown below (Brief 6.1). First, looking meticulously at the empirical interventions you begin determining the main form of negotiations in your research topic. What conceptual meanings are invoked and at play in those negotiations? Think about which forms of organisation and thus the sedimented structures of meanings on which these conceptual expressions rely. It might be disciplines; it might be national cultures; it might be actors organised in a hierarchy of scales; and so forth. Are you primarily facing an issue of functional differentiation where the pivotal fault line is that between disciplines/professions perhaps challenged by the amateur or lay voice? Could your problem set be better analysed through a segmentational frame, where different cultures (national/organisational) are competing for authority or are they perhaps under constant threat from a universalising phenomenon undermining or reconfiguring what it means 
Brief 6.1 How to carry out an empirical translations analysis?

1. Identify the translation zone. Ask: What is the main form of organisation and logic of ordering? Which sedimented structures of meanings do they rely on? How do conceptual meanings meet and how are these meanings negotiated? What conceptual meanings are invoked and at play in negotiations? Identify the means used to mobilise and support the concepts of unwanted futures.

2. Identify the claims on authority. Ask: what claims to authority are made in the process of translation? What is involved in making those claims appear legitimate and authoritative? (e.g. scientific evidence, language of necessity, utility, loyalty, state recognition, etc.)

3. Ask: what is the powerful discursive or physical means used to mobilise the translations? By what means is the unwanted future communicated? (e.g. laws, regulations, digitalisation, institutions, etc.)

4. Analyse the stakes and consequences at play. (new concepts? forms of governance? Other?)

to "be" that culture. Finally, would a stratification looking glass better capture the main divisions in play? Are territory or authority under attack from networks or suppressing networked forms of agency? Often, of course, you will find that your case can be observed as departing from more than one set of differentiations. The next step would be to dig deeper into what takes place in the translations zone. Look about what claims of authority are made concerning how to deal with the unwanted future? What is involved in making those claims appear legitimate? Going through this detailed empirical process you will slowly begin to get a grasp of the contours of the translation of the unwanted future in question. Do these claims resonate with one set of meaning? Or is the claim twisted in this or that way to fit more? As a third step, you could consider by what means the unwanted future is communicated? Laws, regulations, digitalisation, or other forms? An instructive step in this part of the research would be to plot in the empirical material in the matrix we have developed. Preliminary notes towards such an analysis might look like Table 6.4. 
Table 6.4 Example of case study notes guided by our analytical grid and definitions of what to look for

\begin{tabular}{|c|c|c|c|c|}
\hline $\begin{array}{l}\text { Translation } \\
\text { zone }\end{array}$ & $\begin{array}{l}\text { Functional } \\
\text { differentiation }\end{array}$ & Distinction & Authority & $\begin{array}{l}\text { Means of } \\
\text { translation }\end{array}$ \\
\hline \multirow[t]{2}{*}{$\begin{array}{l}\text { Functional } \\
\text { expertise: } \\
\text { Public } \\
\text { health } \\
\text { education }\end{array}$} & $\begin{array}{r}\text { Profession or } \\
\text { Discipline? }\end{array}$ & $\begin{array}{l}\text { Horizontal: } \\
\text { Journalist vs. } \\
\text { Epidemiolog- } \\
\text { ist }\end{array}$ & $\begin{array}{l}\text { Practical utility in } \\
\text { communicating } \\
\text { knowledge }\end{array}$ & $\begin{array}{l}\text { Internal: } \\
\text { Skills/ } \\
\text { Concepts } \\
\text { External: } \\
\text { Resumes }\end{array}$ \\
\hline & Amateur & $\begin{array}{l}\text { Hierarchical: } \\
\text { Expert vs. } \\
\text { Amateur }\end{array}$ & $\begin{array}{l}\text { Formal expertise } \\
\text { vs. Experience } \\
\text { as victim of } \\
\text { COVID }\end{array}$ & $\begin{array}{l}\text { Instruction } \\
\text { vs. Fear }\end{array}$ \\
\hline
\end{tabular}

However important, this meticulous and open form of research is not an aim in itself. Description remains a means to the overall aim of pinpointing possible changes in the concepts and practices for managing unwanted futures. Hence, a final step involves concluding which conceptual changes your translation may point to. Do you see conceptual changes that might have an impact on the handling of the situation in the future? Is one conceptual form of the unwanted future (security, unsustainability, risk) seen taking the victory over others? Are you seeing new hybrid forms of concepts, which are likely to change the path for studies in the future, or did you perhaps see a total rejection of the hybrid form put forward as a solution, with the result that old ways of handling unwanted futures were further fortified? With this final step, you will not only have reached solid and detailed conclusions about your empirical material but also added to the conceptual dialogue and reflection, which a translations approach aspires to making possible and analytically systematic.

Importantly, translations do not follow as set recipe. Hence, it is mandatory in the research process to keep an open eye to the possibility that more differentiations are at play at the same time. Back-check your primary differentiation by constantly letting what seems anomalous be a possible sign that more sedimented differentiations, mediums, and forms of legitimacy are in play.

In the following section, we present what we found when casting our empirical net widely and processing the tales and observations through these four steps.

\subsection{New trends in the management of unwanted futures}

Many prominent scholars in the field of risk and security governance have contributed to this book by providing their empirical observations written in the form of "tales": short empirical presentations of contemporary 
translations. Based on our framework for analysis and these tales, we make some general observations on conceptual changes. The dual purpose of the book is to provide a framework for understanding the main "logics" and modus operandi associated with the management of unwanted futures, and thus observe new and emerging patterns in the current security landscape.

\section{New and emerging patterns}

First, new security authorities are emerging, as new global and unruly threats such as terrorism, cybercrimes, and environmental destruction call for an engagement of citizens and business. As we describe in chapter 3, the traditional divisions between expert and amateur are eroding and have left a translation zone available for negotiations over new forms of authority; negotiations on who are or should be considered a "security professional." While this development can too easily be categorised as an erosion of the state's authority, it is not as straightforward. Rather we need to see the current development as a change in state governance - a change from a form of security governance, which is mediated by clear rules, centralisation, and hierarchies to a form that stresses decentralisation and self-governance. This decentralisation, we argue, is not only a delegation of different tasks and responsibilities for the provision of security to the wider public and the private sector but is also a decentralisation of the "right" to identify, define, and select the unwanted futures to be acted upon. The former "amateur" on security thus becomes co-definer, co-producer, and expert on new threats. In other words, the observations made in this book point to the authority of the "amateur" to legitimise the meaning of security knowledge. Chapter 4 takes up this line of thought by pointing out how these new forms of governance and the rise of new powerful social and economic international networks and actors (especially multinational companies and large NGOs) challenge the foundation of "national sovereignty." Many of those actors, networks, or alliances, we argue, are hybrid zones of translation in the sense that they are at once defined by their national and international belonging, and simultaneously by their private as well as public agency (e.g. cyber criminals). The medium of translation can be referred to as "collaborative learning," imitation and assimilation, which is understood to provide a subtle alternative to traditional forms of legal regulation and sovereignty. Legitimacy is provided on the background of having a common goal in finding effective solutions to new and transnational threats. Relatedly, in chapter 5, we observe how traditional territorial divisions and hierarchies of scale are increasingly transcended and de-territorialised in the name of "networks," paving the way for digital technologies as a forceful means of translation. These observations on the rise of new security authorities trigger important democratic concerns. As such, decentralisation of responsibility, new powerful actors, and co-production generally undermine the fundamental right of equal protection and the possibility of society to discontent 
security decisions. At the same time, this development manifests the liberal ideal of free trade as a path to wealth and freedom.

Second, we observe at least three changes related to our understanding of the "individual subject." While this also relates to the translation zone described above as a push towards a decentralisation of authority, it is important to recognise how the mere meaning of the individual human subject itself has come into question in the acts of translating security. As treated in chapters 4 and 5, the advent of data trails, algorithms, and big data has created a splitting of the individual subject into a physical human being and a "data double." The human subject is, in other words, no longer just human: the human is (also) data. This trend to construct the individual subject as "something" beyond human, as "data," has many complex implications as individual protection becomes both extremely difficult to manage and a highly decentralised responsibility. Lastly, we have also witnessed how the individual subject becomes "super-empowered": a subject, which can create catastrophic situations at the national or the global level, and thus a political symbol in its own right. Think of the right-wing terrorist Anders Breivik in Norway or Edward Snowden as icons of such a trend. As these examples show, the "individual" sometimes out-battles the nationstate as the defining powerful security actor. These individuals have come, at least symbolically, to transcend the way in which we normally think about the power of scales in politics.

The third general trend that we observe in this book is de-territorialisation. This trend is mainly observable in translations between cultures and scales but leaves deep traces in the functional differentiation between private and public actors' roles and responsibilities on security. De-territorialisation is visible as private and international networks gain power and evade the spatial container of the state and its security apparatus. Further, digitalisation as a means of translation has made us aware that the origin and target of cyber-attacks are often hard to locate in both time and space but emanate from or hit somewhere "out there" in cyberspace, making responding to threats extremely difficult. The distinction between the national and the global scale somehow dissolves. At the same time, as we show in chapter 4, in translations between cultures, the close fit between culture and territory is eroding. Culture is increasingly perceived as something crossing borders; as global, regional, or multinational. Global civil society networks and multinational business communities have emerged that stand in a somewhat paradoxical relation to the nation state: Where these groups do refer to many of the legal arrangement of nation states, they also surpass this framework in their call for transcending global ethical standards. Cultural identity is, thus, no longer tied to a national political identity, but is increasingly detached from the nation state. While the negotiations over the meanings of security, risk, and threats can still be studied as translations between cultures, scales, and function, we can also observe how the management and perception of unwanted futures becomes less and less bound to 
the traditional spatial and hierarchical understandings of modern security organisations. However, these developments do not render our well-known territorial and spatial entities obsolete. Cyberspace is connected to "real territory" and the flat space of networks still needs human beings, access to servers, and possibly storage of weapons or means of transportation to succeed. The world we live in is not simply awash in fluidities, but its spatiality is no longer two-dimensional and stable.

Fourth, this book has argued that many of the attempts to re-write the meaning of functionally differentiated professionalism, segmented cultures, and stratified orders of politics point to a growing disbelief in the authority of prediction and control of unwanted futures. In other words, the legitimacy of actions done in the name of security or risk no longer rests on the possibility of forecasting, risk management, and thus control. Instead, concepts such as precaution and resilience are increasingly giving legitimacy to such acts. In the same fashion, a scepticism towards the idea of learning, as a management tool to future perfection within security affairs, arises. Learning is often considered meaningful only within a certain context attached to local practices and experiences. Consequently, learning cannot be based on either experience (to predict the future) or be transferred over distances (as learning from other cultures). A different way to observe this change is to see it as a change in the meaning of knowledge and the role of science: as a move from that of seeing learning as a matter of applying already acquired knowledge that is (somehow) detached from the current context to that of being contextual in time and space. We thus see an increasing disbelief in the classical Humboltian idea of science: a disbelief in exact truths and therefore in the possibilities of using the past as a guide to managing unwanted futures. Accordingly, we argue that the entire idea of learning as key to translations is challenged in today's threat discourses, characterised by dispersed and possibly catastrophic threats. Steering and purposeful action through the refinement of tools have thus come under pressure. One natural consequence would be to give in to a total relativism, yet, as we observe, the call for resilience, emergency management, and big data, increasingly spread as governing devises that accept uncertainty. These new technologies make security an everyday practice and confront the hierarchy of responsibility associated with the modern idea of security provision. The popular "mode two" thinking on interdisciplinary and university-society collaboration can, as we argue in chapter 3, likewise be read as an attempt to rethink the relation between science and socio-economic affairs. Interdisciplinarity and innovation, we argue, can be read as ways out of an otherwise rather gloomy description of the possibilities for managing unwanted futures.

Modern logics of differentiation support established forms of knowledge and state authority - while translation zones beyond these sedimented logics involve challenges to both the state as we have known it and established forms of knowledge. Table 6.3 depicts a number of conceptual challenges to these sedimented forms when analysed through our analytical grid. 
These trends and observations on the current state of security are examples of findings that work to show the potential of the framework for analysing translations of security. The next question then becomes how this fits into the wider debates in security studies; on the concept of security; its role in society; and theory building for the future.

\section{Cascading concepts of security}

Based on these preliminary findings, we can start to draw a picture of how current translations of security, within and across professions, cultures and scales, challenge conventional ideas of security. What we observe in this book is not so much a conceptual shift from security and risk to precaution or resilience, but translations that cast into doubt some of the most fundamental values behind Western security politics. One such value is collectivism, another is professional elitism, and a third is responsibility and accountability.

In their attempt to sophisticate earlier efforts to define the concept of security (Wolfers 1952; Baldwin 1997), Buzan et al argued in 1998 that security politics is about our collective survival and thus that security politics always involves some sense of a collective referent object and definition of a public good (Hansen 2000). While this in some sense still holds true, the examples given above question the moral superiority of the kind of collectivism often referred to in security studies; collectivism associated with the survival of a self-contained collective unity and a politically motivated sense of the common good. As we argue above, in the treatment of the trend towards de-territorialisation, the current internationalisation and privatisation of the practice of security in the name of the collective good push for a security politics based on decentralised structures of self-governance, leaving the practice of defining the public good less centralised and less selfcontained as a category of political management. In other words, we see a move from the security politics as macro planning to that of decentralised practices of governance (e.g. in works on resilience). However, and almost paradoxically, this drive towards individualisation or privatisation in security affairs is deeply embedded in a collective construction of subjectivity, which is based on a form of digitalisation and data-mining that works from a conception of the "average" human.

Following on from this, the examples above also challenge the elitist vision of decision-making in the field of national and international security. By questioning the idea of the state as the main driver of security politics, the meaning of security expertise has broadened to include actors that previously were considered amateurs on security. These new experts are called upon to co-create knowledge on new threats and to steer an otherwise unpredictable future. This development might have grave consequences, not only for the possibility of democratic control with security but also because such great trust in the private management of security threatens the entire 
idea of a liberal economic market; a market free of national security interest. Because, as we argue in chapter 4, decentralisation and the management by the many are not necessarily doing away with geopolitics and a cultural segmentation of threats.

Relatedly, as a number of prominent scholars have also observed (Neal 2019), current practices of security challenge the modern idea of security politics as exceptional (Bigo et al. 2020). Where the "exception" traditionally has been used to describe "a moment" in a liberal democracy (outside of normal politics), authors have argued that the current policy on, e.g. counterterrorism has extended the exceptional moment to everyday politics (Aradau \& Munster 2009). According to these studies, the call for extraordinary measures has become normal politics. While the examples above support this conclusion in stressing the dissolution of the modern distinctions between security professionals and amateurs, and between state bureaucracy and network-based solutions, they also pointed to a cultural and professional inertia in modern institutions: in the workings of state bureaucracies, risk management procedures, and so forth. This trend might support what Andrew Neal (2019) considers a move towards "legislative exceptionalism": a move towards a normalisation (bureaucratisation and institutionalisation) of the exceptional moment.

Last, one can observe a break with the meaning of responsibility and accountability, which has traditionally been understood as tied to the person/organisation performing the speech act of securitization. As we show in our discussions on functional systems (chapter 3) and scales (chapter 5), responsibilities for security are increasingly diffused and managed in global civil society networks and big business (e.g. the tech industry), hybrid organisations, which all, to some extent, operate outside the formal jurisdictions of national bureaucracies. Likewise, a common belief in the possibility of prediction and management of new threats give way to new measures of precaution and resilience, which fundamentally de-responsibilise the socalled securitizing actor. Within a framework of uncertainty about unwanted futures, responsibility and moral obligations are no longer cast in the light of science and known consequences, but responsibility is, as Francois Ewald puts it, "swallowed up in public ethics" (2001: 285).

\subsection{Theory-building for the future}

In the recent history of Critical Security Studies, one can observe a repetitive pattern of condensation and loosening of its conceptual focus. Classical security studies assumed that security was a known category holding the field together. Both explicit arguments but also practical analysis challenged this assumption by widening the agenda of security studies from the late 1970 s to the early 1990s. Securitization theory in turn presented a new focal concept for the field; arguing that it was indeed possible to observe the securitization of a wide range of issues - but specifying just what dynamics 
and criteria made this wide range of phenomena security issues. Critics from other new security schools and especially from risk studies then pointed to a new diversity beyond one fixed form of securitization. From debates on security and risk, the possibility emerged that a securitization-like analysis could evolve into parallel analyses of securitization and riskification (Corry 2011; Diez et al. 2016; Petersen 2011). While some scholars argued that a single form (risk) actually held the whole field together (like "security" supposedly did before), most pointed to increasing diversity.

While it is certainly still worthwhile to develop the different security theories (or "schools") already out there in the disciplinary landscape by careful applications and evaluations, we found that now was a good time for "stepping back"; for taking care not to force cases into pre-established, elaborate theories; and for generating nuanced observations. Hence, in this book we have approached the diversity of concepts head on but in a more systematic way than others who have argued the transformation of security and risk. We have deliberately aimed not to be deductive in terms of what concepts of security, risk, and danger are out there. Rather, we have intended to go fully beyond the contrastive mode of "not-only-but-also" to looking at all forms of politics of unwanted futures with an open analytical frame not predisposed by categories of security or risk.

We have done so by carefully shifting the point of observation of our analysis from inner features of these concepts to a framework for observing - from outside, so to say - the translations occasioned by their meetings in translation zones. In this book, structure is provided, not by individual concepts but, first, by the focus on translations, and, second, by the translation zones identified by the distinct forms of differentiation. (The latter might even prove helpful beyond the particular context of translations of security.) This analytical framework is certainly not placed outside history. Rather, the framework we suggest is historically bounded and identified with the help of conceptual history. It asks what happens to our conventional categories of meaning (concepts), bound up in ideas of functions, scales and cultures, when they meet other practices and concepts related to unwanted futures. We contend that we can both draw lessons for the future and learn from the past from this framework. Nevertheless, we devise the framework in and intended it for a specific point in time. Others can take inspiration from it but should always carefully consider concrete practices and concepts.

In terms of theory, a next step might be to try to capture the whole field from "within" a dominant set of concepts. Working from the foundations laid in this book, there will be a new phase, where it becomes possible to articulate theory centered on the conceptual changes and thus lay down new distinct forms of security, risk, danger, and so forth. While concepts evolve, we cannot expect that one concept alone - security, risk, danger or threat can capture the field in the complexity demonstrated in our analysis. Yet, we might be able to theoretically define some core conceptual logics of the field, 
to make visible their societal and political importance. By then, the dialectic might again have moved on, from theorising that anchors coherence in the nature of the dynamics among concepts and practices related to unwanted futures like in this book - back to theorising that anchors coherence in the inner conceptual structure of key concepts, like shown in Figure 6.1.

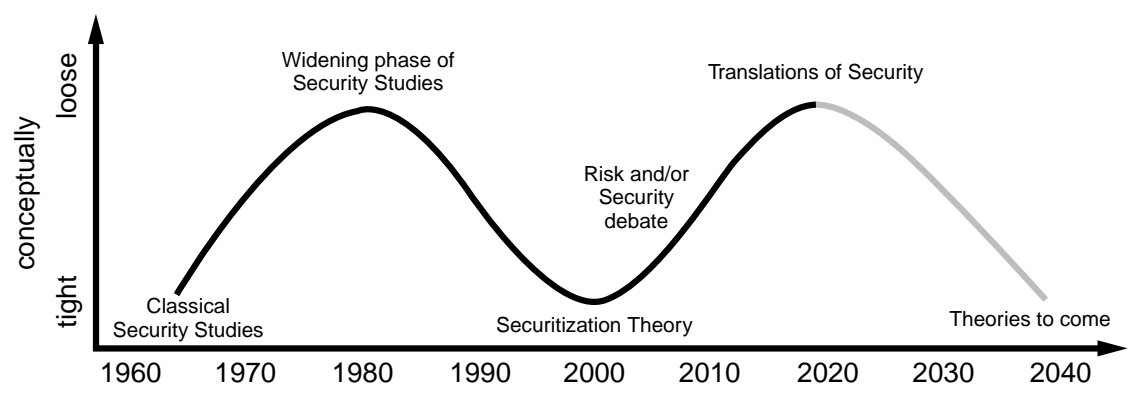

Figure 6.1 Oscillation of conceptual tightness in Security Studies.

As expressed in the first boxed tale of this book, contemporary critical scholars are often asked to reconsider their view of science in the face of climate change and climate scepticism (Kofman, 2018; Latour 2013). Simplistic critics see a straight line from critical science studies that undermined the status of science during the second half of the 20th Century to reactionary political actors in the 21st Century refusing to listen to specialists on climate change, pandemics, crime, or international economics. However, the fragility of science in the contemporary political climate is less a result of critical examinations, and much more a result of an old-fashioned public image of science as purity totally unaffected by social dynamics, because that makes expert statements dependent on an either/or logic that fails in all politicised settings (Jasanoff 2005). Therefore, the real challenge is to cultivate a more robust image of science as both humanely social and distinctly productive of a particular kind of knowledge. If the institution of science is taken seriously, there are situations where the case is very strong for giving it a very prominent place, as with climate change (Oreskes 2019). But in the old-fashioned game of objectivity and truth, it can be disqualified by contemporary populists (Latour 2013: 2-23). This dangerous new challenge can be handled better if society moves towards a general understanding where many different claims legitimately compete on each subject, and discussion has to address squarely the reasons for trusting one institution rather than another, or for mediating different ones in transparent ways (Leander \& Wæver 2018). The old game of objectivity and truth has been lost because science has too long claimed to represent Reality pure and simple. As soon as science has been dislodged from that position, which it 
could never legitimately claim, "politicised science" is free to make everything ultimately a question of individual belief.

However, institutions matter - or as we put it in this book: professions, disciplines, cultures, and scales condition conceptions of unwanted futures. Against the binary choice between "Science Professing Reality" and "You choose what to believe," our approach is a call for taking other people seriously as reasonable and well justified in their conceptions of danger, risk, and insecurity, as coming from different backgrounds. More and more of the big challenges facing individuals and collectives - from intimate groups to all of humanity - are impossible to handle within any one discipline or nation. Moreover, it is equally impossible to envision how most of them may be encapsulated in one new consolidated, synthesised understanding that "lifts" each of the partial knowledges into a fuller, comprehensive one. They will inevitably have to be handled in spaces between, in translations. So, we might as well get better at understanding and managing these translations of unwanted futures, soon.

Similar to other recent theorising in Critical Security Studies, this study has tried to grasp the current struggle over meaning and identity in international security affairs today (Basaran et al. 2016). The aim of the present book was, however, to provide a comprehensive framework for studying these changes in security today. Not by insisting on the extension of one theory, coming out of one discipline, to cover all unwanted futures. Rather, our aim has been to give future students and researchers a common meta-language on concepts for the purpose of evaluating changes in how societies manage unwanted futures. Thus, the approach put forward is not only as a framework for analysis but also as an agenda for doing security research.

However, no approach, meta or not, is neutral. The performativity of both method and theory is unquestionable (Aradau \& Huysmans 2014; Wæver 2011), as any specific approach fixates concepts and key parameters. When there is no one approach which is "the right choice" selected by the object under study itself, but always many possibilities, then the choice becomes the responsibility of the researcher. When furthermore, these different approaches have different effects on different lives in the world, the choice becomes political. What, then, does our framework politicise? And what does it leave depoliticised? Most basically, building an explicit theoretical framework allows other researchers to systematically engage with the analytical choices and makes critical dialogue possible. With this book and the development of a framework for the analysis of how unwanted futures are conceptualised and managed, we hope to have created such a space for dialogue. Thus, this book is an attempt to re-instate science and expertise in a time of post-truth and alternative facts. Instead of undermining truth, the book takes science and expertise at face value and seeks to understand the way scholarly work and other forms of expertise interact and interweave. This is important in a time where science is under attack. 
We make this move at two levels. One is the nature of our own analysis, where we are keen to maintain responsibility for the conclusions we draw. We do so in two ways which are interconnected: By making all assumptions visible for the reader to judge. And by presenting a framework which has a sufficiently clear inner structure that it becomes visible what we are doing and what that doing does. Even when following recognised methods and doing disciplined research, there are always other possible analyses that could have been done in the same terrain, so one produces only one out of many possible outcomes. Hence, every one of us is doing politics, when we do research and present theory. To do not only politics, but do science, we need some criteria for evaluation. The framework of analysis set forward here is meant to provide such criteria for evaluation and thus scientific dialogue.

The second level of our push back against post-truth is the content of our analysis. Where the first had to do with its form, its structuredness that invites analysis of its mechanisms, the second is the focus on translations as such. This perspective implies that each profession, culture, or scale has important inner logics that make concepts of unwanted futures highly consistent and place relevant knowledge systematically in positions where it supports conclusions. However, given that each of these sedimented structures of meaning are contingent and exist in a world of multiplicity and diversity, they meet other approaches that they have to interact with. Many critical approaches in recent decades have pointed to the weakness of the foundations of each form of knowledge. Our approach looks at knowledge in a different way: Our approach underlines the strength, coherence, and reasonedness of each, but insists, at the same time, that each form of knowledge is limited by the fact that they have each become unable to operate independently. The fulcrum of most matters has shifted outside single systems and into the space where they interact and thus have to translate their different knowledges. Knowledge therefore appears inadequate; even while complex knowledge processes actually are ongoing, meaningful, and crucial to every sphere of activity. Only knowledges now work in ways that do not fit the image which most of us expect.

\section{References}

Aradau, Claudia, and Jef Huysmans. 2014. 'Critical Methods in International Relations: The Politics of Techniques, Devices and Acts'. European Journal of International Relations 20(3): 596-619. https://doi.org/10.1177/1354066112474479.

Aradau, Claudia, and Rens van Munster. 2009. Exceptionalism and the 'War on Terror': Criminology meets international relations. British Journal of Criminology 49: 686-701 10.1093/bjc/azp036.

Baldwin, David A. 1997. 'The Concept of Security'. Review of International Studies 23: $13-42$. 
Basaran, Tugba, Didier Bigo, Emmanuel-Pierre Guittet, and R.B.J. Walker (eds). 2016. International Political Sociology: Transversal Lines. Florence: Taylor and Francis; Routledge Studies in International Political Sociology.

Corry, Olaf. 2011. 'Securitisation and 'Riskification': Second-Order Security and the Politics of Climate Change'. Millennium: Journal of International Studies 40(2): 235-58. doi: 10.1177/0305829811419444.

Diez, Thomas, Franziskus von Lucke, and Zehra Wellmann. 2016. The Securitisation of Climate Change: Actors Processes and Consequences. London, UK: Routledge.

Hansen, Lene. 2000. 'The Little Mermaid's Silent Security Dilemma and the Absence of Gender in the Copenhagen School'. Millennium: Journal of International Studies, 29: 285-306 10.1177/03058298000290020501.

Huysmans, Jef. 2011. 'What's in an Act? On Security Speech Acts and Little Security Nothings'. Security Dialogue 24(4-5): 371-383.

Jasanoff, Sheila. 2005. 'Judgment under siege: The three-body problem of expert legitimacy', in Sabine Maasen and Peter Weingart (eds.) Democratization of Expertise? Exploring Novel Forms of Scientific Advice in Political DecisionMaking. Dordrecht: Springer: 209-24.

Koman, Ava. 2018. 'Bruno Latour, the Post-Truth Philosopher, Mounts a Defense of Science', The New York Times Magazine. Available at: https:// www.nytimes.com/2018/10/25/magazine/bruno-latour-post-truth-philosopherscience.html

Latour, Bruno. 2013. An Inquiry into Modes of Existence. Cambridge, MA: Harvard University Press.

Leander, Anna and Ole Wæver. 2018. Assembling Exclusive Expertise: Knowledge, Ignorance and Conflict Resolution in the Global South. London: Routledge.

Neal, Andrew. 2019. Security as Politics: Beyond the State of Exception Beyond the State of Exception. London, UK: Routledge.

Oreskes, Naomi. 2019. (ed.) Why Trust Science? Princeton, NJ: Princeton University Press.

Wæver, Ole. 2011. 'Politics, Security, Theory'. Security Dialogue 42(4-5): 465-80.

Wolfers, Arnold. 1952. 'National Security as an Ambiguous Symbol'. Political Science Quarterly 67(4): 481-502. 


\section{Index}

accountability 5, 56, 78, 79, 98, 205-206 Actor-Network Theory (ANT) 9, 14, 15, 22, 34-36

Afghanistan 58, 73, 110, 114, 121

Africa 121, 172; South Africa 79 agents $34,83,163,184$

AIDS Coalition to Unleash Power (ACT-UP) 173

Al Qaeda 185-186; Al Qaeda network 185

Alaska 125, 153-154, 176, 184

algorithms 164, 180, 203

Al-Saadi, Sami 112

amateurs 8, 18, 42, 52, 74, 76, 80, 91, $163,181,205-206$

American liberalism see liberalism amorphous physical space 163 anthropology 73, 95, 96, 107-108, 114, 143, 148

Andersen, Rune Saugmann 82, 188, 189 anti-colonialist 159

anti-expertise claims see experts

application-driven knowledge

see knowledge

Arar, Maher 182

Arctic 67-69, 73, 90, 153-154, 160;

Arctic Ocean 67, 160

Argentina 153, 184-185

Art History 178-179

artificial intelligence (AI) 81, 183

assimilation 119, 121, 124, 198, 200, 202

audience 16, 31, 59, 75, 79, 157, 177

audit society 56

Austin, Jonathan 110, 113-114, 118, 122-123, 162-163, 188

authority $1,5,16-18,27,34,51-53$, 55-56, 62, 75-76, 80-81, 90-91, 105-106, 119-121, 143, 145, 148-149, $159,160,163-164,173,186,188,195$,
198-204; authoritative political level 161 ; authority claims 53, 106; authority of the profession 91 ; authority of the state 91 ; historical authority 16

Bal, Mieke 178

Beck, Ulrich 4, 41, 136-137

belonging see culture

Bennoune, Karima 132

best practice 77,79

big data see data

Bigelow, Kathryn 150

Bigo, Didier 7, 182, 187

Bin Laden, Osama 151, 185, 188

biometric technology 123

biometric system 123

bioweapons see weapons

bodies 2, 15, 34, 93-95, 106, 111, 123, 144, 147, 163, 182-183, 188

Bosk, Charles 55, 57

Brasil 153

Breivik, Anders 180, 188-190, 203

Buenos Aires 151

business networks see networks

bureaucracy 11, 129, 155

bureaucratisation 91, 129, 206

Buzan, Barry 7, 149, 156-157, 205

Canadian War Museum 93

capitalism 143, 147-148, 158, 160

cartographers 67-69, 74, 90

Castells, Manuel 136

causal chain 110, 172; local causal chain 172

causality 60, 80, 148

Chakrabarty, Dipesh 159

Chamberlain, Neville 166

Chandler, David 137 
chief executive officers (CEOs) 84

chief financial officers (CFOs) 84

China 112

Christian theology see theology

CIA 112

Cienfuegos, Camilo 116

civil rights 186

Civil society 21, 105, 134-136, 163, 180, 195, 203, 206; global civil society 105 , 135-136, 180, 203, 206

civil-military relations see military

classical security studies see security studies

climate change i, 1-2, 20-21, 63-66, 69, 74, 80, 83, 90, 118, 129, 153-156, 160, 184, 195-196, 208; climate experts see experts; climate studies and climate science 69; COP21 20-22

Cold War 37, 85, 111, 125, 157-158; Cold War-era 111

collaboratively learning see learning

collective referent object see referentobjects

collectivism 205

Colombia 183

commercialised intelligence culture see intelligence

commercialised security see security

communication 13-15, 30, 33, 36, 38, 45, $52,61,75,107,119,127,129,133,136$, 171, 177, 180-181, 183, 188; communications technologies 180 ; visual communication 177

communism 159; ending abruptly in 1989159

concepts/sedimented structures of meaning 11; conceptual forms of differentiation: functional differentiation, segmentational differentiation, stratification 17; conceptual history 15,207 ; conceptual meaning 17, 53, 105, 128, 143, 181, 199; conceptual universe $11,13,31$, 61, 196, 198; hyper-complex concept 106

conceptualisation $6-9,12,14,104,142$, 195-196

contradictions 78

Copenhagen School 7-8, 38-39, 117

COP21 see climate change

Corona pandemic 1, 195; COVID-19 56,133

corporate security officers (CSOs) 84
Corry, Olaf 136

cosmology 118, 124; cosmologies 108, $110,123,163$

CO2 164; CO2 vs. climate 174

counter-intelligence see intelligence

counterinsurgency warfare 57

counter-securitization see securitization

counterterrorism see terrorism

crime against humanity 93

criminal networks see networks

Crimp, Douglas 178

crisis of identity see identity

critical security studies (CSS)

see security studies

Cuba 112, 114-115, 117, 156; Cuban revolution 159; liberal democratic fantasy of Cuba 115

cultural identity see identity

cultural security politics see politics

cultural studies 179

Cultural Turn see international relations

Culture, cultures $6,8,12,17,18-20$, 27-28, 30-32, 34, 37-38, 41-42, 50, 52, 58-60, 66, 74, 88, 104-114, 117-126, 128-137, 142, 145, 148, 158-160, 163-164, 171, 188, 195-197, 199-200, 203-205, 207, 209, 210; cultural

belonging 118; cultural otherness 117 ; cultural rights 130-134; European cultures 107; Indigenous culture 118, 126; individual cultures 105; insiders 104; organisational culture 17-18, 104-106, 108-109, 118-119, 128, 195, 197; outsiders 104, 121, 185; postcolonial political and social culture 123; ways of life 104, 122, 162 culturification 130

cyber $2,78,81,83,89-90,137,160,162$, 188, 202-203; cyber-attacks 203; cybercrimes 89-90, 202; cyberspace 203-204

cyber networks see networks cyber security see security

DAF 169

danger i, 2-4, 9-12, 15, 17-19, 21-22, $50-51,53,55-57,75,82,84-86,97$, $108,129,149,154,165,173,181,196$, 198, 207-209; danger replacement 55,57

dangerifications see securitization

Danish Armed Forces 169, 173

Danish kingdom see Denmark 
Danish national discourse see discourse Dannebrog 169

data $34,56,59,68,80-82,130-131,162$, 180, 182-183, 187-188, 203-206; big data $80-81,131,203$; data double 182-183, 187-188, 203; data-driven health service 56 ; decentralisation 202-203, 206; decentralisation of authority 203

DCAF 76

deep ontology see ontology

democracy 70, 157-158, 206; democratic inclusion 75; liberal democracy 206; liberal market democracy 158

Denmark i, 1, 63, 125-126; Danish kingdom 127

de-securitization see securitization de-territorialisation see territory de-territorialised networks see networks diachronic structures 15

diffusion of security knowledge see knowledge

digitalisation 80, 199-200, 205

diplomacy 27, 65, 119, 123, 136-137, 164

disaster myth 155

disciplinary knowledge see disciplines

discipline and governmentality see governmentality

disciplines x, xi, 2-3, 5-6, 11-13, 17-18, 27-28, 31, 41, 50-54, 61-63, 67-68, 74-76, 80-81, 90, 92, 104, 106, 143-145, 160, 178, 195-197, 199, 209; disciplinary knowledge 54; interdisciplinarity 3, 6, 62, 90, 204

discourse 13, 17, 27, 35-36, 39-40, 65, $106-107,114,123,127,126,129-131$, $135,143,150,152,154,169-173,179$, 185, 204; discourse analysis 35 ;

Danish national discourse 171; social discourses 173

discursive sedimentations see sedimented discourses

diversity $3,6,19,64,71-72,119-121$, $169,194,199,207,210$

dogmatic theology see theology

Douglas, Mary 4, 128-129

East Asia 157

Ebola 56

economic networks see networks

economics 54, 61-62, 70-71, 73, 82-84, $90,143,208$; economic prosperity 156 ; economic welfare 169 ; hedges 70 ;

Marxist economics 143

education $51,74,80,91,130-133$,

152-153, 201; universities 88, 92

Egypt 111-112

embedded knowledge see knowledge

empowerment 82, 133; super-

empowered individuals 144, 187-188

energy security see security

English language 179

entrepreneurial university 92

environment 43, 68-69, 71, 84, 90, 95,

137, 154; environmental 2, 4, 63, 69,

73, 128-129, 136, 154, 202;

environmental insecurity 154

environmental politics see politics

epistemic arbitrage 91

essentialism 146; essentialised constructs of difference 146

ethical security see security

ethos $53,61,84$

etymology 107

Europe 32, 107, 126, 158-159; European 7, 67, 98, 107, 116, 122, 124, 159, 182;

European consensus 122; European

Union 122, 123

European consensus see Europe

European cultures see culture

European nation states see nation state

European Union see Europe

Ewald, Francois 206

expertise $\mathrm{x}, 1-2,6,13,18,30,50-51,58$, 62-63, 74-76, 80-81, 83, 85, 87-88,

110-111, 114, 119, 129, 162-164, 195,

195, 197-198, 201, 205-206, 209; anti-

expertise claims 6; security expertise

51, 198, 205

experts $2,13,50,59,63,74-77,80,85$, 110, 114, 129, 183, 186, 205; climate experts 50

explanatory power 83

Facebook 82

far-right wing see right-wing

fifth column 114, 169-170

flat ontology see ontology

formative societal practices see practice

Foucault, Michel 35, 41, 45, 149;

Foucauldian 35, 124

Frederiksen, Mette 1, 195

freedom 70, 132, 157, 203

Fridlund, Mats 41, 164-165

functional differentiation see professions 
Gad, Ulrik Pram 114, 125, 169

Gaddafi, Muammar 112

Galison, Peter 13-14, 52

genetically modified organisms

(GMO) 129

geopolitics 65, 206

Ghraib, Abu 111, 177

Giddens, Anthony 137

global civil society see civil society

global climate 21, 160

global scale see scale

Global South 98, 124, 158, 179

Global War on Terror (GWoT) see war

Google 90

Governance i, ii, 8-9, 39, 53-54, 68, 75, $105,108,135-136,163,165,173,195$, 200-202, 205; hybrid forms of governance 195

governmentality 9, 121, 122, 124, 149; discipline and governmentality 149

Greenland 124-127, 154, 160;

Government of Greenland 126;

Greenlandic independence 126;

Greenland Ice Cap 160; Inughuit

125-127; Thule 124-127; Qaanaaq 126

Greenlandic scale see scale

Guantanamo Bay 110-112, 163, 188

Guantanamo camp 185

Guaraní Aquifer 151

Guevarra, Che 159

Hahnemann, Niels Peter 61, 69-70, 83

Hansen, Lene 176-177

health $2,32,54,56-57,63,83-84,86$, $175,181,183,201$; medical institutions 55,57

hearts and minds 57

hedges see economics

hegemonic struggles 143

hermeneutic theories of language see linguistic translation studies

H5N1 avian influenza virus 86-87

hierarchy see scale

hierarchy of authority see scale

hierarchy of levels see scale

hierarchy of scope see scale

historical authority see authority

HIV/AIDS 177-180

Hobbesian 149

Hofstede, Gert 109

Holbraad, Martin 114, 120, 159

Hoeyer, Klaus 55, 61, 63

Hollywood 121, 150
Hong Kong 112

household livelihood see scale human geography 143, 147, 160

human rights $77,112,120-121,128$, 130-134; universal human rights $120-121,128,130$

Human Terrain System (HTS) 54, 58

Human Terrain Team (HTT) 57, 59;

Human Terrain Team Handbook 59

humanity 93, 148, 209

Humboltian science see science

hybrid forms of governance

see governance

hybrid warfare see war

hybridity 169 ; hybrid actors 136 ; hybrid activities 81 ; hybrid forms of concepts 201

hydro-electric industries 160

identity $\mathrm{x}, 33,35,37,51,54,61-62,105$, $109,112-113,118,120-121,123$, $130-131,133,135-136,162-164$, 169-173, 182-184, 186, 203, 209; crisis of identity 136; cultural identity 113 , 130, 136, 169, 203; national identity $105,130,135,170$; national political identity 203

identity politics see politics

ideology 20, 72, 145, 148, 157-158, 162

Iguazú 150-151; Triborder area 153, 176, 185; The Triple Frontier $150-151,184$

illiberal regimes 186

images 10, 19, 50, 156, 164, 171, 176-179, 190-191

imitation 198-199, 202

imperfect translation see translation

imperialism 107, 123

India 183

indigenous culture see culture

individual cultures see culture

individual scale see scale

individual subject 203

informal communities of practice see practice

(in)security see security

insiders see culture

institutional platforms 81

instrumental theories of language see linguistic translation studies

insurance agencies 50

intelligence 43, 50-51, 61-62, 81-91, 112, 118-119, 122, 136-137, 170, 180, 187; 
commercialised intelligence culture 137; counter-intelligence 104; intelligence agencies 89-90; intelligence expertise 51; intelligence revolution 91; privatisation of intelligence 137

interdisciplinarity see discipline interdisciplinary framework 5

Intergovernmental Panel on Climate Change (IPCC) 63, 74

International Covenant on Economic, Social and Cultural Rights (ICESCR) 131

international networks see networks

International Organisation for Migration (IOM) 174

International Political Economy 143

international relations (IR) 10, 31, 67, $108,143,147,160$

international security see security

international society 143

Internationalisation 205

Internet 52, 82, 89, 161, 170, 174, 180-181, 186

intrastate wars see war

Inughuit see Greenland

invisible hand see liberalism

Iraq 57-58, 85, 111, 121, 150, 189, 191; Iraq War 85

Islam see theology

Islamic State 186; ISIS see terrorism

Islamophobia 180

Jacobsen, Elida 123

Jordan 110-112

Judaic traditions see theology

Jusionyte, Ieva 150, 153, 156, 176, 184-185

Keynes 83

killing 21, 93, 185

Kivalina 118, 154-156, 168, 172, 184; Kivalina Inuit population 184

knowledge i, 2, 31-32, 34, 42-43, 50, 53-54, 58, 60-62, 66, 69-70, 73-76, 80-81, 85-88, 90-92, 105-107, 109-110, 113-114, 117-120, 122-123, $131,133,135-136,143-145,155,162$, 164, 178, 197-198, 201-202, 204-205, 208-210; application-driven knowledge 92; diffusion of security knowledge 90; security-knowledge 198; structure of knowledge 106, 144; tacit knowledge 81, 85-88;

topography of knowledge 81

languages 2, 13, 29, 32-33, 52, 64, 66, 109

Latour, Bruno xi, 2, 14, 20, 34, 161, 182

Leander, Anna 76, 81-82

learning 55, 70, 106, 110, 113, 118, 121, $135,137,202,204$; collaboratively learning 118

legislative exceptionalism 206

legitimacy 18, 91, 114, 118, 136, 173, $186,197,202,204$

liberalism 120-121, 158-159; American liberalism 158; invisible hand 108, 121; liberal mainstream 122; liberal principles 186; liberal subjectivities 120; liberal version of universality 121

liberal democracy see democracy

liberal democratic fantasy of Cuba see Cuba

Libya 110,112

linguistic translation studies $15,29-30$, 32; hermeneutic theories of language 29 ; instrumental theories of language 29; literal translation 29

literal translations see linguistic translation studies

literature $28,31,38-39,75,87,131$, 169,178

local causal chain see causal chain

logical hierarchy see scale

Lomborg, Bjørn 69

London 166-167

Luhmann, Niklas 14-15, 17, 27, $33,35-36$

Luis, Jose 116

macrosecuritization see securitization marginalisation 173

market $14,18,20,65,70,71-73,105$, 119-121, 126, 158, 163, 175, 206; market competition 121; market logic 121

Marxist economics 143

McFate, Montgomery 57

meaning systems 13 ; systems of meaning $13,15,41,153,198$

medical institutions see health

Melanesian 159

meta-map 196

Microsoft 90

Middle Eastern 122, 163; Middle 
Eastern states 163; migration 2, 150,195

military 4, 6-7, 53-54, 56, 58-61, 66, 73, 76, 82, 94-95, 122-123, 125-126, 153-155, 165, 169, 185, 195; civil military relations 54 ; military culture 59; military profession 54, 61; US army 58, 110, 114

MI6 112

misunderstandings 75

mobilisation of concepts see concepts modernity 27, 120, 137, 198

Montreux document (MD) 76, 77;

Montreux +5 76-77, 81

Moon, Ban Ki 173

Moran, Tom 177-179

multiplicity 111,210

Munich Crisis 165

Muslim 32, 114, 122, 169-173, 182; Muslim immigrants 173

national identity see identity national political identity see identity national security i, xi, 2, 50-52, 58, 64, $66,81,84,86,89,91-92,112-113,130$, 157, 169, 172, 186, 198, 206

National Security Agency (NSA) 180; national security advisors see experts National Security Council 45 nation state $4,11,70,105,108,120,124$, 135-136, 143, 153, 156-159, 186, 198, 203; authoritative political level 161; the embryonic nation state 153 ; European nation states 124; nation state programmes $156-157,159$; state sovereignty 142,164 ; territorial container 161

NATO 125

nature 4, 7, 20, 51, 66-69, 74, 77, 81, 84, $90,117,123,136,157,174,184,196$, 198, 208, 210; natural disaster 155, 184

Neal, Andrew 206

neoliberalism 163; neoliberal governance

39, 163; neoliberalisation 163

neoliberal governance see neoliberalism neo-materialist security studies 10,41 networking mode 143

networks 8, 14, 18, 42, 78, 89, 105, 135-136, 144, 151, 160-164, 180-181, 187-188, 190, 199-200, 202-204, 206; business networks 105, 135; criminal networks 135; cyber networks 160 , 162, 188; de-territorialised networks
$18,161,181$; international networks 136, 202-203; professional networks 135; social networks 161-162; spatial connectivity 162 ; terrorist networks 162,188

new security studies/new European security studies see security studies Nixon, Nicholas 177-178 non-government organisation (NGO) 76-78, 108-109, 136, 182-183, 202

non-violent bottom-up resistance see resistance

North America 125, 179

Northern Africa 121

Norway 181, 203

Norwegian government 181

Norwegian Labour Party 180

Nyman, Jonna 63, 129

Obama, Barack 44, 63-66, 129

Occupy activists 163

ontology 33 , 35, 80-81, 148, 161; big data ontology 81 ; flat ontology 35 , 161; ontology of association 80

Oregon 146

organisation theory 31,108

organisational culture see culture

organisational translations 18

organised crime $2,31,123,150,151,153$

Oslo 181

out of scale see scale

outsiders see culture

Paraguay 150, 151, 153, 184

Paris School 7-9, 40

particularism 119, 136

peacebuilding 122, 173-176; peaceful conflict resolution 175

performative power 7 ; performative power of concepts 7; performativity 8, 28, 209

Philipsen, Lise 173

physical geography 146

physical objects $123,164,168,180-181$

physical security see security

plan condor 151

plasticity 162

policies see policy-making

policy-making 5, 35, 86, 136, 173, 195; climate policies 62; government policies 73 ; policies $11,62,70-71,73$, 97, 130, 135-136, 151, 162, 168, 173, $178,184,196$; state policies see state; trade policies 130 
political performativity see performativity

political science see science

political violence 112,190

politicians 50, 56, 89, 96, 126, 195

politicisation 56

politics x, 4, 7-11, 13, 16, 28, 31-32, 65, $67,70,79,89,96,111-112,117,121$, $129,133,142,147,149,155,163-164$, $165,169,172-173,178,183,196,198$, 203-207, 210; cultural security politics 121; environmental politics 4 ; identity politics 133, 164, 169; politics of possibility 9; politics of scale see scale; politics of unwanted futures 13, 207

populists 208

Porsdam, Helle 130-131

postcolonial political and social culture see culture

postmodern interviewing 75

poststructuralist 4

post-truth 209-210

Power, Michael 56, 137

powerful agents see agents

practice i, x, xi, 1-8, 10, 13-14, 16-18, $27,29,32-33,35-36,39-41,43,51-52$, 54-56, 62-64, 67-68, 73, 76-77, 79-80, 82-83, 85, 88-92, 94, 96-98, 108, $110-112,114,118-120,122-124$, 128-129, 137, 144, 147, 149, 150, 161-163, 176, 180-181, 183, 186, 195-196, 198, 201, 204, 205-208; informal communities of practice 91 predictive policing 80

private military and security companies (PMSCs) 76-77, 79

privatisation of intelligence see intelligence productive approaches 9

professional code see professions professional elitism 205

professional judgement see professions professional networks see networks professionalisation see professions

professionalism - formal and functional see professions

professions 2,8, 12, 17-19, 27-28, 40, 42, 50-54, 56-57, 61-63, 67-68, 73-76, 79, 80-82, 89-91, 104, 106, 142, 144-145, 181, 195-199, 205, 209; professional code 73; professional ethics 58; professional identities 51-52, 91; professionalism - formal and functional 83; professionalisation 91; transnational professional identities 91

public private partnerships (PPPs) 81

Qaanaaq see Greenland

raison d'être 31,119

rationality $39,83,90,106,113,119,135$

redefinition of concepts of security see security

referent object $4,121,149,178,186,205$; collective referent object 205

regional or global scales see scale

regional species see scale

religion 4,162

reproduction of structures see structures resistance 75, 77, 79-80, 96, 121-122, 142-143, 149, 158-159, 163-164, 172-173, 176, 199; non-violent bottom-up resistance 176

responsibilisation 52

resource extraction 160

re-territorialisation see territory

right wing 180-181, 203; far-right wing 181

Rio Declaration 130

risk i, x, 2-4, 6-13, 15-19, 33, 38-39, 41, 50-51, 53, 55-56, 62, 66, 70-72, 75, 82-85, 89-90, 92, 98, 104, 106, 108, 123, 128-130, 133, 136-137, 149, 151, 153-155, 169, 181, 184-186, 189, 196, 198, 201, 203-209; risk communication 75,129 ; risk management $4,9,90,123$, $137,204,206$; risk society 137 ; risk thinking 3, 90, 137

risikifications see securitization role of science in society see science Russia 42-45, 125, 157; Russian foe 126; Russian doll 161

\section{sanctions 55}

Sapir-Whorf hypothesis 109

Sarin gas attacks, 2013 see Syria

scalar 18, 142-145, 147-149, 161-164, 181, 184, 186-187; scalar disciplining 161; scalar government disciplining 162; scalar ideologies 145; scalar positions 148

scale $8,12,17-19,22,27-28,31-32,37,50$, 52, 95, 97, 104-109, 124, 142-149, 151-153, 155-164, 168-169, 173, 180-181, 184-188, 195-199, 202-203, 205-207, 209-210; global scale 142-143, 
157-158, 185, 203; Greenlandic scale 160; hierarchy 142-145, 147-148, 160, $163,173,184,187,197-199$; hierarchy of authority 145, 148; hierarchy of levels 147 ; hierarchy of scope 145; household livelihood 160; individual scale 142, 169; local stocks 160; logical hierarchy 145 ; never-ending prospective operation 148 ; out of scale 144; politics of scale 147; regional or global scales 143; regional species 160 ; scaled identities 162; scalejumping 162; scale-making projects 148 ; scope 18, 142, 145, 147, 149, 161, 163, 187; securitized scale 185 ; sedimented hierarchy of scales 144; sedimented scale 144, 147, 160-162; size 142, 147-148; social construction of scale 147 ; supranational scale 160; target scales 163

scale identities see scale

scale-jumping see scale

scale-making projects see scale scaling projects 145 ; universalising projects 18,160

science i, x, 5-6, 9, 11, 14, 19, 32, 34, 36, 53-54, 59-62, 64, 68-71, 74, 80-81, 83-88, 92-93, 133, 147, 183, 198, 204, 206, 208-210; Humboltian science 92, 204; political science 147; role of science in society 92; Science and Nature 84; science and technology studies (STS) 9, 85-86; science professing reality 209 ; social science $11,14,19,32,59-60,69$, $71,86,88,147,198$

Science and Nature see science science and technology studies (STS) see science

science professing reality see science scope see scale

Second World War 158, 164

securitization $\mathrm{x}, 1,6-10,12,37-38$, 40-41, 55, 74, 83-84, 117, 121, 142, 149, 157-158, 181, 186, 196, 206-208; counter-securitization 158 ;

dangerifications 196; de-securitization 131, 134; the exceptionality of securitization 9; macrosecuritization 157-158; risikifications 196; securitization theory $7-10,40$, 117, 206

securitization theory see securitization securitized scale see scale securitizing actors 149 security i, x, xi, 1-13, 15, 17-21, 27-28, $32,35,37-42,44-45,50-53,55-58$, 60-68, 70-71, 73, 75-79, 81-86, 89-92, 95-98, 104, 106, 110-113, 121, 123-131, 137, 142, 149-157, 163-165, 169-173, 176-182, 184-186, 190, 195-196, 198-199, 201-209; cyber security 2, 81, 83, 89-90, 137; energy security 63-66, 129; ethical security 76; (in)security 15, 85, 96-97, 152-154, 178-179, 184, 209; international security 89-90, 127, 205; physical security 169 ; redefinition of concepts of security 83; security apparatus 203; security emotionality 179 ; security expertise see experts; security politics $7,28,89,121,205-206$; security truths 128; security-knowledge 198

security studies i, x, 2-7, 9-12, 19, 28, 39, 39-41, 51, 131, 168, 178-179, 196, 205-206, 208-209; classical security studies 206; critical security studies (CCS) 9-10, 196, 206, 209; new security studies/new European security studies 7

sedimentation 35-36, 145, 149, 161

sedimented discourses 143; discursive sedimentations 149

sedimented hierarchy of scales see scale sedimented scale see scale

sedimented structures of meaning 11,16 , 27, 50, 52, 104, 144, 199, 200;

sedimented bodies of meaning 106 , 144; sedimented constellation of meaning 106, 144

segmentation 18, 50, 104, 142, 144, 187, 206; segmentation of the scalar model 144, 187

segmentational differentiation see culture Sejersen, Frank 118, 123, 153, 160, 168,184

semantic fields 16,38

(semi)professionals 91

Shaheed, Farida 132

Shearer, Christine 154

Sierra Leone 173-174

Singer, David 147

Single Leg Amputee Sports Club (SLASC) 173

size see scale

skills 53-54, 57-58, 61-62, 81, 199

Snowden, Edward 180, 188, 203

social construction of scale see scale 
social demarcations 108

social discourses see discourses

social movements $137,163,180$

social networks see networks

social science see science

social status 54

social terrorism see terrorism

socialism 115-116, 157

societal differentiation 15,18

socio-economic 3 , 174; socio-economic integration 174

sociology 33,148 ; sociology of translation $33-34$

South Africa see Africa

South America 150

sovereign independence 160

Soviet Union 44, 157; Soviet

communism 158

spatial connectivity see networks

Sri Lanka 183

stakeholders 75-76, 92, 174

state 1-2, 4-5, 11, 16, 20-22, 31, 40, 51-54, $56,62,67-70,72-81,82,85,89,90-93$, 95-96, 105, 107-110, 112, 114-122, 124, 126, 129-130, 135-137, 142-143, 145-146, 148-164, 170, 174, 180-182, 183-188, 197-198, 200, 202-206; neoliberal state see neoliberalism; state policies see policy-making; state sovereignty see nation state

Strandsbjerg, Jeppe 66-67, 73, 81, 90

Strathern, Marilyn 146, 159

stratification 17-18, 50, 104, 142, 200; stratificational differentiation see scales; stratificational mode 142

Stritzel, Holger 8, 31, 33, 40, 123

structuralism 11

structure of knowledge see knowledge structures 11-12, 15-16, 27-28, 31-32, 35-38, 40, 50-53, 61, 76, 88, 104-106, $108,137,142-145,160,162,196$, 199-200, 205

Sudan 183

super-empowered individuals see empowerment

supranational scale see scale

sustainability thinking 3

synchronic conceptual negotiations 15

Syria 21, 82; sarin gas attacks 201382 systems of meaning see meaning systems systems theory 14, 27

Sznaider, Natan 136 tacit knowledge see knowledge

target scales see scales

Tatchim Isau 155

technological development 52, 174-175

telecommunication systems 1781

territorial container see nation state

terrorist networks see networks

theology 19, 27, 29-30, 36; Christian theology 29-30; dogmatic theology 30; Islam 29, 161; Judaic traditions 29; translations as a theandric act 30

third parties 31,63

threat i, x, 1-3, 5-7, 20, 21, 31, 33, 40, $43,50,56,66,69,73,81,82,83,85,86$, $97,98,104,106,120,121,122,123$, $128,129-130,135,136,137,149$, $150-151,152,153,158,162,163,164$, $169,171,176,177,180,181,183,184$, $185,186,187,188,191,195,198,199$, 202, 203, 204, 205, 206, 207

Thule see Greenland

topography 79, 81, 162; topography of knowledge see knowledge

trade policies see policy-making

training 53, 55, 56-57, 63, 88, 150, 173,175

translation i, x, xi, 1-3, 5-6, 8-15, 17, 18, 19, 27-42, 50-53, 57, 59, 66-70, 73-74, 76-83, 86, 88, 89, 104-105, 106, 107, $109,110,111,112,113,114,118,119$, $120,122,123,124,125,128,129,135$, $136,137,142,143,144,145,148,149$, $150,153,154,155,156,160,161,162$, 163-164, 172, 176, 180, 181, 183, 186, 189, 190, 191, 195-210; hybrid zones of translation 202; imperfect translation 32; interrogating translations of security 181 ; intranslatability 28 ; translation experiment 86,88 ; translations of security $2-3,8,17,18,19,27,38,39$, $40,41,42,50,52,53,82,104,125,128$, 142, 153, 154, 181, 186, 195, 205, 207, 208; translation zone $3,11,13-18,27$, $28,36-37,42,52-53,62,104,105,106$, $109,118,119,120,123,135,143,145$, 160, 163, 164, 186, 195-204, 207

translations as a theandric act see theology

translations of security see translation transnational 91, 136, 148, 161, 162, 163,202 
transnational professional identities see professions

Tripoli 112

Trump, Donald 42-43, 45, 124

Tsing, Anna 145, 148

Turkey 122, 190

Uganda 183

uncertainty thinking 3

United Nations (UN) 68, 74, 173; UN Framework Convention on Climate Change (UNFCCC) 74; United Nations Educational, Scientific and Cultural Organization (UNESCO) 133, 134; United Nations Environmental Program (UNEP) 74; United Nations Integrated Peacebuilding Office in Sierra Leone (UNIPSIL) 173, 175; UN peacebuilding 169; UN Peacebuilding Fund (UNPBF) 173, 175, 176

United States 57, 63, 110, 114, 122, 124 , 125, 127, 141, 177; U.S 85-86; US Department of Defense 111; US doctrine 157; US government 150 , 151, 188; U.S. Intelligence Community Directive 205, 85; US Special Forces 111

Universal Declaration of Human Rights 131

universal human rights see human rights universalisation 18, 120, 121, 197, 199

universalising projects see scaling projects

universalism 136, 157-158, 197

universities see education

university-society collaboration 204

unwanted future $x, x i, 2-3,6,10,11,12$, $13,14,17,18,19,27,41,51,52,62,63$, $66,69,72,73,80,82,83,84,89,90,93$, $106,109,110,112,117,118,119,120$, $121,122,123,124-126,128,130,135$, $136,137,142,143,144,145,149,153$, $155,156,157,159,160,162,163,164$, $168,170,172,173,176,180,181,184$, 186, 187, 188, 195, 196, 197, 198, 199, 200, 201, 202, 203, 204, 206, 207, 208, 209, 210

URS 155
US army see military

US Department of Defense see United States

US doctrine see United States

US government see United States

U.S Intelligence Community Directive 205 see United States

US Special Forces see United States

visual communication see communication

Vogel, Kathleen M. 81, 84-88

Wæver, Ole 10, 149, 157-159

Waltz, Kenneth 147

war $4,20,22,27,37,54,58,61,85$, 93-95, 97-98, 118, 119, 123, 124, 125, 134, 136, 137, 151, 158, 164, 165-167, 170, 173, 174, 177, 199; Global War on Terror (GWoT) 110, 158, 185; hybrid warfare 137; intrastate wars 141; warfare 57, 94-95, 137, 165, 185; war and diplomacy 27, 118, 123, 136-137, 164; war on terror 97-98, $110,150,158-159,185,191$

Wastell, Sari 146

ways of life see culture

weapons 86, 93-95, 180, 188, 199, 204; bioweapons 86 ; weapons of mass destruction (WMD) 86

Weber, Eugene 153

Weber, Max 28, 91, 129

West 98, 124, 157-158, 170

Western 58, 89, 108, 115, 117, 121, 124, 130, 136, 146, 163, 169, 178, 181, 186, 205; Western democratic order 136; Western ideals 163; Western world 181,186

Whitley, Richard 54

Wildavsky, Aaron 128

World Climate Change Conference 20

World Meteorological Organisation (WMO) 74

World Trade Centre 97, 177

WTO 129

Zehfuss, Maja 54, 57-61, 66, 73, 110, 113-114, 122 


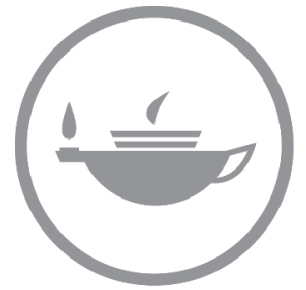

Taylor \& Francis
Taylor \& Francis Group http://taylorandfrancis.com 